\title{
Development of a Fast Spectrum Test Loop at the Advanced Test Reactor
}

\author{
Anton Higgins \\ January 2020
}

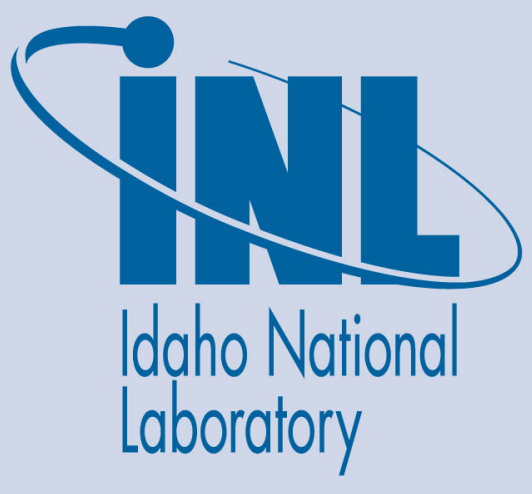

The INL is a U.S. Department of Energy National Laboratory operated by Battelle Energy Alliance 


\title{
Development of a Fast Spectrum Test Loop at the Advanced Test Reactor
}

\author{
Anton Higgins \\ January 2020 \\ Idaho National Laboratory \\ Idaho Falls, Idaho 83415 \\ http://www.inl.gov \\ Prepared for the \\ U.S. Department of Energy \\ Office of Nuclear Energy \\ Under DOE Idaho Operations Office \\ Contract DE-AC07-05ID14517
}





\section{AN ABSTRACT OF THE THESIS OF}

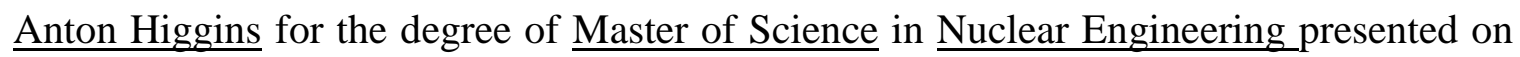
December 11, 2019.

Title: Development of a Fast Spectrum Test Loop at the Advanced Test Reactor

Abstract approved:

Wade R. Marcum

The United States currently has no infrastructure to provide a fast neutron flux for research purposes. With the increased interest in Sodium Fast Reactor (SFR) technology, this type of infrastructure is necessary for further development of key components such as Versatile Test Reactor. The purpose of this research is to characterize the thermal hydraulics of a test loop capable of providing SFR like operating conditions. This includes showcasing feasibility in mechanical design, reaching a high fast to thermal neutron flux ratio ideally near 15, an inlet temperature of $600 \mathrm{~K}$, a temperature increase of $50 \mathrm{~K}$ from inlet to outlet, and test chamber radial temperature profiles similar to SFR fuel rods. Existing infrastructure must be used to provide the neutron flux for the test loop, and it was decided that the Advanced Test Reactor (ATR) was the optimal choice due to its availability and previous work conducted similar to this project.

To achieve the goals of this project, several mechanical designs were put forward with the most feasible design being chosen. The neutronics and thermal hydraulics analysis were conducted in tandem, with an iterative process used to maximize efficiency of both systems. Analysis of the neutronics system was done using Attila and MCNP while the 
thermal hydraulic analysis was done using RELAP5. This document outlines the thermal hydraulic analysis, though it includes the results from the mechanical design and neutronics analysis.

The loop design includes a primary system with molten sodium, a set of "booster fuel plates" to increase the fast flux within the test section, a water system to cool the booster fuel plates, a helium system to separate the sodium and water systems, and a thermal neutron shield to decrease the thermal flux. Each of these systems is modeled in the neutronics and thermal hydraulic analyses.

The RELAP5 model showcased the feasibility of the design proposed by this report. For all designs tested, the desired $50 \mathrm{~K}$ temperature increase from inlet to outlet was reached. The fuel rod radial temperature profile was lower than was expected, likely due to a lower rod thermal power than expected. A parametric study was also conducted to characterize the system with three fuel pins. This study showed the effect of thermal power, fluid pressure, fluid velocity, and inlet temperature on the system. 
CCopyright by Anton Higgins

December 11, 2019

All Rights Reserved 
Development of a Fast Spectrum Test Loop at the Advanced Test Reactor

by

Anton Higgins

\section{A THESIS}

Submitted to

Oregon State University

in partial fulfillment of

the requirements for the

degree of

Master of Science

Presented December 11, 2019

Commencement June 2020 
Master of Science thesis of Anton Higgins presented on December 11, 2019 APPROVED:

Major Professor, representing Nuclear Engineering

Head of the School of Nuclear Science and Engineering

Dean of the Graduate School

I understand that my thesis will become part of the permanent collection of Oregon State University libraries. My signature below authorizes release of my thesis to any reader upon request. 


\section{ACKNOWLEDGEMENTS}

I would like to thank my professor and advisor Dr. Marcum for the invaluable counseling and assistance he provided over the course of my Masters program. His work to set me up for success could never be understated, and I am very grateful to work with him.

I would also like to thank my family, primarily my parents, for all the help they provided during my schooling.

Finally, I would like to thank all those that assisted me with proof reading and preparing for my presentations. 


\section{TABLE OF CONTENTS}

Contents

$\underline{\text { Page }}$

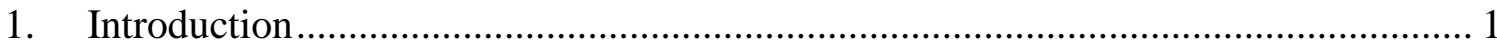

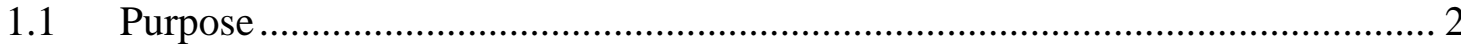

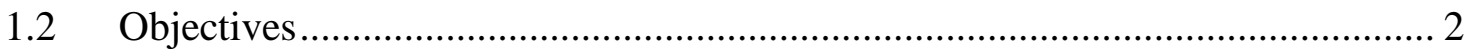

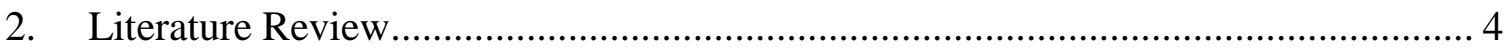

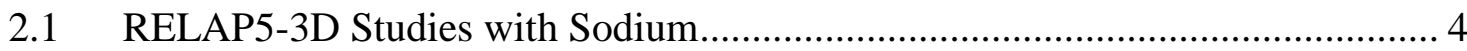

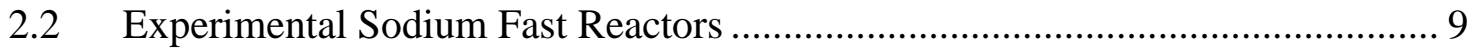

$2.3 \quad$ Numerical Methods ...................................................................................... 14

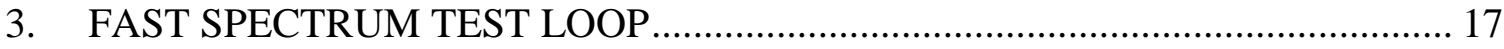

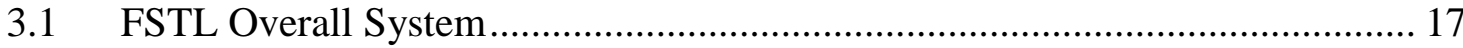

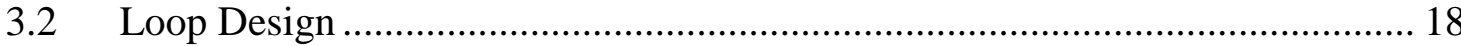

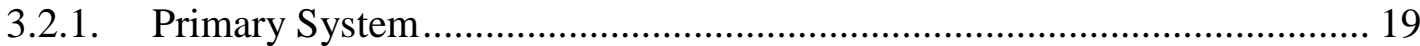

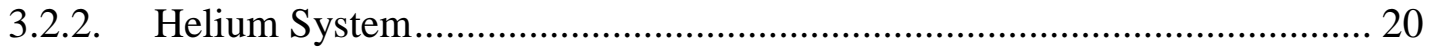

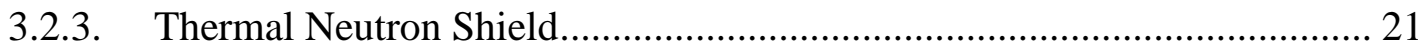

3.2.4. Fuel Plate and Respective Cooling System ........................................ 21

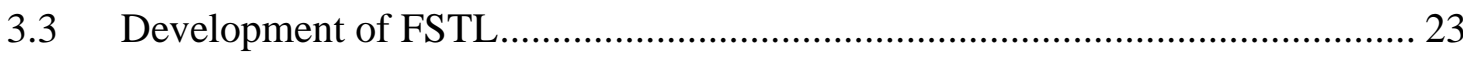

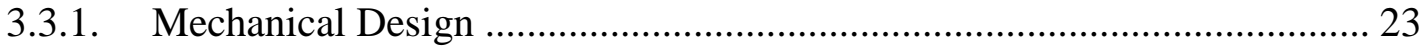

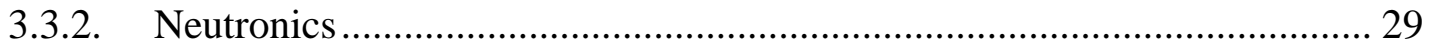

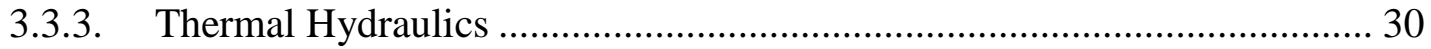

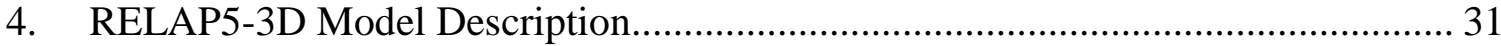

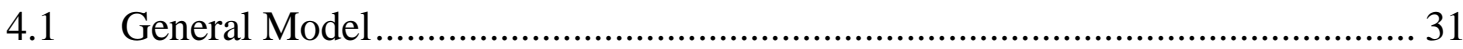

4.1.1. Primary Loop System ..................................................................... 31 


\section{TABLE OF CONTENTS (Continued)}

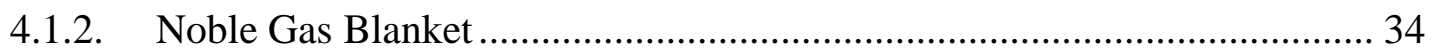

4.1.3. Booster Fuel Plates Coolant ................................................................. 35

4.1.4. Heat Structures ................................................................................. 36

4.2 Stainless Steel Rod Test Section ....................................................... 41

4.3 1 Fuel Pin Test Section........................................................................... 41

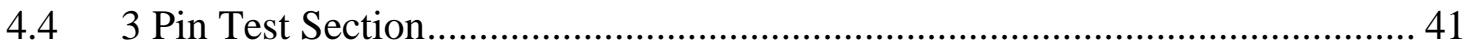

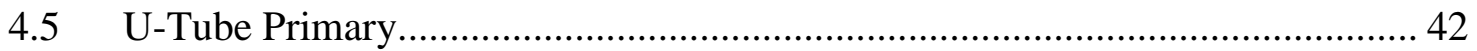

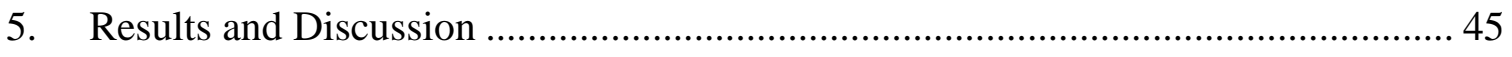

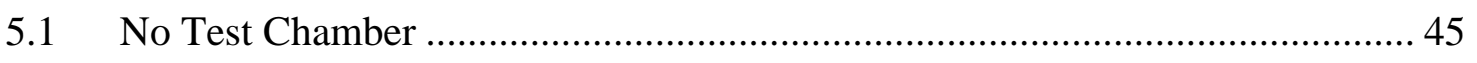

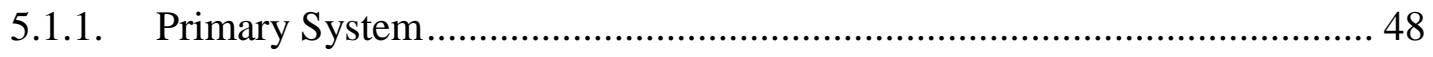

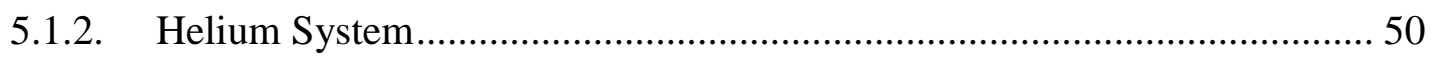

5.1.3. Fuel Plate Cooling System.............................................................. 51

5.2 Stainless Steel Test Section.................................................................. 55

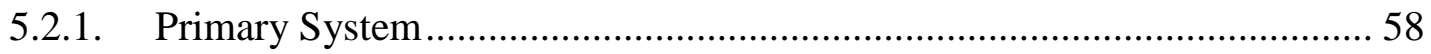

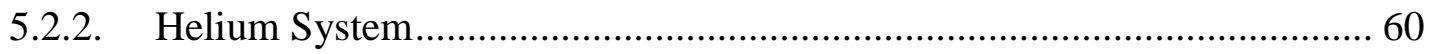

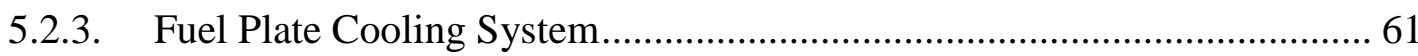

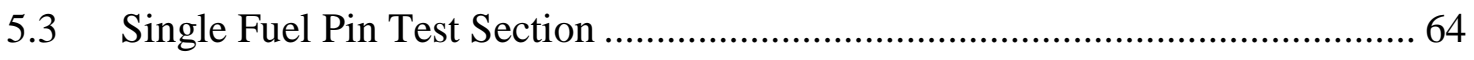

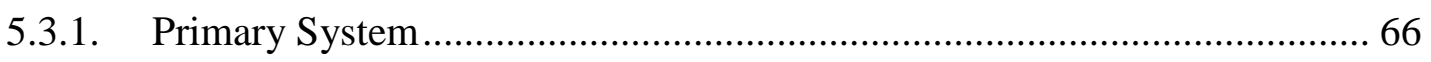

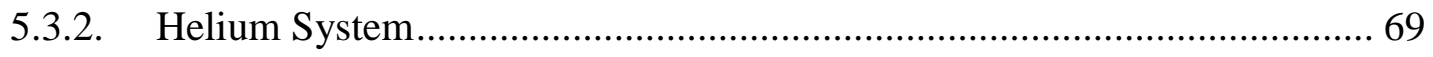

5.3.3. Fuel Plate Cooling System......................................................... 72

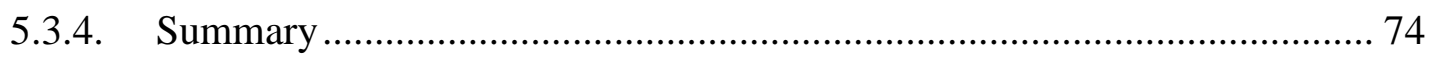

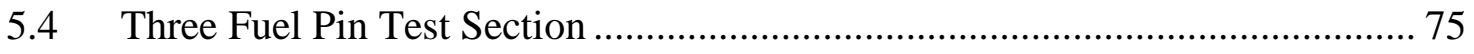

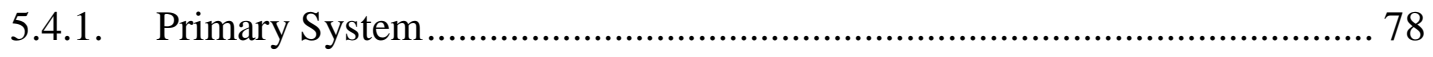

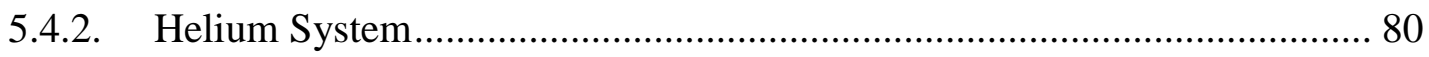




\section{TABLE OF CONTENTS (Continued)}

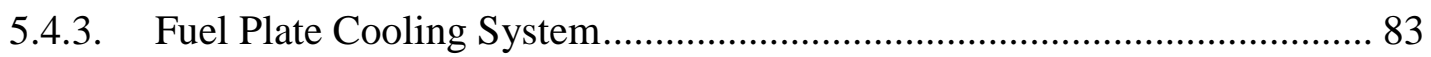

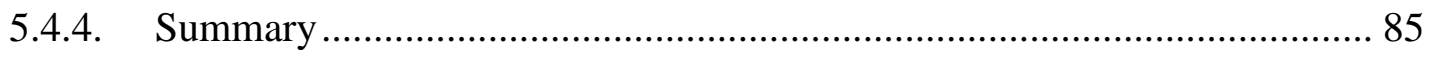

5.5 U-Tube Three Fuel Pin Test Section............................................................ 86

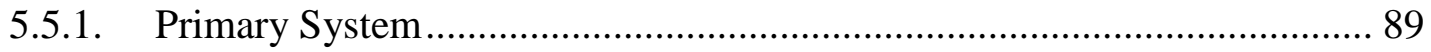

5.5.2. Inner Helium System ...................................................................... 92

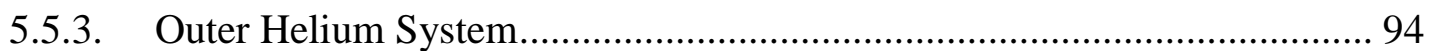

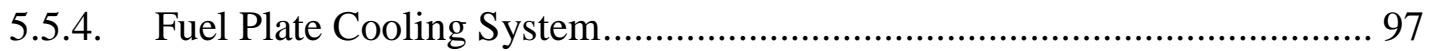

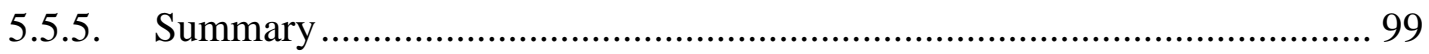

5.6 Parametric Study: Three Fuel Pin Test Section ........................................ 100

5.6.1. Parametric Study: Pin Power with Old Flow Conditions ....................... 100

5.6.2. Pin Power with New Flow Conditions ................................................. 105

5.6.3. Booster Fuel Plate Power.................................................................... 106

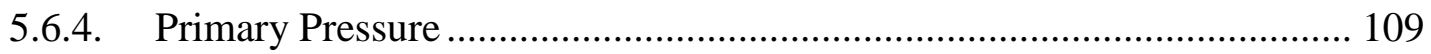

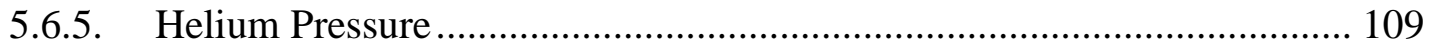

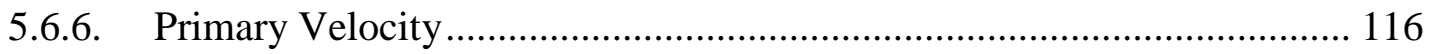

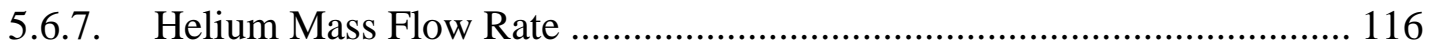

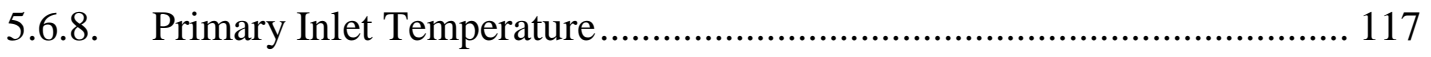

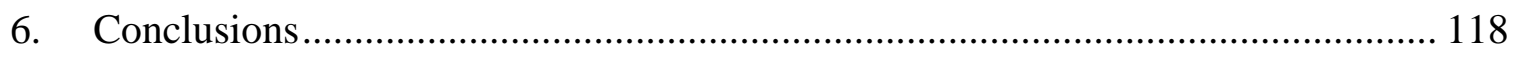

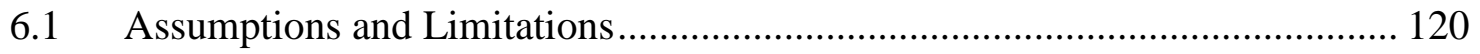

6.1.1. Low Pin Power........................................................................... 120

6.1.2. Axial Heat Conduction .............................................................. 120

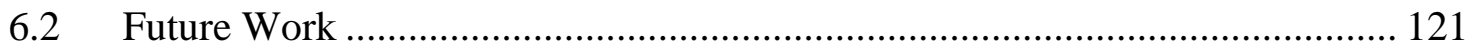

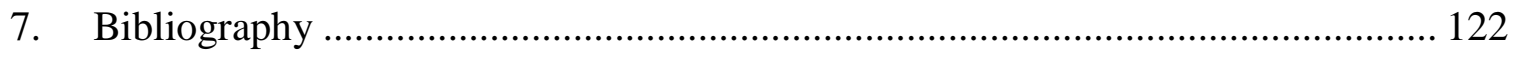




\section{LIST OF FIGURES}

Figure $\quad \underline{\text { Page }}$

Figure 1: Cross Section of Initial FSTL Design with three fuel pins ............................ 19

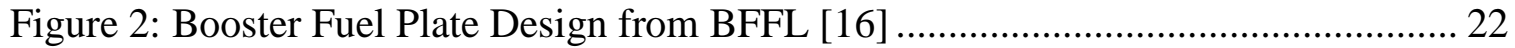

Figure 3: Cross Section of the Test Train for the BFFL [16] ....................................... 22

Figure 4: Schematic (top) and rendering (bottom) of piping routes for FSTL [23] ......... 25

Figure 5: Internal view of ATR with FSTL in place [23] ........................................... 27

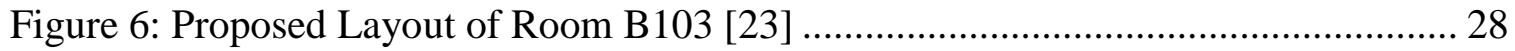

Figure 7: Cut-away schematic of U-shaped internal test loop [23] .............................. 29

Figure 8: Pin Power for Three Fuel Pin Test Case ....................................................... 30

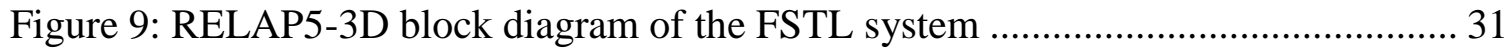

Figure 10: RELAP5-3D Representation of the Primary Loop System .......................... 33

Figure 11: RELAP5-3D Representation of the Noble Gas Blanket ............................... 35

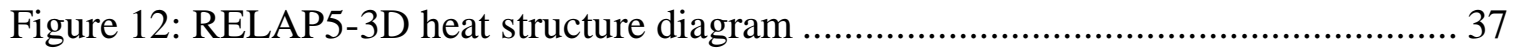

Figure 13: RELAP5-3D Representation of the FSTL test section................................ 38

Figure 14: RELAP5-3D Representation of the Thermal Neutron Filter......................... 39

Figure 15: RELAP5-3D representation of a single booster fuel plate (left) and entire heat

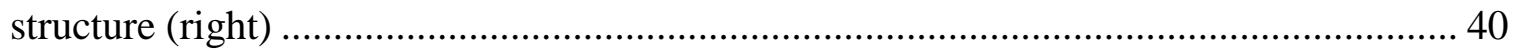

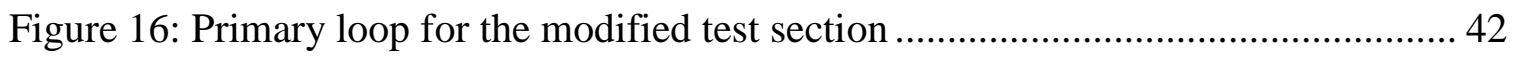

Figure 17: Primary loop connected to volume 701 (helium chamber) ........................... 43

Figure 18: Block diagram of the test section for the modified test chamber case ........... 44

Figure 19: Cross Section of No Experiment Test Case ............................................ 46

Figure 20: Bulk Fluid Temperatures for No Test Chamber....................................... 47

Figure 21: Radial Temperature Distribution at Inlet and Outlet.................................... 48

Figure 22: Primary Piping Surface Temperatures .................................................... 49

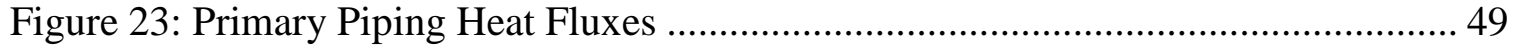

Figure 24: Gas Blanket Piping Surface Temperatures................................................ 50

Figure 25: Gas Blanket Heat Fluxes ................................................................ 51

Figure 26: Fuel Plate Surface Temperatures................................................................ 52

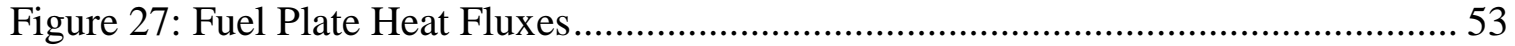

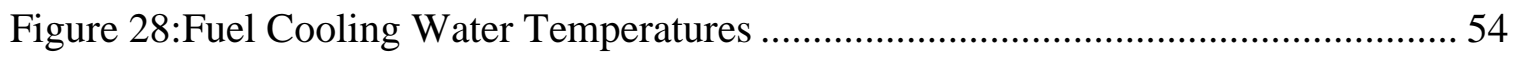




\section{LIST OF FIGURES}

Figure $\quad \underline{\text { Page }}$

Figure 29: Peak Fuel Plate Radial Temperature Distributions ......................................... 55

Figure 30: Cross Section of Stainless Steel Rod Test Case ………………...................... 56

Figure 31: Fluid Temperatures from Inlet to Outlet ………………………………….. 57

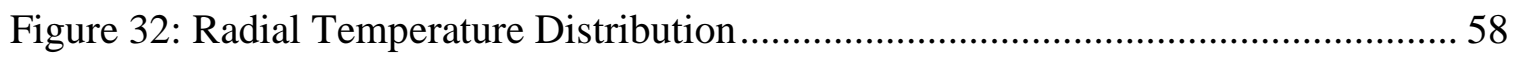

Figure 33: Primary Surface Temperatures ………………............................................. 59

Figure 34: Primary Heat Fluxes ............................................................................ 59

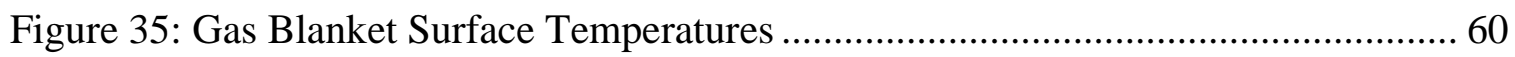

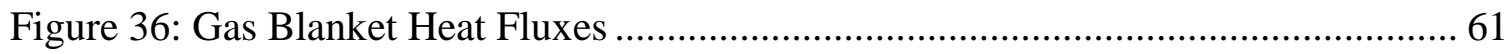

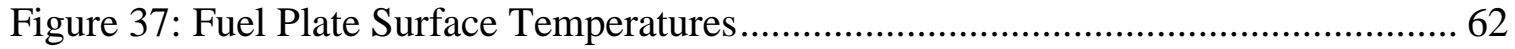

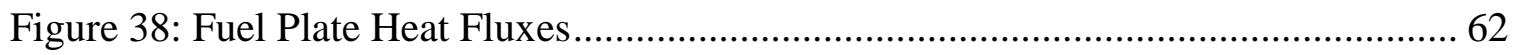

Figure 39: Fuel Plate Cooling Water Temperatures ......................................................... 63

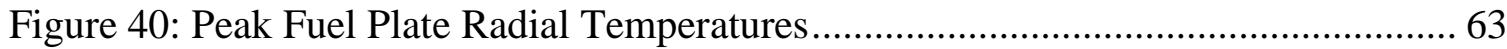

Figure 41: Cross Section of Single Pin Test Case ........................................................... 64

Figure 42: Fluid Temperatures from Inlet to Outlet ...................................................... 65

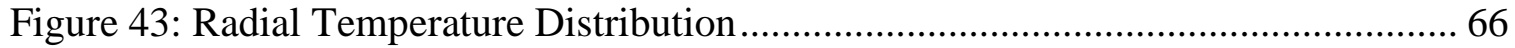

Figure 44: Primary Surface Temperatures ...................................................................... 67

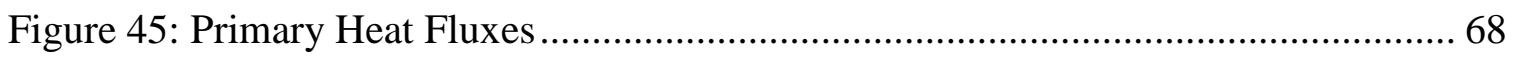

Figure 46: Sodium Temperature from Inlet to Outlet...................................................... 68

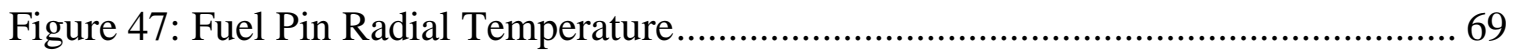

Figure 48: Gas Blanket Surface Temperatures ……………………………………..... 70

Figure 49: Gas Blanket Heat Fluxes .............................................................................. 71

Figure 50: Helium Temperature from Inlet to Outlet ………………………………..... 71

Figure 51: Fuel Plate Surface Temperatures............................................................... 72

Figure 52: Fuel Plate Heat Fluxes................................................................................ 73

Figure 53: Fuel Plate Cooling Water Temperatures …………………………………... 73

Figure 54: Peak Fuel Plate Radial Temperatures............................................................. 74

Figure 55: Cross Section of Three Fuel Pin Test Case ....................................................... 76

Figure 56: Fluid Temperatures from Inlet to Outlet ………………………………….... 77

Figure 57: Radial Temperature Distribution ............................................................. 77 


\section{LIST OF FIGURES}

Figure $\quad \underline{\text { Page }}$

Figure 58: Primary Surface Temperatures ………………………………………..... 79

Figure 59: Primary Surface Heat Fluxes.................................................................. 79

Figure 60: Primary Fluid Temperature from Inlet to Outlet ............................................. 80

Figure 61: Fuel Pin Radial Temperature ...................................................................... 80

Figure 62: Gas Blanket Surface Temperatures ……………......................................... 81

Figure 63: Gas Blanket Surface Heat Fluxes ............................................................. 82

Figure 64: Helium Temperature from Inlet to Outlet ……………………………….... 82

Figure 65: Fuel Plate Surface Temperature ............................................................. 83

Figure 66: Fuel Plate Surface Heat Fluxes ............................................................... 84

Figure 67: Fuel Plate Cooling Water Temperatures ………………………………...... 84

Figure 68: Peak Fuel Plate Temperature Radial Distribution............................................ 85

Figure 69: Cross Section of U-Tube Design............................................................... 87

Figure 70: Fluid Temperatures from Inlet to Outlet ………………………………...... 88

Figure 71: Radial Temperature Distribution of the Primary Loop .................................. 88

Figure 72: Radial Temperature Distribution of Helium and Fuel Plate Cooling Systems 89

Figure 73: Primary Surface Temperatures ................................................................. 90

Figure 74: Primary Surface Heat Fluxes..................................................................... 91

Figure 75: Primary Fluid Temperature from Inlet to Outlet .............................................. 91

Figure 76: Fuel Pin Radial Temperature................................................................ 92

Figure 77: Inner Helium Blanket Surface Temperatures ................................................ 93

Figure 78: Inner Helium Blanket Surface Heat Fluxes.................................................... 93

Figure 79: Inner Helium Temperature from Inlet to Outlet............................................. 94

Figure 80: Outer Helium Surface Temperatures......................................................... 95

Figure 81: Outer Helium Blanket Surface Heat Fluxes ..................................................... 96

Figure 82: Outer Helium Temperatures from Inlet to Outlet........................................... 96

Figure 83: Fuel Plate Surface Temperatures................................................................. 97

Figure 84: Fuel Plate Surface Heat Fluxes ……………………………………...... 98

Figure 85: Fuel Plate Cooling Water Temperatures ………………………………....... 98

Figure 86: Peak Fuel Plate Radial Temperature Distributions .......................................... 99 


\section{LIST OF FIGURES}

Figure $\quad \underline{\text { Page }}$

Figure 87: Outlet Temperatures with No Change to Velocity .................................... 101

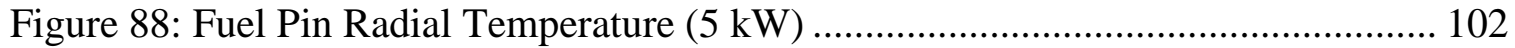

Figure 89: Fuel Pin Radial Temperature Profile $(10 \mathrm{~kW})$......................................... 102

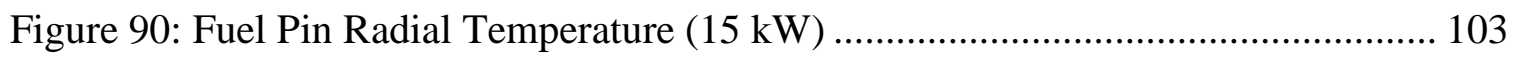

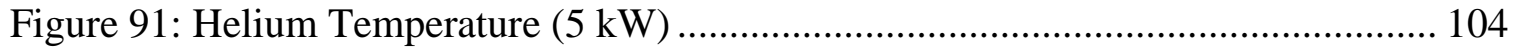

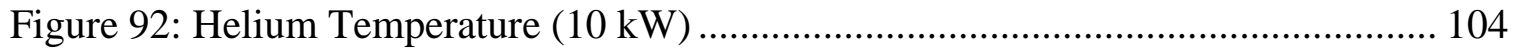

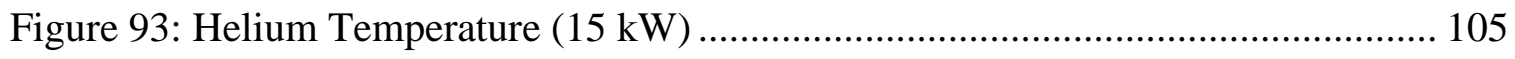

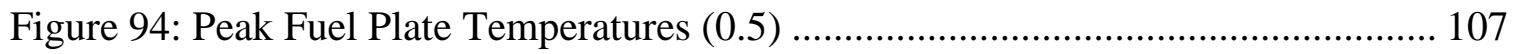

Figure 95: Peak Fuel Plate Temperatures (1.5) ........................................................... 107

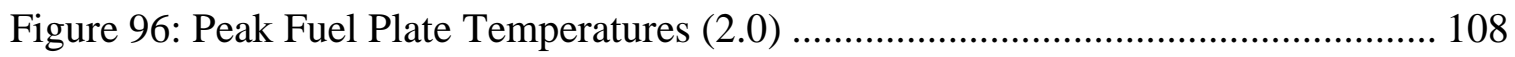

Figure 97: Peak Fuel Plate Temperatures (2.5) ........................................................ 108

Figure 98: Primary Surfaces Temperature (1.5 Helium Pressure) ............................... 110

Figure 99: Primary Sodium Temperature (1.5 Helium Pressure) ............................... 110

Figure 100: Helium Piping Surface Temperature (1.5 Helium Pressure)...................... 111

Figure 101: Helium Temperature (1.5 Helium Pressure) ........................................ 111

Figure 102: Primary Surface Temperature (2.0 Helium Pressure) ............................... 112

Figure 103: Primary Sodium Temperature (2.0 Helium Pressure) .............................. 112

Figure 104: Helium Piping Surface Temperature (2.0 Helium Pressure)...................... 113

Figure 105: Helium Temperature (2.0 Helium Pressure) ......................................... 113

Figure 106: Primary Surface Temperatures (2.5 Helium Pressure) ............................. 114

Figure 107: Primary Sodium Temperature (2.5 Helium Pressure) .............................. 114

Figure 108: Helium Piping Surface Temperature (2.5 Helium Pressure)..................... 115

Figure 109: Helium Temperature (2.5 Helium Pressure) ......................................... 115

Figure 110: Primary Velocity vs Outlet Temperature .............................................. 116 


\section{LIST OF TABLES:}

Table $\quad \underline{\text { Page }}$

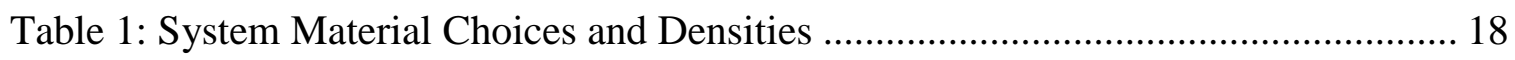

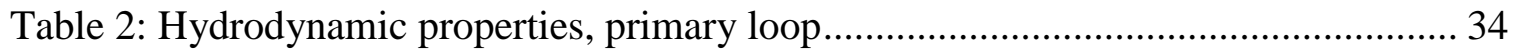

Table 3: Hydrodynamic properties, inert gas blanket .................................................. 35

Table 4: Hydrodynamic properties, booster fuel plate coolant ..................................... 36

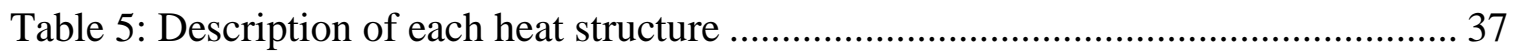

Table 6: Detailed description of booster fuel plate structures ...................................... 40

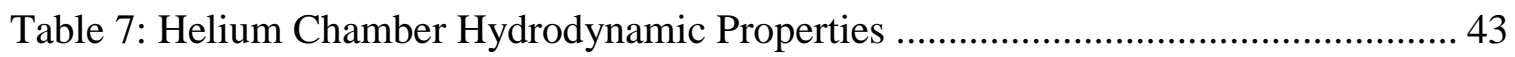

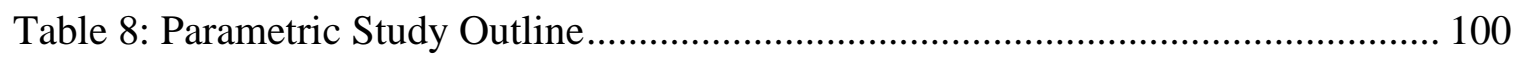

Table 9: Parameters Used for New Flow Conditions ................................................. 105

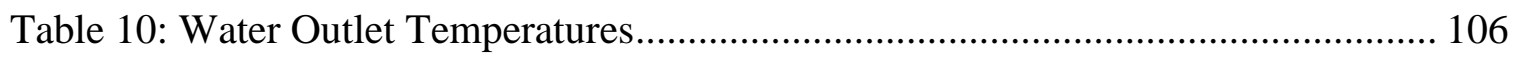

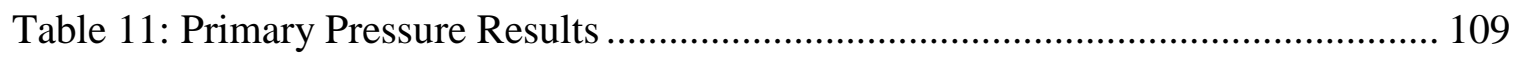

Table 12: Effects of Helium Mass Flow Rate on Primary Outlet Temperature ............. 117

Table 13: Effects of Inlet Temperature on Primary System ..................................... 117 


\section{INTRODUCTION}

Sodium fast reactors (SFR) are arguably the most promising of the Generation IV fast reactors due to their superior thermophysical, material, neutronic, and safety properties when compared to other Gen IV reactors. Sodium makes for an excellent coolant, with notably superior heat transfer rates and given its low vapor pressure operates in a singlephase thermodynamic system. The neutronic properties of sodium as a coolant for fast reactors are also ideal, with very low neutron absorption and extremely low moderation. These reactors also add the benefit of being able to breed nuclear fuels from almost all actinides. This greatly helps with the problem of nuclear waste generation and increases the production of energy from nuclear fuels.

The future deployment of these reactors requires further research and development (R\&D) into several key aspects of SFRs, notably fuel qualification and fuel performance testing. The fuel qualification $R \& D$ cycle requires irradiation and transient testing for all new fuel designs, prior to operational deployment for commercial use. However, there presently exists no infrastructure in the United States for performing such activities on SFR fuel that requires a fast neutron spectrum. While there are no test reactors that facilitate irradiation of fuel with a fast neutron spectrum, there are a number of high performance research reactors that provide large quantities of thermal neutrons. One of these reactors is the Advanced Test Reactor located at Idaho National Laboratory (INL). The ATR has 77 testing positions that facilitate a variety of existing irradiation experiment capabilities, including those that simply drop into the core, and alternates that are placed within an isolated (self-contained) loop and hold their own coolant forms. While this world class facility does not provide neutrons to support SFR fuel, its infrastructure and operational capabilities are flexible by design leading to the question "can an experiment be designed within the ATR to support SFR technology irradiation?" Previous alternate studies suggest through inference that this is feasible through the addition of "booster fuel plates" added to the core region to increase neutron flux and harden the neutron spectrum. 


\subsection{Purpose}

The purpose of this study is to leverage upon existing concepts such as the booster fuel plates to design a test loop that supports irradiation of SFR fuel technology within the ATR. This study will be performed through the application of RELAP5-3D to perform the thermal hydraulic analysis of the irradiation loop and compliment the design of internals that comprise the loop.

\subsection{Objectives}

The objectives of this research are to develop and optimize the mechanical design and thermal hydraulics of a test facility to be placed within the ATR that will mimic SFR-like operating conditions for the purposes of SFR fuel technology testing. RELAP5-3D will be used to analyze the thermal hydraulics of the facility. This study will be executed through the following activities:

- Develop the mechanical design of the of the test facility based on the existing infrastructure of the ATR.

- Characterize the thermal hydraulic properties of the test facility using RELAP5$3 \mathrm{D}$.

- Conduct a parametric study of the loop within RELAP5-3D to identify the maximum operating envelope of the test facility.

The development of the mechanical design and the characterization within RELAP5-3D of the test facility will be performed in tandem with each other and will be updated through an iterative process. Furthermore, this research will work in tandem with other work being done to optimize the neutron characteristics (i.e. flux and spectrum) of the system which will also contribute to the iterative updates to the test facility.

In summary, this work will seek to develop a working test loop within RELAP5-3D to be placed in the ATR I drum to model SFR operating conditions. This test loop will have several test sample positions that will have a fast neutron flux spectrum incident upon them, will have a form factor similar to SFR fuel assemblies, and will have SFR coolant surrounding them. This model will also seek to explore any potential shortcomings that 
come with using RELAP5-3D to model these conditions and seek to mitigate these shortcomings. This facility would greatly advance U.S. fast reactor technology and would become the primary SFR fuel testing method. 


\section{LITERATURE REVIEW}

\subsection{RELAP5-3D Studies with Sodium}

When conducting a computational analysis of a system, it is of upmost importance that the tools being used are appropriate for the situation. For this purpose, several other studies focused on modeling sodium fast reactor systems in RELAP5-3D are examined in this section. RELAP5-3D was originally designed for LWR systems, where axial heat conduction is usually negligible. However, molten sodium has a thermal conductivity 100 times that of water, and heat conduction in the fluid can play a large role in the system. The Peclet number is used to determine the effect axial heat conduction will have on a system [1]

$$
P e=R e * P r
$$

where Re is the Reynolds number and Pr is the Prandtl number. A large Peclet number indicates that energy transfer through advection is greater than axial heat conduction. The axial effects can be considered negligible if the Peclet number is greater than 100 and are still very small even up to a value of 10 . The equation relating a system's Nusselt number to the Peclet number is given by Kays and Crawford [1] as

$$
\begin{array}{ll}
N u=4.180654-0.183460 P e & \text { for } P e<1.5 \\
N u=4.180654-0.183460 P e & \text { for } P e<1.5
\end{array}
$$

Sabharwall [2] used a modified version of the Pe number by nondimensionalizing the energy balance equation with heat conduction.

$$
\frac{D T^{+}}{D t^{+}}-\frac{1}{P e^{*}} \frac{\partial^{2} T^{+}}{\partial x^{+2}}=Q_{w}^{+}
$$




$$
P e^{*}=\operatorname{RePr}\left(\frac{L}{D_{h}}\right)
$$

Based on the length and hydraulic diameter of the component. Axial heat conduction will be 1 percent of the convection term if $\mathrm{Pe}^{*}=100$ and will increase in significance as $\mathrm{Pe}^{*}$ decreases. RELAP5-3D can account for up to third order effects, so axial heat conduction may be important when $\mathrm{Pe}^{*}$ is less than 100 .

The first study examined in the section was conducted by C.B. Davis [3], where RELAP53D was used to model a subassembly (XX09) in the Experimental Breeder Reactor (EBRII) to determine RELAP5's ability to model the Actinide Burner Test Reactor. The ABTR was designed to be a sodium cooled fast reactor that could burn actinides from LWR's. Both a one-dimensional (1D) and two-dimensional (2D) model were developed in this report. The $1 \mathrm{D}$ model was used to evaluate the effects of axial heat conduction and the $2 \mathrm{D}$ model was used to evaluate radial mixing. The 1D model consisted of an inlet, the reactor core, the gas plenum, and an outlet. To evaluate the axial conduction's effects on the system, several steady state calculations were performed at five different operating conditions to compare the effects of the modified Peclet number; in this case, it varied from $10^{4}$ to 1 . A separate numerical method was employed to model the same system with axial heat conduction to compare with the results from RELAP5-3D. By specifying the same operating conditions for both tests, they were able to show that axial heat conduction did not significantly affect the modified Peclet number. For each modified Peclet number, the axial fluid temperature profile across the inlet, core, and gas plenum was compared. The RELAP5-3D results were shown to be almost the same for all Pe values, as to be expected with no axial heat conduction. The numerical method with axial conduction's results showed that the effects were not noticeable to the system until the modified Peclet was $\sim 10$ ( 0.1 percent design conditions). For the strongest case, where the modified Peclet number was 0.8 (0.01 percent design conditions), it was seen that the lower core and upper inlet regions temperature were higher with a max fluid temperature difference of 95 Kelvin from the RELAP5 model. A transient test was also conducted, with three simulations of a lossof-flow transient; where one neglected axial conduction in the fluid and heat structures, 
one accounted for axial conduction with the earlier mentioned numerical methods, and one increased the conductance in the models to account for both axial conduction in the fluid and heat structures. Axial temperature profiles of fuel cladding and fluid were compared, and the effects on both were once again comparatively small.

The 1D model and 2D model were nearly identical to each other except the core and gas plenum were divided into five parallel components with crossflow between the adjacent components allowed by multi-junction components. Experimental data obtained from a previous study showed that the radial fluid temperature could vary by up to $100 \mathrm{~K}$ near the top of the subassembly. For the RELAP5 model, the radial temperature distribution at the top of the core was determined from steady state calculations with the same varied operating conditions used in the 1D subassembly; with radial heat transport, without radial heat transport, and with radial mixing. The results were similar for operating conditions of 1 percent and lower, where the temperature profiles were shown to be flat due to buoyancy affecting the flow in the interior compared to the exterior of the flow. When the power was 100 or 10 percent, frictional effects on the flow were more pronounced and the buoyancy was insignificant, causing a temperature drop near the exterior wall. Comparing the effects of radial conduction for these operating conditions, the temperature profile began decreasing closer to the interior of the flow when radial conduction was accounted for. This showed these effects are significant for these design values. Radial mixing results were very similar to the results of the radial conduction models, though radial mixing was shown to have a greater effect at full power while radial conduction alone was shown to have a greater effect at 10 percent operating condition. Comparatively, the fluid temperature in the $1 \mathrm{D}$ model was $50 \mathrm{~K}$ lower than that of the $2 \mathrm{D}$ model, showing that natural circulation within the subassembly can be significant in this system. A loss of flow transient test was also done at full operating conditions to compare the maximum cladding temperature with no radial conduction, radial conduction, and radial mixing. These were vastly different from that of the 1D method since the 2D model could account for buoyancy effects and natural circulation, and as such, radial conduction and mixing were determined important in certain scenarios. 
The next study examined the applicability of RELAP5-3D for performing SFR subchannel analyses on hexagonal fuel assemblies with wire wrapped fuel rods [4]. The process of a subchannel analysis is to separate a fluid volume surrounding a fuel assembly into individual fuel rods and their equivalent coolant; the adjacent subchannels are able to exchange mass, momentum, and energy. The RELAP5 model developed consisted of 1/12 of an assembly due to geometric and power distribution symmetry. Cross flow was modeled by using multi-junction components to connect the sides of subchannels to allow flow and energy transfer between subchannels. This cross flow is significant due to pressure gradients between subchannels as well as mixing induced by the wire wrapped around the fuel rods. This study also referenced the usage of the unmodified and modified Peclet number to determine effects of coolant conduction, where Pe $>>1$ indicates radial heat conduction is negligible and $\mathrm{Pe}^{*}>100$ indicates axial heat conduction is negligible. For the assembly used in this study, $\mathrm{Pe} \sim 343$ and $\mathrm{Pe}^{*} \sim 150000$, showing coolant conduction is negligible. This model was compared to another subchannel model in SUPERENERGY II and physical data acquired from a 19-pin test from ORNL. The comparison with SUPERENERGY II gave outlet coolant temperatures within $\sim 3.5 \mathrm{C}$ of each other (2 percent). The RELAP5-3D model was also shown to agree with the results from ORNL, with a maximum discrepancy in the outlet temperature distribution of $\sim 8$ percent. These results show the capability of RELAP5-3D to perform subchannel analysis for SFRs.

This study was expanded upon in Memmott's PhD dissertation, where RELAP5-3D was used to evaluate innovative fuel configurations such as annular fuel rods and bottle shaped fuel rods; model a full SFR plant with station blackout transients; and an analysis of a super-critical carbon dioxide power conversion system.

Memmott applied the RELAP5-3D subchannel analysis method to three separate cases: the base fuel rod, annular fuel rods, and bottle shaped fuel rods. The annular fuel rods were modeled to have coolant flowing on the interior and exterior of the fuel rods, with both an oxide and metal fuel meat examined. The results of the subchannel analysis for the annular rods showed that these fuel assemblies in a low conversion ratio core could reduce the oxide cladding temperature by up to $62 \mathrm{C}$ and a power uprate of 44 percent, while the metal 
cladding temperature could be reduced by $18 \mathrm{C}$ with a power uprate of 43 percent. However, it was also shown that these fuel types, especially the oxide, could experience clad failure as a result of interior-annular subchannel blockage. Bottle-neck fuel rods could result in a significant decreased pressure drop across the core for higher conversion ratio reactor cores. For oxides, fuels this pressure drop was decreased by 31 percent with a core height increase of 16 percent while the metal fuels resulted in a decreased pressure drop of 36 percent with a core height increase of 18 percent.

Using these fuel configurations, a full SFR model was developed in RELAP5-3D to analyze these fuel assemblies for steady state and station blackout transients. This full plant model consisted of the reactor core, primary system, secondary system, power conversion system, and DRACS. The refinement of this model is far too great to go into detail in this survey of literature, though it is worth noting that this model's design was based on the Advanced Burner Reactor (ABR1000) and was designed as a $1000 \mathrm{MW}_{\text {th }}$ pool type SFR. With a core composed of the base fuel rod assemblies, annular fuel rod assemblies, and bottle-necked fuel assemblies, the models operated at steady state conditions safely within operating parameters of an actual SFR. These models were then used to perform transient testing. The transient tests conducted were an unprotected loss of heat sink, station blackout, and an unprotected transient overpower accident. Each of these transients was performed for the different fuel assembly configurations, fuel meat materials, and conversion ratios. The results of these transient tests showed that metal fuels were acceptable for all transients in high CR base fuel assemblies, and metal fuels for bottlenecked and annular assemblies could survive a station blackout. However, the oxide fuels were shown to fail during station blackout and should be avoided in SFRs.

The final study focused on developing a RELAP5-3D model for a Hybrid Loop-Pool SFR [5]. This type of reactor combines the two main SFR designs, where the primary loop is contained within a buffer pool of coolant. The focus of this study was to verify the behavior of passive safety systems, the pool reactor auxiliary cooling system (PRACS), and the direct reactor auxiliary cooling system (DRACS), and their ability remove decay heat during a Loss of Forced Circulation (LOFC) transient through natural circulation. The 
RELAP5 model was comprised of the primary coolant system, the PRACS, buffer pool, and the DRACS. The primary system consisted of the reactor core, inlet plenum, outlet plenum, hot pool, and primary pumps. The core was then separated into 7 different parallel components to accurately represent non-uniform heat generation. The cold pool was also separated into three axially separated control volumes to account for thermal stratification, which RELAP5-3D is incapable of. After steady state conditions were met using core power distributions based on the Advanced Burner Test Reactor, the system experiences a LOFC transient and reactor power decay due to a scram. It was assumed that PRACS was the only method of decay heat removal from the primary to the buffer pool. The main temperatures examined were the peak cladding, hot pool, and reactor inlet temperatures. The peak cladding temperature reached a value of $\sim 660 \mathrm{C}$ and it was shown that the PRACS was capable of safely transferring the decay heat to the buffer pool in this transient. Several parametric studies were also conducted on PRACS heat exchangers surface area, intermediate heat exchanger primary side flow area, and primary pump coast-down time. Variation of the PHX surface area effects on peak cladding temperature was shown to be very minor. Peak cladding temperature was also shown to change very slightly with a 30 percent reduction in IHX flow area. The effects on pump coast-down time were shown to be significantly different when varied from the original 200 seconds to 400 seconds, where the peak cladding temperature was decreased by $30 \mathrm{C}$.

\subsection{Experimental Sodium Fast Reactors}

Sodium fast reactors can easily be argued to be the most promising of the Gen-IV reactors due to the optimal heat transfer properties of sodium, the relatively low operating pressure of the primary systems, and the passive safety system of natural convection cooling within the primary. While no SFRs exist in the United States today, this section showcases several experimental SFRs and SFR-like test loops that furthered the development of SFR technology.

The EBR-II is often used as the golden standard for SFR code validation. This pool type $62.5 \mathrm{MW}_{\text {th }}$ reactor was built in 1964 at Argonne National Laboratory and reached criticality in 1965. The EBR-II was built with the fuel cycle optimization being the primary goal, and 
as such the main focus of the primary system was its reliability and operability [6]. One specific goal was that the primary system, coupled with several passive safety systems, could remove decay heat without the secondary systems functioning. At normal operating conditions, the inlet and outlet temperatures were $700 \mathrm{~F}$ and $900 \mathrm{~F}$, respectively. The designed maximum coolant flow velocity was around 25 feet per second. The primary coolant system utilized two pumps to flow coolant through the reactor, and both pumps supplied both a high-pressure and low-pressure flow into the lower plenum of the reactor. Both pumps were operated in parallel during normal operations. Each pump was capable of supplying 4700 gallons of sodium per minute at 55 pounds of head. Many experiments used this reactor to further SFR research.

One such study was the EBR-II X501 experiment [7]. This experiment was meant to show how a homogenous recycle fuel scheme could burn off minor actinides. The main focus of this study was to examine the effects of actinide burning on fuel-cladding chemical interaction, the redistribution of americium, and the release of helium from the fuel. The fuel used as a metallic U-20\% $\mathrm{Pu}-10 \% \mathrm{Zr}$ fuel cast in a silica mold with two actinides, $2.1 \% \mathrm{Am}$ and $1.3 \% \mathrm{~Np}$. These fuel pins were irradiated within the central core of the EBRII for 339 effective full power days. Postirradiation examination (PIE) of gamma scanning, optical microscopy, microprobe analysis, and metallography was conducted on these fuel pins. The results showed that these fuel pins behaved optimally, with the minor actinides not affecting the behavior of this fuel.

Other EBR-II experiments include the heat removal transients SHRT-17 and SHRT-45R, which have been compared to subchannel analysis codes in recent years [8]. The SHRT17 test began by scramming the reactor and shutting off the primary and intermediate pumps simultaneously and allowing the reactor to cool itself through natural circulation. The SHRT-45R test was similar, though an auxiliary electromagnetic pump remained active to provide a small amount of primary cooling. The mass flow rate of the SHRT-45R experiment was around two times higher than that of the SHRT-17. An instrumented subchannel analysis was performed in COBRA-IV-I, where 61 pins within the subassembly were wrapped by wire spacers. The results showed that the radial temperature 
profile was correct near the top of the subassembly, and temperatures measured near the top of core thermocouples and other 14 thermocouples had a good agreement. There was a discrepancy between the simulation and data for the mid-plane thermocouples, and the axial power distribution of the pin was cited as too difficult to predict. Overall, SHRT-45R peak coolant temperatures had good agreement between the simulation and experimental values, though the SHRT-17 peak temperatures were significantly less accurate.

The CABRI research reactor is a pool type research reactor located in southern France operated by the French Alternative Energies and Atomic Energy Commission (CEA). This facility was originally designed with an in-house sodium loop, which finished testing and was removed in 2003. One key characteristic of this facility was the hodoscope onsite, allowing post irradiation examination such as tracking motions within the fuel rods and fuel expansions. This test loop was able to conduct fast transient testing on one or three fuel pins at a time, making it very similar to the loop designed in this thesis.

One study [9] conducted by this facility performed control rod withdrawal accident transient tests on two different mixed oxide industrial fuel pin types, the Ophelie. 6 and Viggen.4 pins. The primary goal of these experiments was to measure the responses of these fuel rods to these transients beyond their end of life conditions. The Ophelie. 6 pins are annular and hollow while Viggen.4 pins are solid. The purpose of these tests was to examine the behavior of these fuel types during these transients, especially failures of the fuel rods. It could be seen that for the Ophelie.6 pins fuel melting occurred within the pins early when the linear power reached $73 \mathrm{~kW} / \mathrm{m}$. These fuel pins also showed little to no difference in cladding diameters before and after testing. Overall the experiments was able to show that these fuel pins could safely withstand the thermal and neutronic conditions of a sodium fast reactor. The experimental results for the solid pins were more difficult to analyze because the hodoscope had not detected anything before the pins failed, though the failure occurred at a linear power of $81 \mathrm{~kW} / \mathrm{m}$. This failure was attributed to several factors such as fuel pressurization resulting in swelling. The cladding showed a deformation of up to 0.6 percent. This experiment did result in the injection of some molten fuel into the primary coolant. The reactor was able to shut down $150 \mathrm{~ms}$ after the pin failure, so the 
conditions of the system could be studied very close to the time of failure. The hodoscope was also able to track the radial and axial fuel motion within the fuel pin during the 150 ms between failure and scram.

The Phenix SFR was built in France in 1973. This reactor was a $560 \mathrm{MW}_{\text {th }}$ pool type SFR [10]. At normal operating conditions, the reactor had a core flow rate of $3000 \mathrm{~kg} / \mathrm{s}$, an inlet temperature of $380 \mathrm{C}$, and an outlet temperature of $530 \mathrm{C}$. The core was separated into three different regions, with 50 percent of the mass flow rate travelling through the inner core, 40 percent through the outer core, and 10 percent through the "fertile zone". The primary system of was composed of the core, three primary pumps, and six intermediate heat exchangers. The intermediate heat exchangers allow heat to be transferred to a secondary sodium system, which were made up of two IHXs, a steam generator, and an expansion tank. This reactor had three of these secondary circuits.

Near the end of this reactor's life, several tests were performed including a natural convection test in June 2009 [11]. The main goal of this test was to improve thermal hydraulic simulation capabilities. However, the reactor was not fully operational during these tests because a secondary system was down. For these tests, the two IHXs for this unfunctional system were replaced by components that restricted any flow through them. The power of the reactor during this test was $120 \mathrm{MW}_{\text {th }}$, and the core flow rate was reduced to $1280 \mathrm{~kg} / \mathrm{s}$. The core inlet and outlet temperature were also reduced to $360 \mathrm{C}$ and $435 \mathrm{C}$ respectively. After these operating conditions were reached, a manual dry out of the steam generators was performed as an unprotected loss of heat sink transient. After that, a manual scram was induced $460 \mathrm{~s}$ later, followed by the primary pumps being shut off and a decrease in secondary pump speed allowing natural convection to begin. The test was broken up into three different phases, the initial phase of the primary pumps being shut off, the second phase of secondary systems creating no heat sink for the primary, and the third phase of opening the steam generator to allow air natural circulation in the casing. This third phase allows some heat sink to exist for the secondary systems. The three simulations used for analysis were: a blind pre-test analysis with assumed conditions, a blind post-test analysis with limited measured data, and a full post-test analysis with results. The results 
of this test showed that the steam generator dry out decreased the reactor power to $50 \mathrm{MW}_{\text {th }}$ before the scram. Natural convection was able to passively cool the reactor efficiently, such that the core outlet temperature began decreasing within five minutes. The natural air convection induced in the steam generators was able to reduce the inlet and outlet temperatures of the core. The blind calculations were shown to have several discrepancies with the experimental data, including the increase of core inlet temperature after dry-out, the decrease of core outlet temperature after dry-out, and heat exchanger inlet temperatures. The heat exchanger inlet temperature discrepancies are likely due to thermal stratification within the hot pool, which is difficult to predict. The post test results were overall closer to the experimental data, though core outlet temperatures were still difficult to compare.

In 2004, the need to test fast reactor technology was recognized and worked on by INL [12]. This proposed loop was named the Gas Test Loop (GTL). The loop was originally designed to be a helium cooled loop placed within the Advanced Test Reactor that could reach a high fast to thermal neutron ratio within the test section. The initial conceptual design used a "booster" fuel assembly surrounding the test section to harden the neutron spectrum [13]. These curved plates formed three annular rings around the test section, with each ring broken into four separate Al-6061 clad $\mathrm{U}_{3} \mathrm{Si}_{2}$ fuel plates. A thermal neutron shield also surrounded the test section to increase the fast to thermal ratio. The loop would ideally be able to reach a fast flux of $10^{15} \mathrm{n} / \mathrm{cm}^{2}$ and a fast to thermal ratio of at least 15 . The test section could house a single test up to $7.5 \mathrm{~cm}$ in diameter and had high velocity helium as the coolant for the test section. The fuel plates surrounding the test section had a water coolant system contained by an aluminum baffle. Initial estimates claimed the test section would need to remove $550 \mathrm{~kW}$ from the experiments. Thermal hydraulic analysis conducted using RELAP5-3D [14] concluded that the design was viable, with the peak temperature of the experiment tube reaching around $690 \mathrm{~F}$ while the fuel plates stayed below $500 \mathrm{~F}$. However, this configuration was projected to be rather expensive, and an alternative cooling assessment was conducted to both find a more effective than using pressurized gas while also reducing the cost [15]. The project was also renamed the Boosted Fast Flux Loop, named so after the innovative "booster" fuel plates. This new design used Hafnium dispersed Aluminum to fill the test section with room for three 
separate experiments cooled by Helium. This Hafnium Aluminum had a separate water cooling system, and acted both as a thermal neutron shield and a heat sink for the experiments. The "booster" fuel plates for this project were manufactured and subjected to thermal hydraulic testing as well as irradiation testing [16]. Post irradiation examinations showed no problems with these designs, and the overall cost of the new design was estimated to be $\sim \$ 30 \mathrm{M}$ lower than the initial GTL design.

\subsection{Numerical Methods}

In engineering, the construction of full scale physical systems can be incredibly costly. Numerical analysis offers an opportunity to solve large systems of equations of a defined domain without resources spent on physical systems. For thermal hydraulic numerical analysis, these systems of equations typically include conservation of mass, momentum, and energy, along with phase change equations. RELAP5-3D was chosen for the thermal hydraulic assessment of this project, though numerous other software packages exist, such as GOTHIC, Fluent, and TRACE. Choosing the correct software for the job is a crucial step. Each individual software package may vary with their methods for solving the systems of equations or may solve different systems of equations entirely.

RELAP5-3D uses a semi-implicit finite difference method to solve its system of equations (though another method called a nearly-implicit finite difference method is available as well) [17]. Finite difference methods are a common tool for solving systems of partial differential equations when regular shaped grids such as boxes and rectangles can be used to represent the domain geometry. Finite difference methods are less effective with irregular shaped geometries due to the difficulty dealing with boundary conditions.

To begin a finite difference approximation, the domain of the problem must be defined in terms of a discrete set of grid points [18]. For a 1-D model such as RELAP5-3D uses, these data points can be labeled $\mathrm{x}_{0}, \mathrm{x}_{1}, \ldots \mathrm{x}_{\mathrm{N}}$. The system of partial differential equations is solved for at these grid points using a Taylor series expansion to approximate the derivative of the function at said grid points. RELAP5-3D specifically uses a central differencing method for its spatial hydrodynamic model with a fixed and staggered grid [17] [19]. The derivative 
at $\mathrm{x}_{\mathrm{j}}$ is solved using the Taylor expansions at $\mathrm{x}_{\mathrm{j}-1}$ and $\mathrm{x}_{\mathrm{j}+1}$. For a function $\mathrm{f}(\mathrm{x})$ on a uniform grid spacing of $h$,

$$
\begin{aligned}
& f_{j+1}=f_{j}+h f_{j}^{\prime}+\frac{h^{2}}{2} f_{j}^{\prime \prime}+\cdots \\
& f_{j-1}=f_{j}-h f_{j}^{\prime}+\frac{h^{2}}{2} f_{j}^{\prime \prime}-\cdots \\
& f_{j}^{\prime}=\frac{f_{j+1}-f_{j-1}}{2 h}-\frac{h^{2}}{6} f_{j}^{\prime \prime \prime}+\cdots
\end{aligned}
$$

This method is considered $2^{\text {nd }}$ order accurate due to the largest error of Eqn ( 8 ) being in terms of $\mathrm{h}^{2}$. It is also possible to calculate $f_{j}^{\prime \prime}$ by adding Eqns ( 6 ) and ( 7 ), resulting in

$$
f_{j}^{\prime \prime}=\frac{f_{j+1}-2 f_{j}+f_{j-1}}{h^{2}}-O\left(h^{2}\right)
$$

Where $\mathrm{O}\left(h^{2}\right)$ is the error term. RELAP5-3D also utilizes a staggered grid for solving conservation equations [17] [19]. A staggered grid means the spatial grid is also defined at points $x_{j+1 / 2}, x_{j-1 / 2}$, etc. Scalar variables, such as mass and pressure, are solved at nonstaggered grid points $\left(x_{0}, x_{1}, \ldots\right)$ while the velocities are solved at the staggered grid points $\left(x_{j-1 / 2}, x_{j+1 / 2}\right)$.

The above equations only describe the way RELAP5-3D discretizes the systems of PDEs with respect to space. RELAP5-3D uses a semi-implicit method to discretize with respect to time. The goal of a semi-implicit numerical method is to discretize certain linear terms implicitly while maintaining linearity in dependent variables. This is done by solving the pressure and velocity terms implicitly while solving all other terms in the conservation equations explicitly. This method also avoids problems with choosing a Courant number. The Courant-Friedrichs-Lewy condition dictates stability in numerical analysis of PDEs when using explicit time discretization [20]. By using an implicit method for time, the time step used is not limited by this law. 
As mentioned earlier, choosing the correct software is a critical step in conducting a CFD based study. Eqn ( 1 ) gives the Peclet number, which describes the primary heat transfer method of a system. A large Pe number indicates advection terms dominate while a small Pe number indicates diffusive terms dominate. Molten sodium has a very large thermal conductivity, meaning molten sodium systems tend to have small Pe numbers. Due to these different methods of heat transfer, different discretization methods are preferred for varying Pe numbers. Typically, small Pe systems $(<2)$ use a central differencing method, as described above for RELAP5-3D, while large Pe systems (>2) use upwind differencing methods [21]. Upwind differencing schemes are dependent on the direction of the flow. Discretized points upwind of the discretized point being solved for are used in the discretization of the PDEs, to properly account for influence those points will have further downstream. RELAP5-3D uses central differencing method to solve for its momentum equations, though it is still somewhat unsuitable for low Pe number flows. RELAP5-3D was originally designed for 1-D two-phase LWR analysis, which typically have high Pe numbers. An assumption made during the software development was that turbulence parameters, Reynolds stresses, and Reynolds heat fluxes can be neglected since axial heat conduction is small compared to axial convective flux of momentum and energy [17] [19]. This means for low Pe number flows where axial heat conduction in the fluid is a large contributor to heat transfer RELAP5-3D could fail to correctly model the physical system. 


\section{FAST SPECTRUM TEST LOOP}

As described in Chapter 1, there is a need for infrastructure capable of simulating SFR operating conditions before future SFR technology can be developed in the United States. The proposed test loop presented in this thesis was dubbed the Fast Spectrum Test Loop (FSTL). While the primary purpose of this thesis is to develop and showcase the thermal hydraulic aspects of the FSTL, a comprehensive study of this loop was conducted involving the mechanical design and neutronics assessment.

One main hurdle in this project is to provide a fast neutron spectrum representative of an SFR. No infrastructure exists in the US capable of providing this spectrum under normal operating conditions. Chapter 2.4 examines the Boosted Fast Flux Loop (BFFL) project that used the ATR, a thermal spectrum dominant reactor, coupled with fuel plates surrounding a test chamber to "boost" the fast flux within said test chamber. Coupled with a thermal neutron shield, the flux spectrum would be hardened within the test chamber; and would ideally be similar to that seen in an SFR core. INL provided the test section (including the fuel plates) design from the BFFL project to be used in the FSTL project. The Large I position within the ATR was chosen as the ideal position for the FSTL, due to its availability and its large diameter.

The FSTL would also need to provide SFR-like thermal hydraulic operating conditions within the test chamber. Molten sodium acting as the primary coolant presents another challenge since the primary coolant of the ATR is water. To prevent water and sodium from interacting, the primary leg of the FSTL would be isolated from any water systems by a noble gas chamber $(\mathrm{He})$.

\subsection{FSTL Overall System}

To summarize, the FSTL is comprised of the following systems:

- Test Section - test samples contained within a sodium cooled loop with Inconel piping within the ATR core. 
- Test Train - the booster fuel plates, their water cooling system, and test section contained within the outer pressure tube.

- Test Loop - test train and all cooling systems and hardware and instrumentation required for operation

- Noble Gas Blanket - Helium gas loop separating sodium loop from water coolant with Inconel piping.

- Thermal Neutron Shield - A thin layer of Hafnium surrounding the Test Section to harden the neutron spectrum. An aluminum support tube exists on the exterior of the shield to separate the Hf from water.

- Booster Plates - Curved U3Si2 Al-dispersed fuel plates surrounding the Test Section to harden the neutron spectrum. These plates used AL-6061 as cladding. Also includes a separate water-cooling loop to remove excess heat from said fuel plates.

\subsection{Loop Design}

This section covers in detail each system of the proposed FSTL, namely the primary loop, helium blanket, thermal neutron shield, and booster plates (with their respective cooling system).

Table 1 shows the materials and properties used in each section, and Figure 1 shows a cross section of the loop through the core. Note that this case has three $\mathrm{U}-\mathrm{Zr}$ fuel pins.

Table 1: System Material Choices and Densities

\begin{tabular}{|l|c|c|}
\hline \multicolumn{1}{|c|}{ Region } & Material & $\begin{array}{c}\text { Density } \\
\left(\mathrm{g} / \mathrm{cm}^{3}\right)\end{array}$ \\
\hline Test Section & Sodium & 0.8539 \\
\hline Pressure Tube Piping & Inconel AMS 5 & 8.22 \\
\hline Gas Gap & Helium & 0.0001956 \\
\hline Envelope Tube Piping & Inconel AMS 5 & 8.22 \\
\hline Water Channels & Water & 0.979 \\
\hline Support Tube & Al-6061 & 2.7 \\
\hline Cladding & Al-6061 & 2.7 \\
\hline Fuel Plates & U3Si2 (20\%), Al dispersed & 12.48 \\
\hline Outer Aluminum Sheath & Al-6061 & 2.7 \\
\hline
\end{tabular}




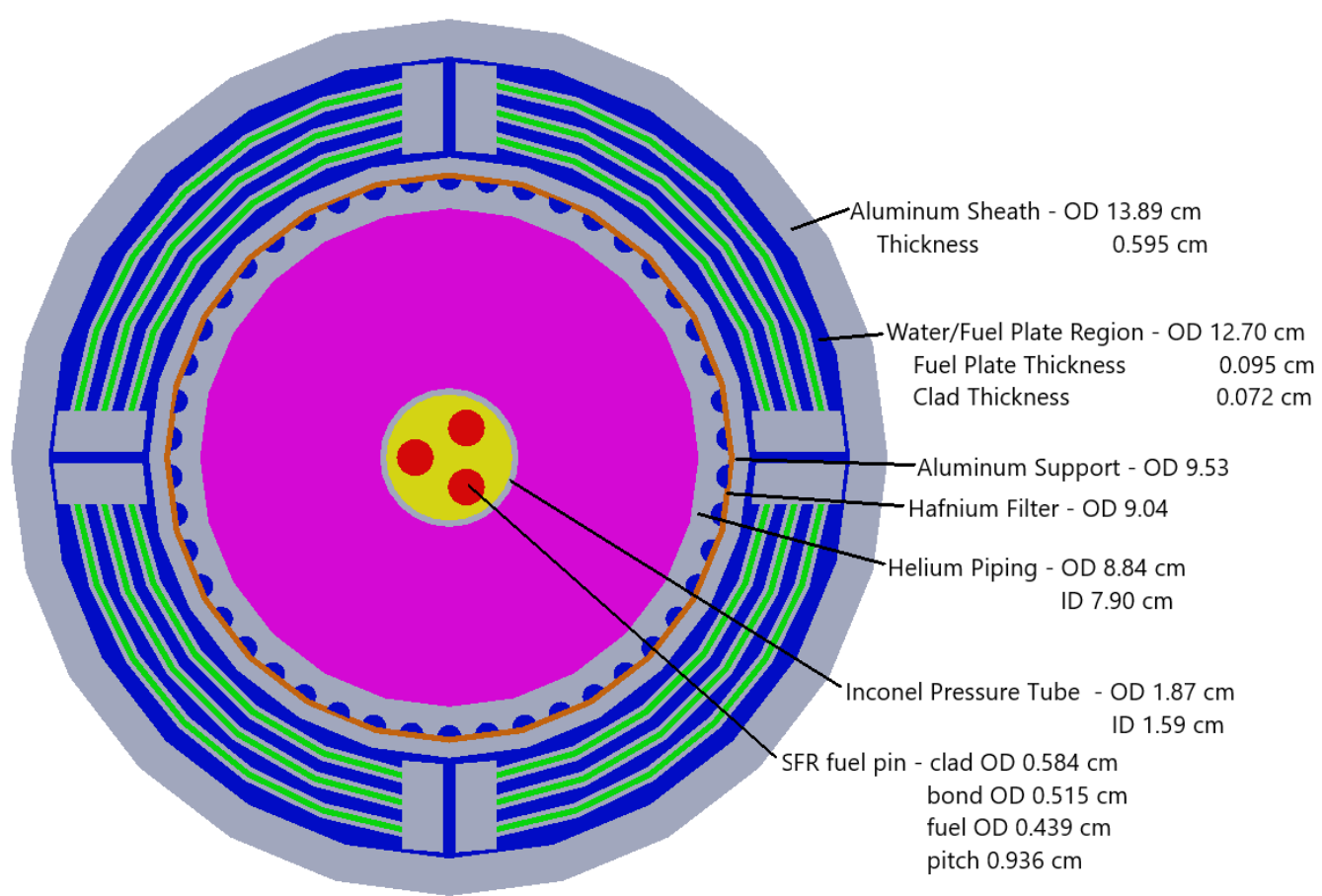

Figure 1: Cross Section of Initial FSTL Design with three fuel pins

\subsubsection{Primary System}

The only way to simulate SFR thermal operating conditions is to use molten sodium as the primary coolant. One key parameter for the any fuel pins within the primary loop is to reach a temperature increase from the inlet to outlet that simulates a real SFR. Nuclear Systems Volume 1 [22] gives key operating parameters for SFRs. A typical SFR core has a $50 \mathrm{~K}$ temperature increase during normal operating conditions. Operating pressure for an SFR is at atmospheric pressure, $101 \mathrm{kPa}$. A single SFR fuel pin is 1.27 meters long and $2.92 \mathrm{~mm}$ in outer diameter, and as such the primary system must be able to accommodate for one to three fuel pins. While a typical SFR has a primary fluid velocity of $\sim 2 \mathrm{~m} / \mathrm{s}$ through the core, the flow rate for this test section will be adjusted to ensure the $50 \mathrm{~K}$ temperature increase is reached across the core. The primary loop would consist of a pump capable of meeting the needs of this project, placed within the equipment room at the ATR facility. All FSTL equipment, such as heat exchangers and pumps, would be housed in the equipment room. The cold leg would travel through existing piping routes to the ATR and enter the ATR through the L-flange, to use an existing reactor pressure vessel penetration. 
The cold leg would travel to the bottom of the ATR core, and the test section would travel through the large I position in the core. The hot leg would then travel out of the pressure vessel through the L-flange and back to the ATR equipment room.

To correctly model flow conditions of an SFR, equivalent subchannel flow areas are used for each fuel pin. These flow areas are calculated based on hexagonal SFR fuel arrays with known pin pitch and rod diameters. This system uses a slightly larger than normal fuel pitch than a typical SFR due to the neutronics of the system, with a pitch to diameter ratio of 1.603 instead of 1.15. This does result in a larger flow area per pin, though a lower flow velocity will result in a similar mass flow rate. The equation for a hexagonal subchannel is given from Table J.3 in Nuclear Systems Volume 1 [22],

$$
A_{f l}=\frac{\sqrt{3}}{4} P^{2}-\frac{\pi D^{2}}{8}
$$

Each subchannel cools an equivalent of a half of a fuel pin due to the hexagonal geometry, so the primary flow area for this system will be equal to the area of two subchannels per pin. Chapter 4 lists each case study examined with their respective flow areas and pressure differences, while Chapter 5 explains the results of each test and gives the resulting flow velocity.

\subsubsection{Helium System}

The surrounding helium system serves two primary purposes: to provide a barrier between the primary loop and any water systems, and to provide passive cooling to the primary loop through the core. To provide conditions typical of a helium system, the helium enters the core near atmospheric pressure and should enter the test section of the core at a temperature similar to the primary loop. Since the booster fuel plates are already developed, the outer dimension for the helium system is a constant. The flow area for the helium system is entirely dependent on the flow area of the primary system, where a large primary diameter results in a smaller flow area of the helium system. The mass flow rate for this system is relatively small, on the order of $1 \mathrm{E}-2-1 \mathrm{E}+0 \mathrm{~kg} / \mathrm{s}$. Chapter 4 lists each case study examined with their respective flow areas and pressure differences, while Chapter 5 explains the 
results of each test and gives the resulting mass flow rate. The helium system encapsulates the entire primary loop through the core and would enter and exit the pressure vessel through the L-flange with the primary loop. Supporting equipment for the helium loop would also be placed in the ATR equipment room with the piping following the primary loop.

\subsubsection{Thermal Neutron Shield}

A single layer of hafnium surrounds the test section to shield the test section from thermal neutrons. This is to optimize the fast to thermal neutron ratio within the test section. The group that designed the BFFL system originally included a cooling system for the Hf filter, though neutronic analysis for the current system shows that heat generation within the Hf filter is on the order of $100 \mathrm{~W}$, and the water cooling used for the booster fuel plates is sufficient to cool the filter. This filter has an inner diameter of $88.39 \mathrm{~cm}$ and an outer diameter of $90.42 \mathrm{~cm}$.

\subsubsection{Fuel Plate and Respective Cooling System}

To generate a high fast to thermal neutron flux ratio in the test section, "booster" fuel plates designed by the BFFL project surround the test section and are cooled by a water system. These fuel plates are composed of $\mathrm{U}_{3} \mathrm{Si}_{2}$, and are clad by Al-6061. The design for these plates is shown in Figure 2, where four trains each house three plates. Figure 3 then shows the cross section of the BFFL, showcasing these fuel plates surrounding the test section. The cross section of the FSTL is largely based on the cross section of the BFFL, though with several key differences due to the nature of SFRs. The BFFL plates were not originally designed for the Large-I position, and as such needed to be scaled down for this project. As such this design was slightly modified to optimize the fast to thermal flux ratio of the system during the neutronics analysis. During the neutronics analysis, the thermal power of each plate was reported to the thermal hydraulics analysis to ensure the plates could be safely cooled within the test section. The cooling system for these plates had already been determined to be optimized at $1.033 \mathrm{MPa}(150 \mathrm{psi}), 8 \mathrm{~m} / \mathrm{s}$, and an inlet temperature of 340 $\mathrm{K}(152 \mathrm{~F})$. The flow area for these plates remained unchanged across each different case study examined, as the outer aluminum baffle of the test section could not be changed. 


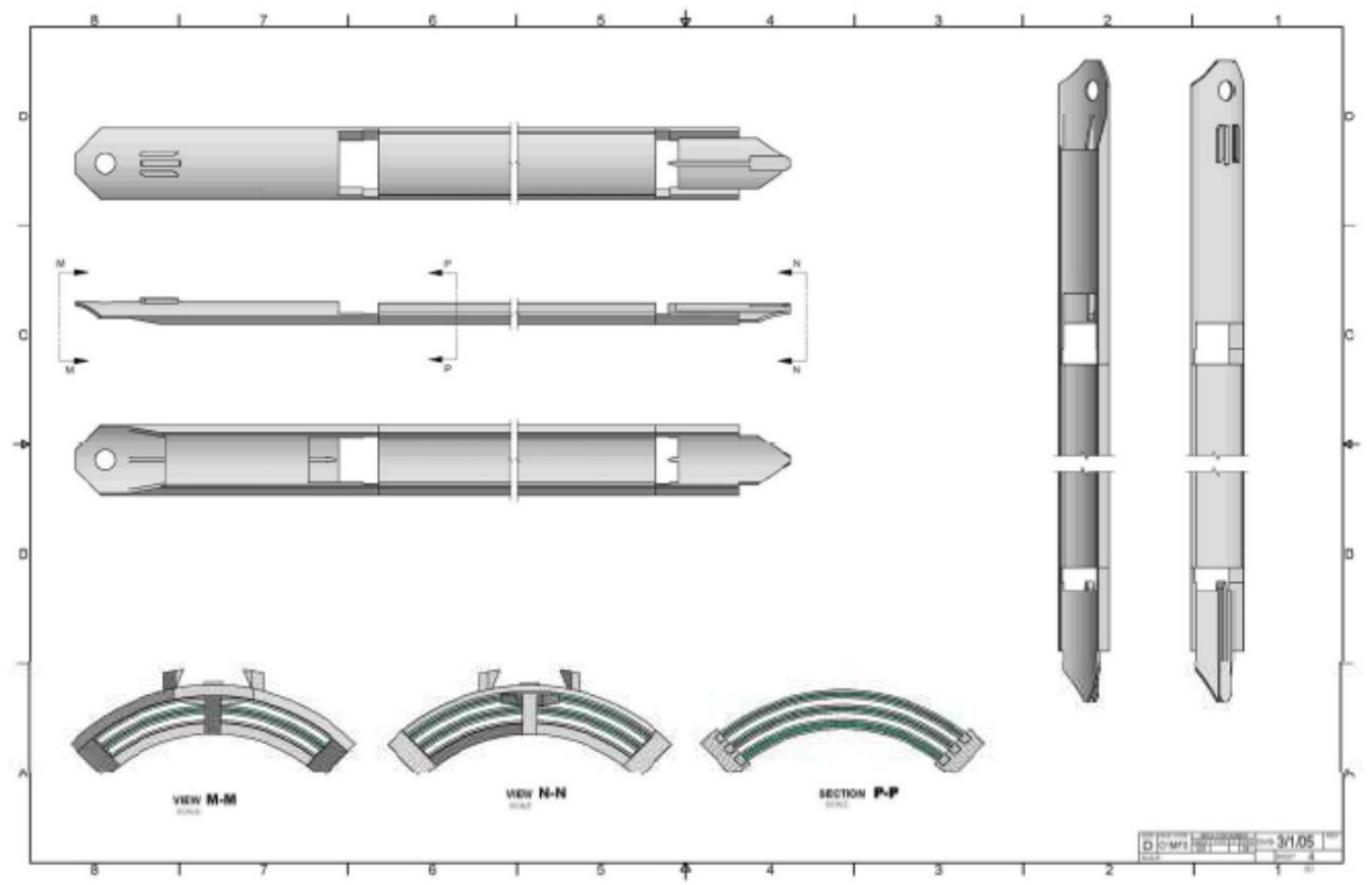

Figure 2: Booster Fuel Plate Design from BFFL [16]

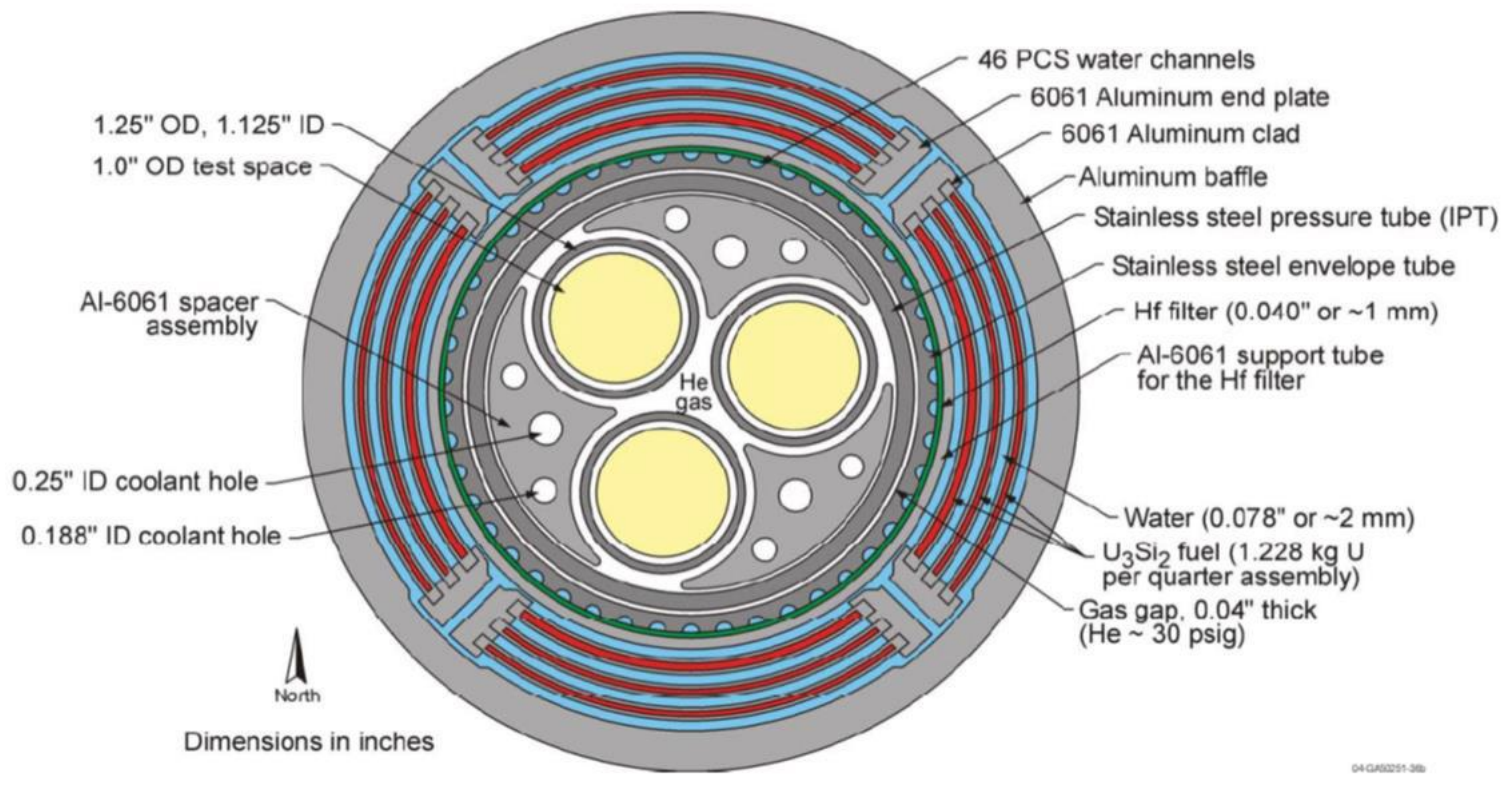

Figure 3: Cross Section of the Test Train for the BFFL [16] 


\subsection{Development of FSTL}

Many unique challenges arose during the development of this loop, including the feasibility of installing and running the loop, inserting test sections within the ATR, and optimizing the neutronics and thermal hydraulics of the system. To optimize the design of the loop, several programs were used to model proposed designs. The neutronics and thermal hydraulics were tested separately in parallel and iteratively updated together.

\subsubsection{Mechanical Design}

One of the greatest challenges facing this project is the safe design of a sodium loop within the ATR, a light water reactor. Primarily, several considerations must be accounted for in this feasibility study:

- Flowing Sodium Loop

- Experiment Insertion

- Experiment Removal

- Penetration into RPV

- Piping Routing

- Equipment Space

- Sample Space

Flowing sodium through a water cooled reactor could be a safety issue, and as such a helium blanket is considered as part of the design to separate the sodium loop from the water cooling systems. The installation of a sodium flowing loop provides another challenge, as sodium is a solid at atmospheric temperature and pressure. The installation plan is to install the primary system while the reactor is experiencing downtime. The primary piping will have solid sodium within it during installation. The loop components would be lowered through the reactor head and installed with the frozen sodium. When the reactor is started again and the loop will be used for experiments, heaters will be used to heat the sodium and turn it to a liquid form. During future reactor downtimes the molten sodium will be allowed to cool down and return to a solid form.

Insertion and removal of test experiments within a molten sodium loop provides another challenge. The installation plan for test experiments is to use one time use test sections 
installed and removed during reactor downtime. The test section must be prepped with frozen sodium and the test experiments already installed. The test section will be lowered through the upper head to be installed, connected to the rest of the loop via double flanges. When the test is completed and test section is ready to be removed, during the next reactor downtime the test section will be removed from the rest of the loop and extracted from the reactor via the ATR canal transfer. This infrastructure is typically used for removal of test sections from the core and would work for this experiment.

Installation of a new loop through the ATR would require the use of a penetration into the reactor pressure vessel. The operators and maintenance workers on the ATR would likely prefer if a new penetration of the ATR was avoided, and as such existing penetrations through the RPV are the primary considerations for this project. The penetration planned for this project is the L-flange given the ideal positioning on the upper section of the RPV. Equipment space and sample space exist within the ATR equipment rooms, and piping routes exist to go to and from the L-flange and equipment rooms. The equipment rooms would house the necessary pumps and heat exchangers required for the FSTL. Figure 4 illustrates a schematic and render of the planned piping routes to be used for the FSTL. 


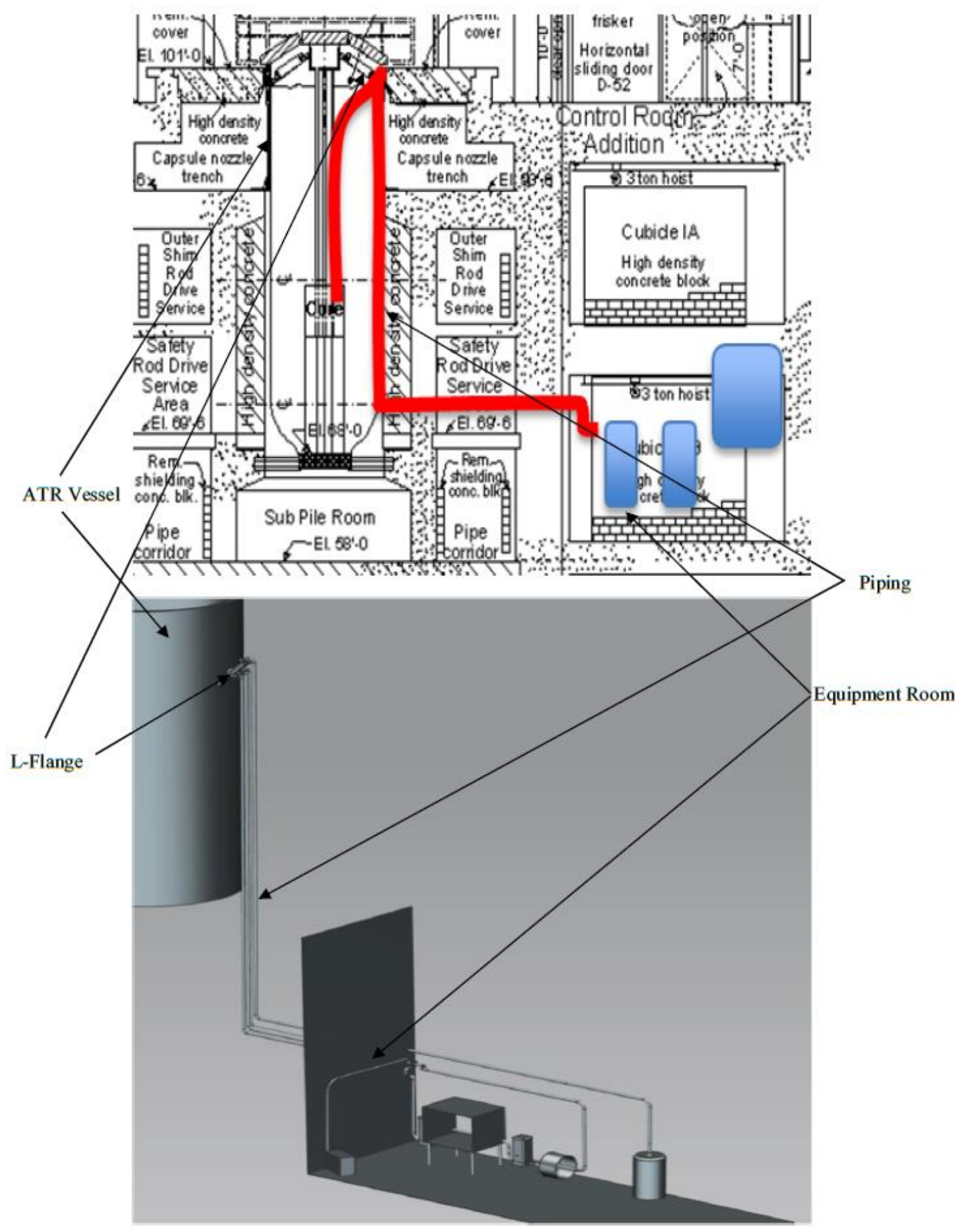

Figure 4: Schematic (top) and rendering (bottom) of piping routes for FSTL [23] 
Figure 4 shows the overall piping routing for the FSTL, though this can be divided into three separate regions: the connection to the outside of the pressure vessel at the L-flange, the piping connecting the test loop to the equipment room, and the equipment room. The FSTL test train would connect directly to the reactor vessel through the L-flange, shown in Figure 5. Several equipment rooms in the ATR basement are potential candidates for housing the FSTL heat exchangers, pumps, and other equipment. Room B103 would house the pumps and heat exchangers for the sodium and helium systems, while instrumentation and control cables would pass through Room B104 along the routing to Room B103. Figure 6 shows the proposed layout of this equipment room. 


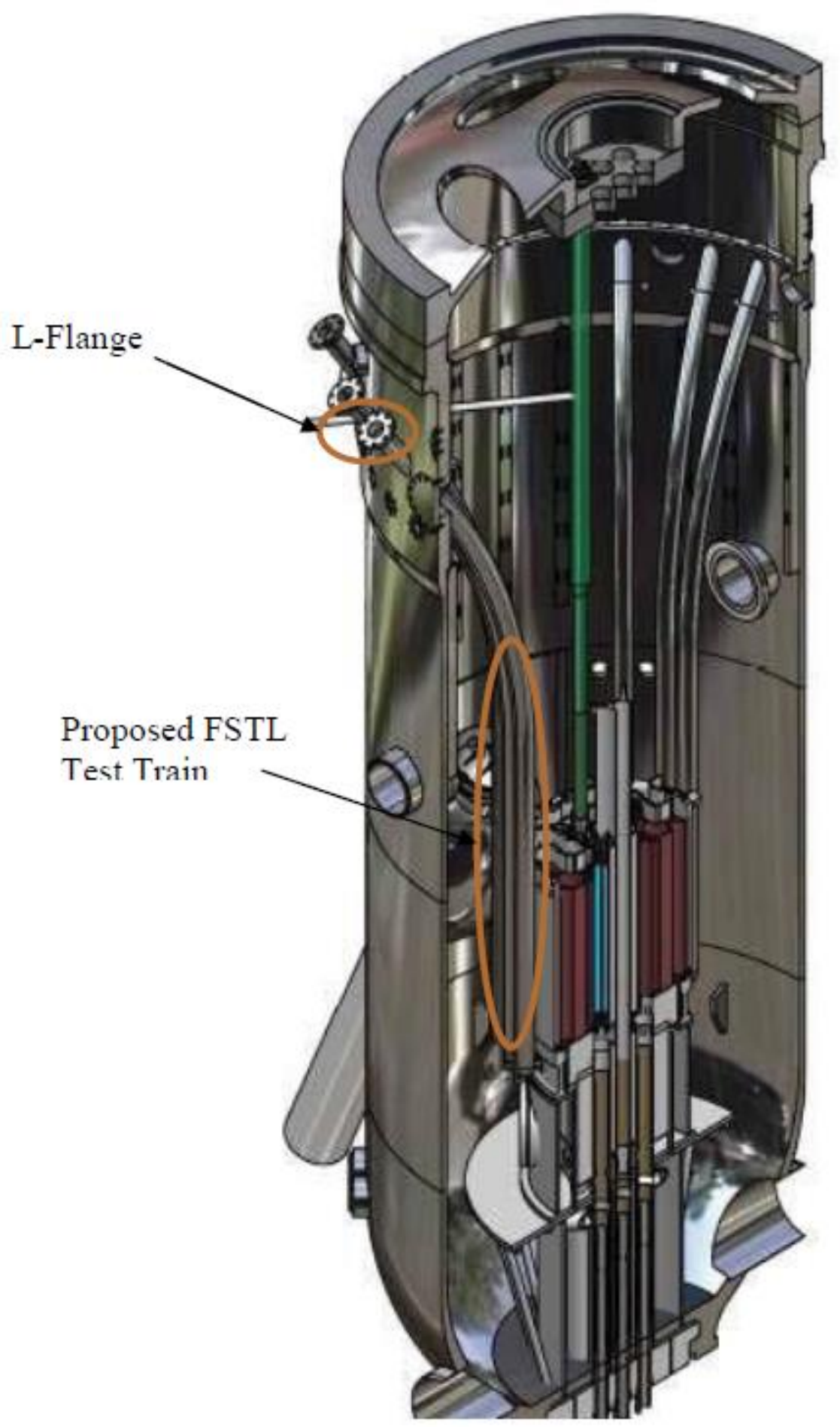

Figure 5: Internal view of ATR with FSTL in place [23] 


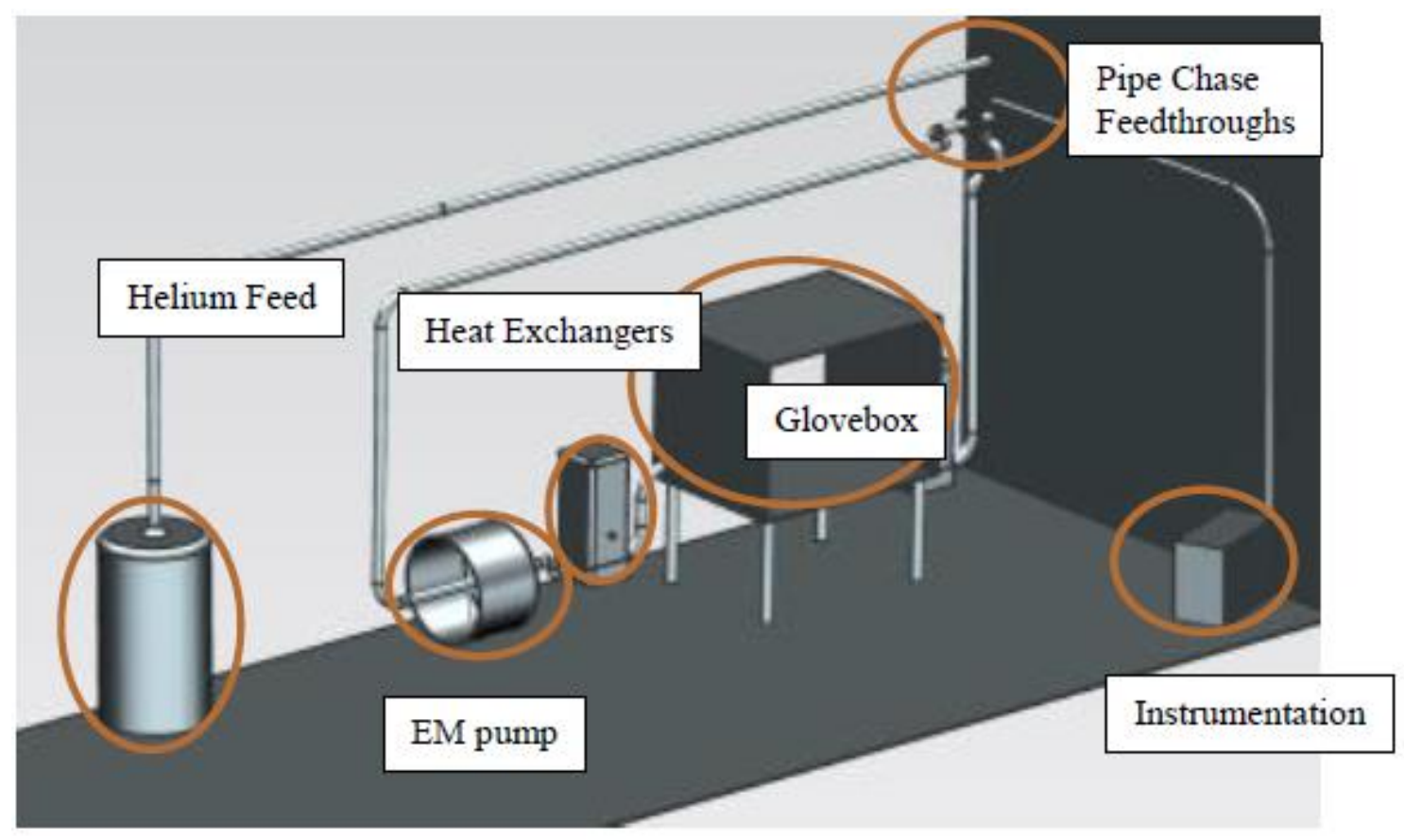

Figure 6: Proposed Layout of Room B103 [23]

The initial design, with a cross section shown in Figure 1, incorporates a single pass through design, where sodium entered and exited the test loop from a single port. Coolant is supplied via the cold leg, with sodium flowing downwards through the ATR. The loop would approach the core from the bottom, and coolant would flow upwards through the test section. The hot leg would the return the heated coolant to the equipment room. However, a second design of a test section was also examined, incorporating a U-shaped loop of the primary through the test section. Figure 7 shows how this design would enter the Large I position and test section. 


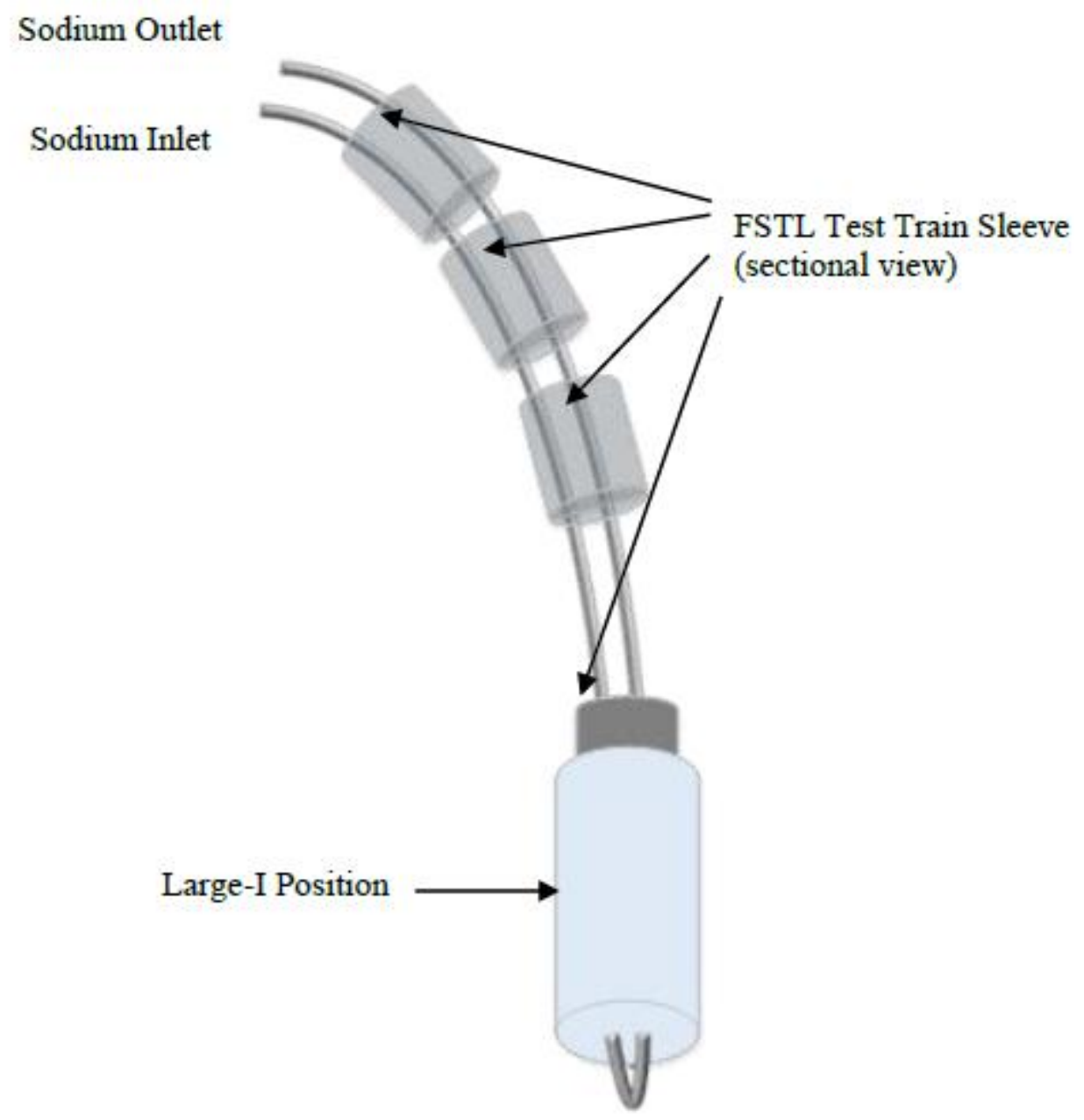

Figure 7: Cut-away schematic of U-shaped internal test loop [23]

\subsubsection{Neutronics}

As mentioned previously, INL provided the SolidWorks models of the BFFL test section to Oregon State University for the FSTL project. It is important to note that the size of the fuel plates had to be slightly scaled down to be used for the Large I position in the ATR. Attila was chosen as the primary neutronics software used to analyze this system. The primary goals of these assessments were to ensure that neutron spectrum within the test section was similar enough to SFR operating conditions, as well as determining heat generation within fueled regions of the test section. This includes both the booster fuel plates and SFR fuel pins placed within the test chamber. These heat generation values are then used in the thermal hydraulics assessment of this project. Figure 8 shows the provided 
heat generation values for a test case with three SFR fuel pins within the test section of the FSTL.

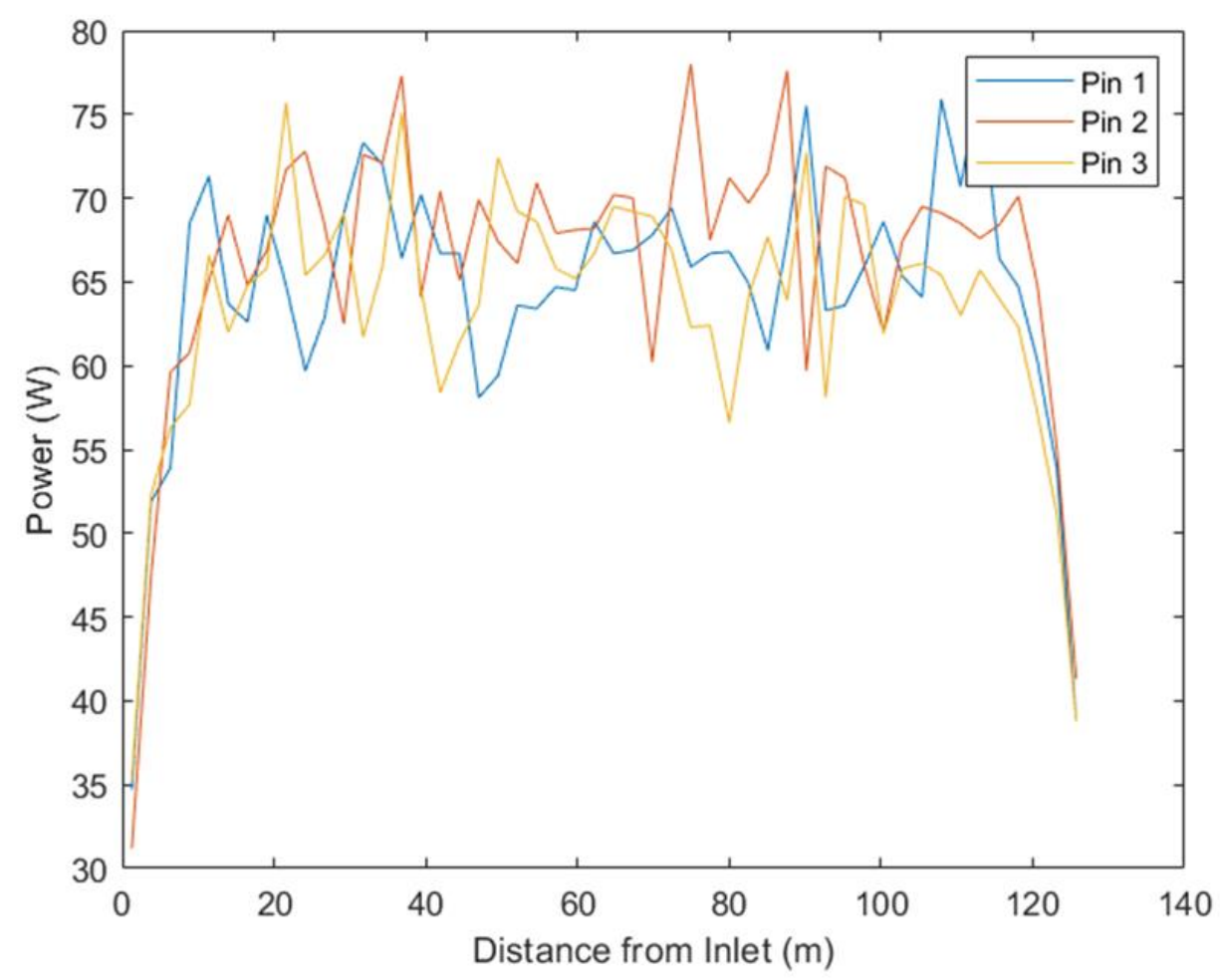

Figure 8: Pin Power for Three Fuel Pin Test Case

\subsubsection{Thermal Hydraulics}

The nuclear standard thermal hydraulic code RELAP5-3D was used to assess the thermal and hydraulic balance within the vehicle and core region for the FSTL. RELAP5-3D is capable of modeling all fluids used in this project: molten sodium, water, and helium. The EBR-II is used as the baseline model for SFR operating conditions, with the sodium inlet temperature and pressure of $640.0 \mathrm{~K}$ and $1 \mathrm{~atm}$ respectively. The goal of the thermal hydraulics assessment was to determine whether the loop could feasibly and safely be cooled given the heat generation and required operating conditions. Chapter 4 details the RELAP5-3D model used to analyze several different test chamber designs this loop must accommodate for. 


\section{RELAP5-3D MODEL DESCRIPTION}

\subsection{General Model}

The RELAP5-3D model constructed for this project currently utilizes seventeen hydrodynamic volumes and three heat structures. Six of hydrodynamic volumes (100-105) represent the primary loop, using sodium as the working fluid; three volumes (300-302) represent the protective noble gas blanket and use helium as the working fluid; and eight volumes $(500-505,600-601)$ represent the water coolant system. A block diagram of the overall model is provided in Figure 9.

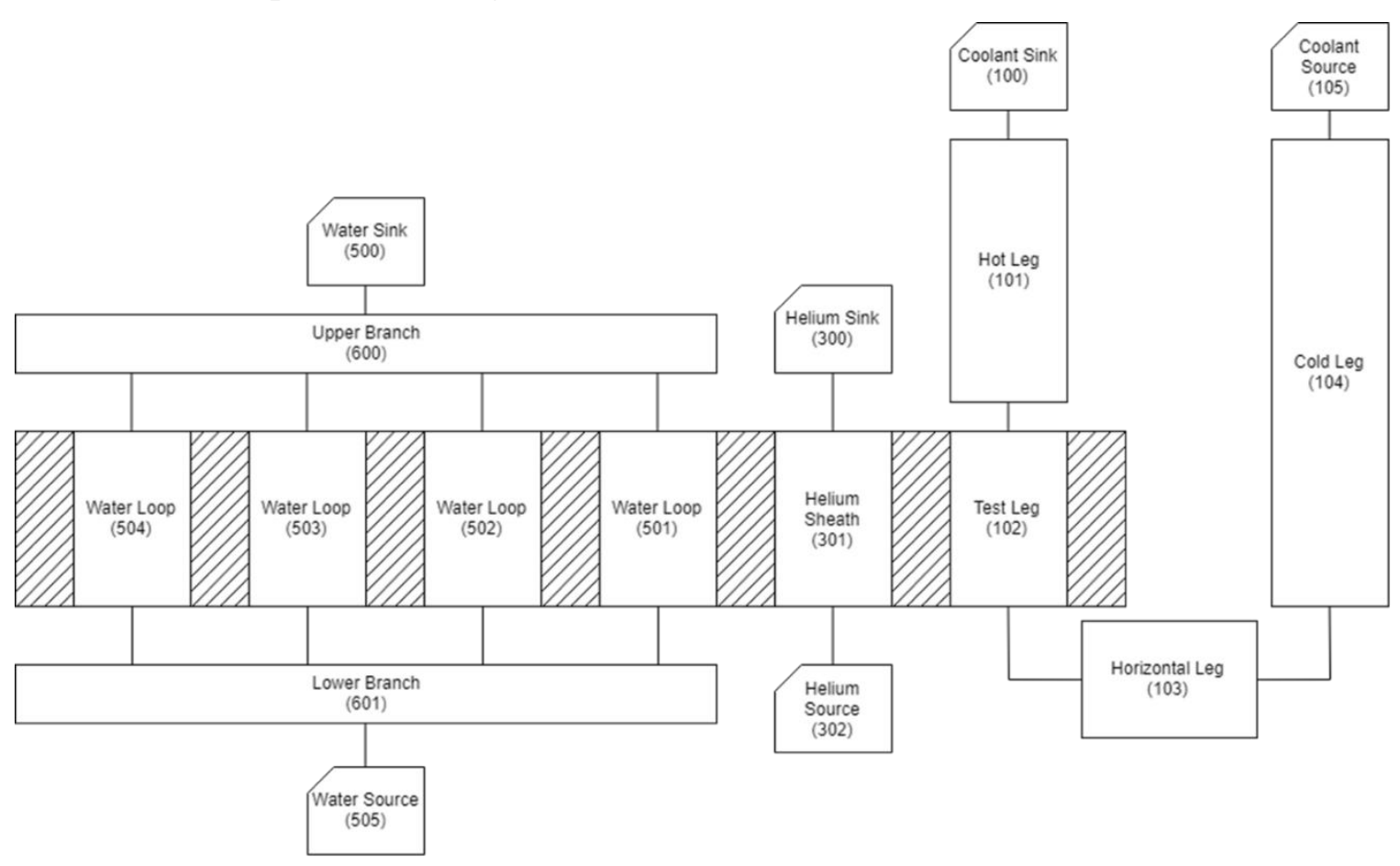

Figure 9: RELAP5-3D block diagram of the FSTL system

\subsubsection{Primary Loop System}

The primary system is modeled in RELAP by six hydrodynamic components. These include two time dependent volumes to supply and remove coolant from the system, the cold leg and horizontal leg that transport coolant from the inlet to the test leg, the hot leg that transports coolant from the test leg to the outlet, as well as the test leg itself. The test leg design varies across the five separate case studies in this report, described in detail in 
Sections 4.1-4.5. The first case study contains no test chamber or experiment within the test leg.

Volumes 100 and 105 are the primary coolant sink and source, respectively, and are modeled as a time dependent volume. These volumes provide temperature and pressure boundary conditions for the model. A pressure differential of $13.675 \mathrm{kPa}$ is implemented to provide the driving force for the primary flow. Volumes 101, 103, and 104 are the hot, horizontal, and cold legs, respectively, for the primary coolant. These volumes represent the path that the sodium flow must take to enter and exit the test section.

Volume 102 is the test section including the primary coolant (sodium). This test train is modeled with $50 \mathrm{sub}$-volumes of equal length $(2.54 \mathrm{~cm})$. The outer boundary of the test section is coupled to heat structure (HS) 112, which represents the Inconel piping separating the primary coolant from the helium gas blanket. All 50 sub-volumes are coupled to this heat structure. The inner boundary of this volume is coupled to HS 102, which serves as the internal test section for the FSTL. A graphic of the primary loop structure is provided in Figure 10. 


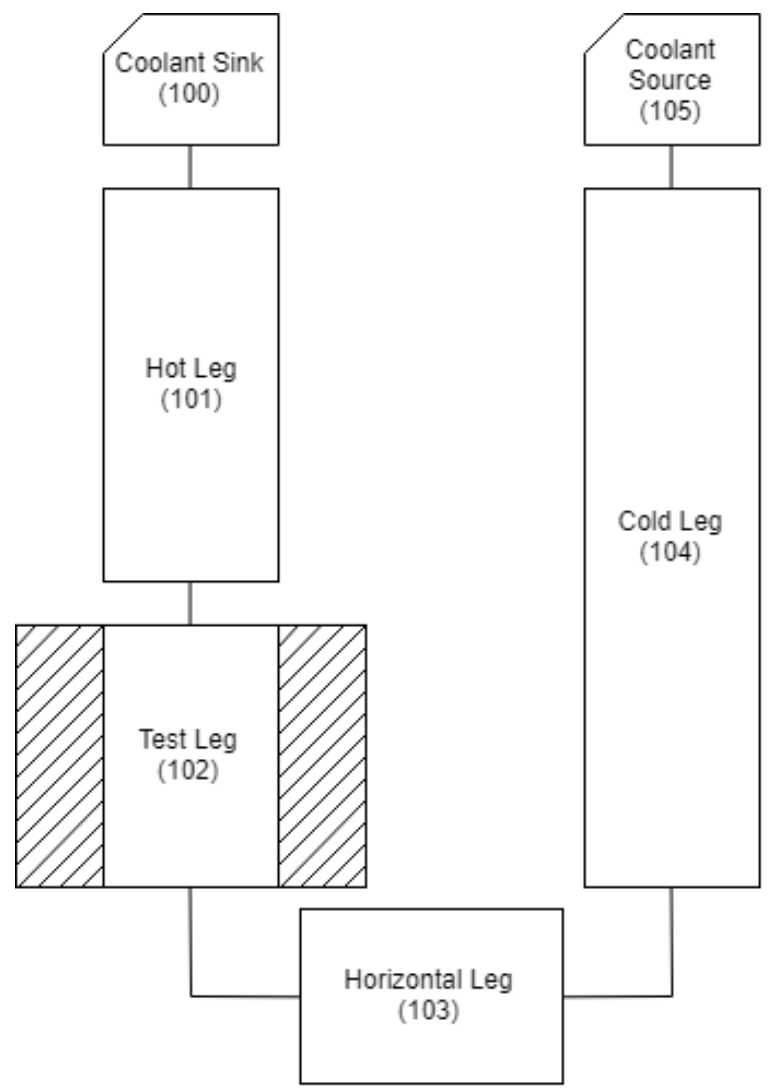

Figure 10: RELAP5-3D Representation of the Primary Loop System

Table 2 shows the hydrodynamic properties (flow area, length, and hydraulic diameter) of each sub-volume within the primary loop. 
Table 2: Hydrodynamic properties, primary loop

\begin{tabular}{|l|c|c|c|c|c|c|}
\hline $\begin{array}{c}\text { Volume } \\
\#\end{array}$ & $\begin{array}{c}\text { Sub-Volume } \\
\#\end{array}$ & $\begin{array}{c}\text { Length } \\
(\mathbf{c m})\end{array}$ & $\begin{array}{c}\text { Flow Area } \\
\left(\mathbf{m m}^{\mathbf{2}}\right)\end{array}$ & $\begin{array}{c}\mathbf{D} \mathbf{h} \\
\mathbf{( \mathbf { c m } )}\end{array}$ & $\begin{array}{c}\mathbf{T} \\
\mathbf{( K )}\end{array}$ & $\begin{array}{c}\mathbf{P} \\
\mathbf{( k P a )}\end{array}$ \\
\hline 100 & 1 & 100.0 & 66.14 & N/A & 600.0 & 101.325 \\
\hline 101 & 1 & 100.0 & & & & \\
\hline 102 & $1-50$ & 2.54 & & & & \\
\hline 103 & 1 & 1.000 & & & & \\
\hline 104 & 1 & 227.0 & & & & \\
\hline 105 & 1 & 100.0 & & & & 108.000 \\
\hline
\end{tabular}

\subsubsection{Noble Gas Blanket}

The noble gas blanket is modeled in RELAP with three hydrodynamic volumes. The components include two time-dependent volumes to supply and remove helium from the system, with a single annular pipe connecting the two.

Volumes 300 and 302 are the helium gas blanket sink and source, respectively, and are modeled as time dependent volumes. The pressure differential across the helium gas blanket was adjusted in the early stages of simulation, as having a large pressure differential for the blanket dramatically increased the simulation run time.

Volume 301 is the helium gas blanket surrounding the test leg of the primary loop. This leg is modeled with 10 sub-volumes of equal length $(12.7 \mathrm{~cm})$. This volume is coupled with two heat structures, which can be seen in greater detail in Figure 11. The inner boundary of this volume is coupled to HS 112, meant to represent the Inconel piping separating the primary coolant from the helium gas blanket; where five sub-volumes of HS 112 are coupled to a single sub volume of Volume 301. The outer boundary of this volume is coupled with HS 301, meant to represent the outer piping for the helium gas blanket where five sub-volumes of HS 301 are coupled to a single sub volume of Volume 301. Table 3 provides the hydrodynamic properties of each sub-volume in the noble gas blanket assembly. 


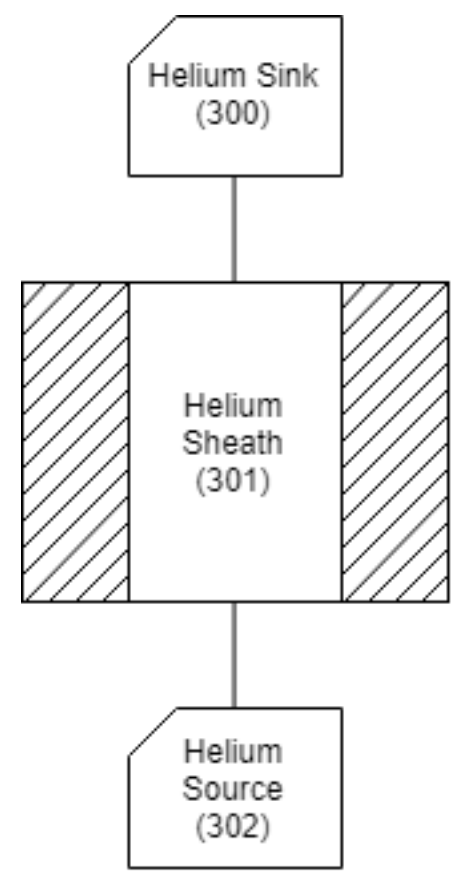

Figure 11: RELAP5-3D Representation of the Noble Gas Blanket

Table 3: Hydrodynamic properties, inert gas blanket

\begin{tabular}{|l|c|c|c|c|c|c|}
\hline $\begin{array}{c}\text { Volume } \\
\#\end{array}$ & $\begin{array}{c}\text { Sub-Volume } \\
\#\end{array}$ & $\begin{array}{c}\text { Length } \\
(\mathbf{c m})\end{array}$ & $\begin{array}{c}\text { Flow Area } \\
\left(\mathbf{m m}^{\mathbf{2}}\right)\end{array}$ & $\begin{array}{c}\mathbf{D} \mathbf{h} \\
(\mathbf{m m})\end{array}$ & $\begin{array}{c}\mathbf{T} \\
(\mathbf{K})\end{array}$ & $\begin{array}{c}\mathbf{P} \\
\mathbf{( k P a})\end{array}$ \\
\hline 300 & 1 & 100.0 & 4797 & 67.57 & 510.0 & 101.325 \\
\hline 301 & $1-50$ & 2.54 & & & & 101.325 \\
\hline 302 & 1 & 100.0 & & & & 101.380 \\
\hline
\end{tabular}

\subsubsection{Booster Fuel Plates Coolant}

The booster fuel plates coolant system is modeled in RELAP with eight hydrodynamic volumes. There are two time-dependent volumes to supply and remove helium from the system, two branches to split flow into four separate channels, and these four channels represent the different flow paths water can travel through the fuel plate bundles.

Volumes 500 and 505 are time dependent volumes and define the boundary conditions for the simulation. Conditions for the flowing water were assumed to be constant at $1.033 \mathrm{MPa}$ $(150 \mathrm{psi}), 8 \mathrm{~m} / \mathrm{s}$, and an inlet temperature of $340 \mathrm{~K}(152 \mathrm{~F})$. Some variation may exist within separate branches of the system, though the inlet and outlet velocity must remain 8 $\mathrm{m} / \mathrm{s}$. 
Volumes 600 and 601 are the upper branch and lower branch respectively. These branches separate flow from the coolant source and sink into four separate hydrodynamic volumes. The dimensions of these different flow areas are listed in Table 4.

Volumes 501, 502, 503, and 504 act as the components that interact with thermal neutron filter (HS 301) and the triad of fuel plate assemblies (401, 402, and 403), respectively. Volumes 501 - 504 are modeled as annular pipes so each can remove heat from the surrounding fuel plates. Each volume has 50 axial subdivisions of equal length $(2.54 \mathrm{~cm})$. Their hydrodynamic properties are provided in Table 4.

Table 4: Hydrodynamic properties, booster fuel plate coolant

\begin{tabular}{|l|c|c|c|c|c|c|}
\hline $\begin{array}{c}\text { Volume } \\
\#\end{array}$ & $\begin{array}{c}\text { Sub-Volume } \\
\#\end{array}$ & $\begin{array}{c}\text { Length } \\
(\mathbf{c m})\end{array}$ & $\begin{array}{c}\text { Flow Area } \\
\left(\mathbf{c m}^{2}\right)\end{array}$ & $\begin{array}{c}\mathbf{D}_{\mathbf{h}} \\
(\mathbf{c m})\end{array}$ & $\begin{array}{c}\mathbf{T} \\
(\mathbf{K})\end{array}$ & $\begin{array}{c}\mathbf{P} \\
(\mathbf{k P a})\end{array}$ \\
\hline 500 & 1 & 100.0 & 27.825 & 0.2507 & 340.0 & 1033.00 \\
\hline 501 & $1-50$ & 2.54 & 6.6188 & 0.4330 & & \\
\hline 502 & $1-50$ & 2.54 & 6.1742 & 0.3705 & & \\
\hline 503 & $1-50$ & 2.54 & 6.0785 & 0.3374 & & \\
\hline 504 & $1-50$ & 2.54 & 11.408 & 0.5852 & & \\
\hline 505 & 1 & 100.0 & 27.825 & 0.2507 & & \\
\hline
\end{tabular}

\subsubsection{Heat Structures}

All the heat structures utilized in this model are tied together in succession from the test section, radially outward, to the outer aluminum sheath; the representation of the assemblage of these heat structures is provided in Figure 12. 
HS 404 Vol 504 HS 403 Vol 503 HS 402 Vol 502 HS 401 Vol 501 HS 301 Vol 301 HS 112 Vol 102 HS 102

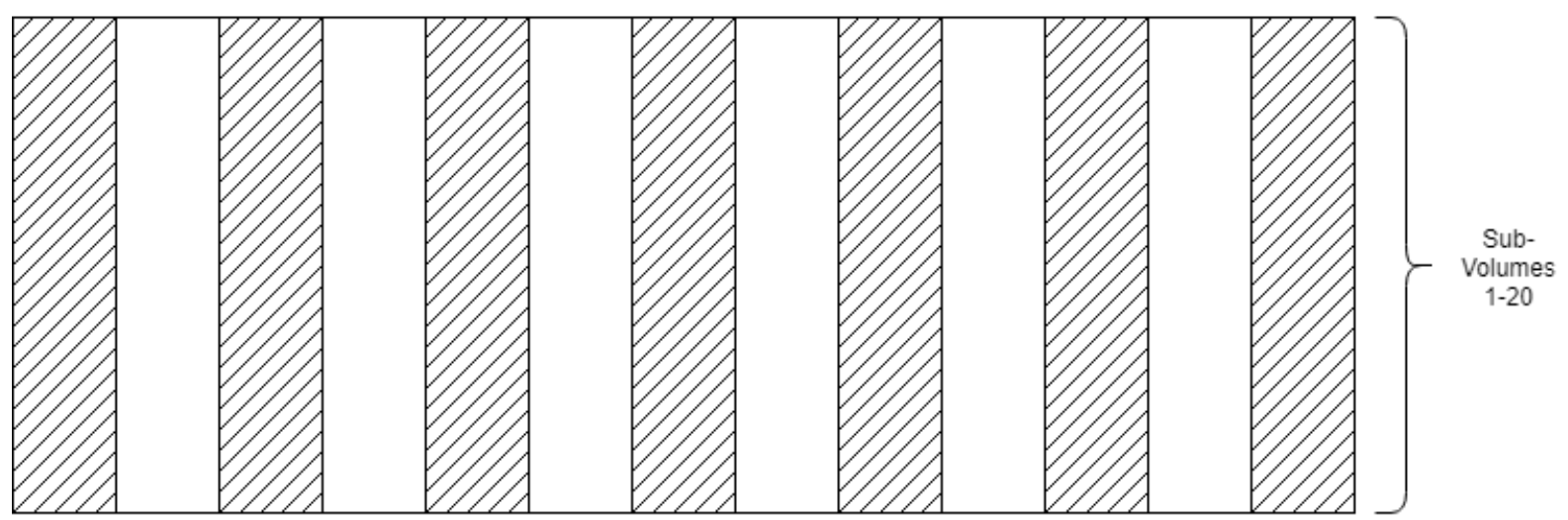

Figure 12: RELAP5-3D heat structure diagram

The physical description for each heat structure in the RELAP5-3D structure is provided in Table 5.

Table 5: Description of each heat structure

\begin{tabular}{|l|l|}
\hline Heat Structure & Description \\
\hline 102 & Internal Test Section \\
\hline 112 & Primary Loop Piping \\
\hline 301 & Gas Piping, Hf Filter, and Inner Al-6061 Sheath \\
\hline 401 & Inner Booster Fuel Plate \\
\hline 402 & Middle Booster Fuel Plate \\
\hline 403 & Outer Booster Fuel Plate \\
\hline 404 & Outer Al-6061 Sheath \\
\hline
\end{tabular}

Heat structure 112 is the outer piping of the primary coolant, separating the primary sodium coolant (Volume 102) from the helium gas blanket (Volume 301). No internal heat generation takes place within this structure. This heat structure has 50 axial sub-volumes and each axial sub-volume is $2.54 \mathrm{~cm}$ long. The radial sub-volume length was chosen only to divide each sub-volume equally. The inner boundary is coupled to the Volume 102, subvolumes 1-50; and uses a convective boundary condition. The outer boundary is coupled to the Volume 301, sub-volumes 1-50; and uses a convective boundary condition. 


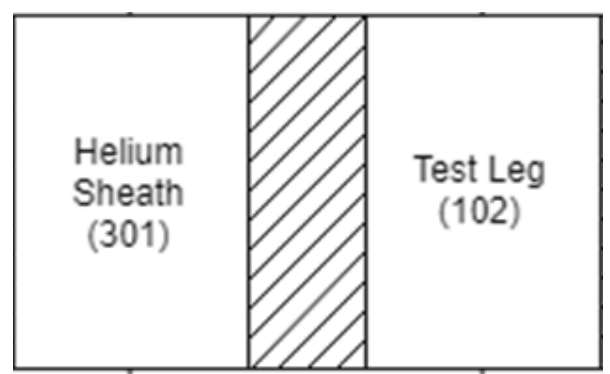

Figure 13: RELAP5-3D Representation of the FSTL test section

Heat structure 301 is the outer piping of the noble gas blanket (Figure 14). This is modeled as a $0.476 \mathrm{~cm}$ thick Inconel pipe in contact with the helium gas, a $0.0952 \mathrm{~cm}$ layer of hafnium, and a $0.238 \mathrm{~cm}$ layer of Al-6061 in contact with the water channel. Internal heat generation takes place within this heat structure, and is dependent on the thermal power distribution produced through the accompanying neutronic analysis. The heat structure has 50 axial sub-volumes and eight radial sub-volumes; each axial sub-volume is $2.54 \mathrm{~cm}$. The inner boundary of this heat structure is coupled to hydrodynamic volume 301, sub-volumes $1-50$, and uses a convective boundary condition. The outer boundary is coupled to volume 501, sub-volumes 1-50, and uses a convective boundary condition. 
HS 301
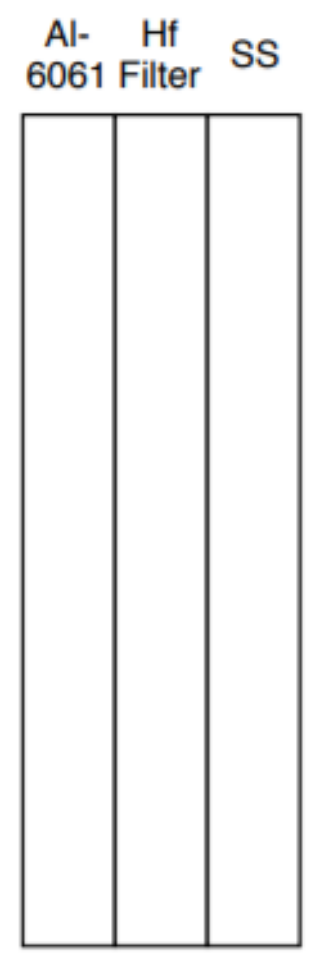

Figure 14: RELAP5-3D Representation of the Thermal Neutron Filter

Heat structures 501, 502, and 503 represent the innermost, middle, and outermost fuel plate assemblies, respectively. Each heat structure is $127 \mathrm{~cm}$ long, and has 50 axial sub-volumes; each sub-volume is $2.54 \mathrm{~cm}$ long. The volume is radially divided into seven intervals - the two outermost intervals representing Al-6061 cladding material, and the center five intervals representing $\mathrm{U}_{3} \mathrm{Si}_{2}$ fuel material. Heat generation takes place within the $\mathrm{U}_{3} \mathrm{Si}_{2}$ section of the heat structure, and is based on information provided from the neutronic analysis of this system. The inner boundary condition is convective, and coupled to volumes 501, 502, and 503, respectively. The outer boundary condition is convective, and is coupled to volumes 502, 503, and 504, respectively. An example of the structure of a single booster fuel plate, along with a representation of all of the heat structures, is provided in Figure 15. 


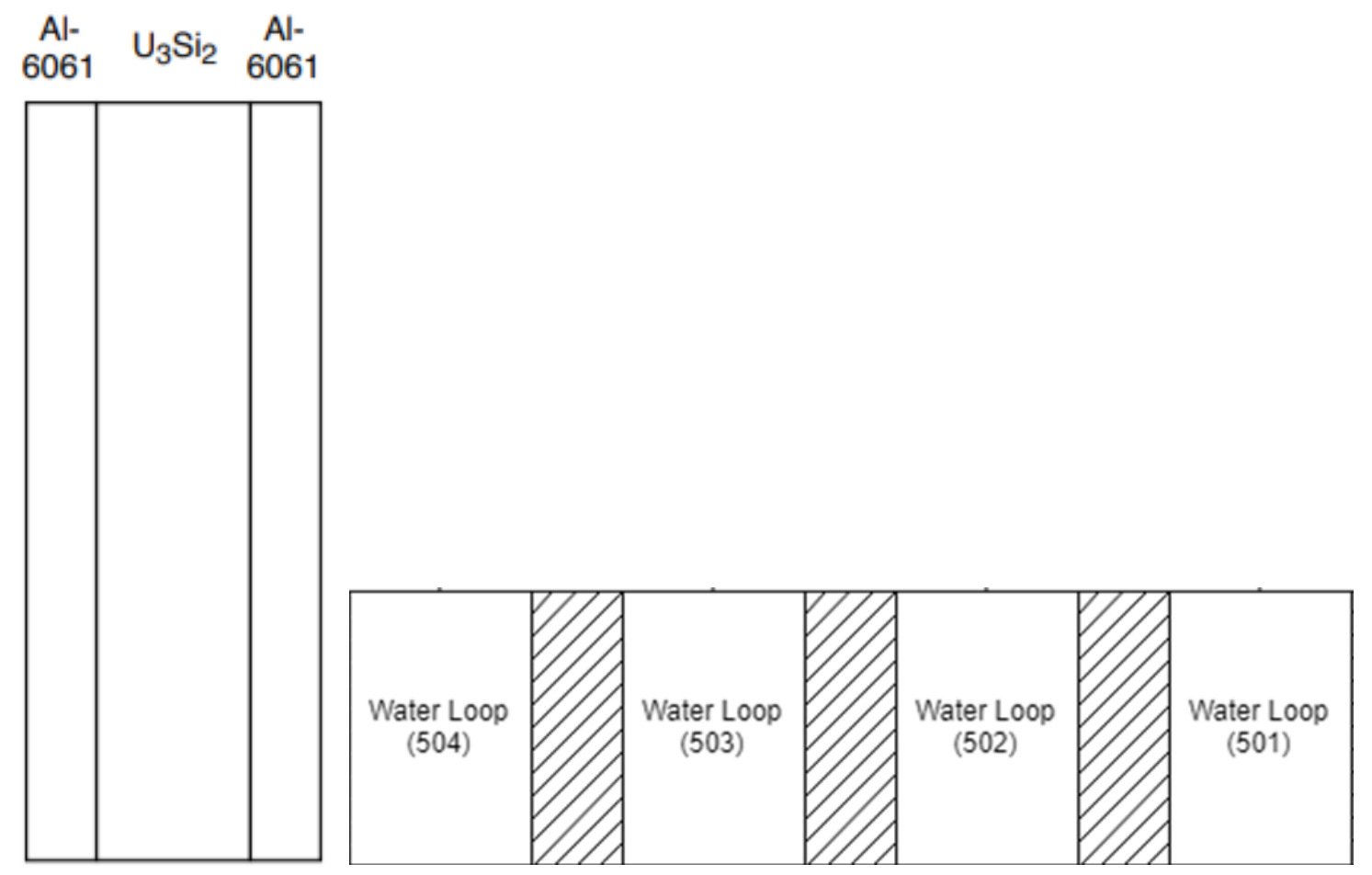

Figure 15: RELAP5-3D representation of a single booster fuel plate (left) and entire heat structure (right)

Table 6: Detailed description of booster fuel plate structures

\begin{tabular}{|c|c|c|c|c|c|}
\hline $\begin{array}{c}\text { Heat } \\
\text { Structure }\end{array}$ & $\begin{array}{l}\text { Length } \\
\text { (cm) }\end{array}$ & $\begin{array}{c}\text { Radius, } \\
\text { inner }(\mathbf{c m})\end{array}$ & $\begin{array}{c}\text { Radius, } \\
\text { outer (cm) }\end{array}$ & $\begin{array}{c}\text { Cladding } \\
\text { thickness } \\
\text { (cm) }\end{array}$ & $\begin{array}{c}\text { Fuel } \\
\text { thickness } \\
\text { (cm) }\end{array}$ \\
\hline 501 & \multirow{4}{*}{127} & 4.97 & 5.21 & \multirow{3}{*}{0.0714} & \multirow{3}{*}{0.0952} \\
\hline 502 & & 5.40 & 5.64 & & \\
\hline 503 & & 5.82 & 6.06 & & \\
\hline 504 & & N/A & N/A & N/A & N/A \\
\hline
\end{tabular}

Heat structure 504 is the outer piping of the water coolant loop. This is modeled as the outer Al-6061 in place within the ATR. Internal heat generation does not take place within this heat structure. The heat structure has 50 axial sub-divisions, and each axial subdivision is $2.54 \mathrm{~cm}$ long. The inner boundary of this heat structure is coupled to volume 501 , sub-volumes $1-50$, and uses a convective boundary condition; the outer boundary is adiabatic. 


\subsection{Stainless Steel Rod Test Section}

The general model was adapted to also model loops with fuel pins within the test chamber. The first of these contained a single stainless steel rod within the test section. This heat structure, HS 102, has 50 axial sub-divisions, each $2.54 \mathrm{~cm}$ long. The inner boundary of this heat structure is adiabatic, and the outer boundary is coupled to volume 102, subvolumes 1-50. The flow area for volume 102 is changed to $39.35 \mathrm{~mm}^{2}$, and the hydraulic diameter is $3.337 \mathrm{~mm}$. Since the rod in this section is stainless steel, no heat generation is used within the heat structure. The heat structure is also divided into two radial subdivisions to examine the radial temperature profile in the rod.

\subsection{Fuel Pin Test Section}

The next modified model used a single $\mathrm{U}-\mathrm{Zr}$ fuel pin within the test chamber. This heat structure, HS 102, has 50 axial sub-divisions, each $2.54 \mathrm{~cm}$ long. The inner boundary of this heat structure is adiabatic, and the outer boundary is coupled to volume 102, subvolumes 1-50. The flow area for volume 102 is changed to $39.35 \mathrm{~mm}^{2}$, and the hydraulic diameter is $3.337 \mathrm{~mm}$. The fuel pin has five radial subdivisions: three to represent the U$\mathrm{Zr}$ fuel meat, one to represent a sodium buffer, and one to represent the HT-9 cladding. The axial heat generation profile within the fuel meat is calculated from the MCNP model.

\subsection{Pin Test Section}

The next modified model used three U-Zr fuel pins within the test chamber. These heat structures, HS 101, 102, and 103, each have 50 axial sub-divisions, each $2.54 \mathrm{~cm}$ long. The inner boundary of each heat structure is adiabatic, and the outer boundary of each is coupled to volume 102. The new flow area for volume 102 is now $118.1 \mathrm{~mm}^{2}$, and the hydraulic diameter is $4.499 \mathrm{~mm}$. The fuel pins each have five radial sub-divisions: three to represent the U-Zr fuel meat, one to represent a sodium buffer, and one to represent the HT-9 cladding. The axial heat generation profile within each fuel pin is calculated from the MCNP model. 


\subsection{U-Tube Primary}

The following section provides an explanation to the augmentation of the original test section model to accommodate the U-shaped loop design. The cold leg (volume 104) has been divided into 51 sub-volumes, with the lower sub-volumes (1-50) being $2.54 \mathrm{~cm}$ long and the top sub-volume (51) being $100 \mathrm{~cm}$ long. This reflects the geometry in the test section (volume 102) and the hot leg (Volume 101). The flow area and hydrodynamic diameter of volumes 100-105 are identical to the 3 fuel pin test geometry. The entire primary leg also now has heat structures coupled to them to act as piping:

- HS 112 serves as the piping for Volume 101 and 102

- HS 113 serves as the piping for 103

- HS 114 serves as the piping for Volume 104

This modified primary loop structure is provided in Figure 16.

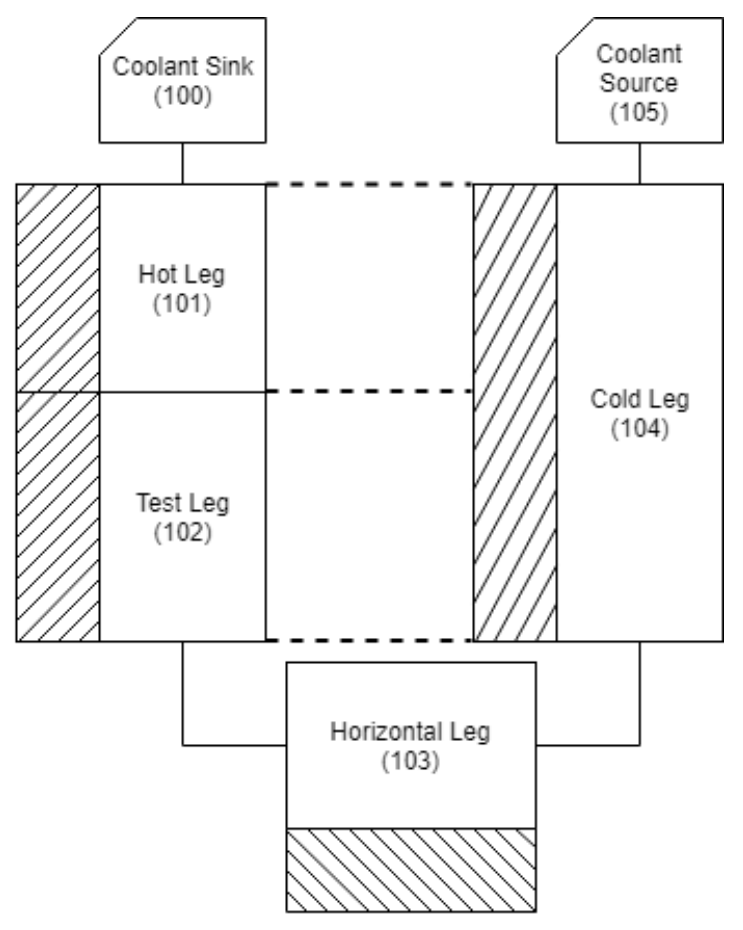

Figure 16: Primary loop for the modified test section

These heat structures are all connected to a new structure, volume 701, which acts as the inert gas chamber. Figure 17 shows how these heat structures align with the new component. This chamber has 52 sub-volumes, where sub-volume 1 is connected to the hot leg and the upper section of the cold leg, sub-volumes 2-51 are connected to sub-volumes 
$1-50$ of the test leg and the cold leg, and sub-volume 52 is connected to the horizontal leg. The boundary conditions for the helium chamber are set by time-dependent volumes 700 and 702, which represent the sink and source, respectively; no pressure differential exists between them, so that minimal flow occurs in this section.

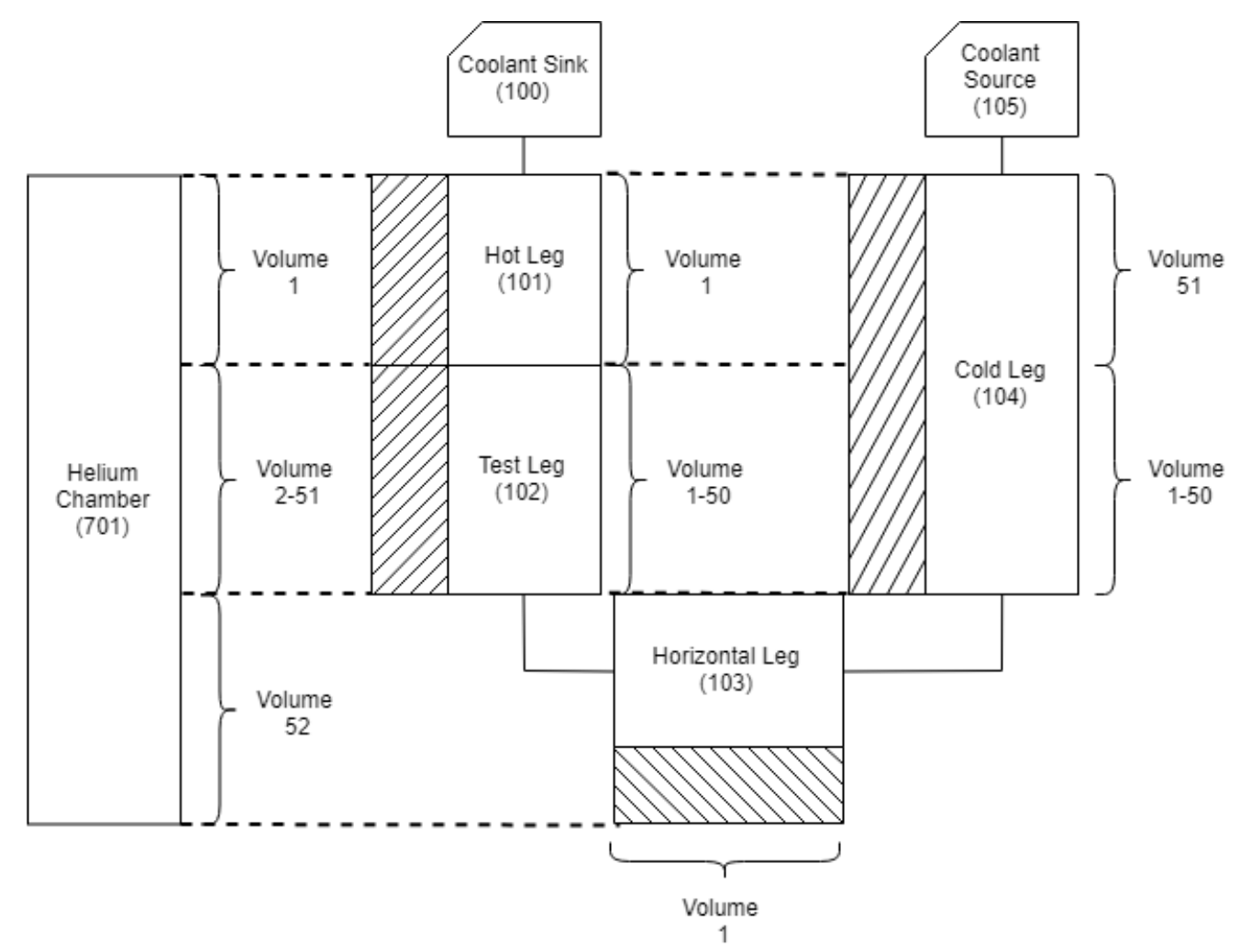

Figure 17: Primary loop connected to volume 701 (helium chamber)

Table 7: Helium Chamber Hydrodynamic Properties

\begin{tabular}{|c|c|c|c|c|c|c|}
\hline $\begin{array}{c}\text { Volume } \\
\#\end{array}$ & $\begin{array}{c}\text { Sub-Volume } \\
\#\end{array}$ & $\begin{array}{c}\text { Length } \\
(\mathbf{c m})\end{array}$ & $\begin{array}{c}\text { Flow Area } \\
\left(\mathbf{m m}^{2}\right)\end{array}$ & $\begin{array}{c}\text { Dh } \\
(\mathbf{m m})\end{array}$ & $\begin{array}{c}\mathbf{T} \\
\mathbf{( K )}\end{array}$ & $\begin{array}{c}\mathbf{P} \\
(\mathbf{k P a})\end{array}$ \\
\hline 700 & 1 & 0.01 & 4797 & 67.57 & 640.0 & 101.325 \\
\hline 701 & 1 & 100 & & & & 101.325 \\
\hline & $2-51$ & 2.54 & & & & 101.325 \\
\hline & 52 & 2.667 & & & & 101.325 \\
\hline 702 & 52 & 0.01 & & & & 101.325 \\
\hline
\end{tabular}

The helium chamber is then connected to HS 200, which represents the piping between this volume and the helium blanket (volume 301). Volume 301 retains the radial geometry as 
shown in Figure 13. Figure 18 shows the new geometry up to the helium blanket. Note that extending from volume 301 outwards, all 50 sub-volumes are retained, and align with subvolumes 2-51 of volume 701. Though not shown, the fuel plates and their corresponding cooling systems are identical to all other models.

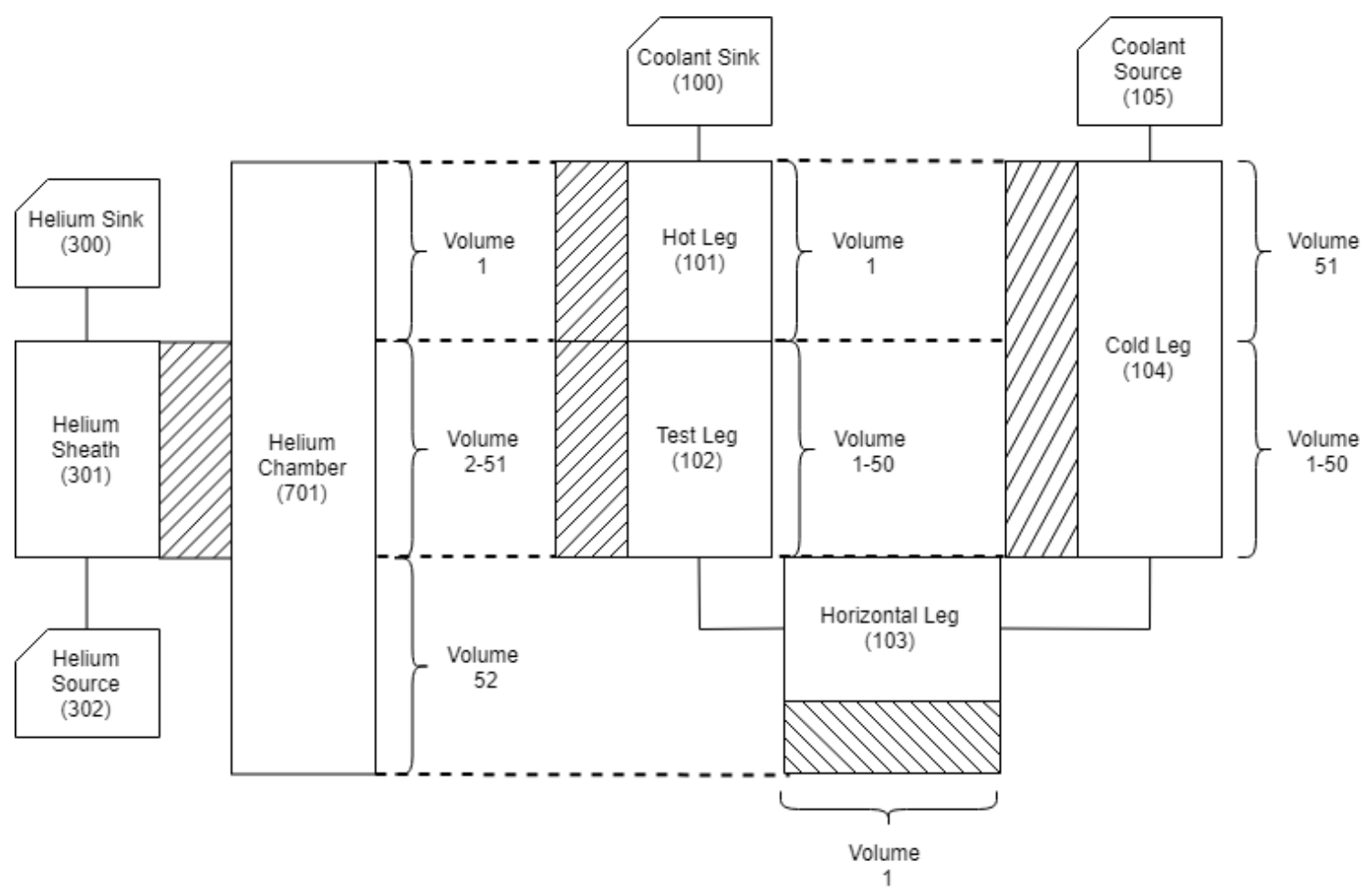

Figure 18: Block diagram of the test section for the modified test chamber case 


\section{RESULTS AND DISCUSSION}

Chapter 5 of this thesis will examine the results of the RELAP5-3D models described in Chapter 4. For each of the five models, pertinent parameters such as temperature distributions in hydrodynamic volumes and heat structures, and heat fluxes through heat structures. Section 5.6 examines a parametric study of the three fuel pin case with varying operating pressures, flow velocities, and pin powers.

\section{$5.1 \quad$ No Test Chamber}

The following section showcases several temperature profiles spanning across the subvolumes within the test section when sodium passes through the test section with no test chamber. Sub-volume 1 is the outlet at top of the test leg, and sub-volume 50 is the inlet at the bottom of the test leg. This information is taken after 100 seconds of simulation time to ensure steady state conditions are attained. At these temperatures and pressures, the primary coolant has a liquid fraction of 100 percent, the helium has a gas fraction of 100 percent, and the water system has a liquid fraction of 100 percent. Figure 19 shows the cross section of this test case. 


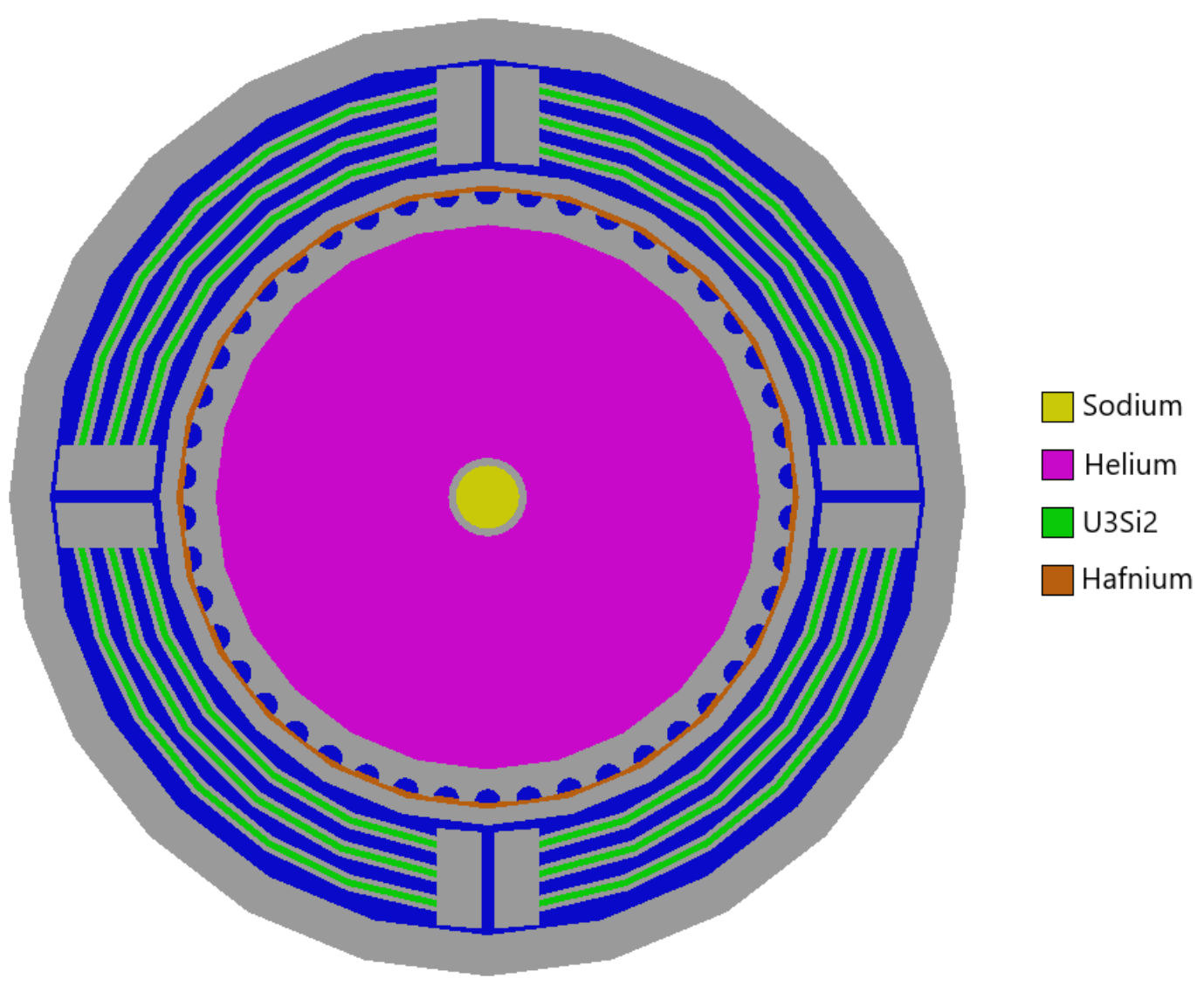

Figure 19: Cross Section of No Experiment Test Case

Figure 20 shows the fluid temperature distributions from inlet to outlet. Heat generation only takes place in the booster plates, so the primary and helium fluids are cooled by the surrounding lower temperature systems. Only the fuel plate cooling fluid shows an increase in temperature. 


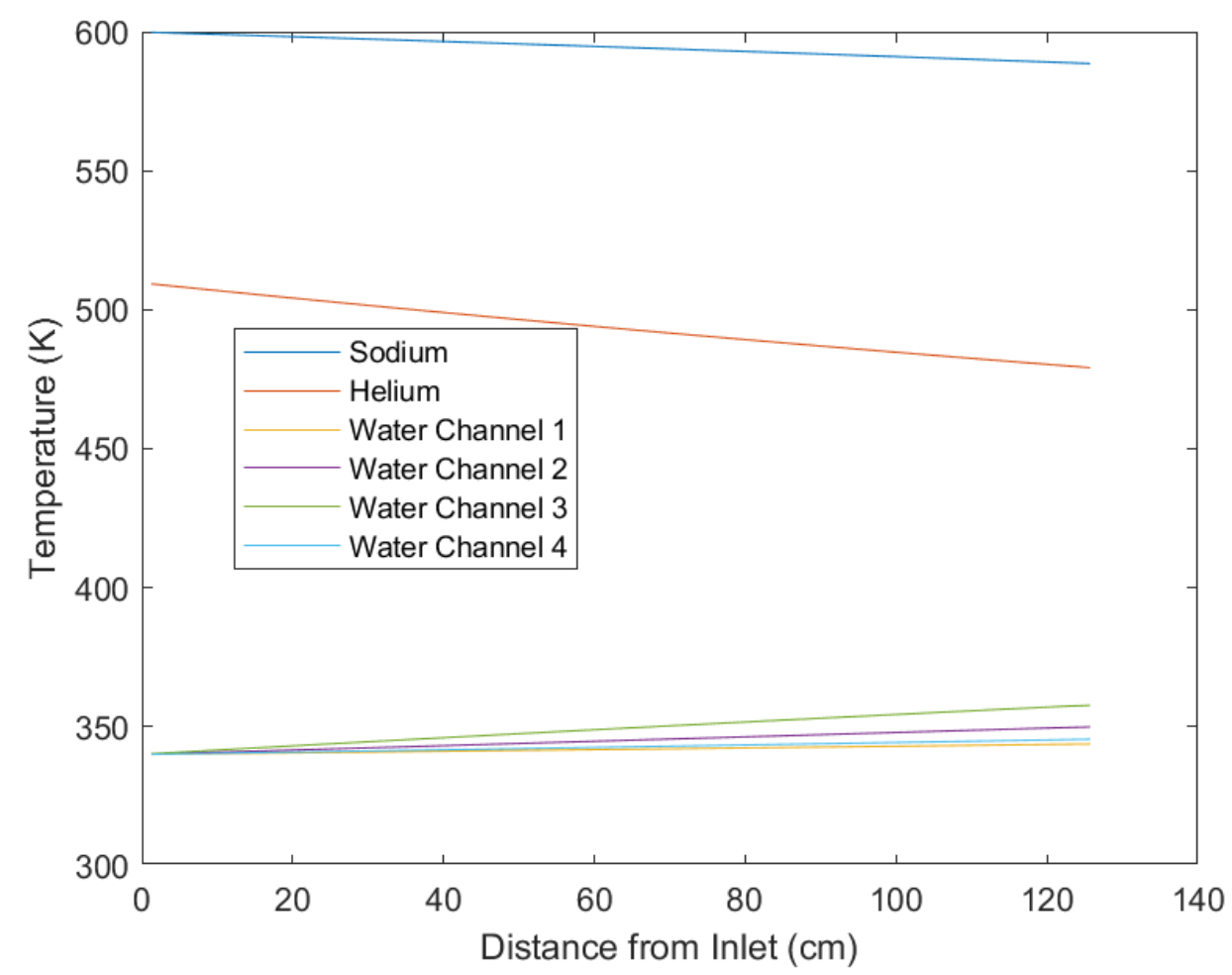

Figure 20: Bulk Fluid Temperatures for No Test Chamber

Figure 21 shows the radial temperature profile from the center of the test section to the outer aluminum baffle of the test section at both the inlet and outlet. The fuel plates far from the center are easily identifiable by the three flat profiles at the inlet. Also worth noting is the large temperature drop across the helium system, from nearly $600 \mathrm{~K}$ at on surface to $340 \mathrm{~K}$ at the opposing surface. 


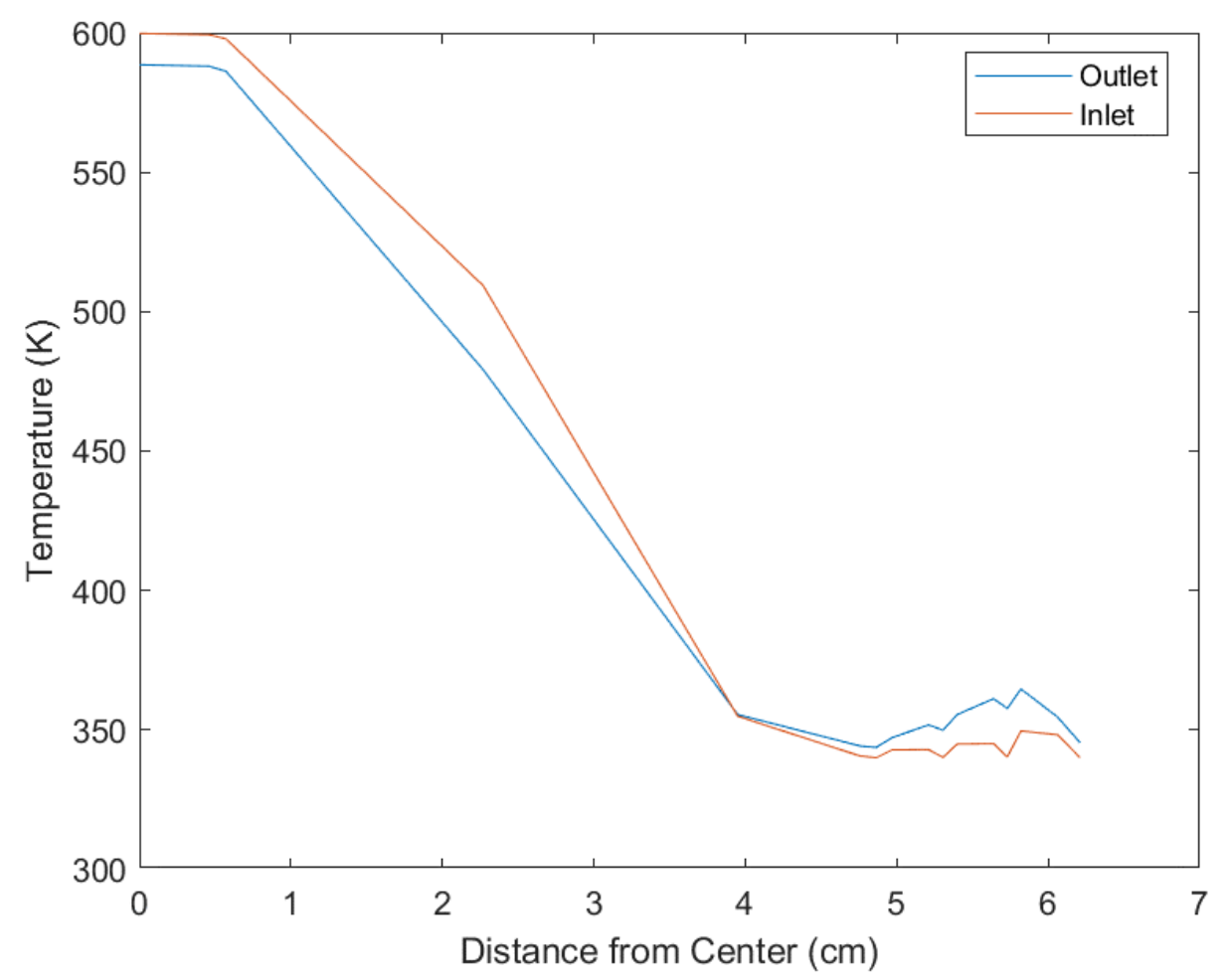

Figure 21: Radial Temperature Distribution at Inlet and Outlet

\subsubsection{Primary System}

Figure 22 shows the primary piping surface temperature, and Figure 23 shows convective heat fluxes through the piping separating the primary system and helium system. A positive value indicates heat flux out of the structure, while a negative value indicates a heat flux into the structure. No heat generation takes place within this section, so it is expected that the temperature of the primary fluid will decrease approaching the outlet due to heat transfer into the lower temperature helium system. The heat convection values though the piping show this taking effect. A flow rate of $1.1 \mathrm{~m} / \mathrm{s}$ through the test section was used for this model. 


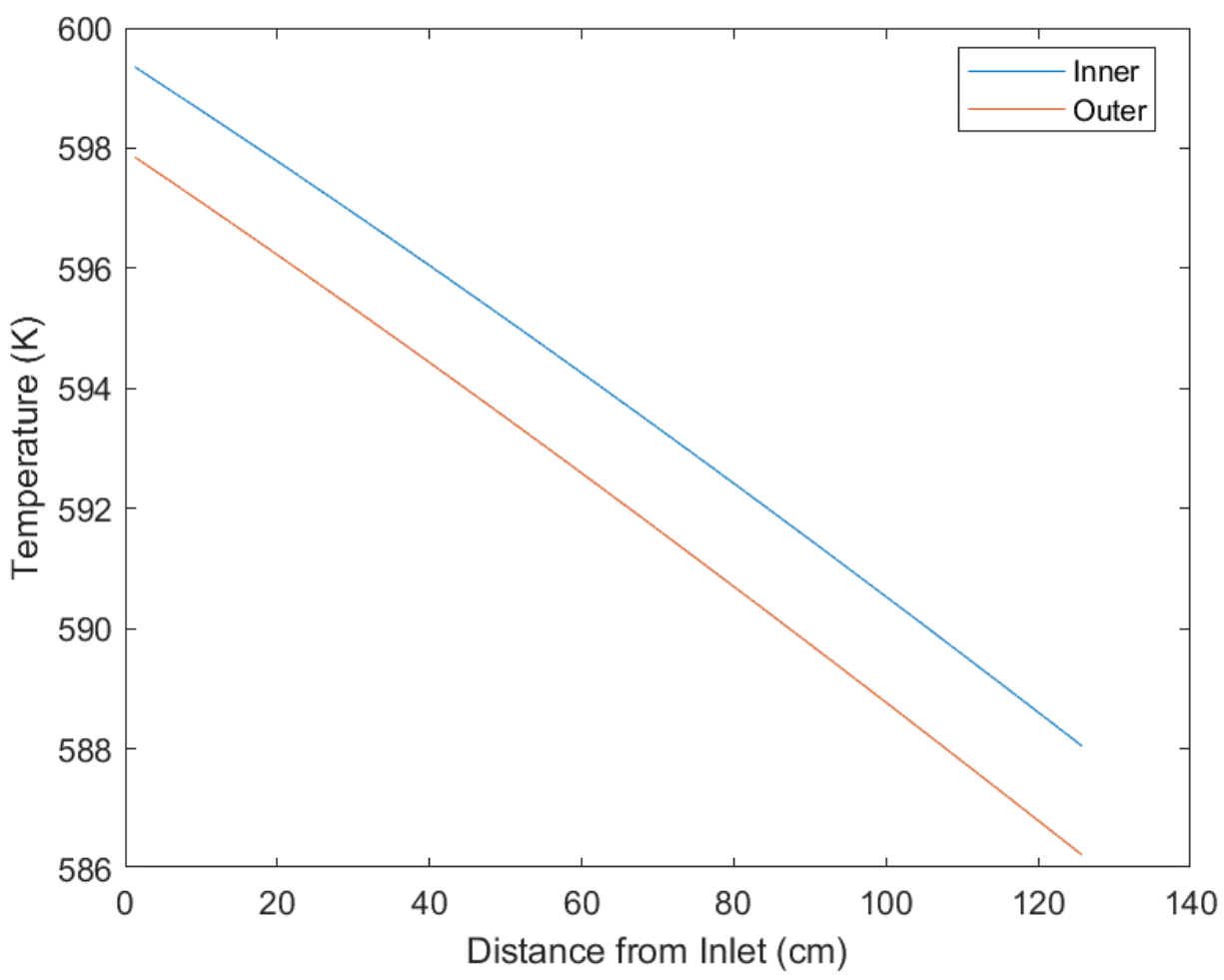

Figure 22: Primary Piping Surface Temperatures

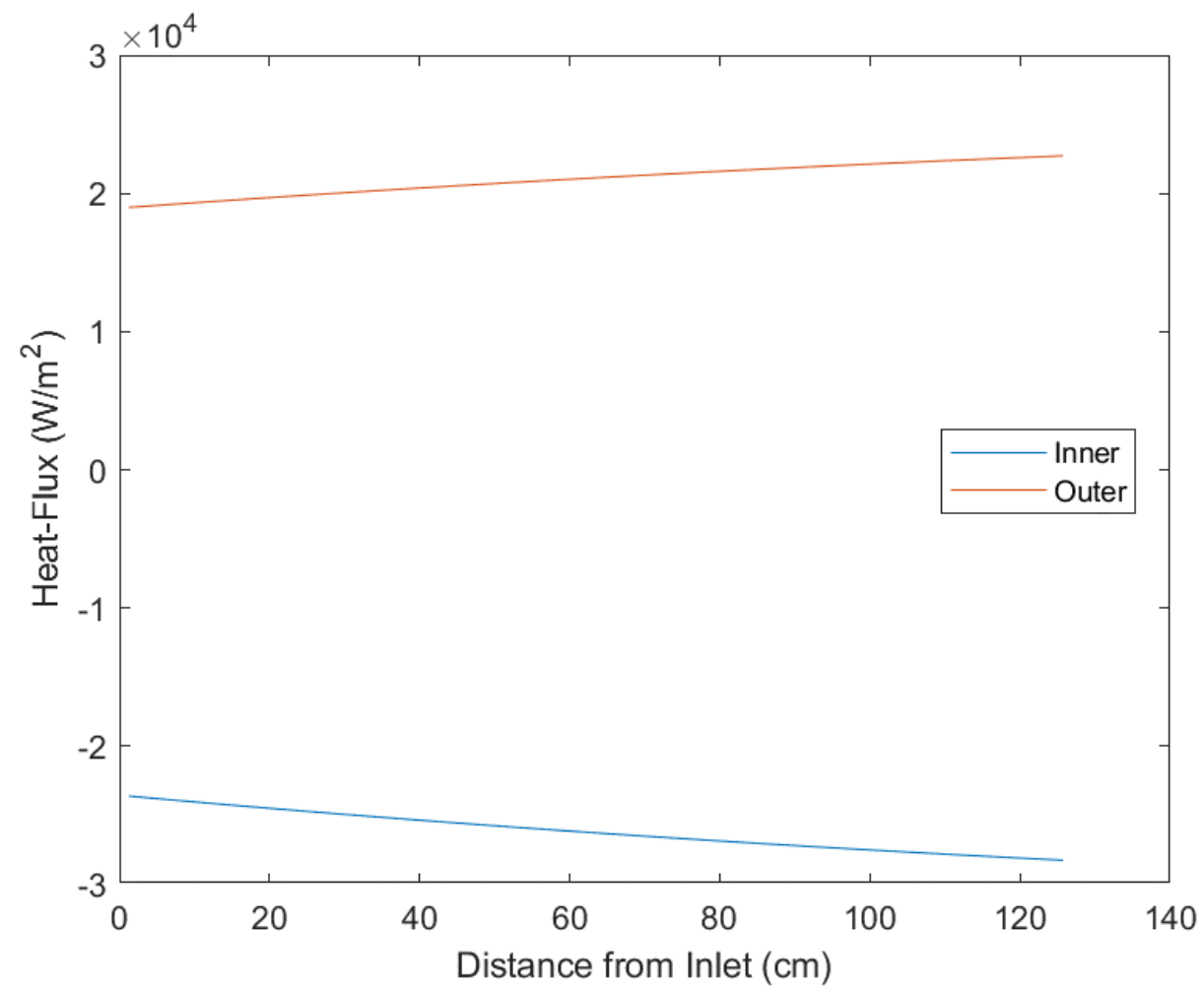

Figure 23: Primary Piping Heat Fluxes 


\subsubsection{Helium System}

Figure 24 shows the surface temperature of the piping separating the helium system and the water system, and Figure 25 shows the convective heat flux through this piping. A positive value indicates heat flux out of the structure, while a negative value indicates a heat flux into the structure. The temperature increases as the fluid approaches the outlet, which is to be expected with heat being transfer into the system from the primary system. The piping is significantly lower than the temperature of the helium system due to the cooling effect from the lower temperature water system. A flow rate of $22 \mathrm{~m} / \mathrm{s}$ was used for this system.

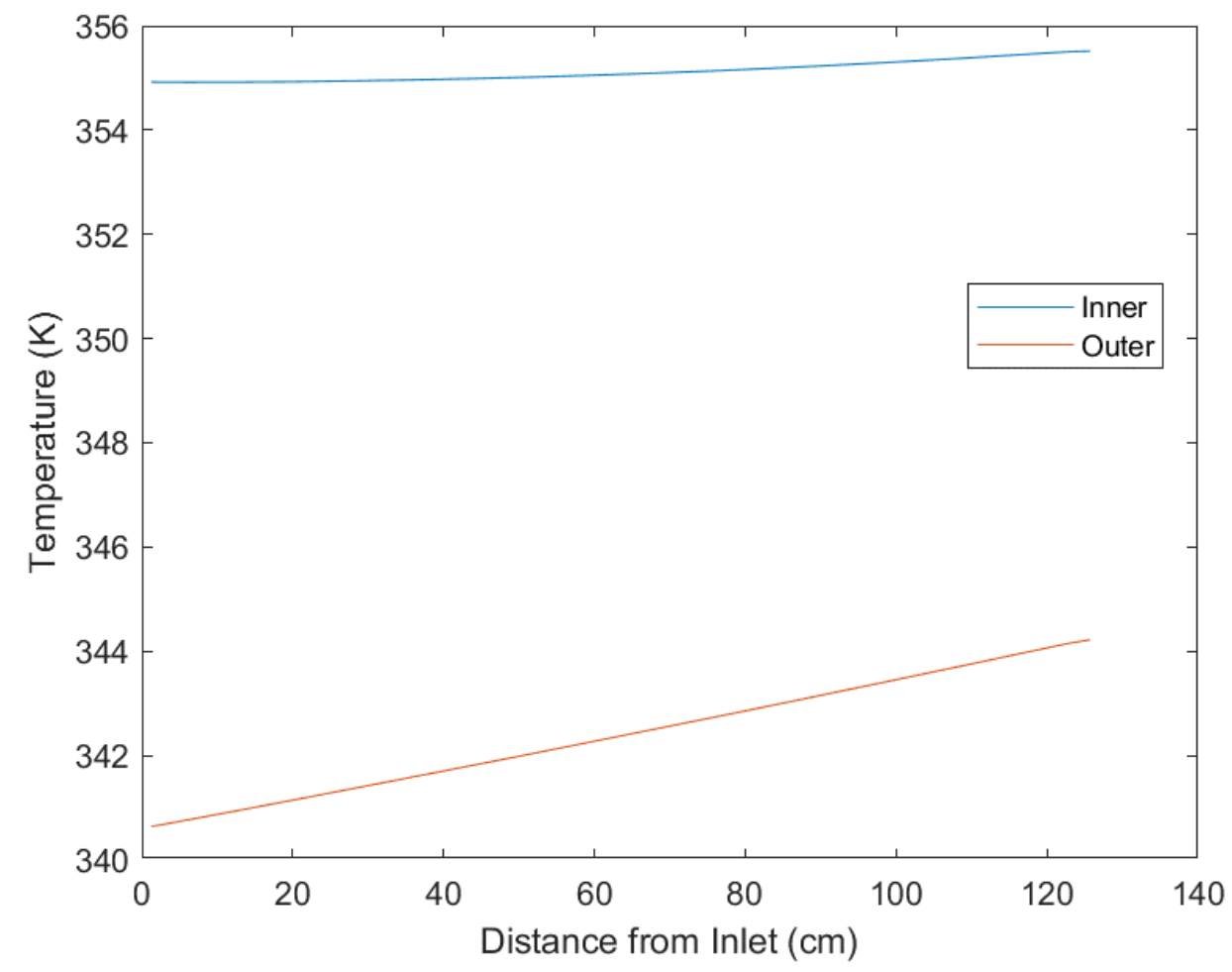

Figure 24: Gas Blanket Piping Surface Temperatures 


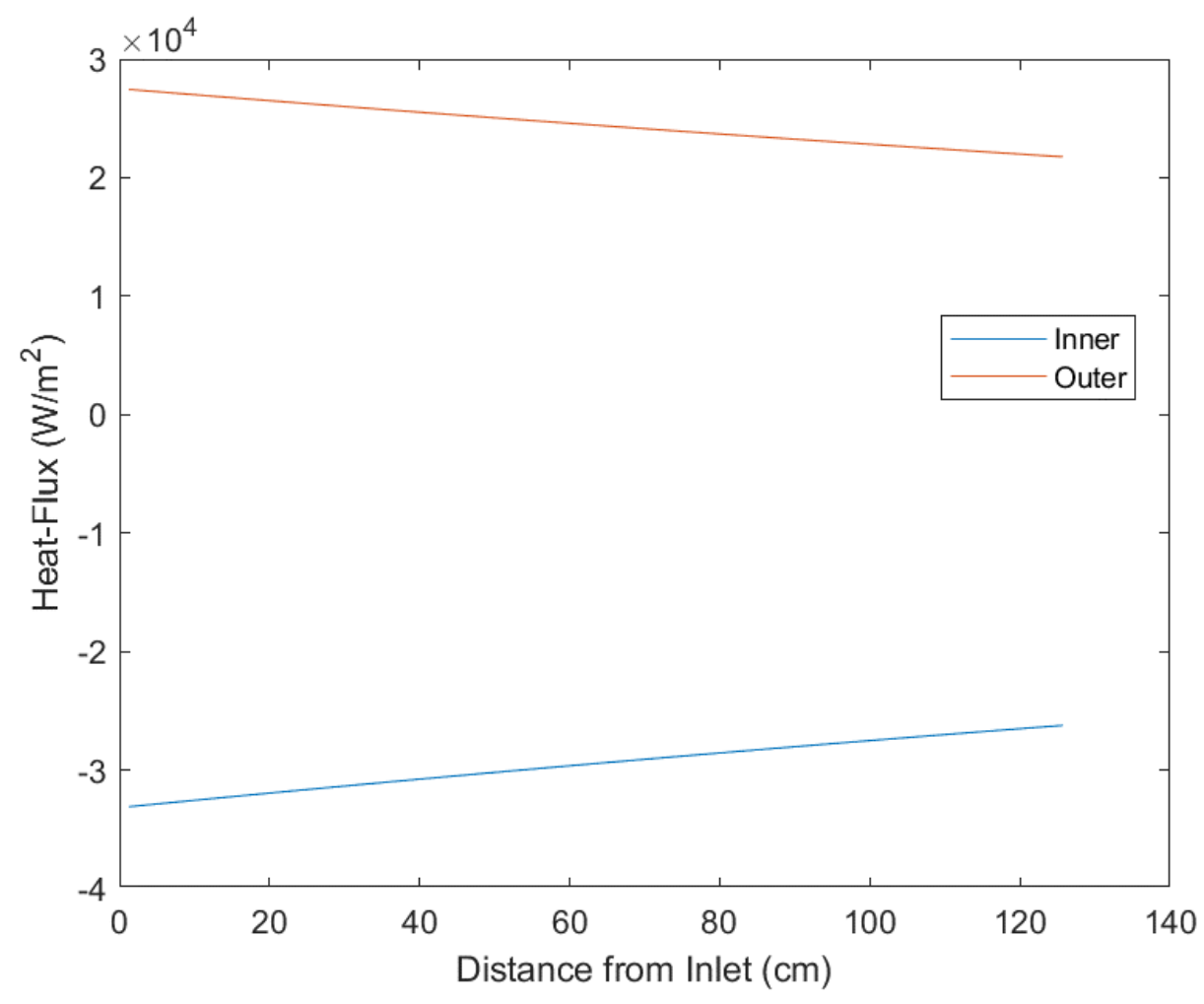

Figure 25: Gas Blanket Heat Fluxes

\subsubsection{Fuel Plate Cooling System}

Figure 26 shows the surface temperatures of the fuel plates from inlet to outlet. Each plate shows an increase in temperature closer to the outlet, as is expected. The linear decrease in temperature near the ends of the plates are likely due to a significantly lower amount of heat generation in those sub-divisions of the fuel plates. The value for the heat generation in these sub divisions is roughly 75 percent of what the average value is for the rest of the fuel plate. Surface temperatures on the inner fuel plate are the lowest, ranging from $343 \mathrm{~K}$ to $352 \mathrm{~K}$, due to this plate having the lowest power. The middle fuel plate surface temperatures range from $345 \mathrm{~K}$ to $362 \mathrm{~K}$. For both of these plates, the outer surface temperature is larger than the inner surface, though by less than $6 \mathrm{~K}$ for any point along the length of the fuel plate. The outer most plate's inner surface temperature ranges from 350 $\mathrm{K}$ to $366 \mathrm{~K}$, while the outer surface temperature ranges from $348 \mathrm{~K}$ to $356 \mathrm{~K}$. This is due to the outer being connected to a hydrodynamic volume that is not connected to another fuel plate surface, meaning the cooling is more effective. 


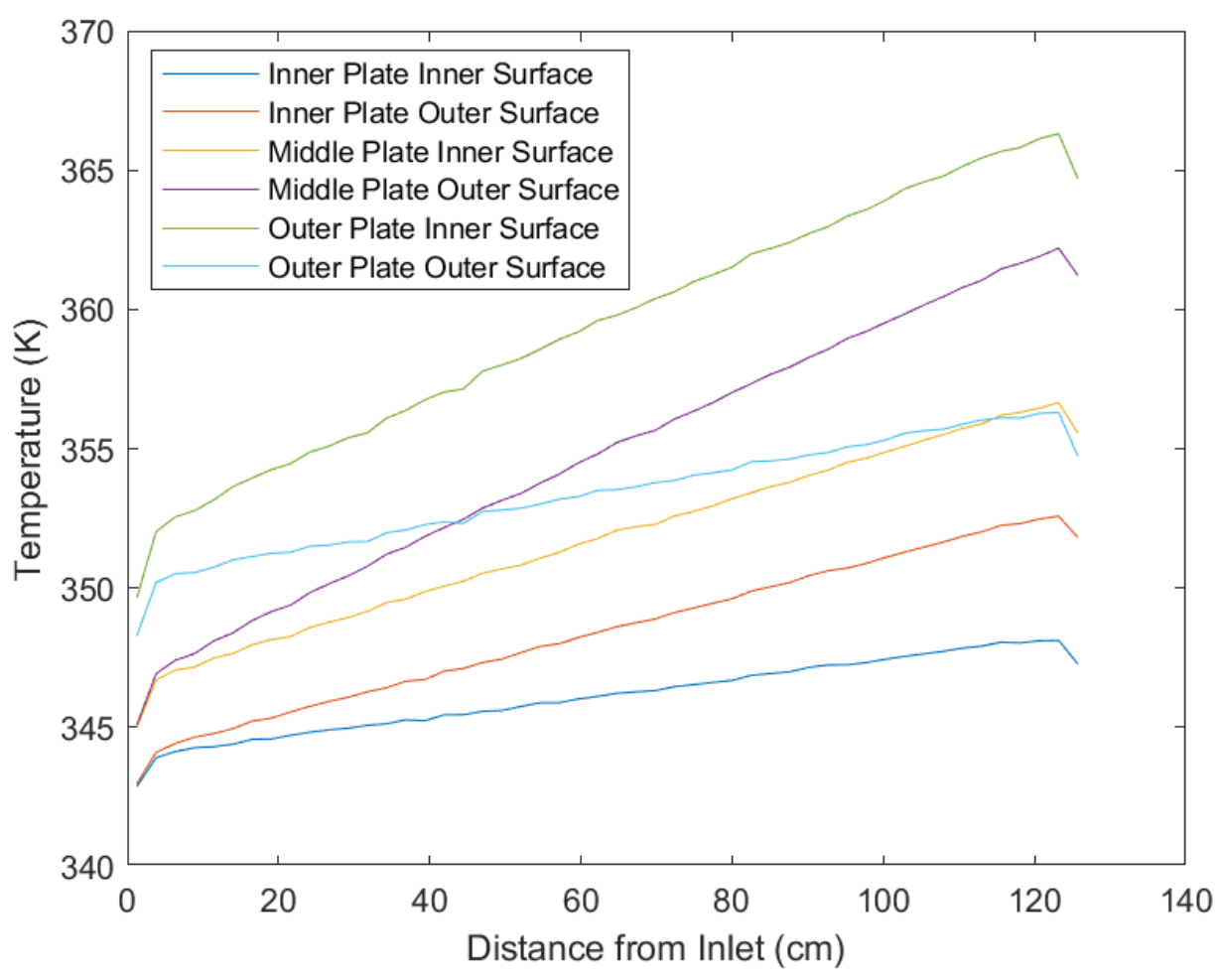

Figure 26: Fuel Plate Surface Temperatures

Figure 27 shows the convective heat fluxes of each surface of the fuel plates. A positive value indicates heat flux out of the structure, while a negative value indicates a heat flux into the structure. The linear decrease in the heat fluxes near the ends of the plates can once again be attributed to a significantly lower amount of heat generation in the sub-divisions. The heat fluxes for the inner plate range from $91 \mathrm{~kW} / \mathrm{m}^{2}$ to $221 \mathrm{~kW} / \mathrm{m}^{2}$, lower than the other plates due to the lower internal power. The heat fluxes for the middle plate range from $171 \mathrm{~kW} / \mathrm{m}^{2}$ to $336 \mathrm{~kW} / \mathrm{m}^{2}$, and the outer plate's range from $342 \mathrm{~kW} / \mathrm{m}^{2}$ to $589 \mathrm{~kW} / \mathrm{m}^{2}$. 


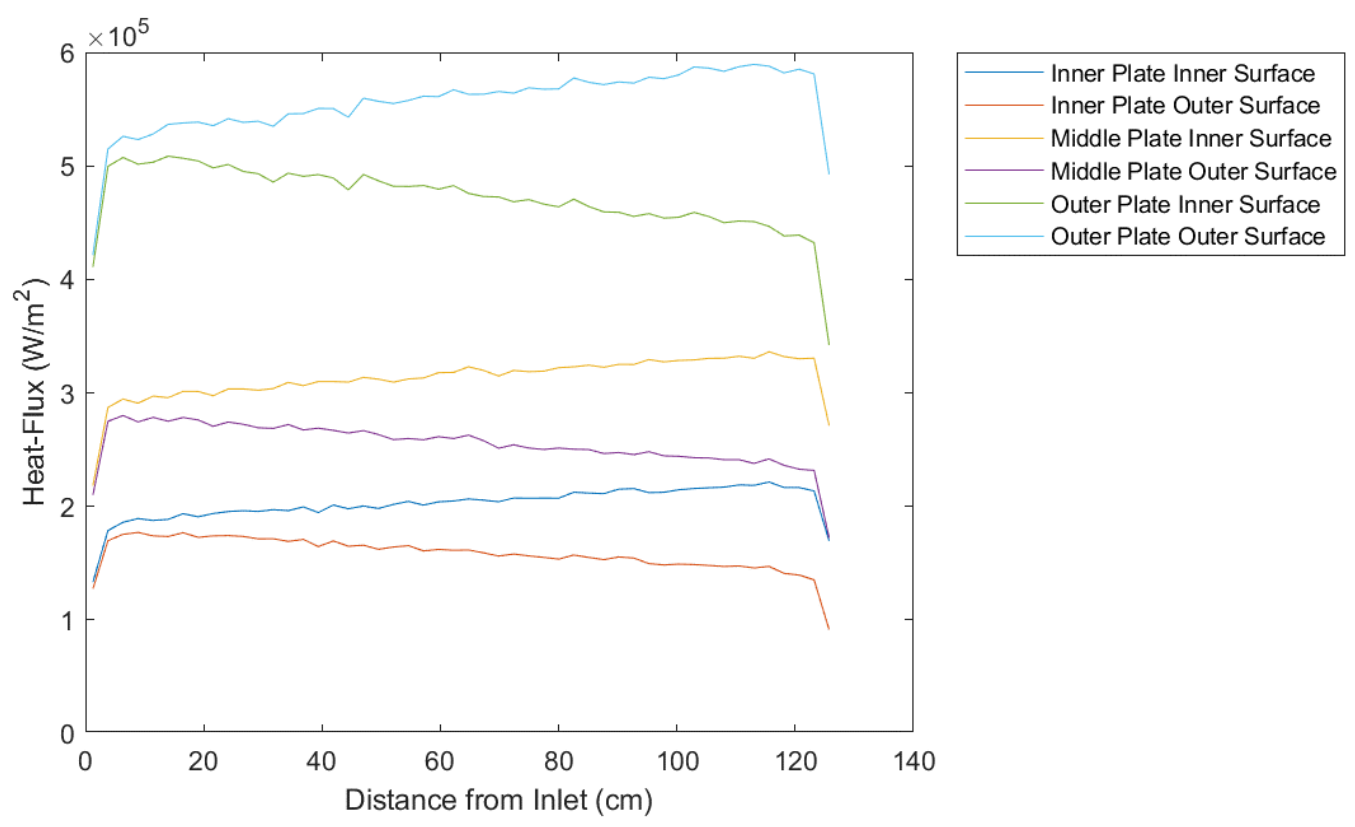

Figure 27: Fuel Plate Heat Fluxes

Figure 28 shows the temperature distribution of each water channel from inlet to outlet. Each channel inlet temperature is $340 \mathrm{~K}$, and outlet temperatures range from 344-358 K, well within safe operation conditions. As mentioned when discussing the fuel plate temperatures, the outermost water channel in only connected to the outermost fuel plate's outer surface. This means that heat is only deposited into the outermost channel from this surface, significantly lowering the temperature increase in this channel. While it is likely that some heat transfer takes place between the ATR core region and the outer surface of this test section which could change the temperature increase in the outermost water channel, it is unlikely to greatly affect the rest of the system. 


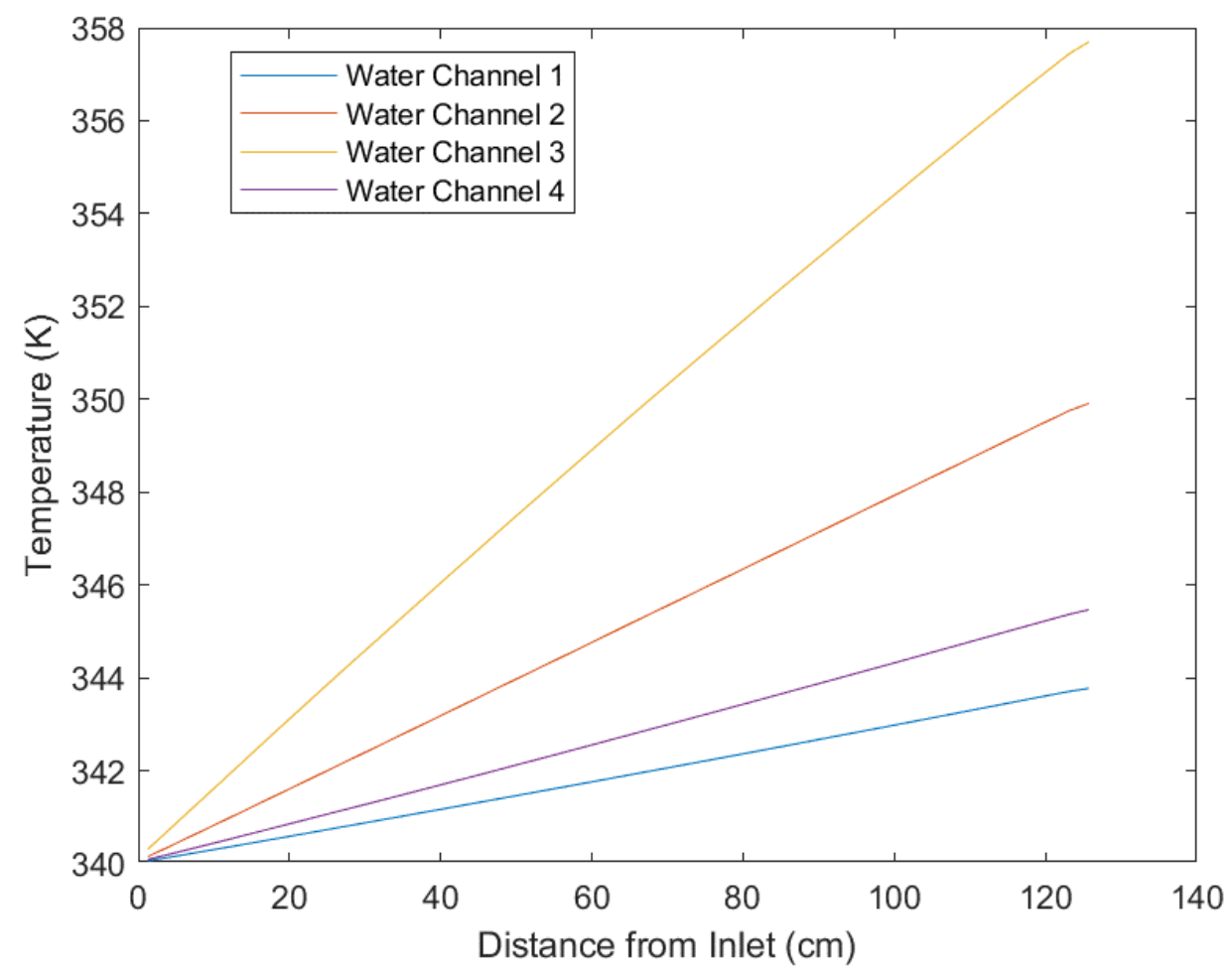

Figure 28:Fuel Cooling Water Temperatures

Figure 29 shows the temperature distribution through each fuel plate at an axial length where the peak radial temperature is at its maximum value. The innermost fuel plate has the lowest power at $146 \mathrm{~kW}$, the middle fuel plate has a power of $250 \mathrm{~kW}$, and the outermost fuel plate as a power of $488 \mathrm{~kW}$. This explains the great difference in the temperature distributions between fuel plates. Also worth noting, the fluid void fraction is 1.0 for each sub-division of all hydrodynamic volumes in this system (500-504). 


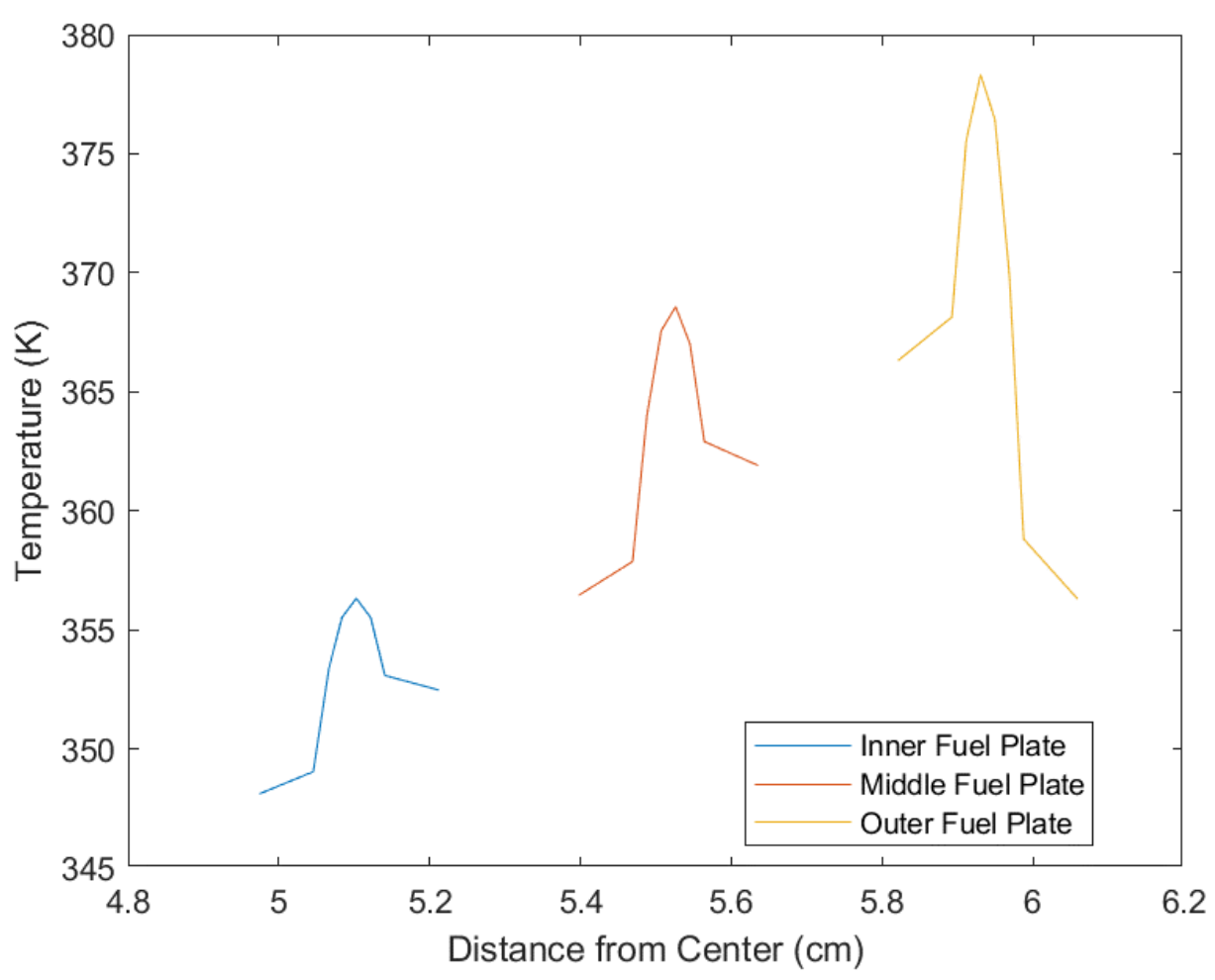

Figure 29: Peak Fuel Plate Radial Temperature Distributions

Overall, this data shows that for the given fuel plate power, the designed system can safely and effectively cool the booster plates. A flow rate of $8 \mathrm{~m} / \mathrm{s}$ was used for this system, though some variation exists across the four channels. The surface temperatures of the fuel plates are safe to operate, the heat flux through the fuel plates do not result in any boiling in the water, and the outlet temperature of the fluid is within a safe operating window.

\subsection{Stainless Steel Test Section}

The following section showcases several temperature profiles spanning across the subvolumes within the test section when sodium passes through the test section with a stainless-steel rod (2.92 mm OD, $1.27 \mathrm{~m}$ length) within the test chamber. Sub-volume 1 is the outlet at top of the test leg, and sub-volume 50 is the inlet at the bottom of the test leg. This information is taken after 100 seconds of simulation time to ensure steady state conditions are attained. At these temperatures and pressures, the primary coolant has a liquid fraction of 100 percent, the helium has a gas fraction of 100 percent, and the water 
system has a liquid fraction of 100 percent. Figure 30 shows the cross-section of this test case.

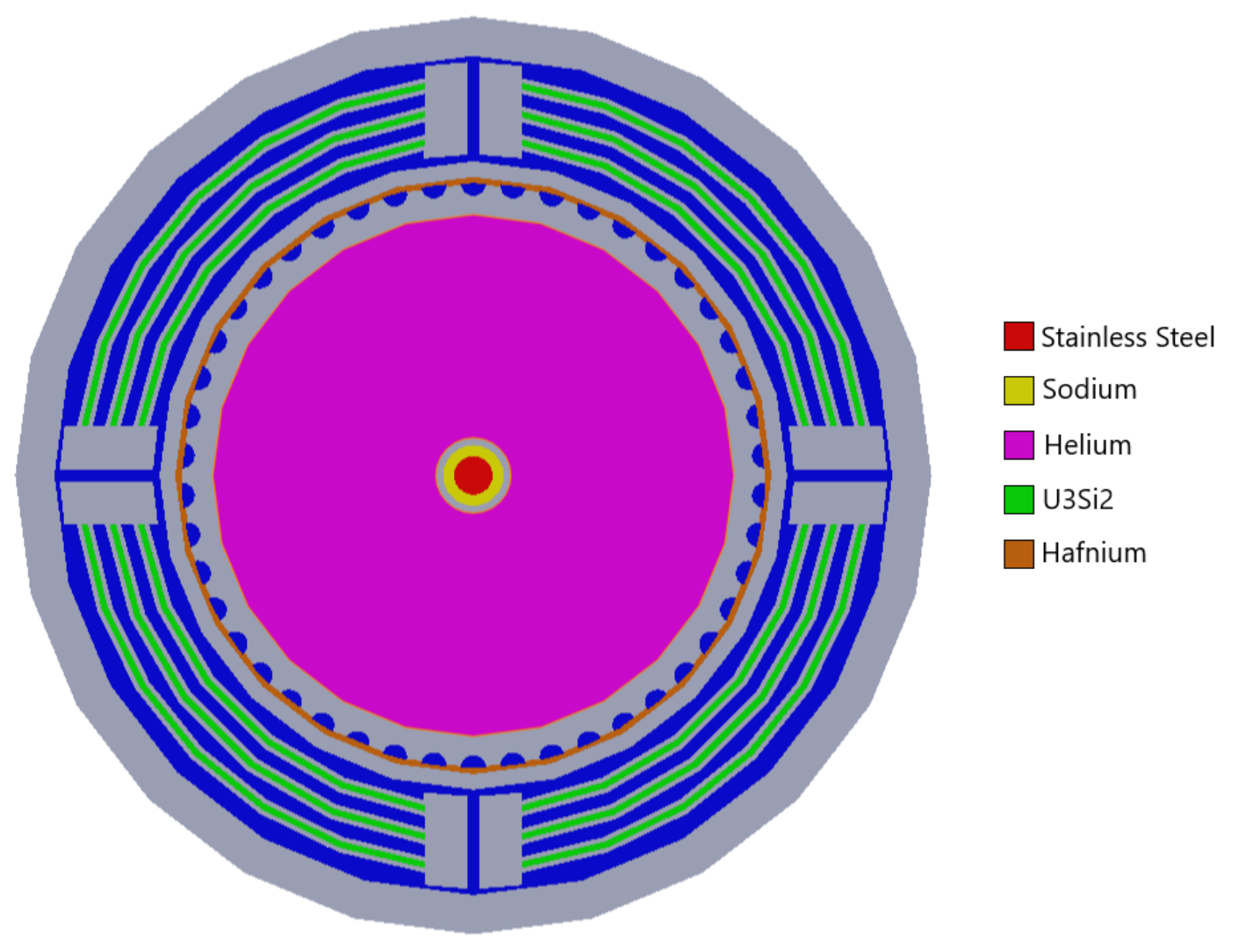

Figure 30: Cross Section of Stainless Steel Rod Test Case

Figure 31 shows the fluid temperature distributions from inlet to outlet. Heat generation only takes place in the booster plates, so the primary and helium fluids are cooled by the surrounding lower temperature systems. Only the fuel plate cooling fluid shows an increase in temperature. These results are near identical to the previous case study, as no extra heat is added to any system. 


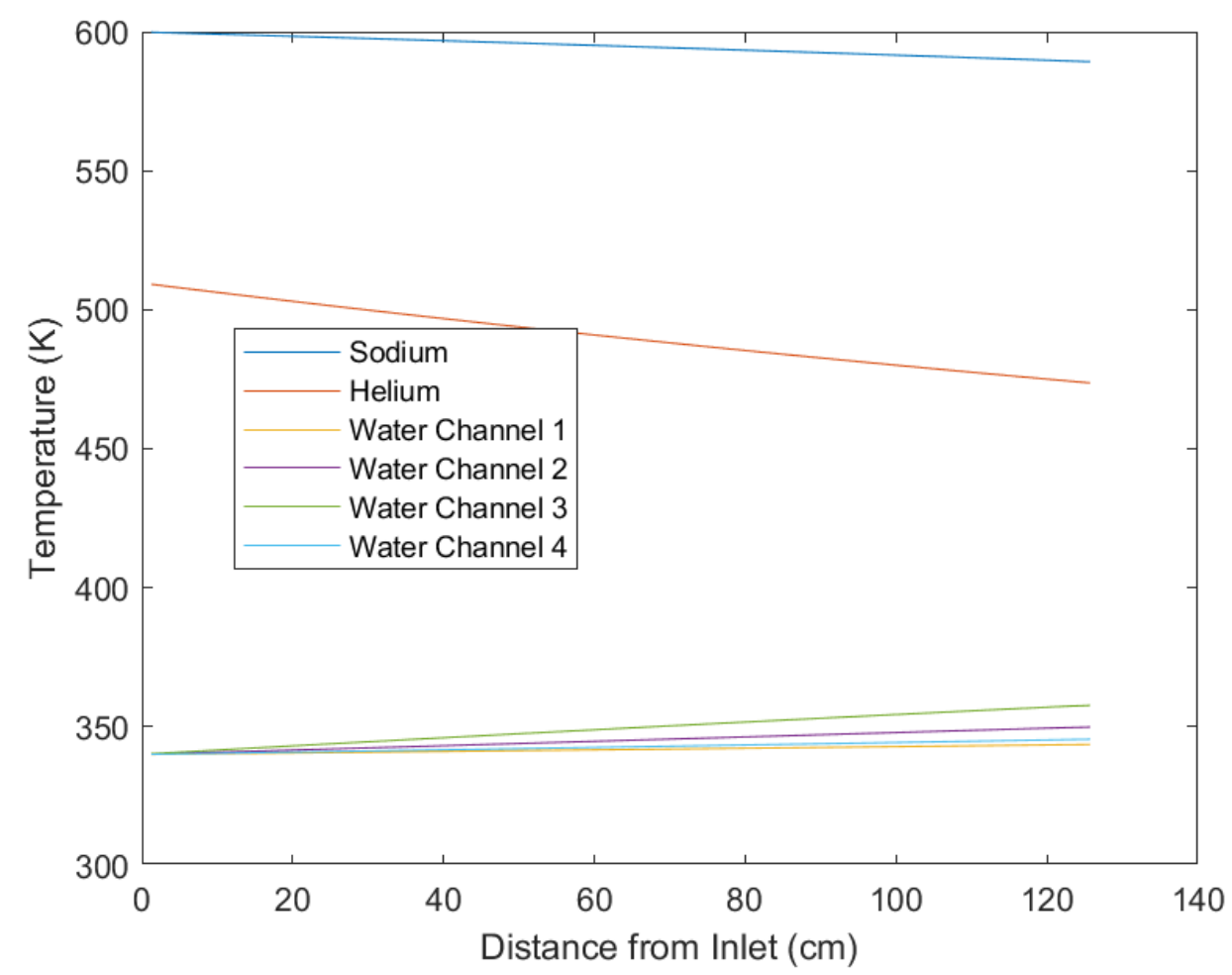

Figure 31: Fluid Temperatures from Inlet to Outlet

Figure 32 shows the radial temperature profile from the center of the test section to the outer aluminum baffle of the test section at both the inlet and outlet. The fuel plates far from the center are easily identifiable by the three flat profiles at the inlet. Also worth noting is the large temperature drop across the helium system, from nearly $600 \mathrm{~K}$ at on surface to $340 \mathrm{~K}$ at the opposing surface. With no heat added to the primary system and the fuel plates having the same power, these results are also near identical to the previous case. 


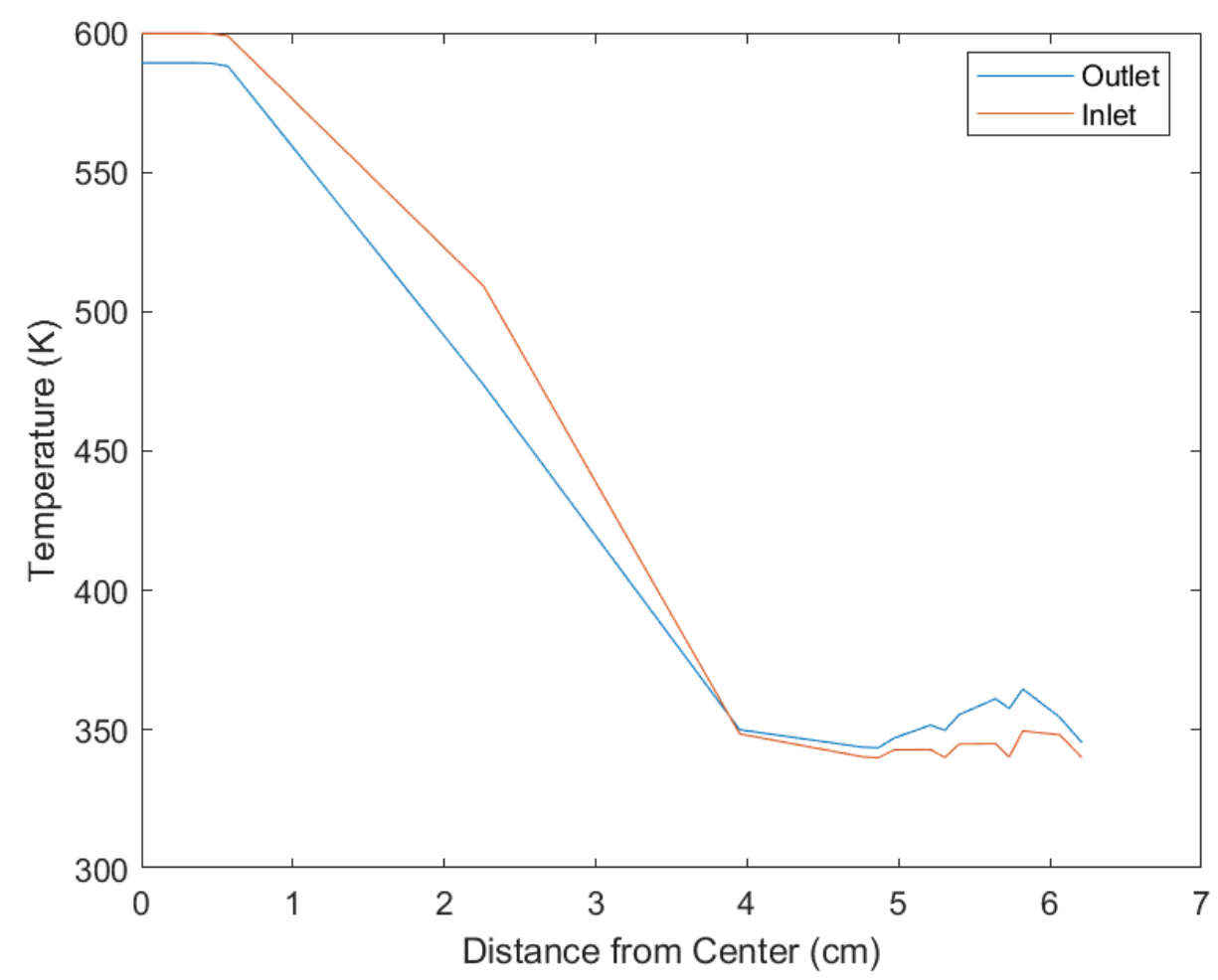

Figure 32: Radial Temperature Distribution

\subsubsection{Primary System}

Figure 34 shows the primary piping surface and steel rod temperature, and Figure 34 shows convective heat fluxes through the steel rod and the piping separating the primary system and helium system. A positive value indicates heat flux out of the structure, while a negative value indicates a heat flux into the structure. No heat generation takes place within this section, so it is expected that the temperature of the primary fluid will decrease approaching the outlet due to heat transfer into the lower temperature helium system. The heat convection values though the piping show this taking effect. Since no heat generation takes place within the steel rod, it is also expected that once steady state is reached, there will be no heat flux through the rod and no radial temperature differential will be seen. Both figures show this expectation. A flow rate of $1.1 \mathrm{~m} / \mathrm{s}$ through the test section was used for this model. 


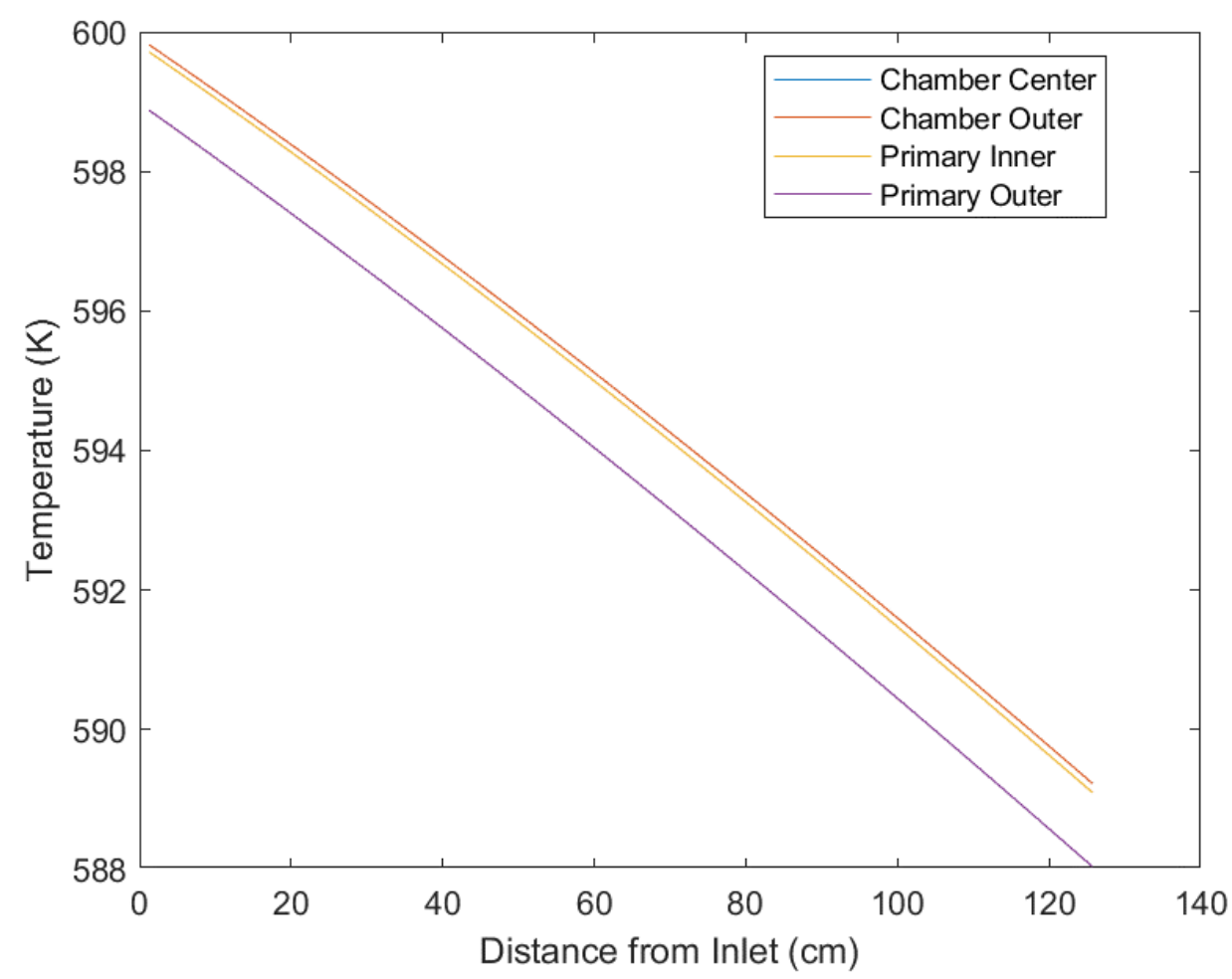

Figure 33: Primary Surface Temperatures

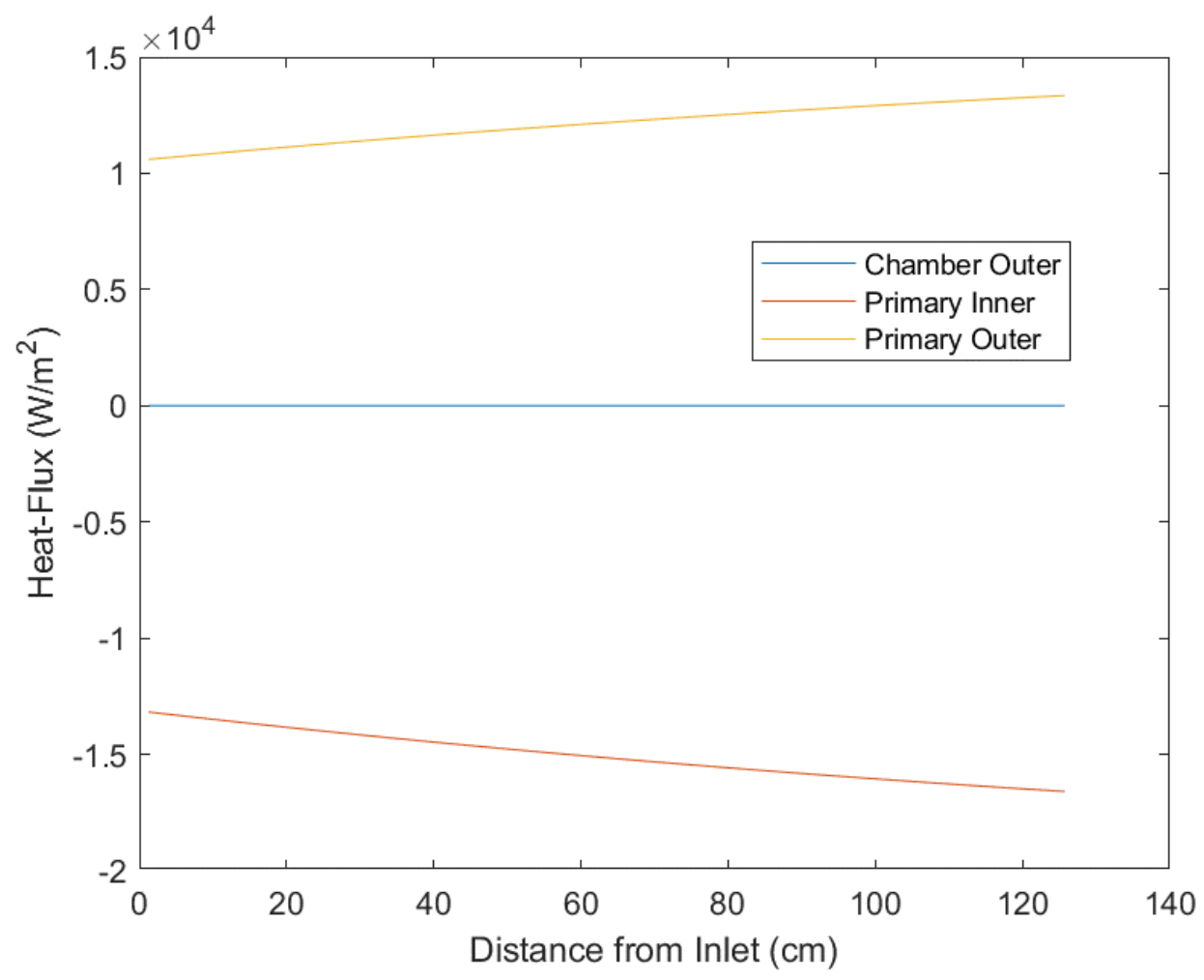

Figure 34: Primary Heat Fluxes 


\subsubsection{Helium System}

Figure 35 shows the surface temperature of the piping separating the helium system and the water system, and Figure 36 shows the convective heat flux through this piping. A positive value indicates heat flux out of the structure, while a negative value indicates a heat flux into the structure. The temperature increases as the fluid approaches the outlet, which is to be expected with heat being transferred into the system from the primary system. The piping is significantly lower than the temperature of the helium system due to the cooling effect from the lower temperature water system. With no heat generation in the primary and the same power used in the fuel plates as the previous case, the results here are near identical to the previous results. A flow rate of $22 \mathrm{~m} / \mathrm{s}$ was used for this system.

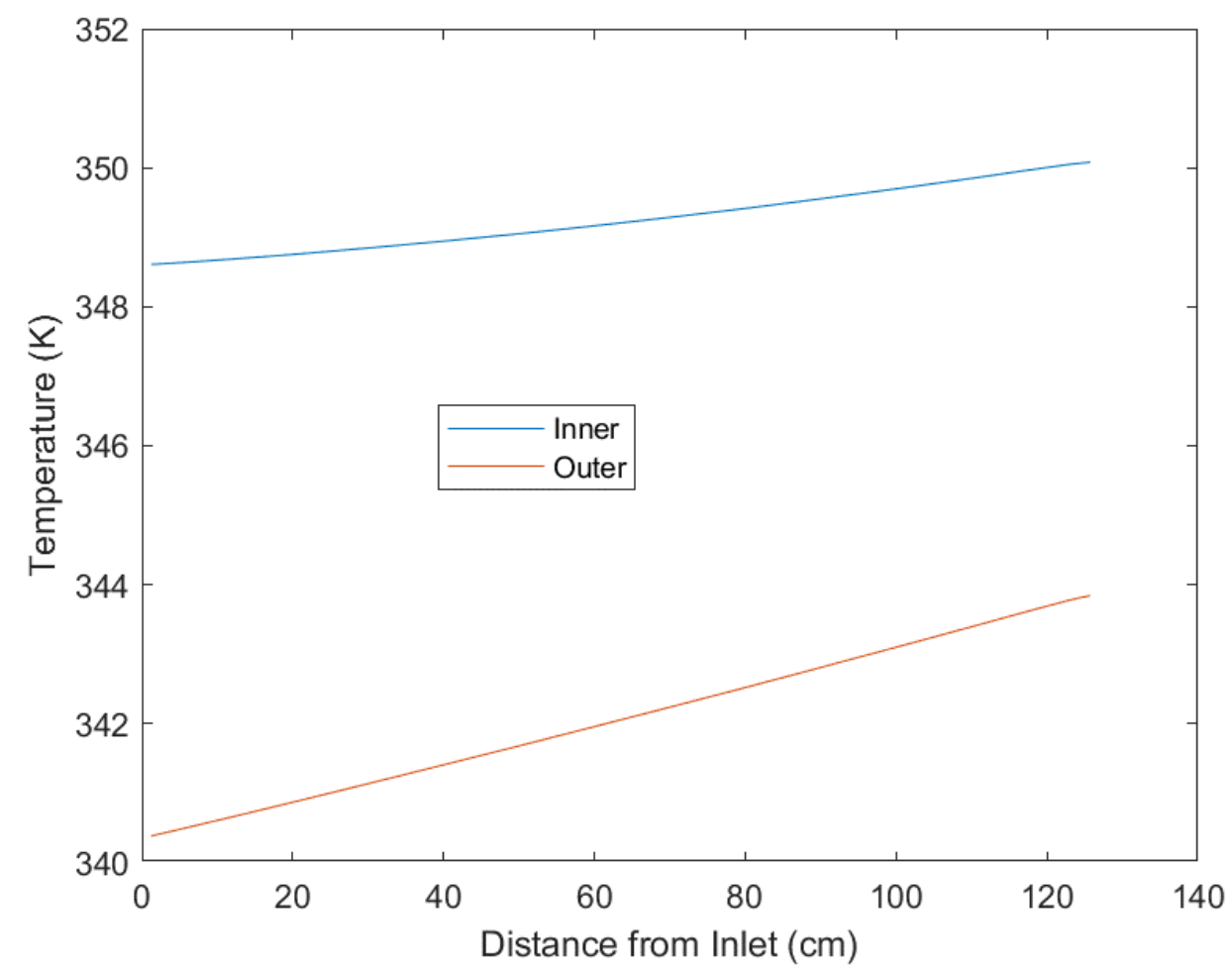

Figure 35: Gas Blanket Surface Temperatures 


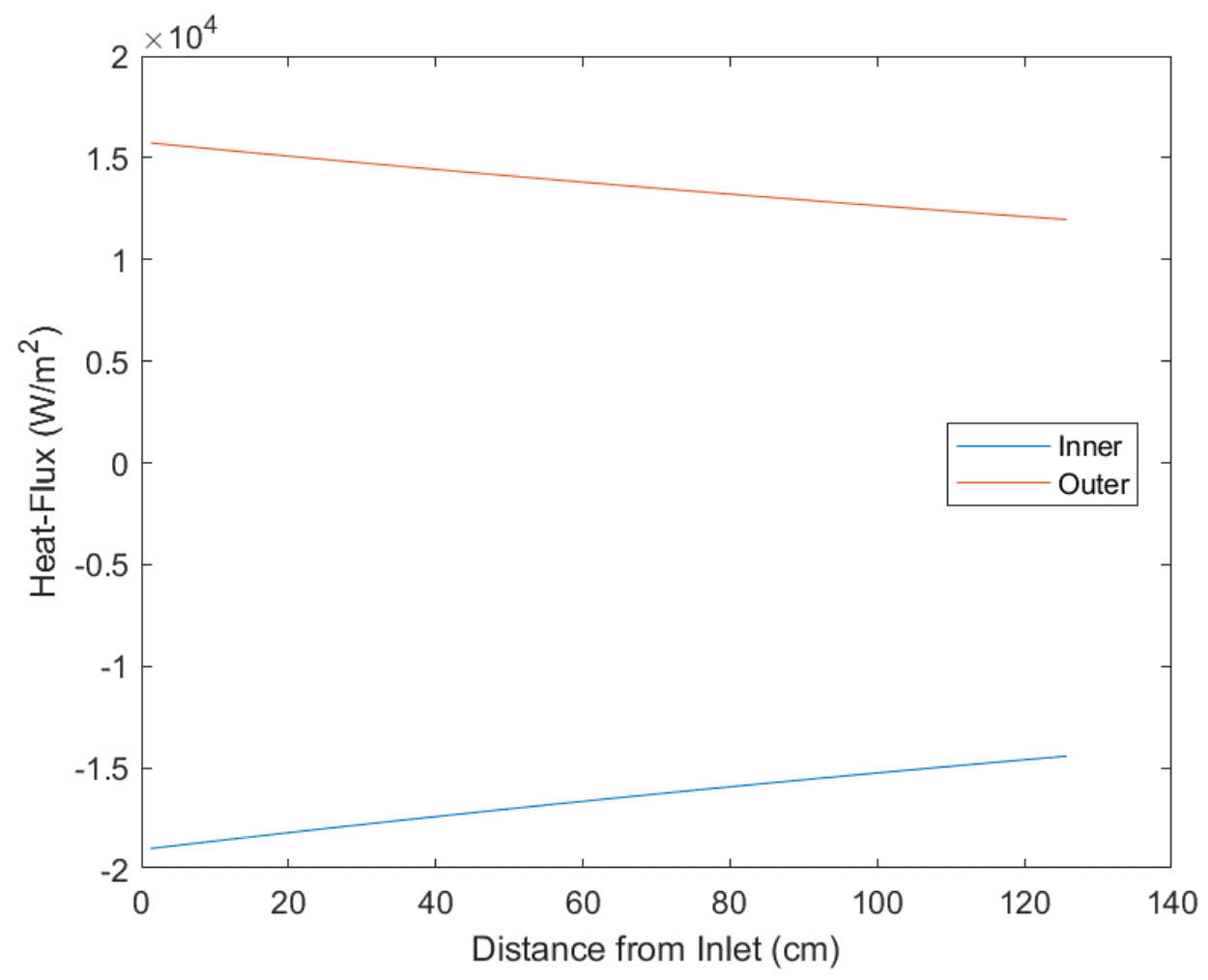

Figure 36: Gas Blanket Heat Fluxes

\subsubsection{Fuel Plate Cooling System}

The fuel plate cooling system is almost identical to the previous case, with no changes to the fuel plate power. The results are still included here, though a busy reader may skim them. 


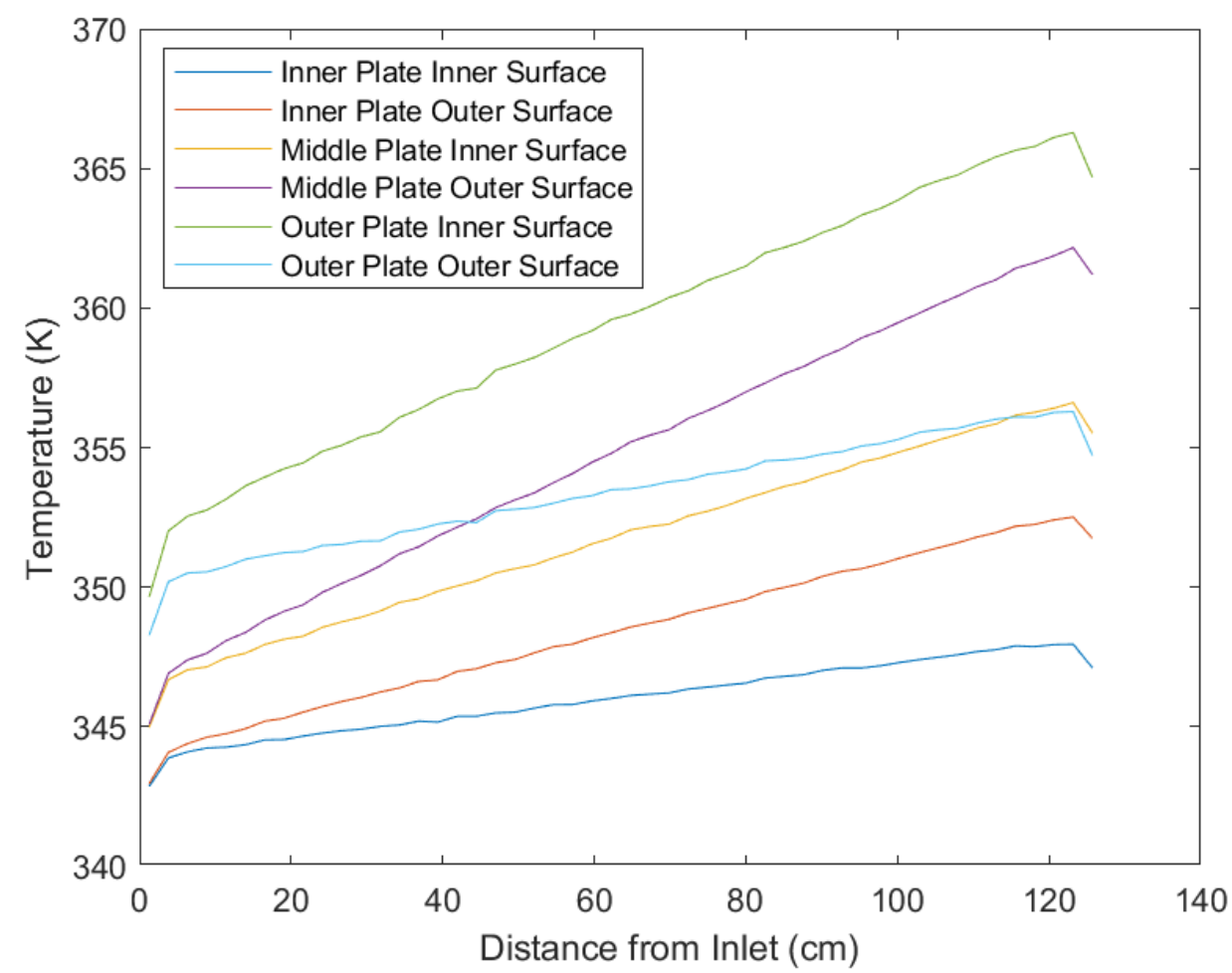

Figure 37: Fuel Plate Surface Temperatures
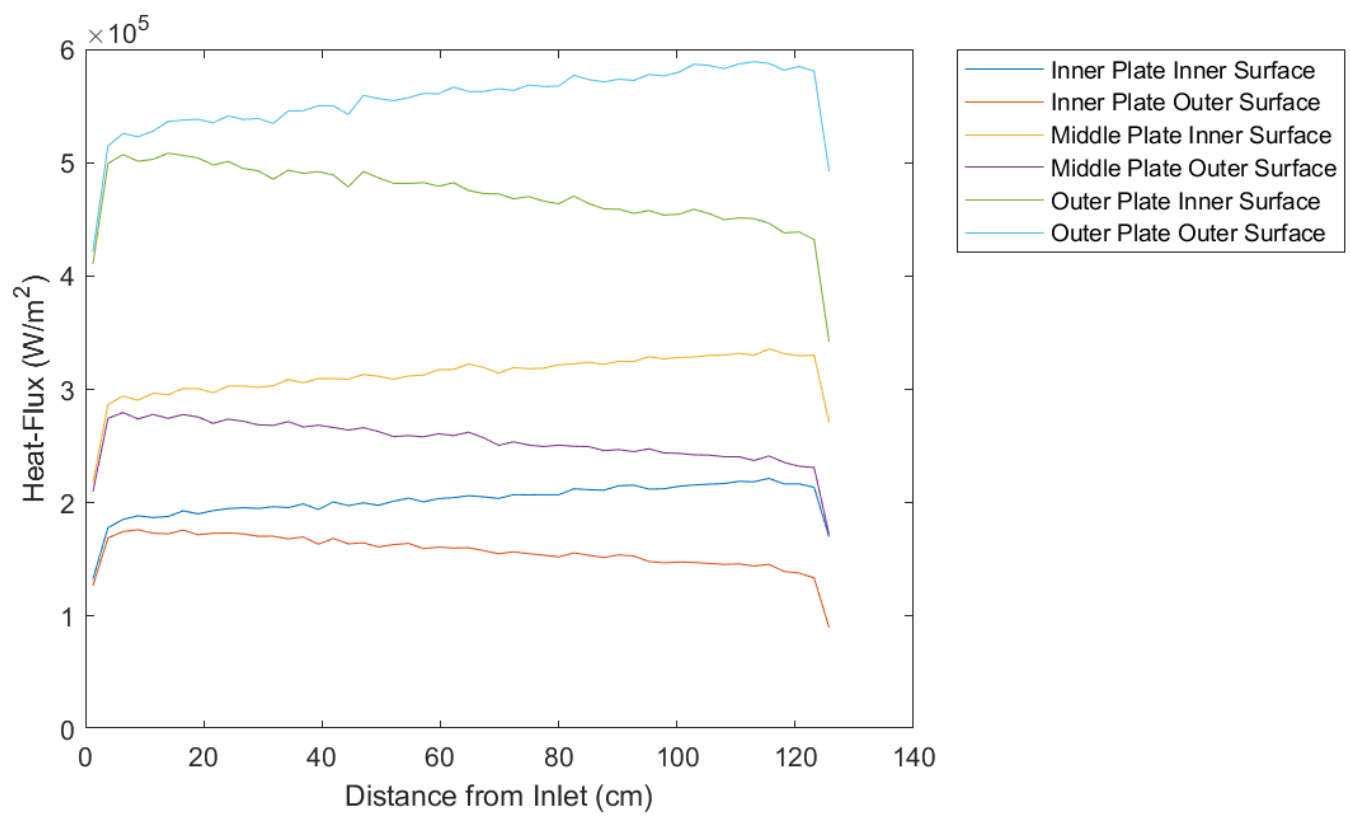

Figure 38: Fuel Plate Heat Fluxes 


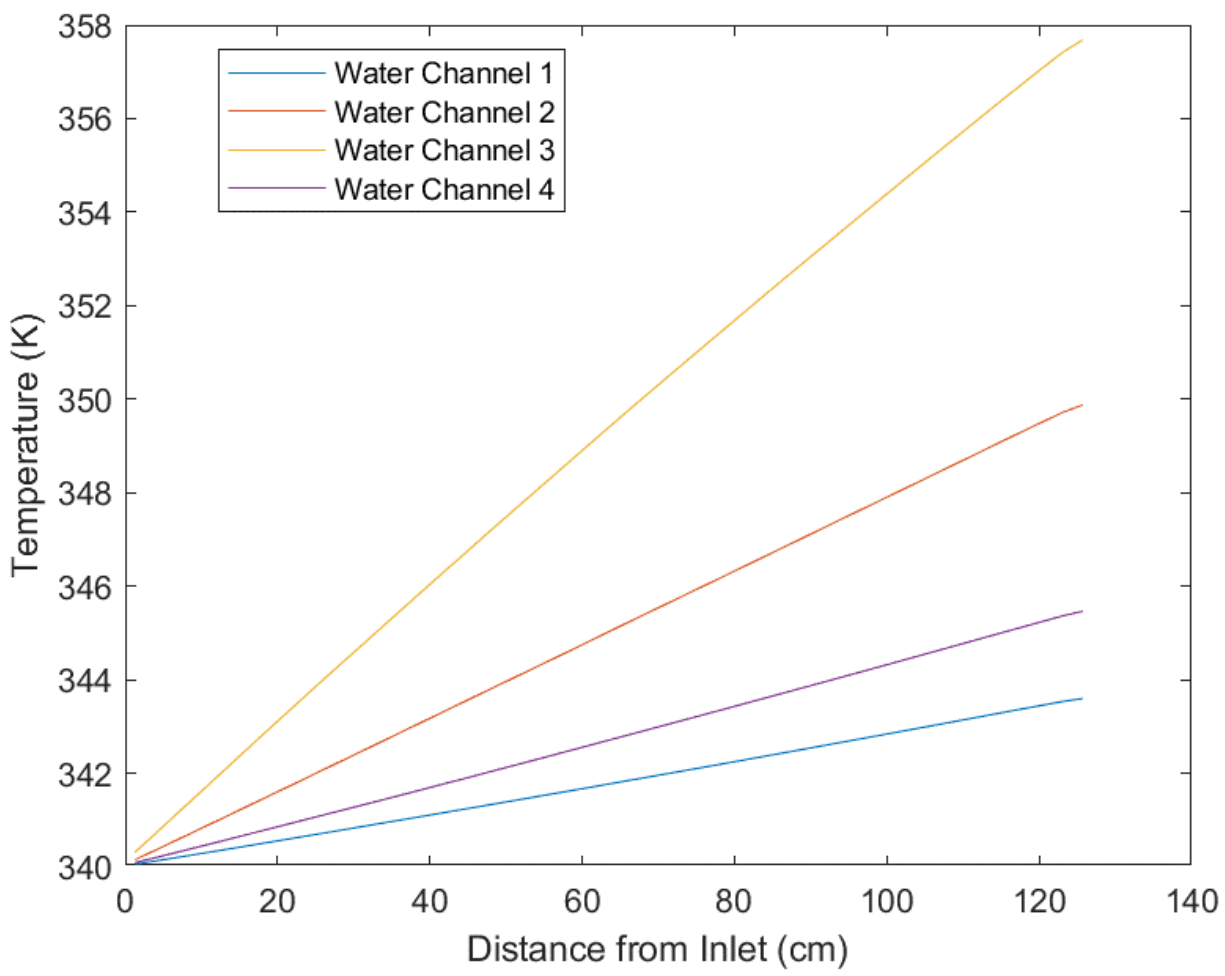

Figure 39: Fuel Plate Cooling Water Temperatures

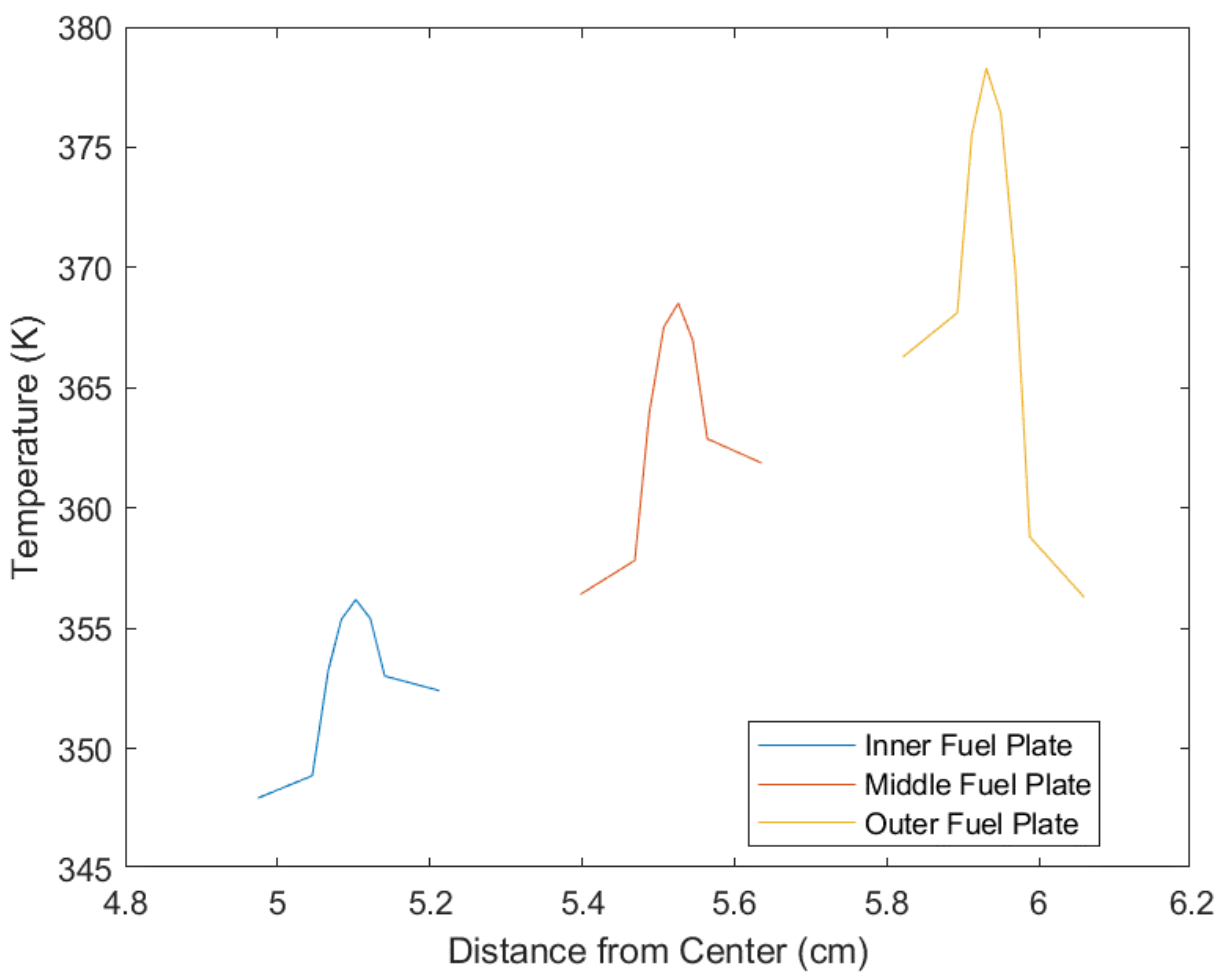

Figure 40: Peak Fuel Plate Radial Temperatures 


\subsection{Single Fuel Pin Test Section}

The following section showcases several temperature profiles spanning across the subvolumes within the test section when sodium passes through the test section with a single U-Zr SFR fuel pin (2.92 mm OD, $1.27 \mathrm{~m}$ long) within the test chamber. Sub-volume 1 is the outlet at top of the test leg, and sub-volume 50 is the inlet at the bottom of the test leg. This information is taken after 100 seconds of simulation time to ensure steady state conditions are attained. At these temperatures and pressures, the primary coolant has a liquid fraction of 100 percent, the helium has a gas fraction of 100 percent, and the water system has a liquid fraction of 100 percent. Figure 41 shows the cross section of this test case.

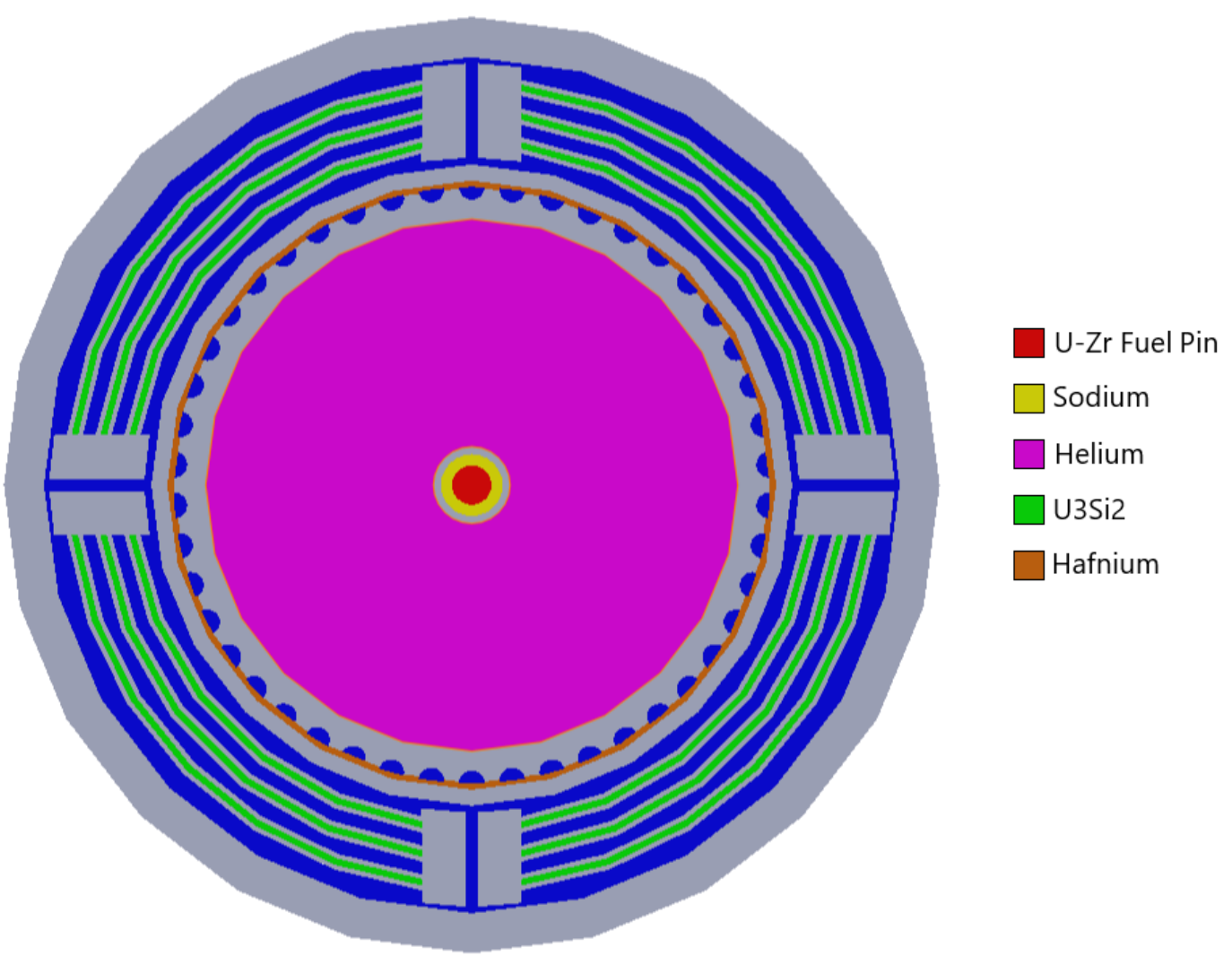

Figure 41: Cross Section of Single Pin Test Case

Figure 42 shows the fluid temperature distributions from inlet to outlet. Heat generation takes place within both the fuel pin and the fuel plates for this case, so the primary fluid increases in temperature as the fluid approaches the outlet. The primary and helium systems 
for this case are very different than the previous cases, though the fuel plate cooling system changed only slightly.

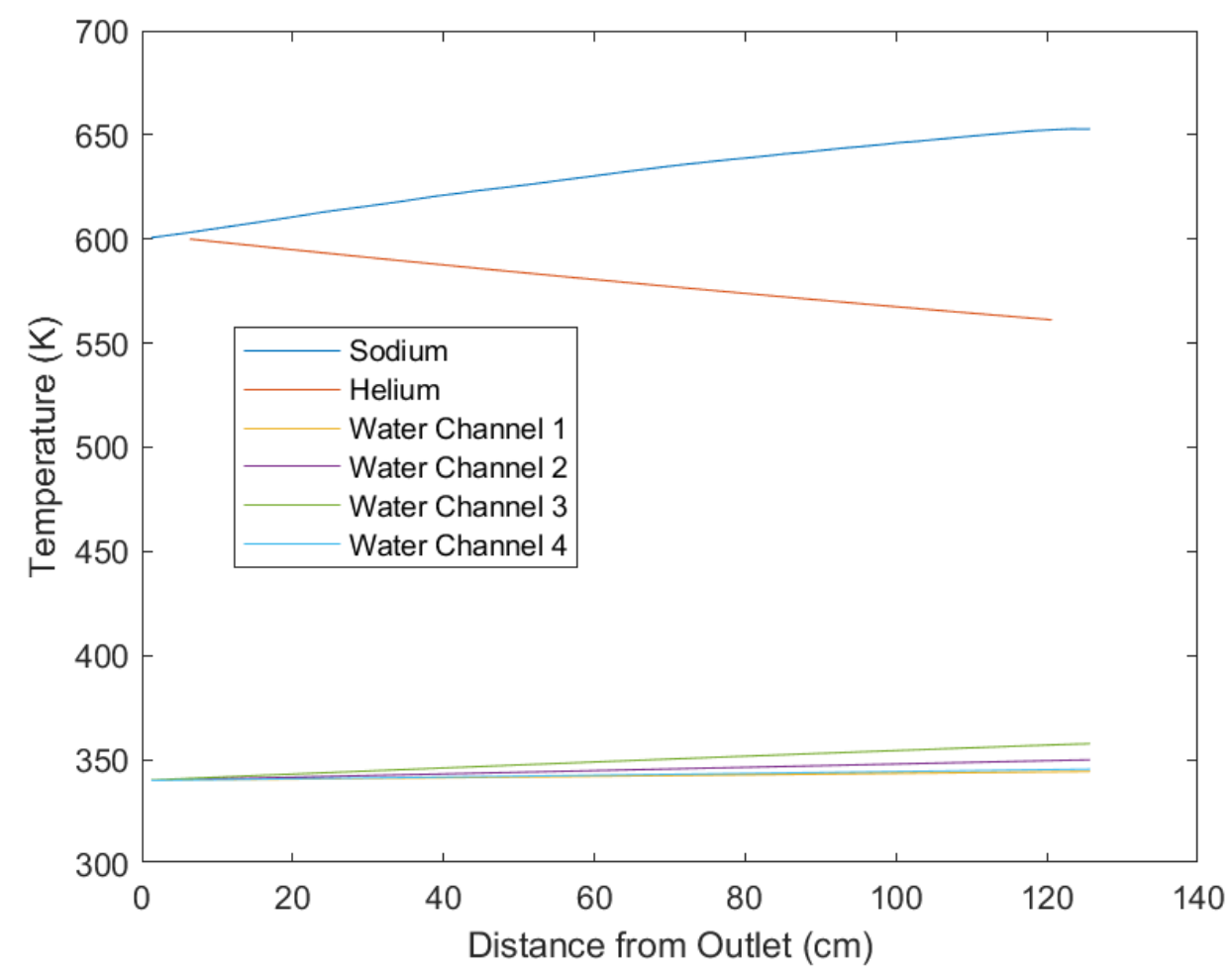

Figure 42: Fluid Temperatures from Inlet to Outlet

Figure 43 shows the radial temperature profile from the center of the test section to the outer aluminum baffle of the test section at both the inlet and outlet. At the inlet, the sodium and helium enter the system at $600 \mathrm{~K}$, creating a flat profile. As the fluid passes through the test section, the helium is cooled by the water while the sodium is cooled by the helium and heated by the fuel pin. This results in a higher center temperature but lower helium temperature at the outlet when compared to the inlet. 


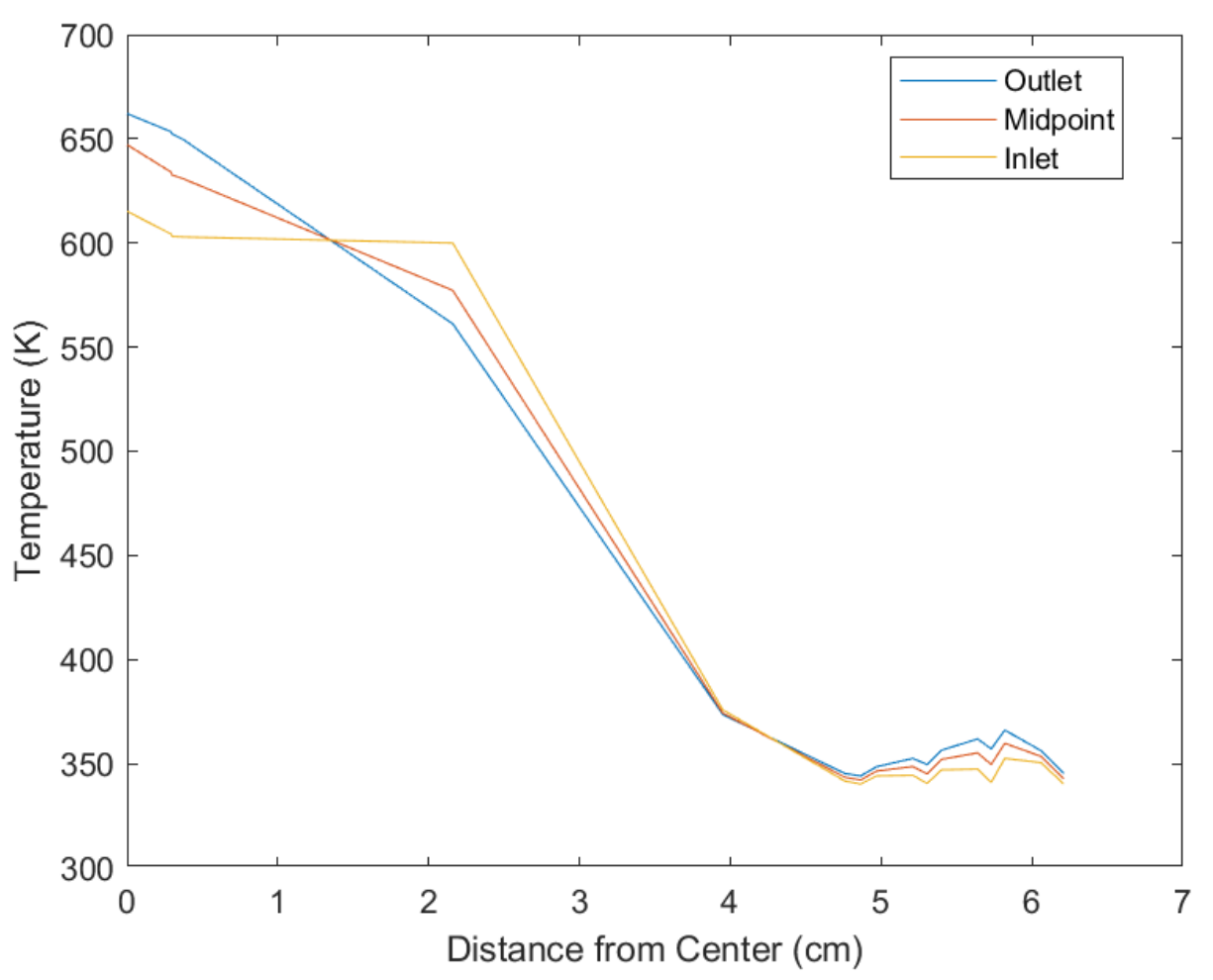

Figure 43: Radial Temperature Distribution

\subsubsection{Primary System}

Figure 44 shows the primary piping surface and fuel rod surface temperature, and Figure 45 shows convective heat fluxes through the fuel rod and the piping separating the primary system and helium system. A positive value indicates heat flux out of the structure, while a negative value indicates a heat flux into the structure. Heat generation takes place within the fuel rod at a pin power of $3.7 \mathrm{~kW}$, and the primary fluid temperature will increase as it approaches the outlet. SFR fuel rods typically experience an inlet-outlet temperature rise of $50 \mathrm{~K}$, so the primary fluid pressure differential across the test section is tailored to force this $50 \mathrm{~K}$ rise. A pressure difference of $8.675 \mathrm{kPa}$ creates a fluid velocity through the test section of $1.1 \mathrm{~m} / \mathrm{s}$, and Figure 46 shows the rise in temperature of the primary fluid. As can be seen, the $50 \mathrm{~K}$ rise in temperature has been achieved. The fuel pin experience a maximum centerline temperature of $664 \mathrm{~K}$, well within operating conditions. The helium is simultaneously heated by the sodium and cooled by the water, and near the outlet is 560 $\mathrm{K}$. This produces a larger heat flux through the primary piping near the outlet, as can be seen in Figure 45. Near the inlet, the heat flux through the piping is roughly $2 \mathrm{~kW} / \mathrm{m}^{2}$, while 
near the outlet the heat flux is near $41 \mathrm{~kW} / \mathrm{m}^{2}$. This explains the slight drop in temperature in the primary fluid at the outlet. However, the jagged peaks found in the test chamber surfaces do not represent what should be physical. This is likely caused by a combination of two separate limitations of the model used: the fact that RELAP does not account for axial heat conduction through heat structures, and a relatively large amount of variance in the heat generated within each cell. The heat generated per cell was calculated via Attila in the neutronic analysis of the system, and the variation from cell to cell are great. With no axial heat conduction in the heat structures, this causes variations in the heat structures surface temperatures.

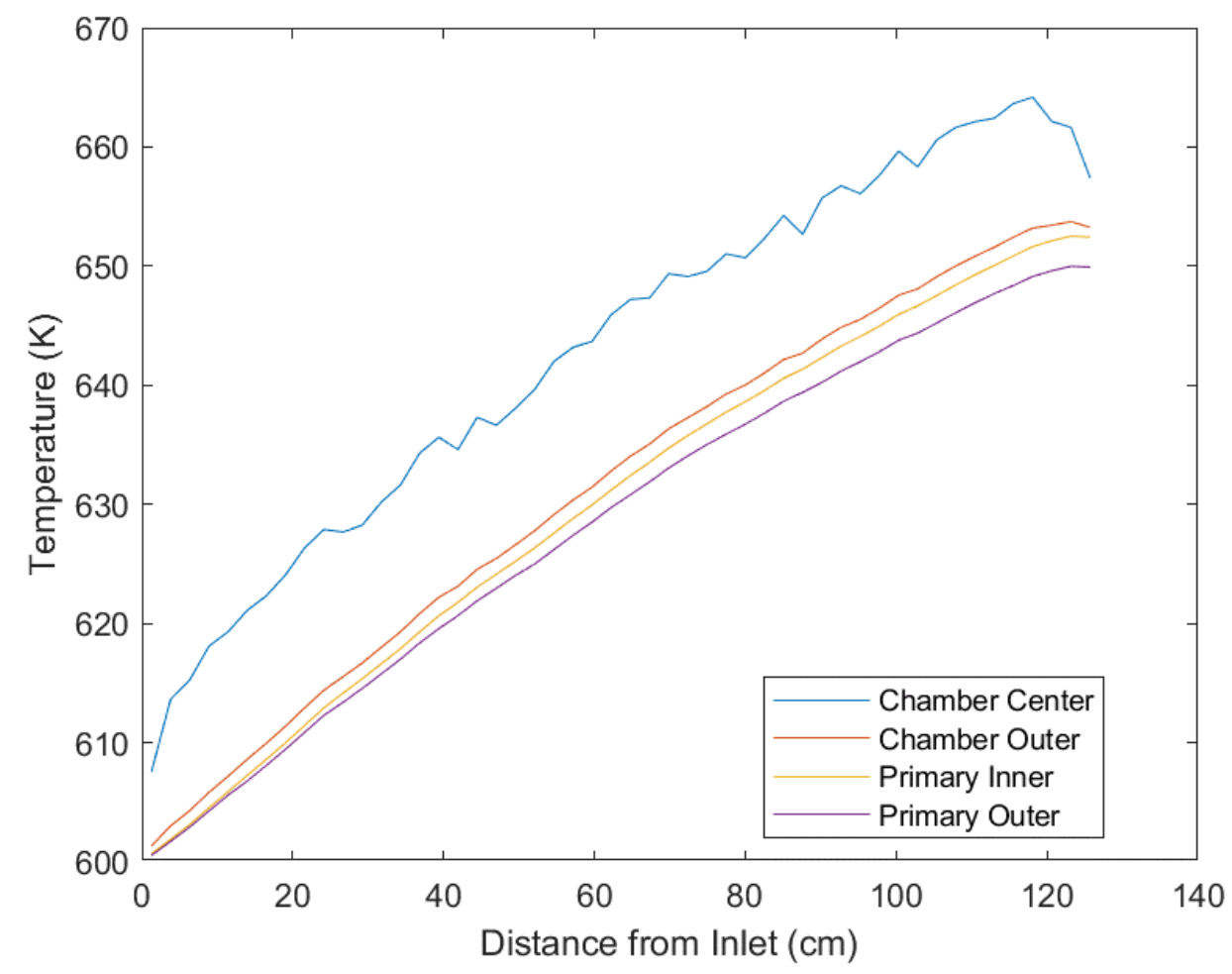

Figure 44: Primary Surface Temperatures 


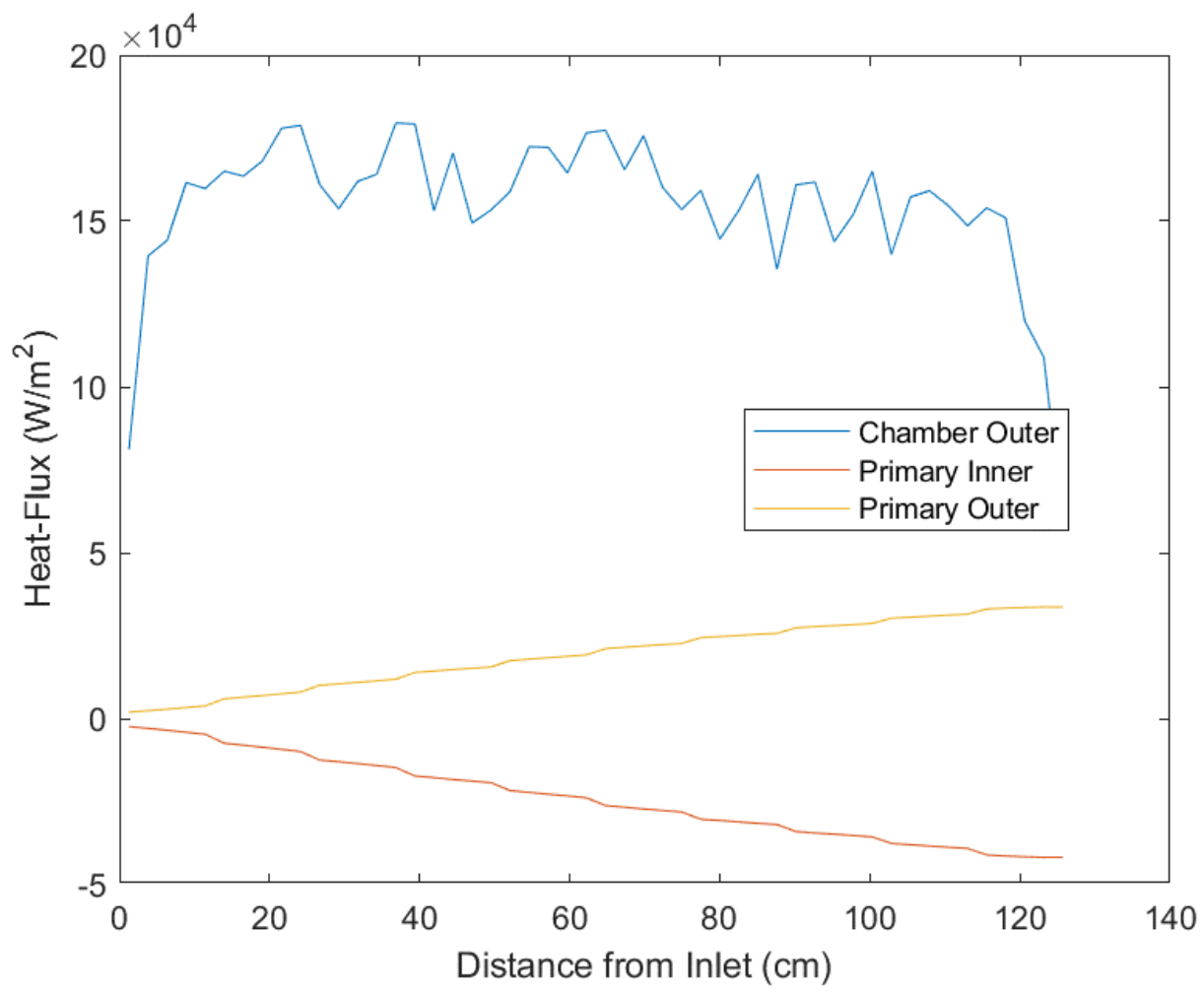

Figure 45: Primary Heat Fluxes

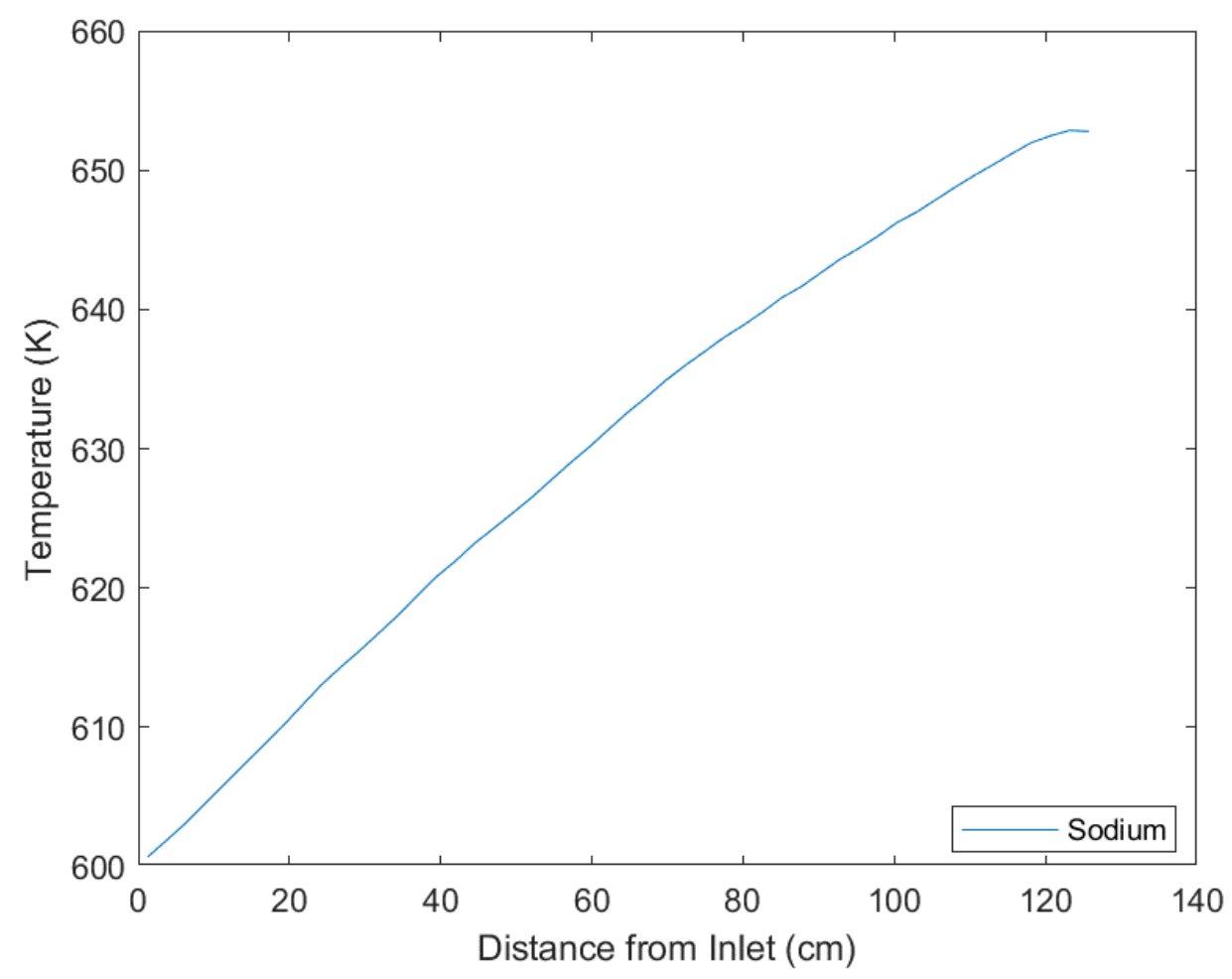

Figure 46: Sodium Temperature from Inlet to Outlet 
Figure 47 shows the radial temperature distribution of the fuel pin at several locations along its axial length. An SFR fuel pin is typically rated to $649 \mathrm{C}$ to $704 \mathrm{C}$ for steady state operations, $788 \mathrm{C}$ for anticipated transients, and $871 \mathrm{C}$ for unlikely events [22]. As shown, for these operating conditions the fuel pin cladding reaches outlet temperatures of $654 \mathrm{~K}$ (381 C), and is well within the desired safety limits.

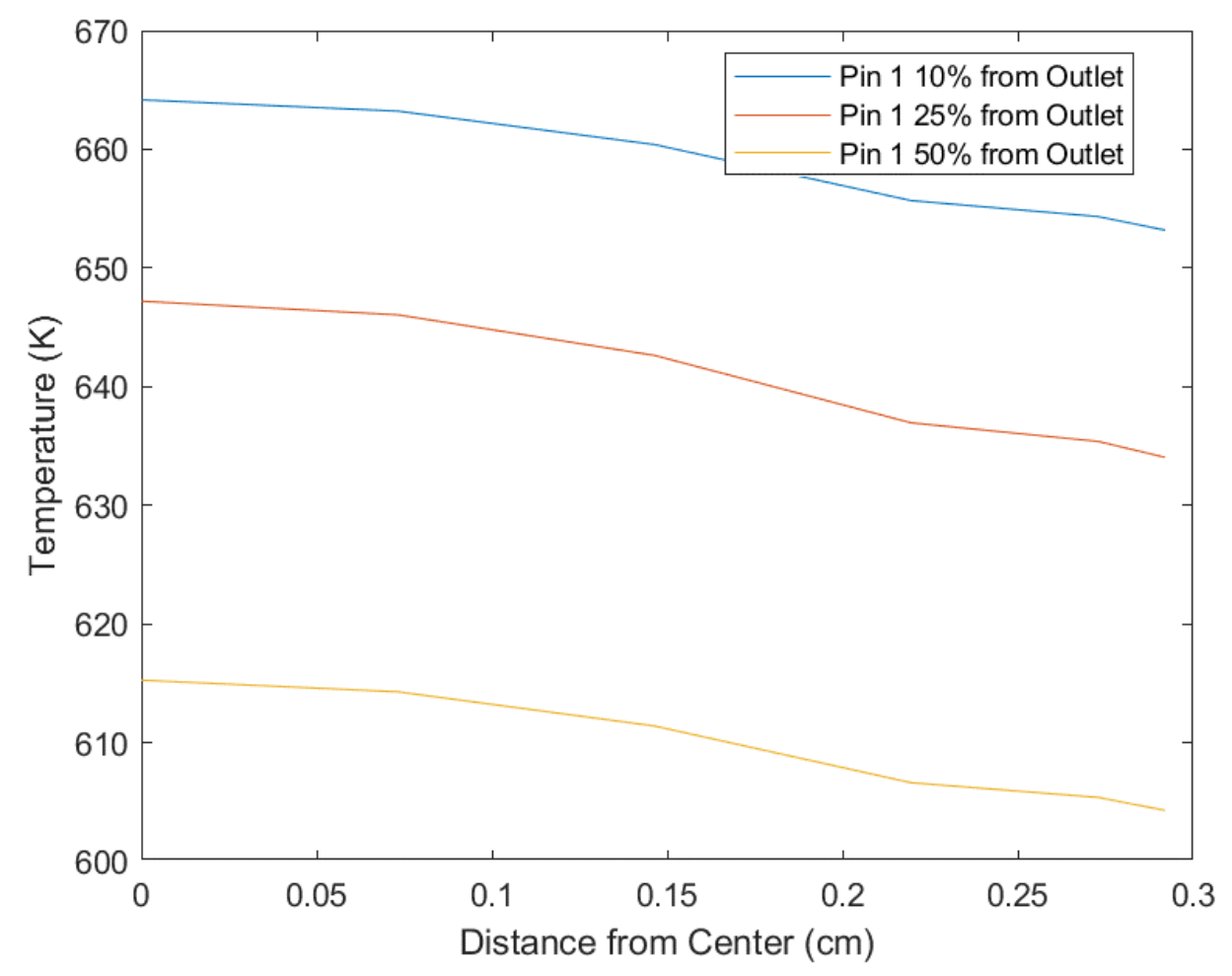

Figure 47: Fuel Pin Radial Temperature

\subsubsection{Helium System}

Figure 48 shows the surface temperature of the piping separating the helium system and the water system, and Figure 49 shows the convective heat flux through this piping. A positive value indicates heat flux out of the structure, while a negative value indicates a heat flux into the structure. Figure 50 also shows the helium temperature from inlet to outlet. The temperature decreases as the fluid approaches the outlet, which is to be expected with heat being transferred out of the system to the water system at a greater rate than heat is transferred into the system from the primary loop. The piping is significantly lower than the temperature of the helium system due to the cooling effect from the lower temperature water system. A mass flow rate of $.0989 \mathrm{~kg} / \mathrm{s}$ was used for this system. It is important to 
note that for systems with fueled test sections the number of cells in the helium system was reduced from 50 to 10 . This was to reduce calculation times, as the helium temperature profiles are not of great importance to the work done. This results in the large plateauing sections of these plots.

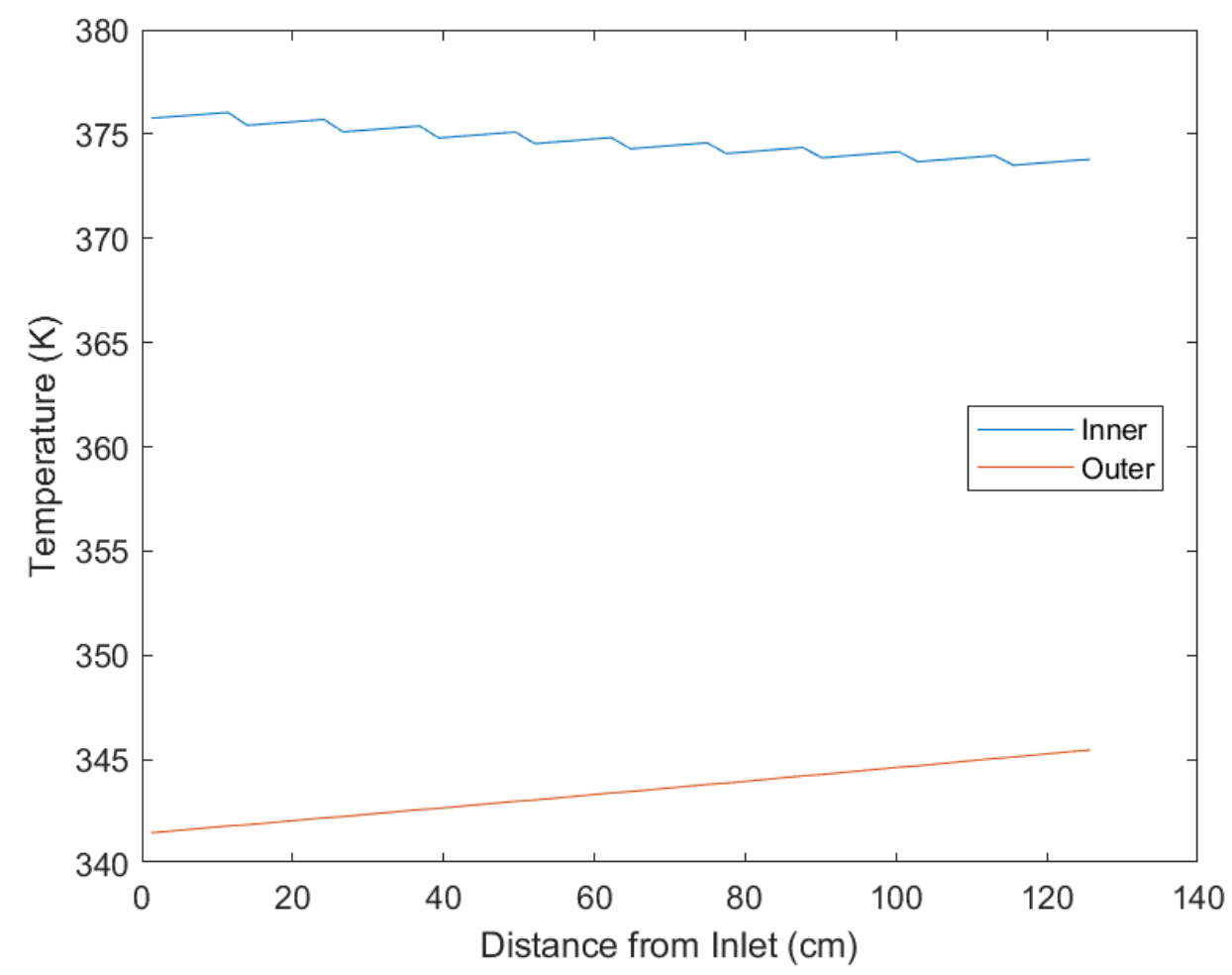

Figure 48: Gas Blanket Surface Temperatures 


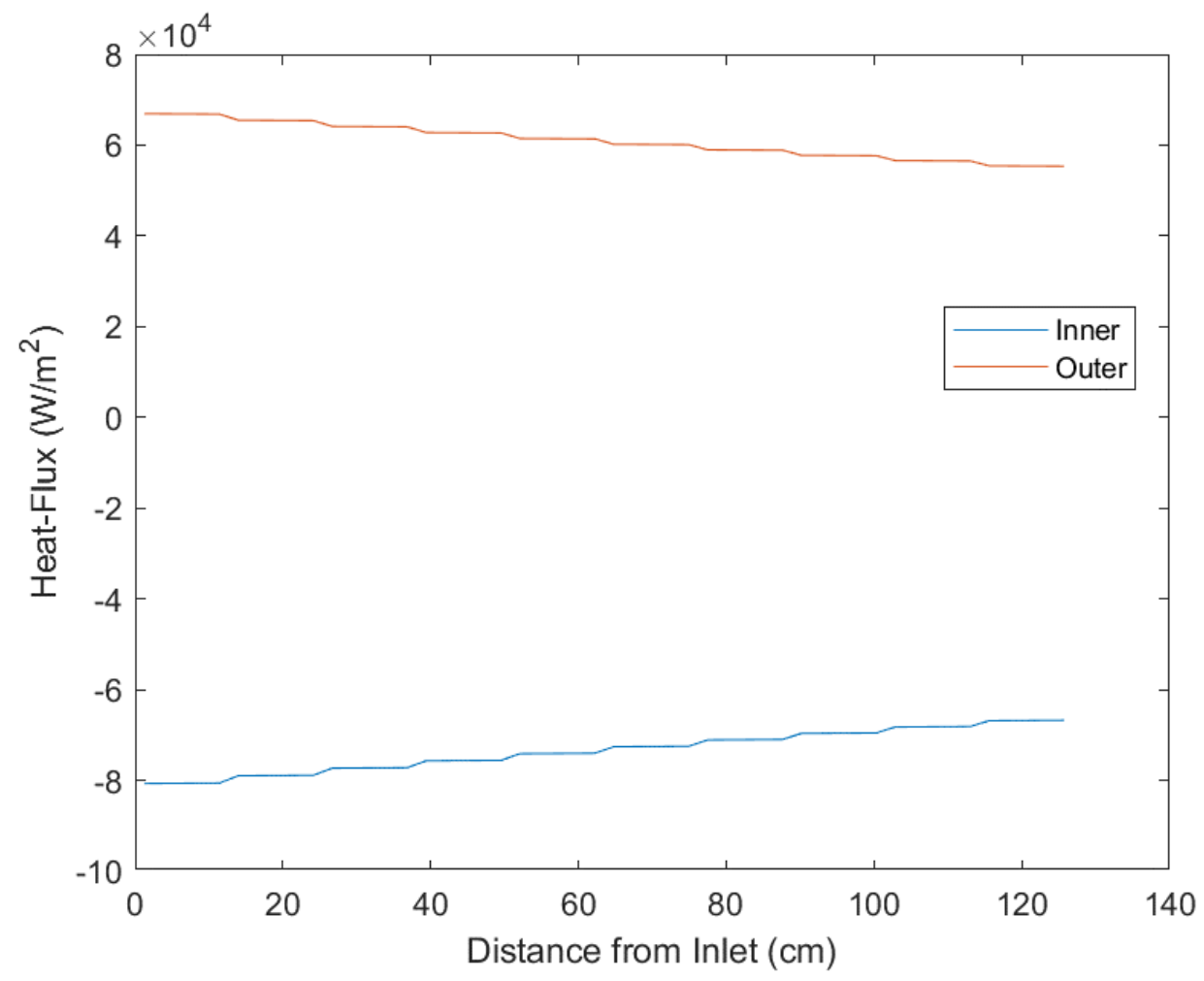

Figure 49: Gas Blanket Heat Fluxes

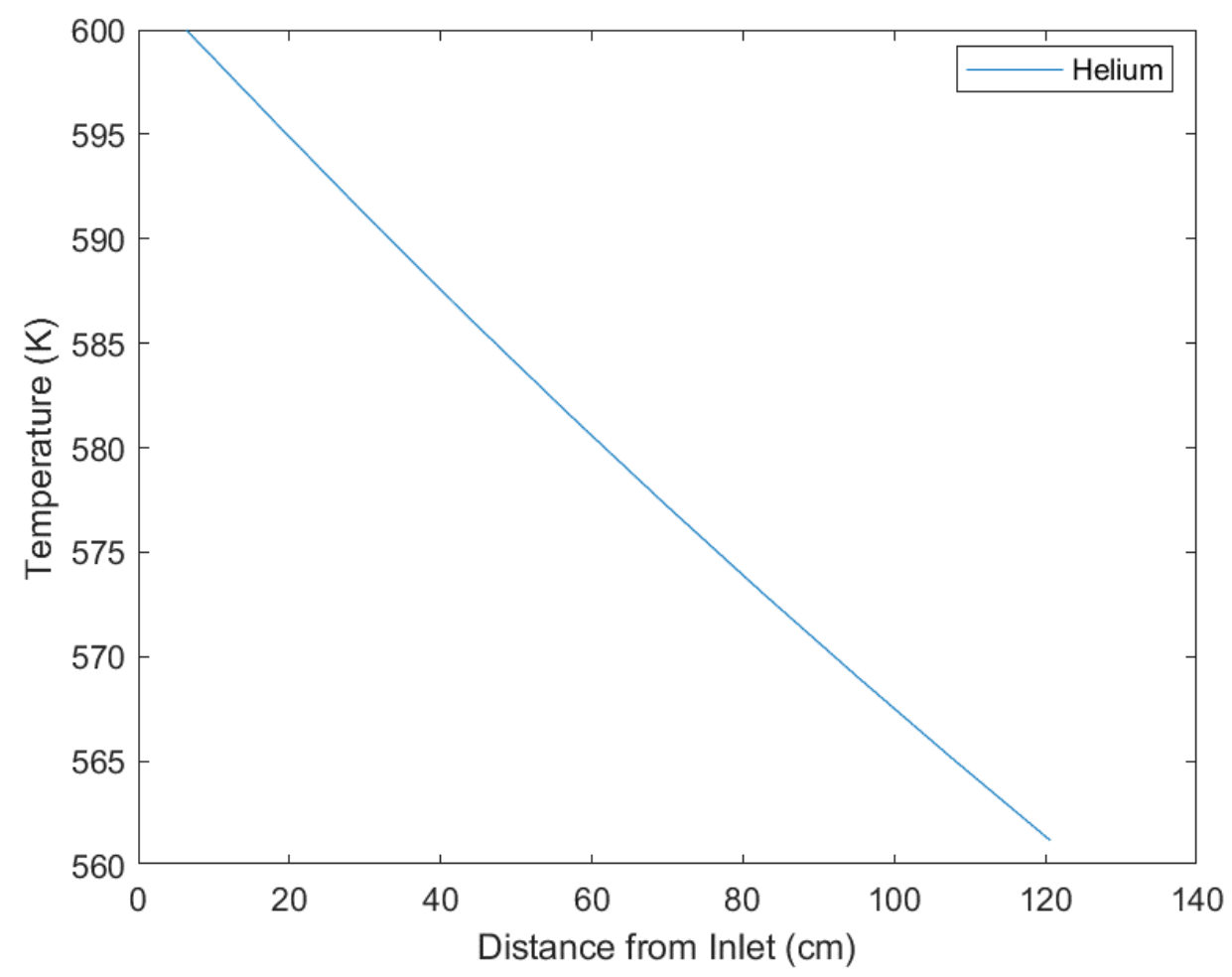

Figure 50: Helium Temperature from Inlet to Outlet 


\subsubsection{Fuel Plate Cooling System}

The fuel plate cooling system is almost identical to the previous case, though the introduction of the fuel pin could slightly change the power within the fuel plates. Neutronics testing for this system done by another student showed that the resulting change in the plate power is less than 1 percent for each plate. As such, the only difference in this system from the one described in Section 5.2 is the amount of heat transferred in from the helium system. With the helium system being hotter in this case due to a heated primary system, the inner water channel is slightly higher in temperature than the previous case.

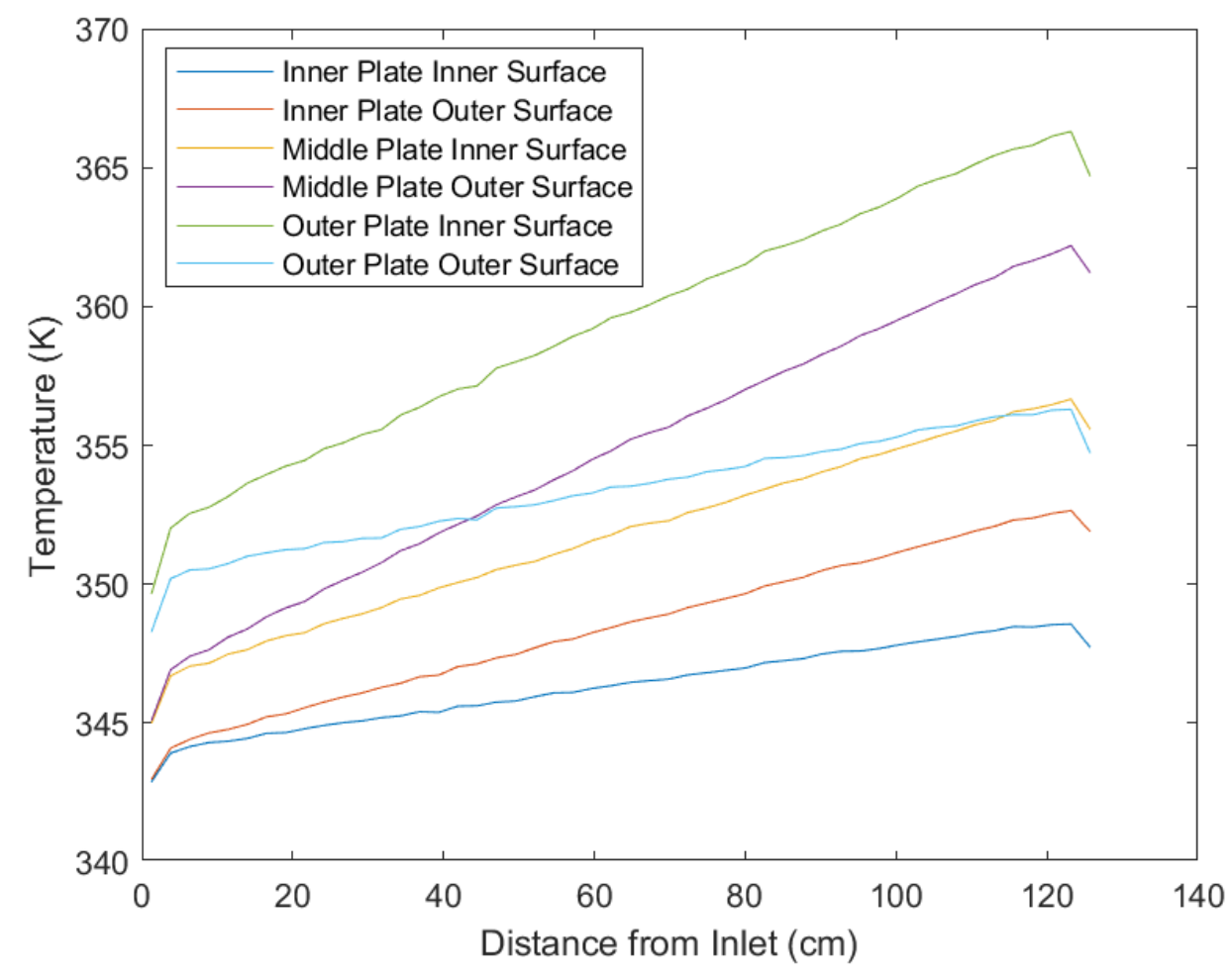

Figure 51: Fuel Plate Surface Temperatures 

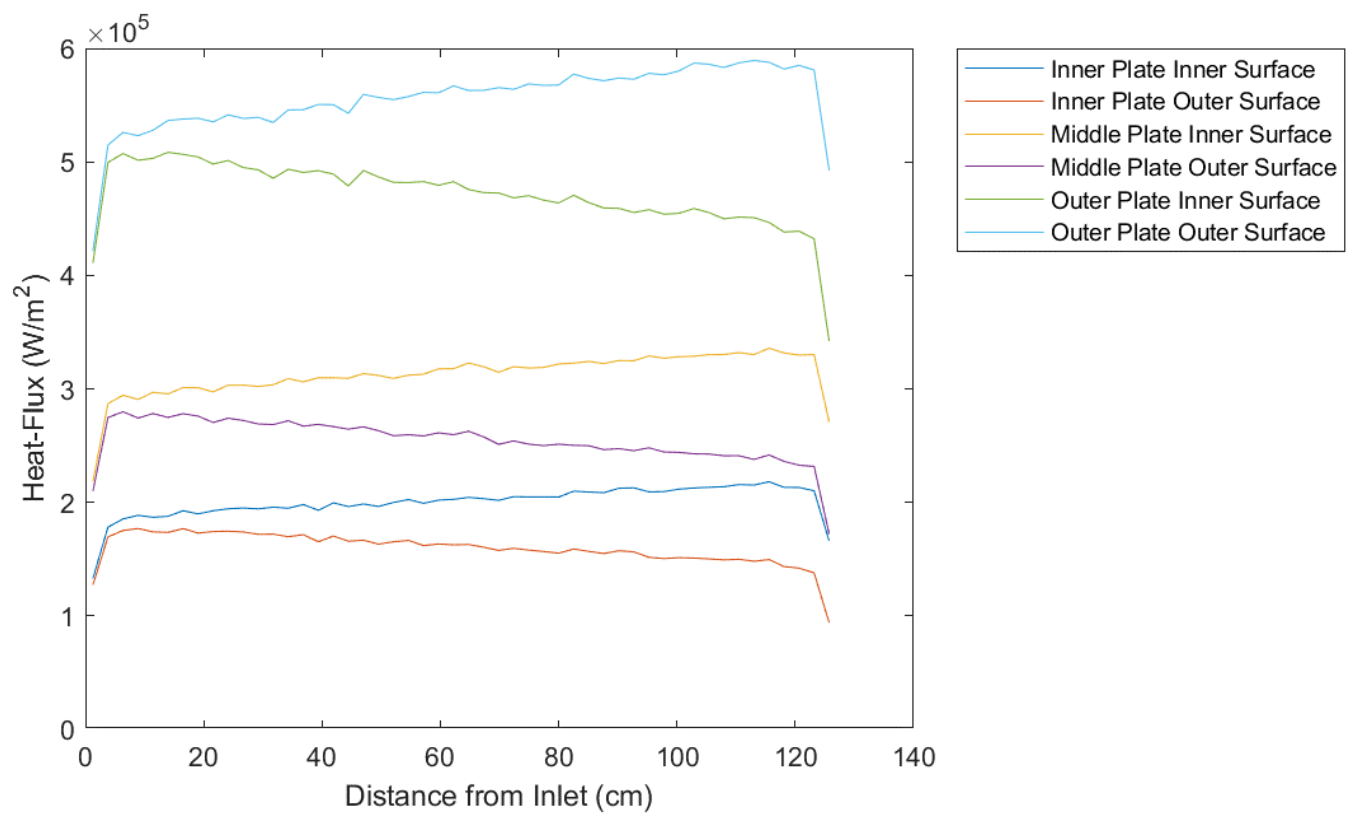

Figure 52: Fuel Plate Heat Fluxes

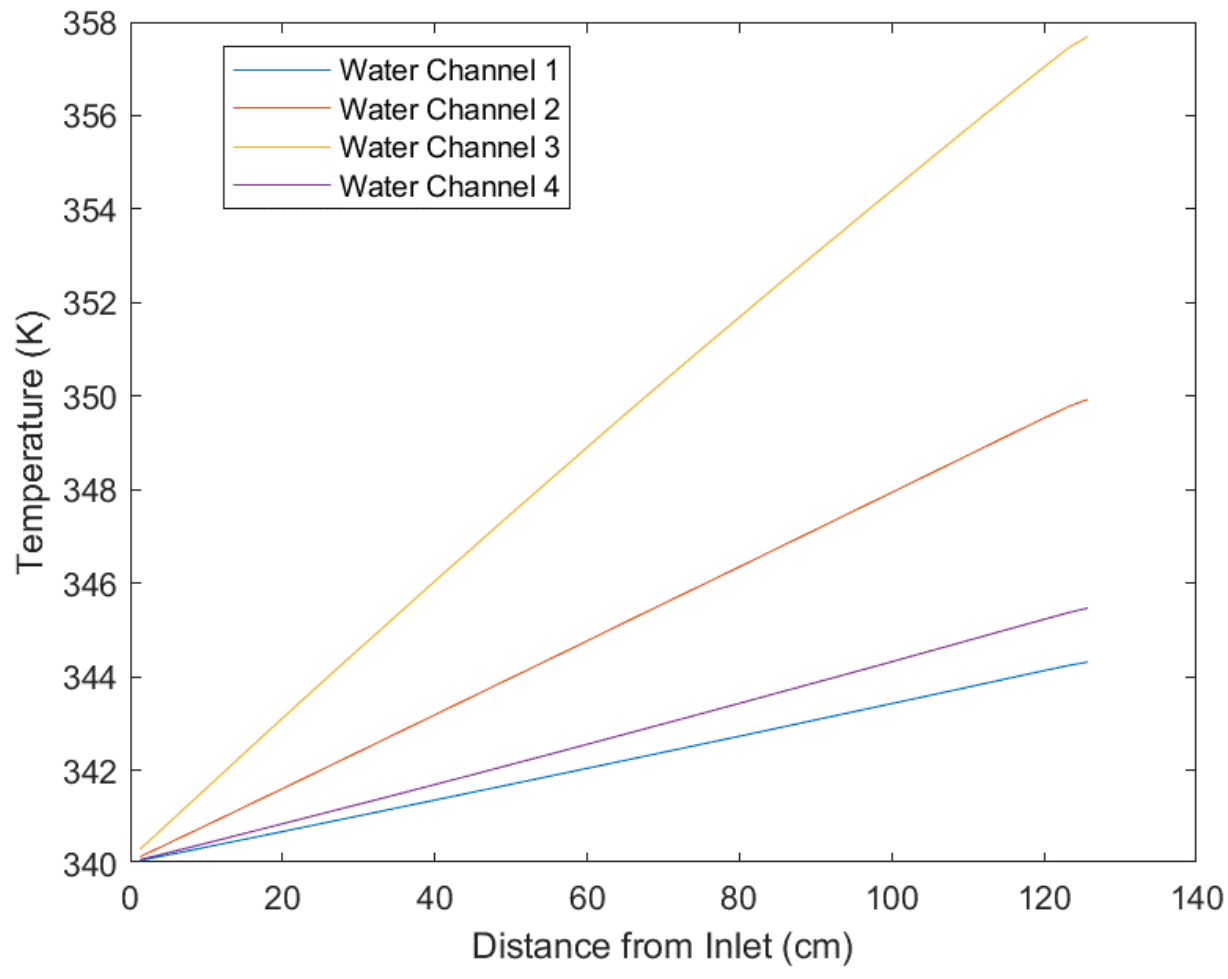

Figure 53: Fuel Plate Cooling Water Temperatures 


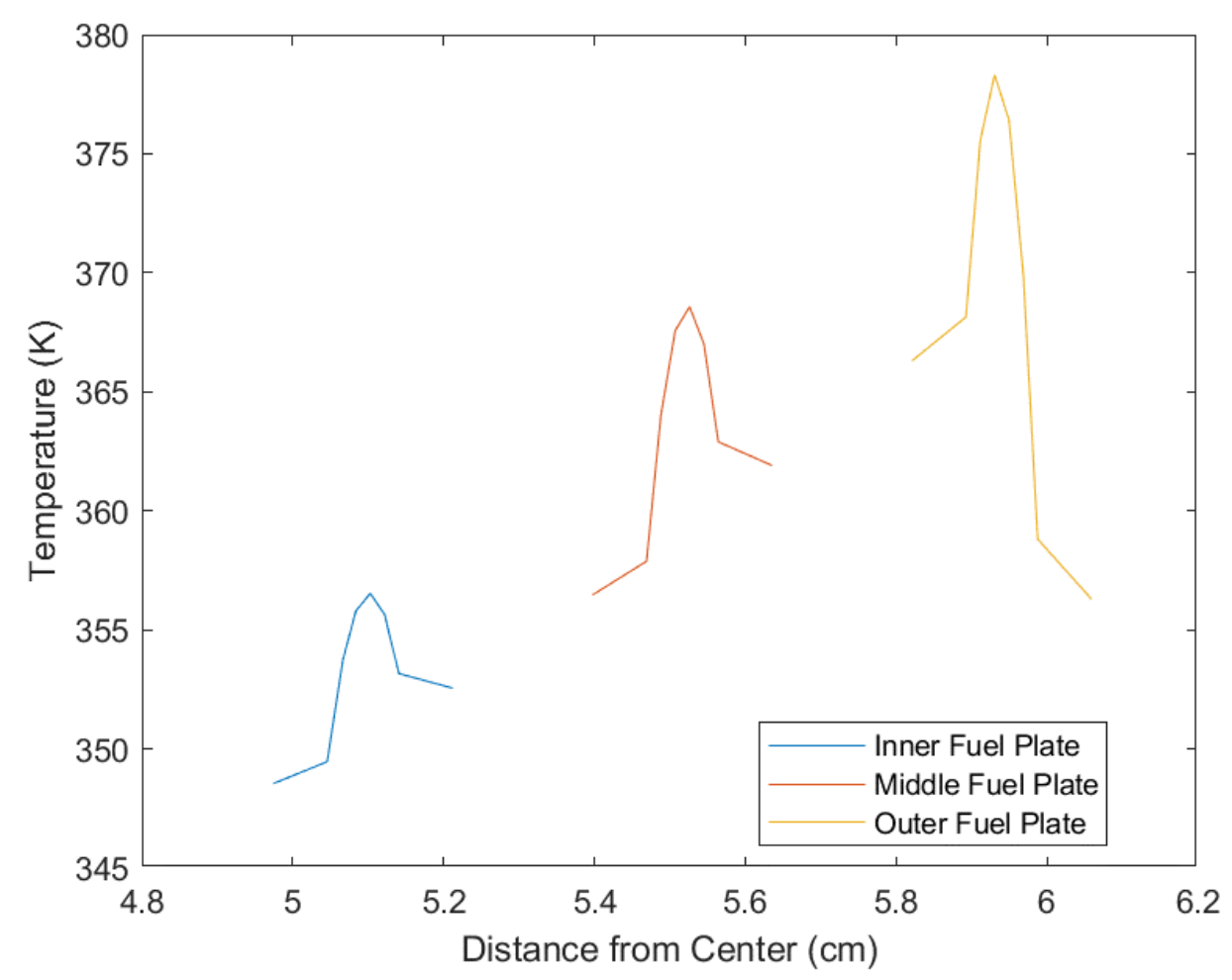

Figure 54: Peak Fuel Plate Radial Temperatures

\subsubsection{Summary}

With a single fuel rod in the test section, this system shows it is capable of replicating several key factors of the thermal hydraulic conditions necessary for testing SFR fuel rods. The primary goal of reaching a $50 \mathrm{~K}$ sodium coolant temperature increase from inlet to outlet was reached using a coolant velocity of $1.1 \mathrm{~m} / \mathrm{s}$. This velocity is somewhat low compared to typical SFR coolant velocity, though the neutronic analysis showed that using the available space within the ATR would likely result in a lower fast neutron spectrum in the test section, resulting in a lower pin power. Fuel rod radial temperature profiles show that the maximum centerline temperature reaches $654 \mathrm{~K}$, on the lower end of designed operating conditions for SFR fuel rods. The jagged peaks in the test chamber surface temperature and heat fluxes are caused by a large variation in the axial pin power found by the neutronic analysis as RELAP has no way of modeling axial heat conduction in the heat structures. Other than this discrepancy, this model overall shows the primary system design can provide SFR like operating conditions for a single SFR fuel pin. 
While the booster fuel plate coolant system and helium blanket system do not change greatly from previous iterations, it is still important to point out that this model shows they can be operating safely and do not have a great impact on the primary system. The water channels do not reach boiling at any point and the booster fuel plates remain within safe temperatures reaching a maximum of $378 \mathrm{~K}$. Reaching all of these requirements, the RELAP model indicates the FSTL could safely provide thermal hydraulic operating conditions for a single fuel pin.

\subsection{Three Fuel Pin Test Section}

The following section showcases several temperature profiles spanning across the subvolumes within the test section when sodium passes through the test section with three U$\mathrm{Zr}$ SFR fuel pins ( $2.92 \mathrm{~mm}$ OD, $1 \mathrm{~m}$ long) within the test chamber. Sub-volume 1 is the outlet at top of the test leg, and sub-volume 50 is the inlet at the bottom of the test leg. This information is taken after 100 seconds of simulation time to ensure steady state conditions are attained. At these temperatures and pressures, the primary coolant has a liquid fraction of 100 percent, the helium has a gas fraction of 100 percent, and the water system has a liquid fraction of 100 percent. Figure 55 shows the cross section of this test case. 


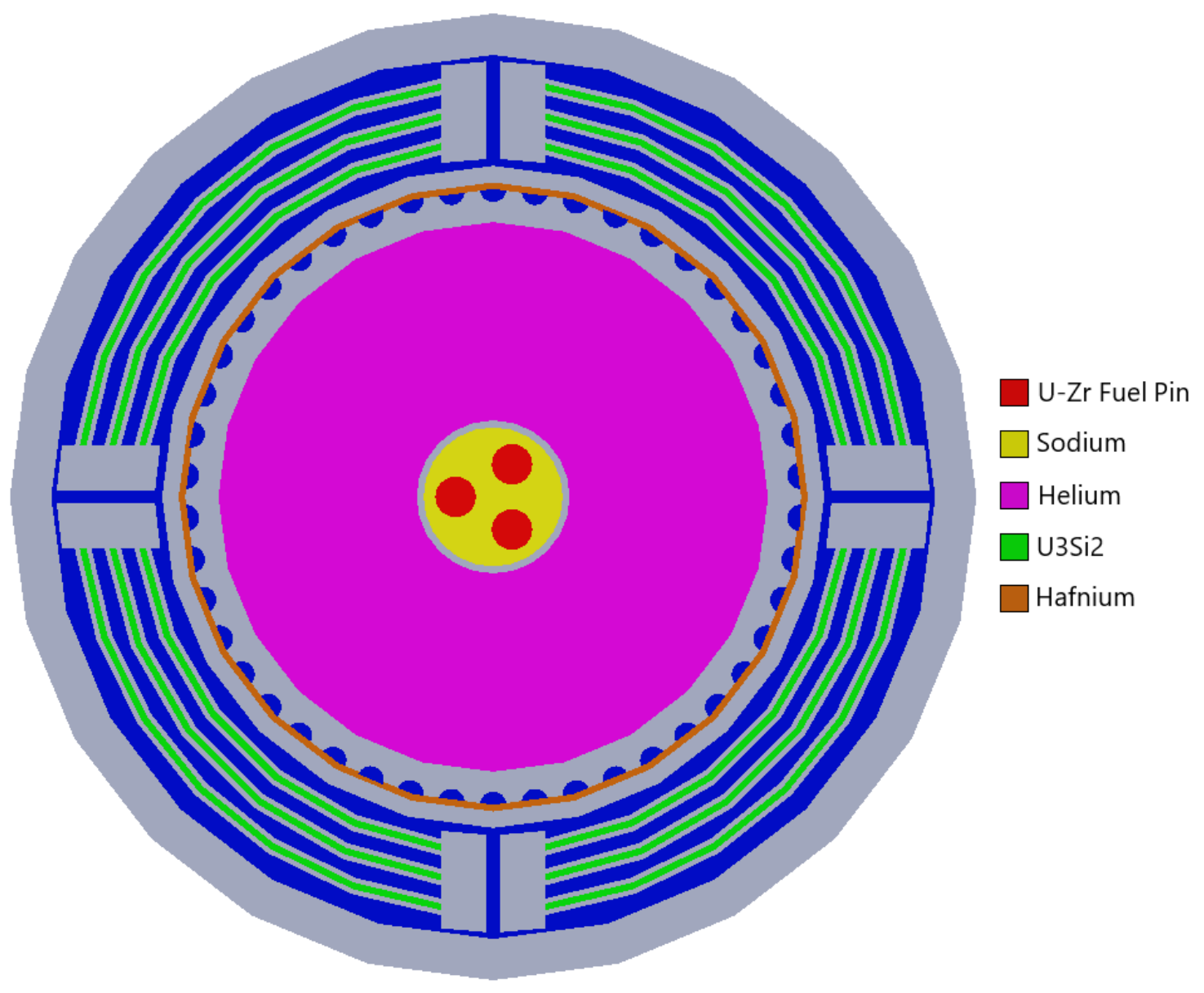

Figure 55: Cross Section of Three Fuel Pin Test Case

Figure 56 shows the fluid temperature distributions from inlet to outlet. Heat generation takes place within both the fuel pin and the fuel plates for this case, so the primary fluid increases in temperature as the fluid approaches the outlet. Note that Figure 57 shows the radial temperature at the inlet, halfway point, and outlet. The innermost temperature is taken from the center of one of the fuel pins, not the center of the test section. 


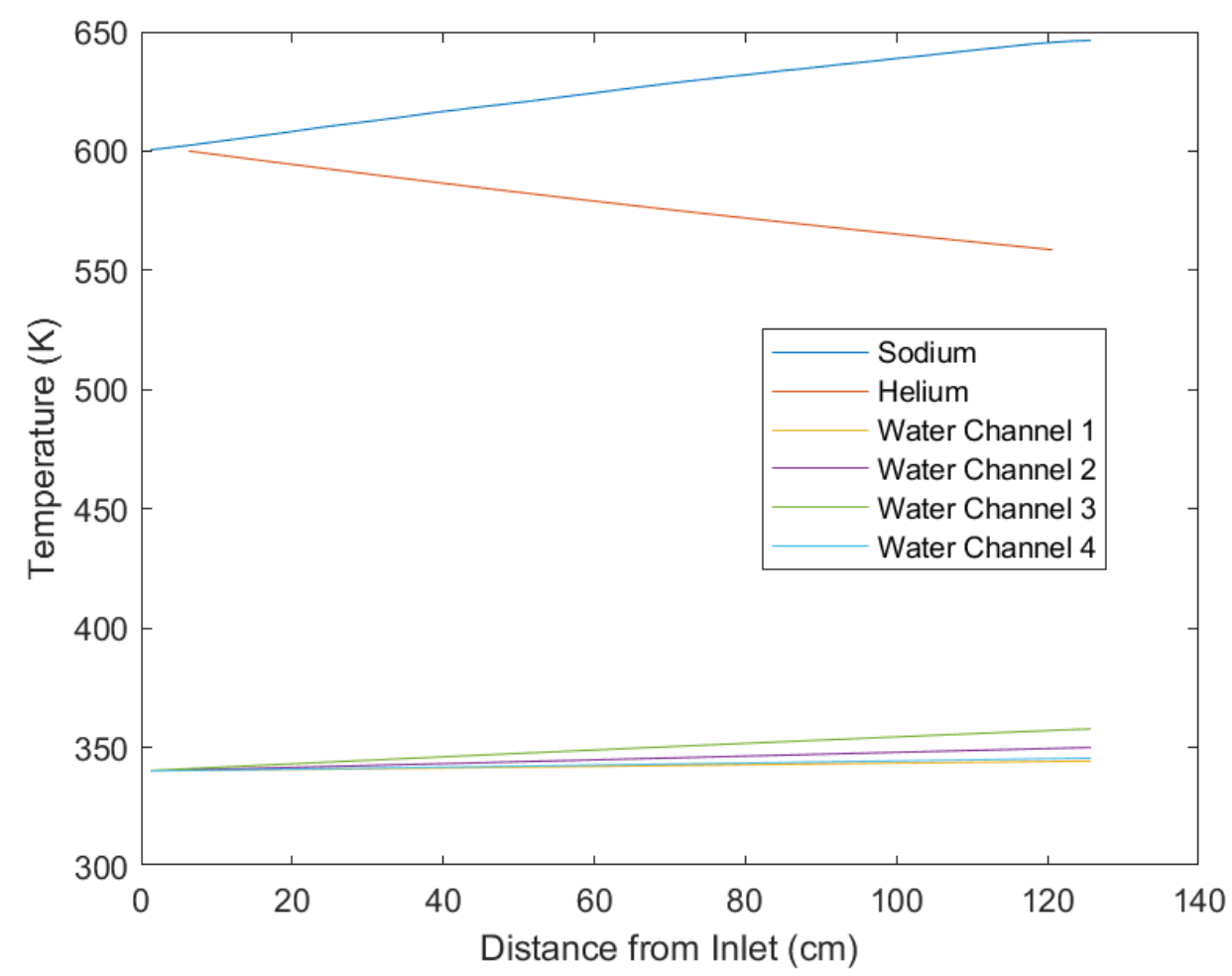

Figure 56: Fluid Temperatures from Inlet to Outlet

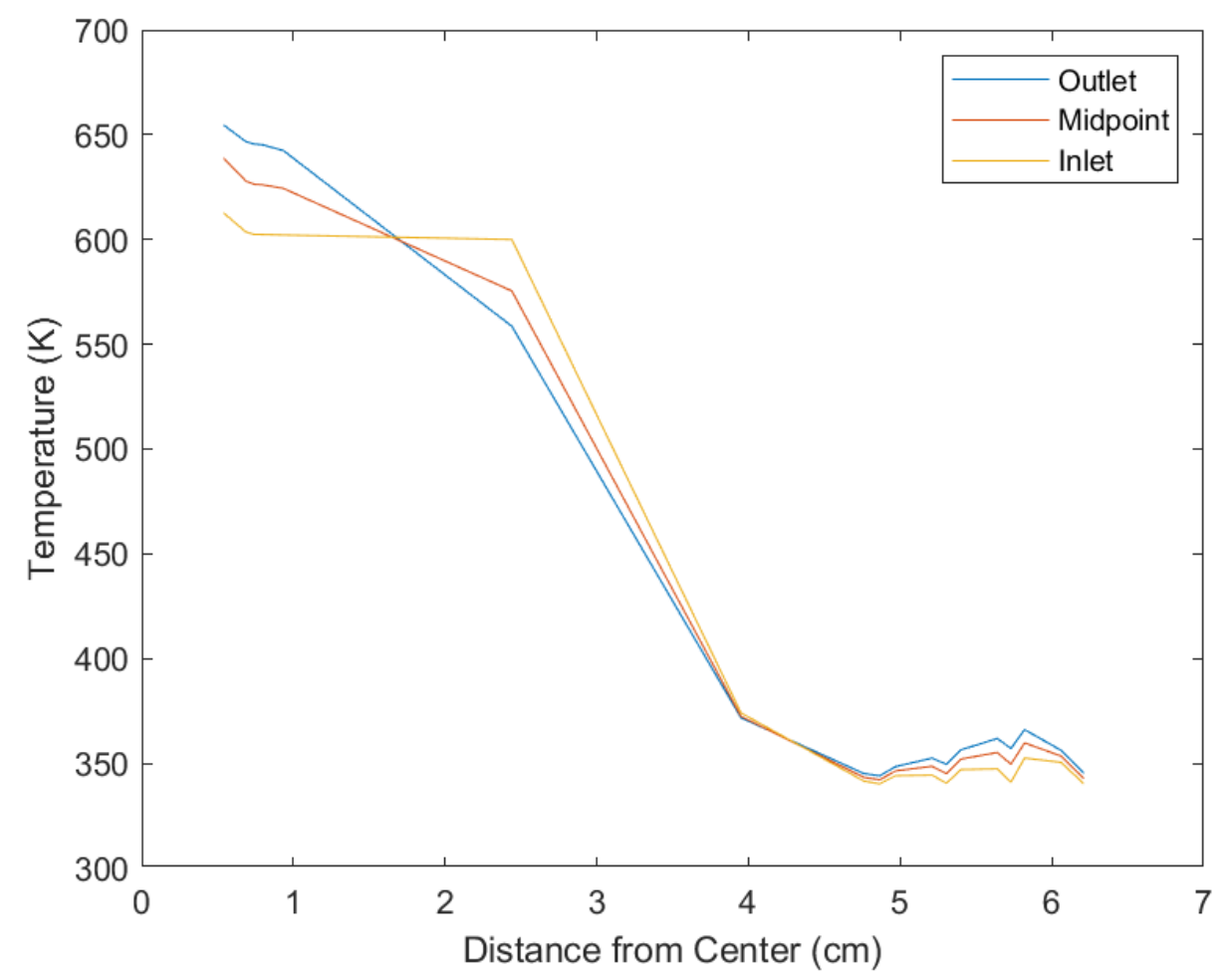

Figure 57: Radial Temperature Distribution 


\subsubsection{Primary System}

Figure 58 shows the primary piping surface and fuel rod surface temperature, and Figure 59 shows convective heat fluxes through the fuel rod and the piping separating the primary system and helium system. A positive value indicates heat flux out of the structure, while a negative value indicates a heat flux into the structure. Heat generation takes place within all three fuel rods at pin powers of $3.06 \mathrm{~kW}, 3.17 \mathrm{~kW}$, and $3.04 \mathrm{~kW}$, and the primary fluid temperature will increase as it approaches the outlet. SFR fuel rods typically experience an inlet-outlet temperature rise of $50 \mathrm{~K}$, so the primary fluid pressure differential across the test section is tailored to force this $50 \mathrm{~K}$ rise. A pressure difference of $6.675 \mathrm{kPa}$ creates a fluid velocity through the test section of $1.3 \mathrm{~m} / \mathrm{s}$, and Figure 60 shows the rise in temperature of the primary fluid. As can be seen, the $50 \mathrm{~K}$ rise in temperature has been achieved. The fuel pins experience a maximum centerline temperature of $656 \mathrm{~K}$, well within operating conditions. The helium is simultaneously heated by the sodium and cooled by the water, and near the outlet is $560 \mathrm{~K}$. This produces a larger heat flux through the primary piping near the outlet, as can be seen in Figure 59. Near the inlet, the heat flux through the piping is roughly $2 \mathrm{~kW} / \mathrm{m}^{2}$, while near the outlet the heat flux is near $67 \mathrm{~kW} / \mathrm{m}^{2}$. This explains the slight drop in temperature in the primary fluid at the outlet. Figure 61 shows the radial temperature profile of the three fuel pins, well below the thermal design limits of typical SFR fuel cladding of $649-704$ C. 


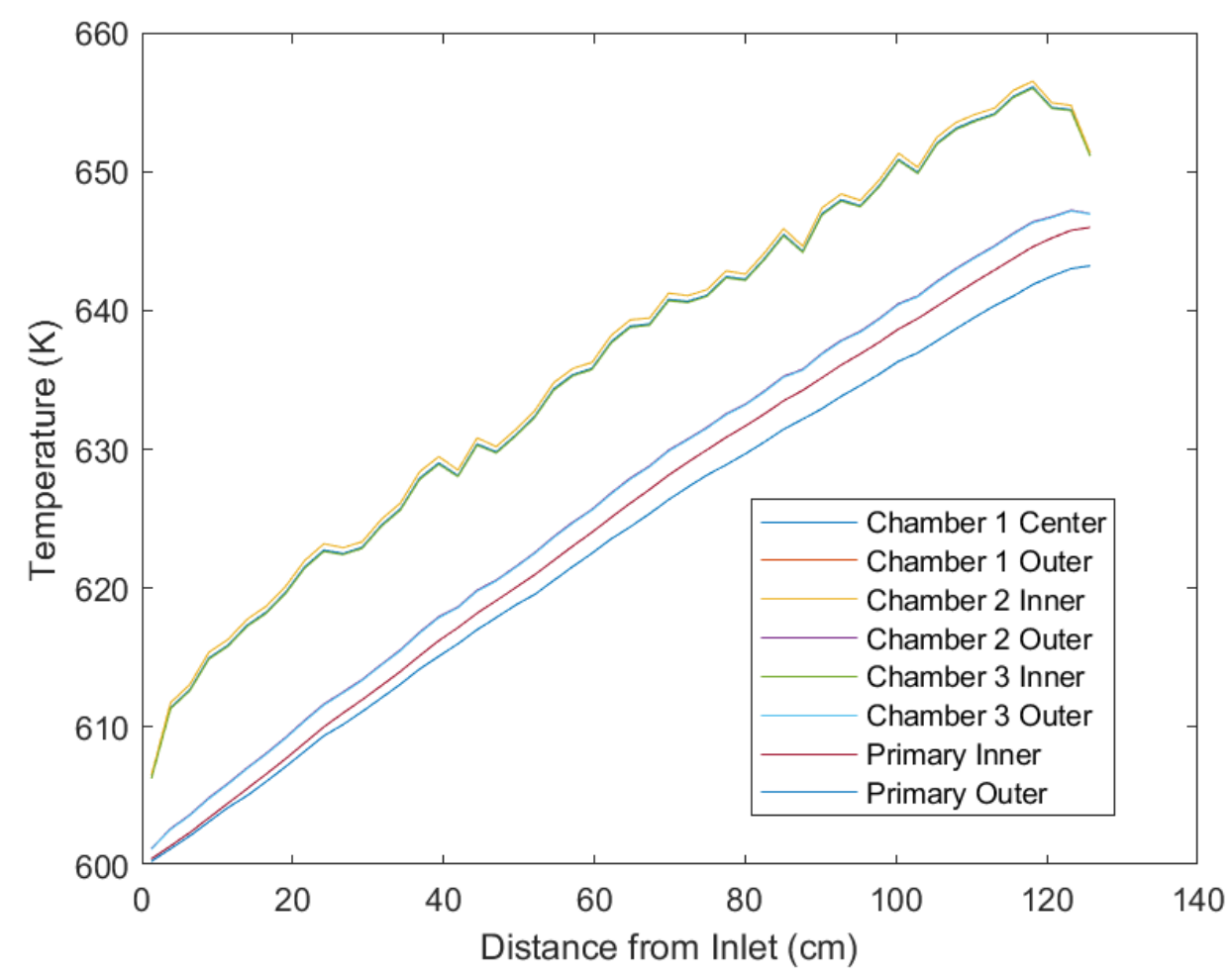

Figure 58: Primary Surface Temperatures

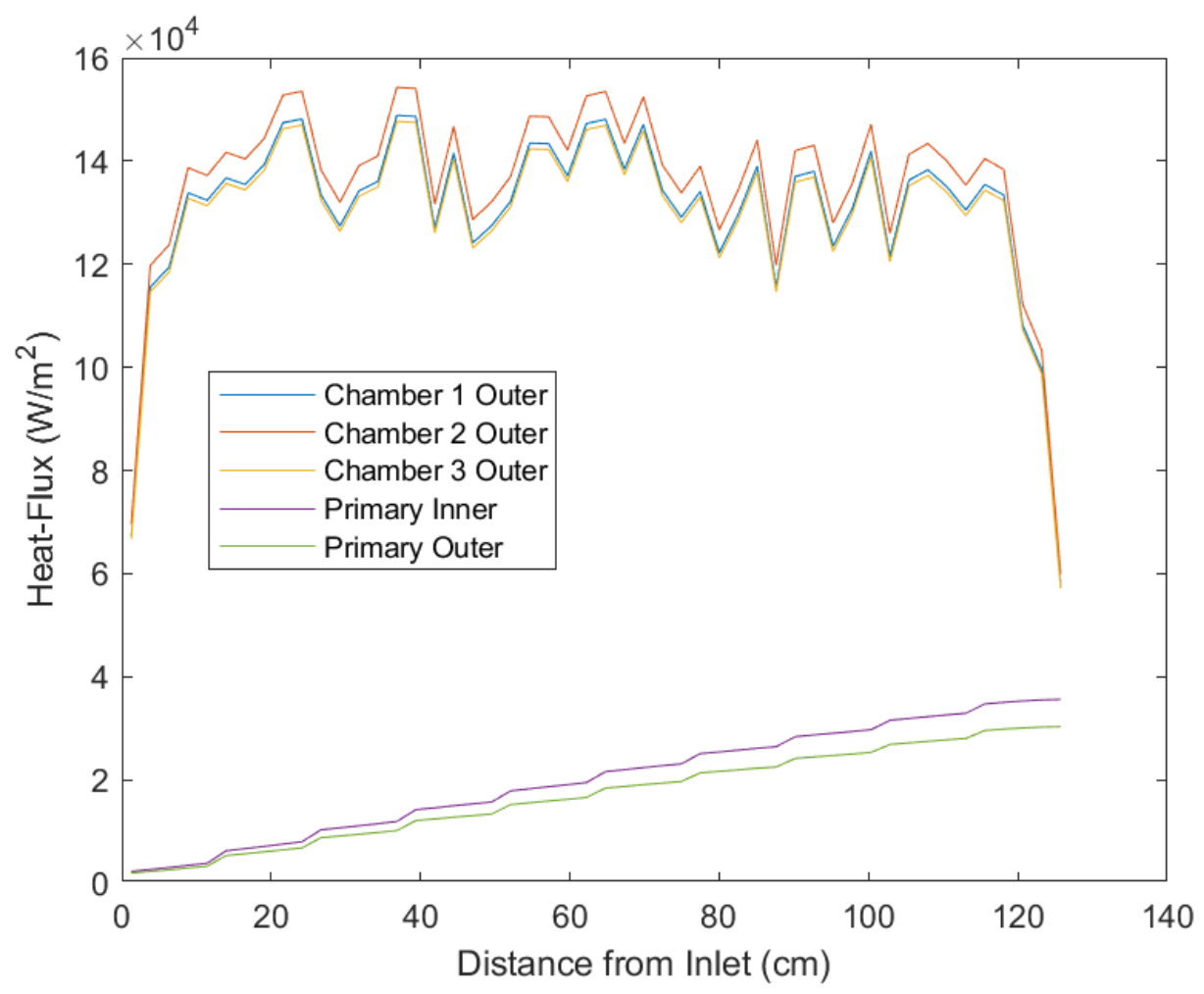

Figure 59: Primary Surface Heat Fluxes 


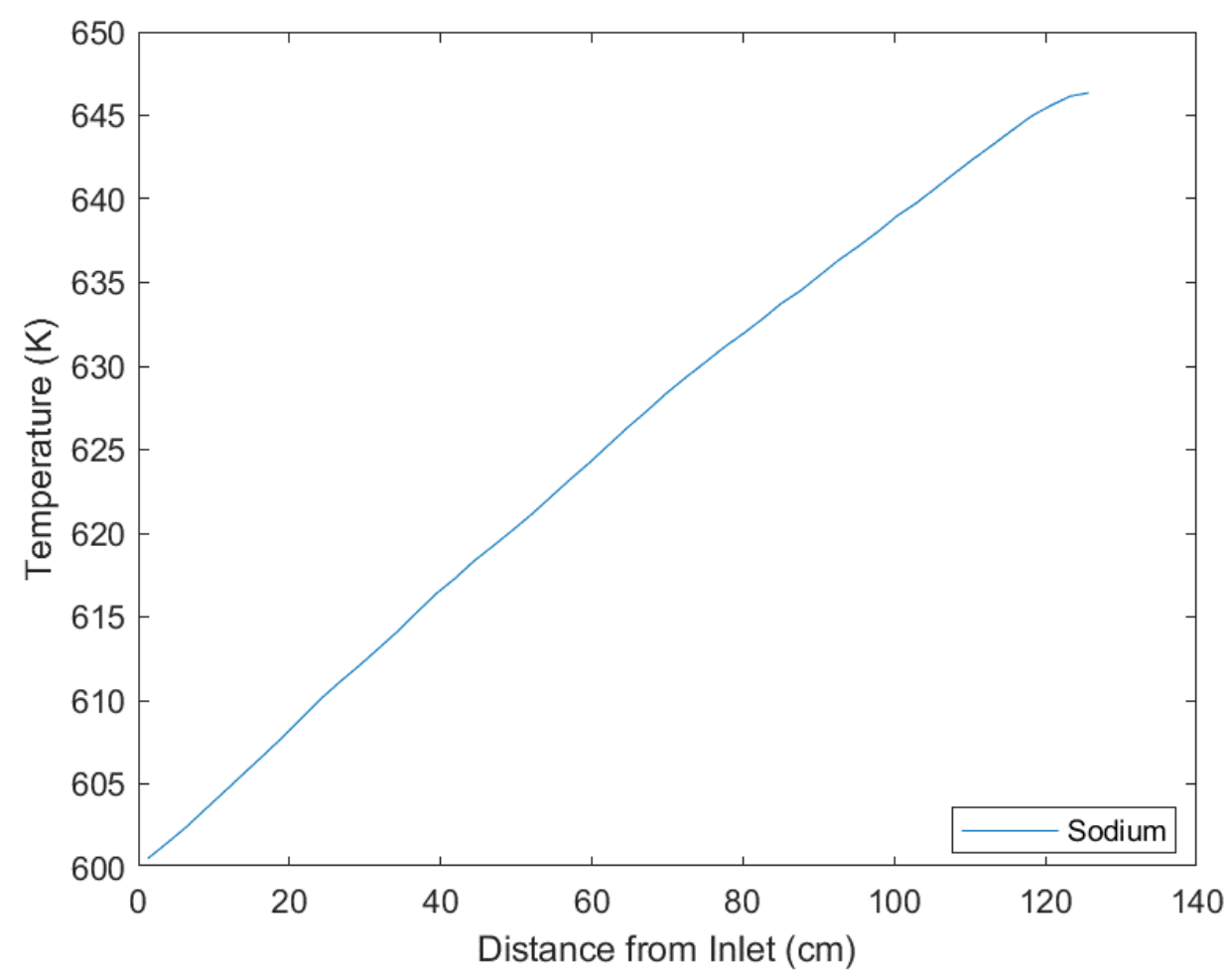

Figure 60: Primary Fluid Temperature from Inlet to Outlet
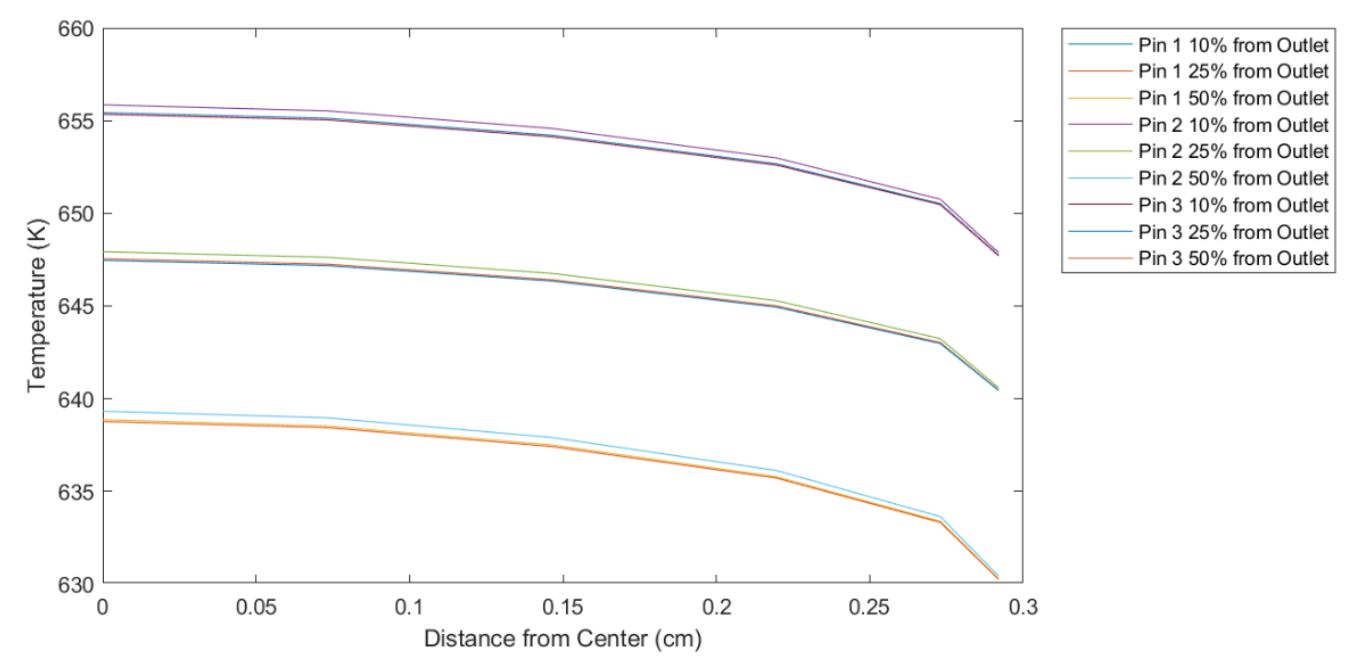

Figure 61: Fuel Pin Radial Temperature

\subsubsection{Helium System}

Figure 62 shows the surface temperature of the piping separating the helium system and the water system, and Figure 63 shows the convective heat flux through this piping. A positive value indicates heat flux out of the structure, while a negative value indicates a heat flux into the structure. Figure 64 also shows the helium temperature from inlet to 
outlet. The piping temperature is significantly lower than the temperature of the helium system due to the cooling effect from the lower temperature water system. While very similar to the previous case examined in Section 5.3, the flow area of this system is slightly decreased since the primary flow area was increased. A mass flow rate of $.0862 \mathrm{~kg} / \mathrm{s}$ was used for this system. The plateauing effect is also seen in this case due to the decrease in number of hydrodynamic components in the helium system.

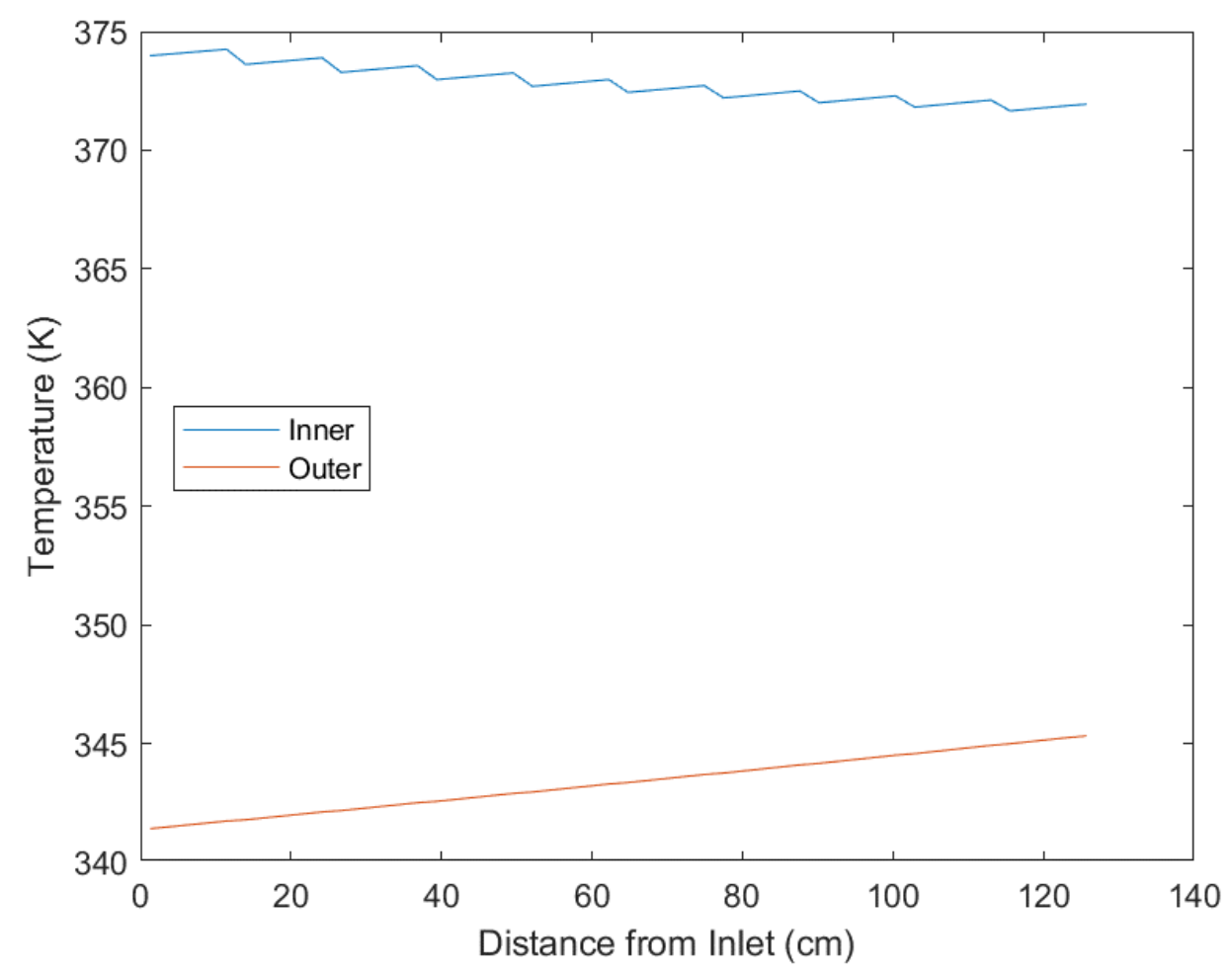

Figure 62: Gas Blanket Surface Temperatures 


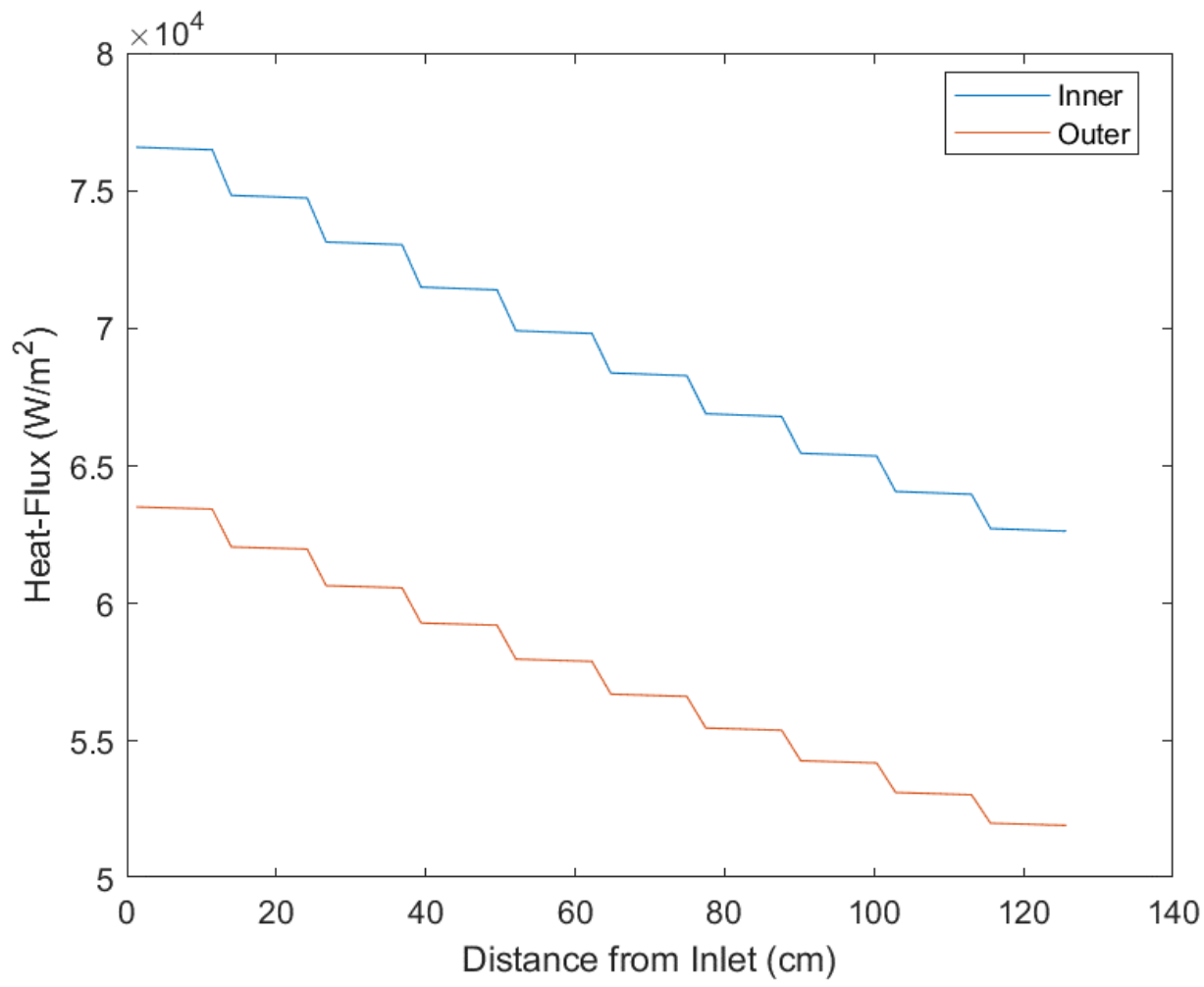

Figure 63: Gas Blanket Surface Heat Fluxes

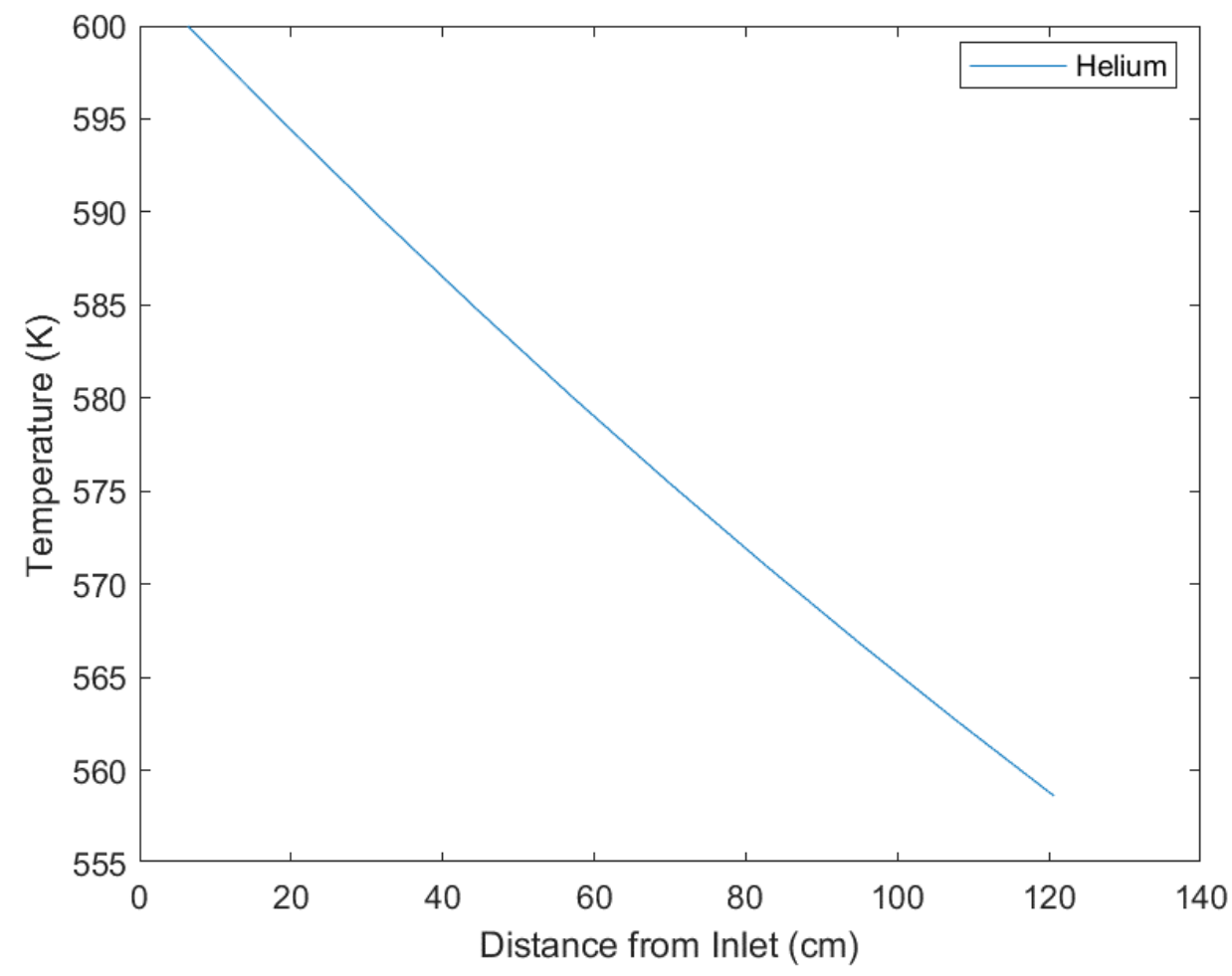

Figure 64: Helium Temperature from Inlet to Outlet 


\subsubsection{Fuel Plate Cooling System}

The fuel plate cooling system is almost identical to the previous case, though once again the extra two fuel pins could affect the power of the fuel plates. Neutronics testing for this system done by another student showed that the resulting change in the plate power compared to the single fuel pin system is less than 1 percent for each plate. The helium system is also nearly identical compared to the single fuel pin system, and as such there is almost no difference in the fuel plate cooling system. The following four figures showcase this behavior.

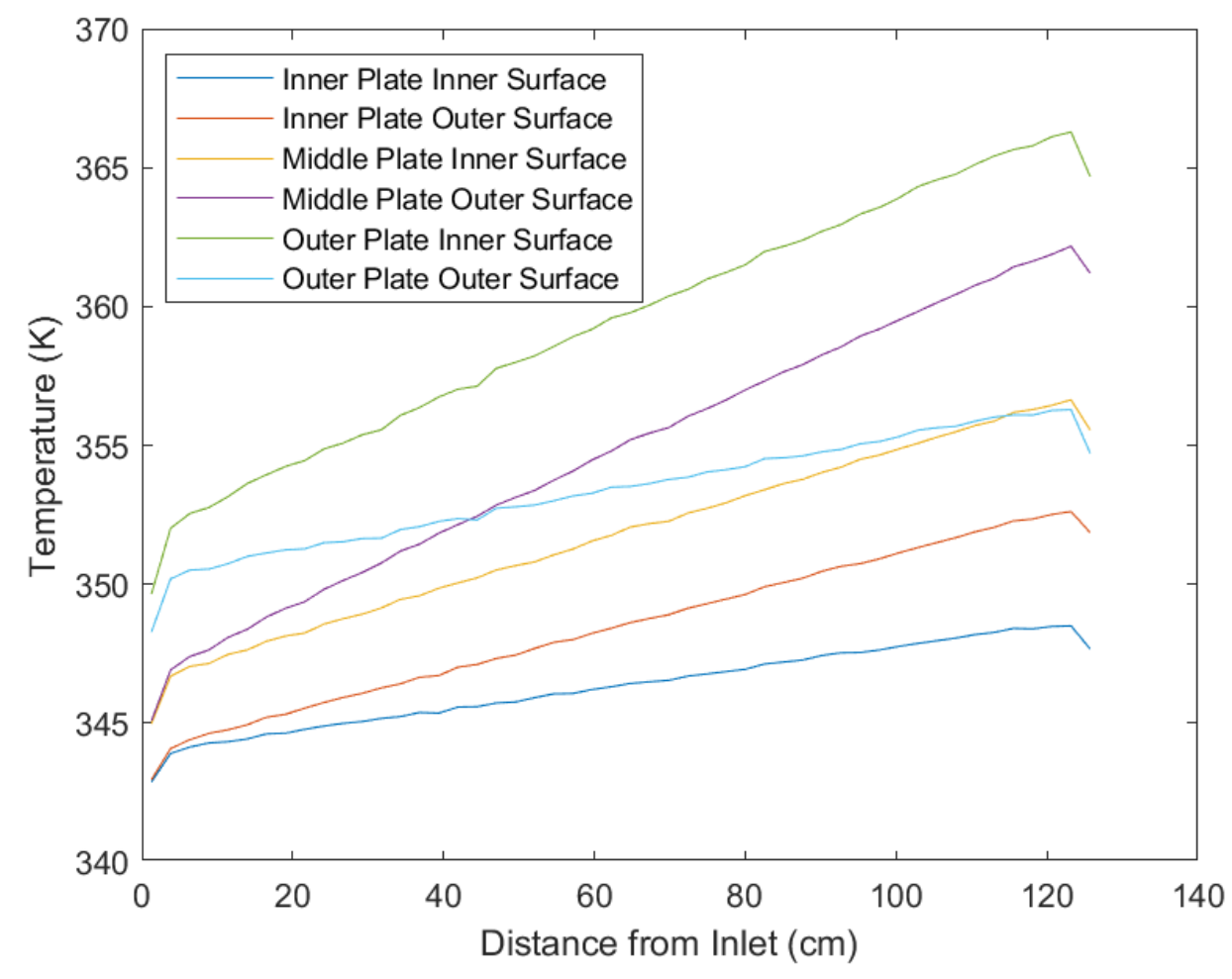

Figure 65: Fuel Plate Surface Temperature 

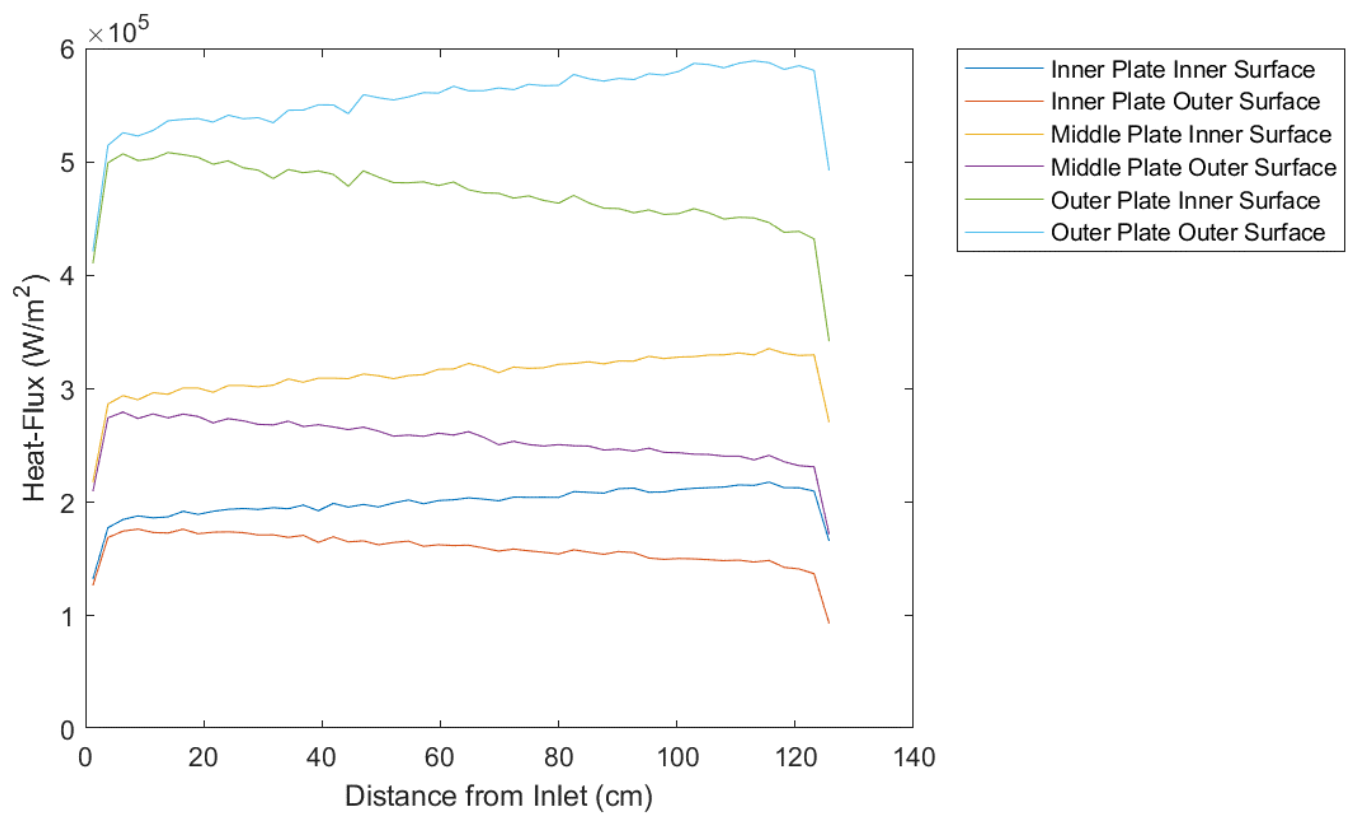

Figure 66: Fuel Plate Surface Heat Fluxes

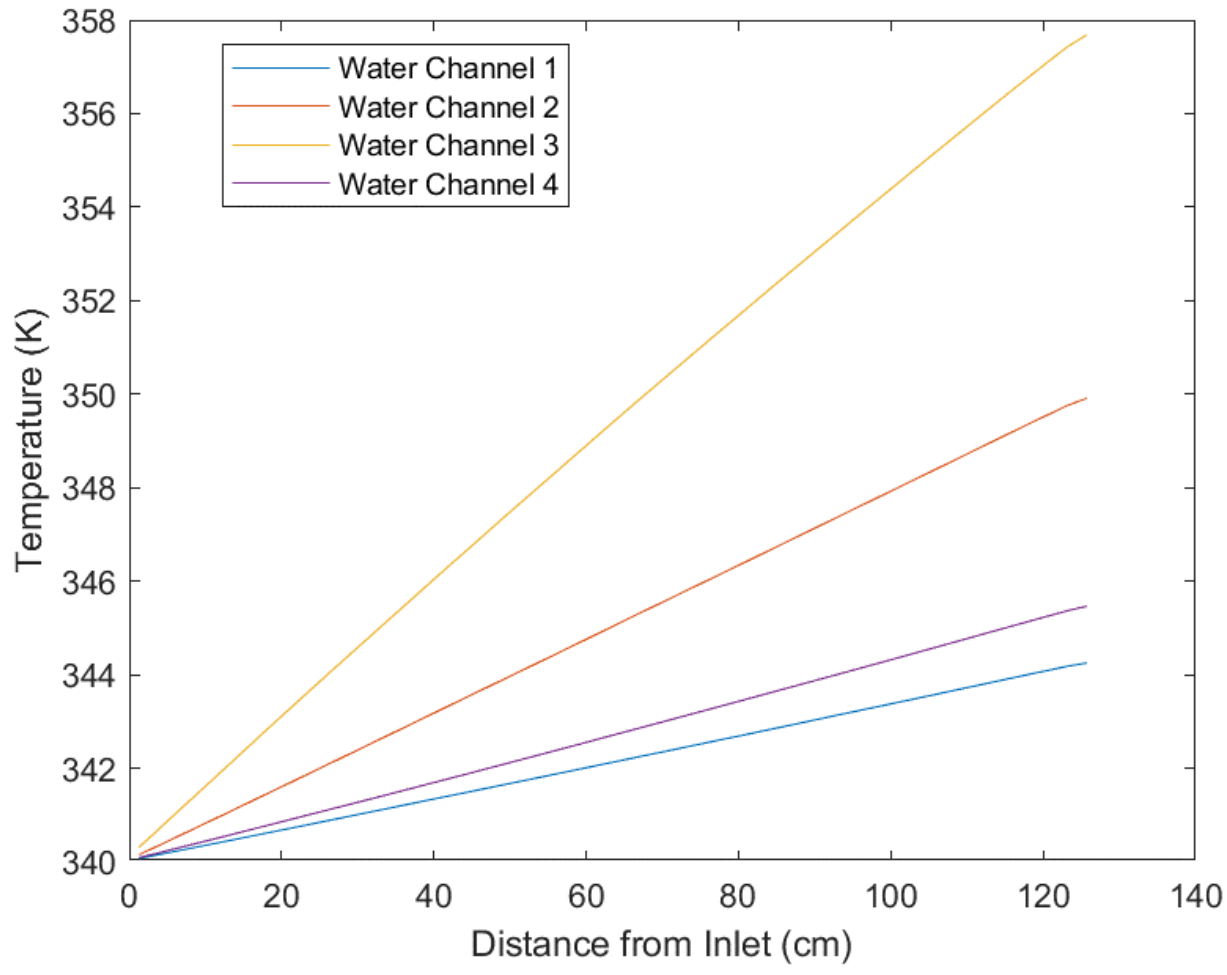

Figure 67: Fuel Plate Cooling Water Temperatures 


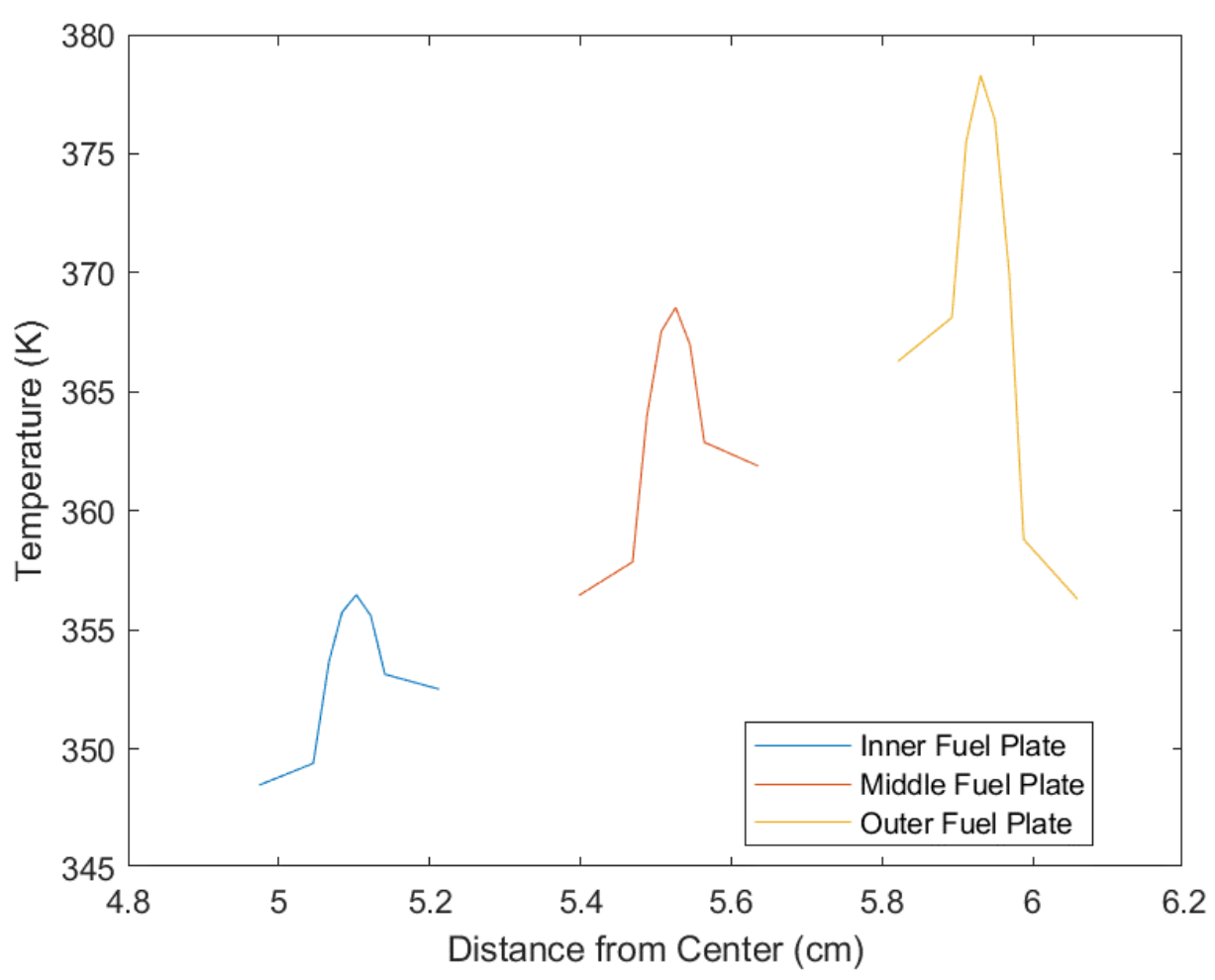

Figure 68: Peak Fuel Plate Temperature Radial Distribution

\subsubsection{Summary}

With three fuel rods in the test section, this model shows it is capable of replicating the required key factors of the thermal hydraulic conditions necessary for testing SFR fuel rods. The primary goal of reaching a $50 \mathrm{~K}$ sodium coolant temperature increase from inlet to outlet was reached using a coolant velocity of $1.3 \mathrm{~m} / \mathrm{s}$. Once again, due to the relatively low fast flux within the test chamber the fuel pin power is also lower than anticipated. Fuel rod radial temperature profiles show that the maximum temperature of $656 \mathrm{~K}$, on the lower end of designed operating conditions for SFR fuel rods. The jagged peaks in the test chamber surface temperatures and heat fluxes are caused by the large variation in pin power mentioned previously. This model also overall shows the primary system design of the FSTL could provide SFR like operating conditions for a design with three fuel pins.

While the booster fuel plate coolant system and helium blanket system do not change greatly from previous iterations, it is still important to point out that this model shows they can be operating safely and do not have a great impact on the primary system. The water channels do not reach boiling at any point and the booster fuel plates remain within safe 
temperatures reaching a maximum of $378 \mathrm{~K}$. Reaching all of these requirements, the RELAP model indicates the FSTL could safely provide thermal hydraulic operating conditions for a single fuel pin.

\subsection{U-Tube Three Fuel Pin Test Section}

The following section showcases several temperature profiles spanning across the subvolumes within the test section when sodium passes through the test section with three UZr SFR fuel pins (2.92 mm OD, $1 \mathrm{~m}$ long) within the test chamber of the U-Tube design. Sub-volume 1 is the outlet at top of the test leg, and sub-volume 50 is the inlet at the bottom of the test leg. This information is taken after 200 seconds of simulation time to ensure steady state conditions are attained. At these temperatures and pressures, the primary coolant has a liquid fraction of 100 percent, the helium has a gas fraction of 100 percent, and the water system has a liquid fraction of 100 percent. Figure 69 shows the cross section of this design. 


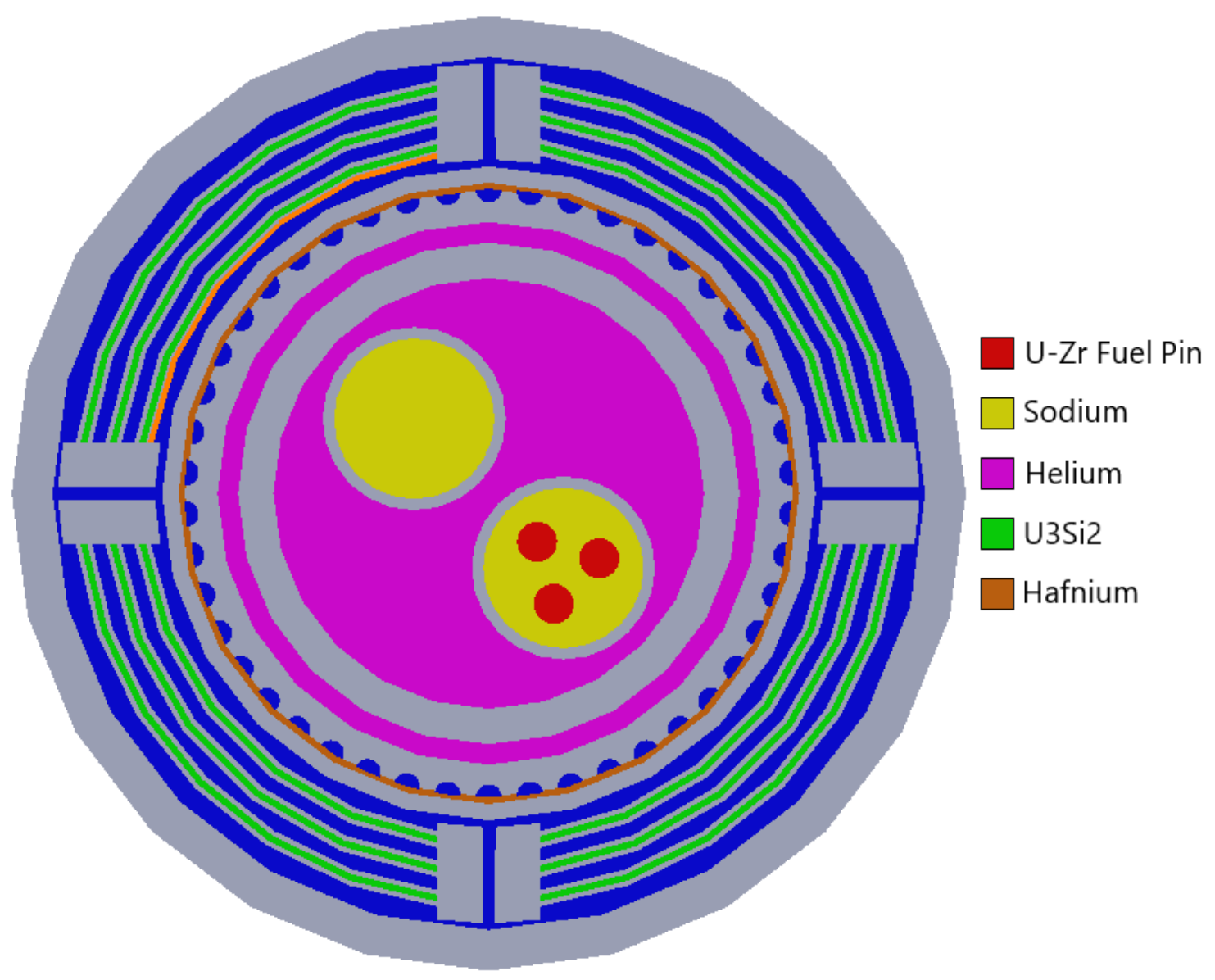

Figure 69: Cross Section of U-Tube Design

Figure 70 shows the fluid temperature distributions from inlet to outlet. Heat generation takes place within both the fuel pins and the fuel plates for this case, so the primary fluid increases in temperature as the fluid approaches the outlet. Note that Figure 71 shows the radial temperature for the primary system at the inlet, halfway point, and outlet. The innermost temperature is taken from the center of one of the fuel pins, not the center of the test section. Figure 72 shows the radial temperature distribution of the system not including the primary system. 

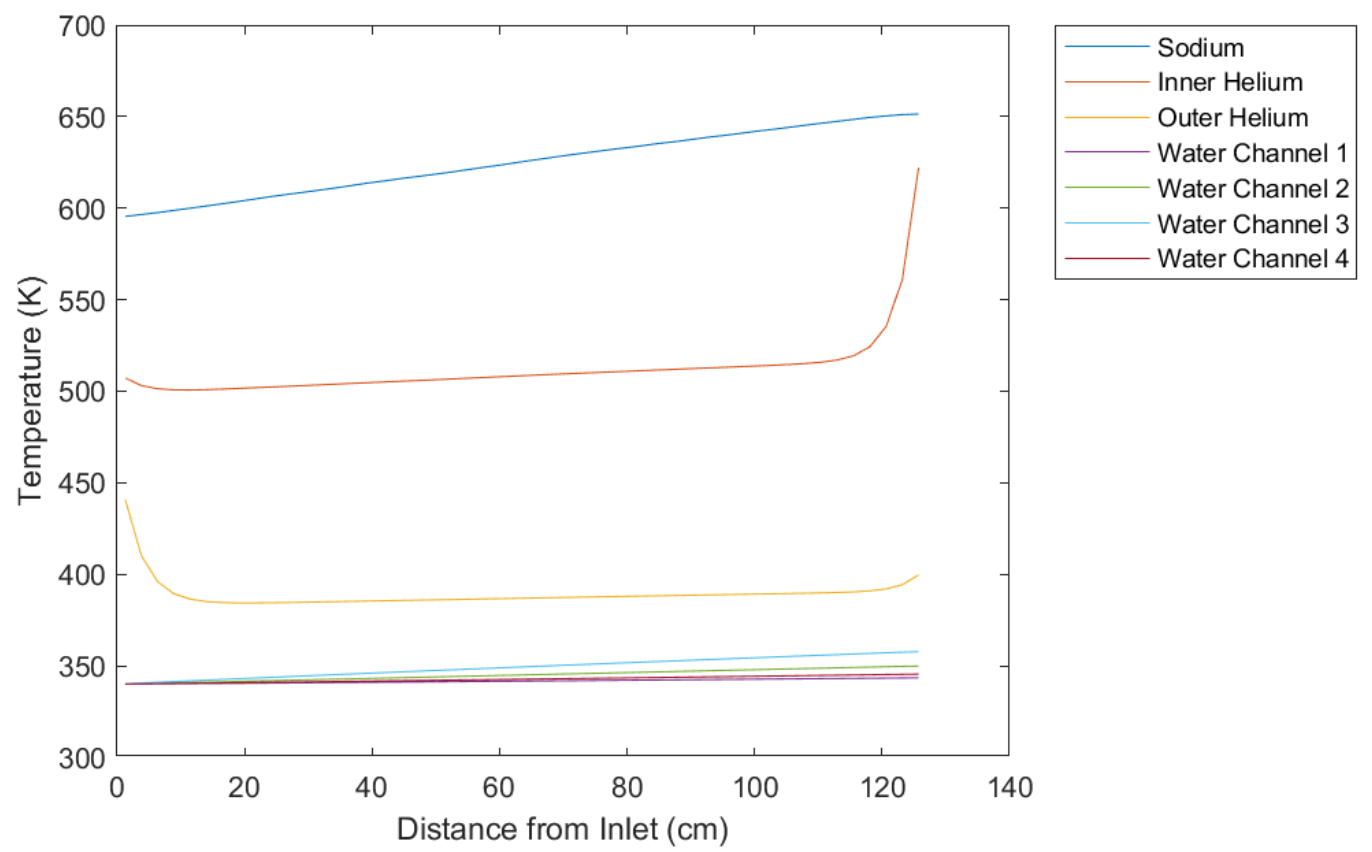

Figure 70: Fluid Temperatures from Inlet to Outlet

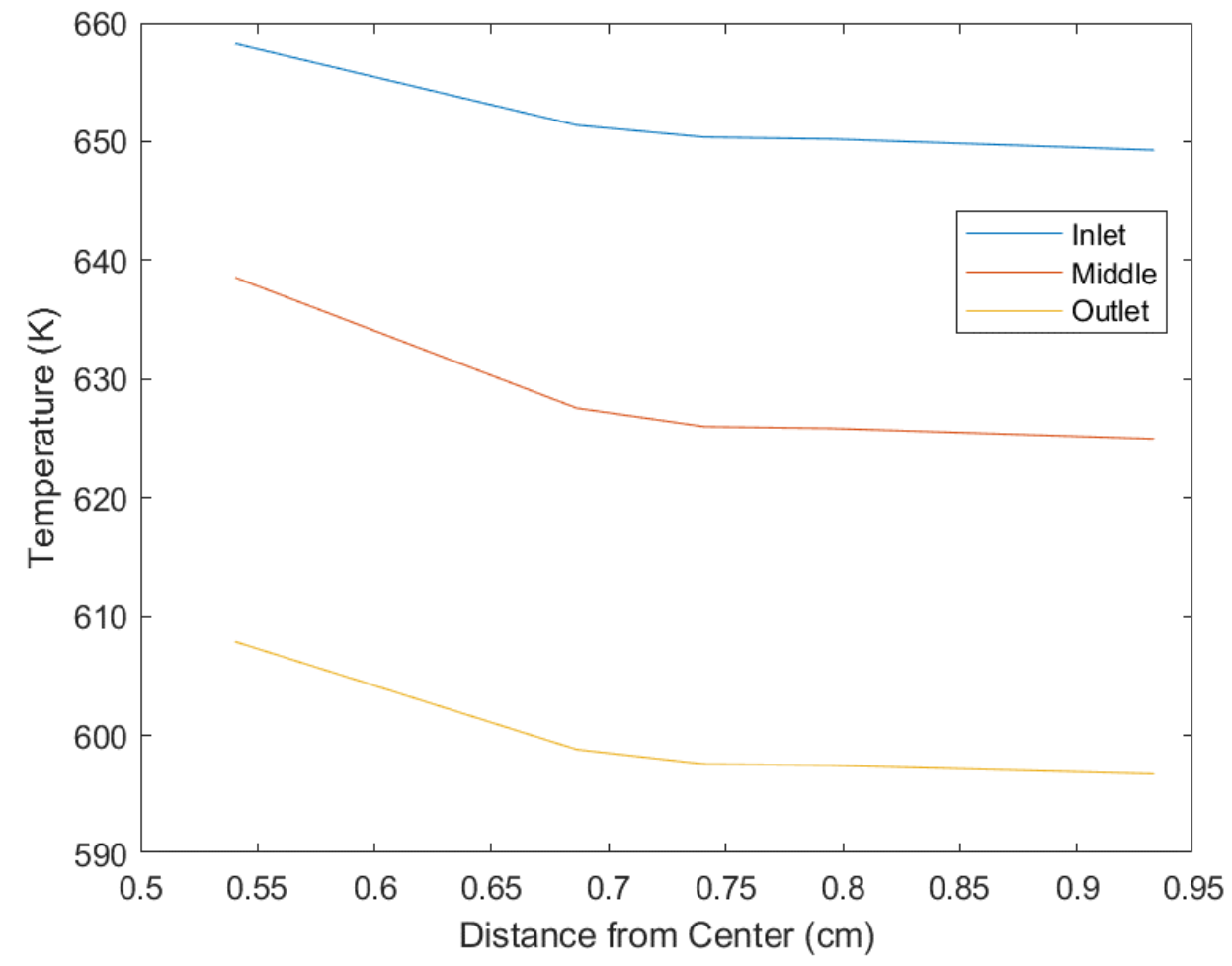

Figure 71: Radial Temperature Distribution of the Primary Loop 


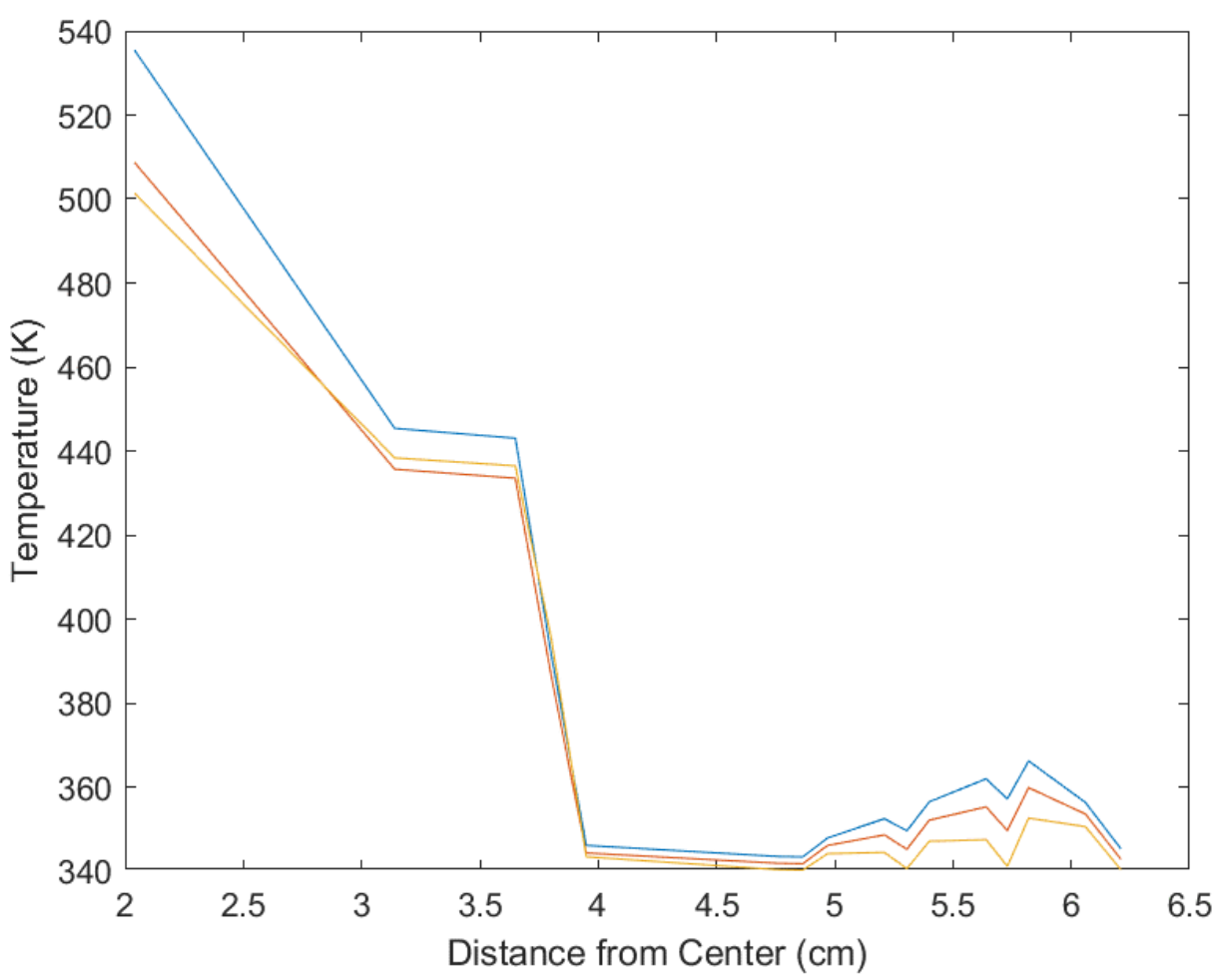

Figure 72: Radial Temperature Distribution of Helium and Fuel Plate Cooling Systems

\subsubsection{Primary System}

Figure 73 shows the primary piping surface and fuel rod surface temperature, and Figure 74 shows convective heat fluxes through the fuel rod and the piping separating the primary system and helium system. A positive value indicates heat flux out of the structure, while a negative value indicates a heat flux into the structure. Heat generation takes place within all three fuel rods at pin powers of $3.08 \mathrm{~kW}, 3.09 \mathrm{~kW}$, and $2.95 \mathrm{~kW}$, and the primary fluid temperature will increase as it approaches the outlet. SFR fuel rods typically experience an inlet-outlet temperature rise of $50 \mathrm{~K}$, so the primary fluid pressure differential across the test section is tailored to force this $50 \mathrm{~K}$ rise. A pressure difference of $6.675 \mathrm{kPa}$ creates a fluid velocity through the test section of $1.1 \mathrm{~m} / \mathrm{s}$, and Figure 75 shows the rise in temperature of the primary fluid. As can be seen, the $50 \mathrm{~K}$ rise in temperature has been achieved. The fuel pins experience a maximum centerline temperature of $660 \mathrm{~K}$, well within operating conditions. The inner helium system is simultaneously heated by the sodium and cooled by the outer helium system, and near the outlet is $560 \mathrm{~K}$. This produces a larger heat flux through the primary piping near the outlet, as can be seen in Figure 74. 
Near the inlet, the heat flux through the piping is roughly $2 \mathrm{~kW} / \mathrm{m}^{2}$, while near the outlet the heat flux is near $67 \mathrm{~kW} / \mathrm{m}^{2}$. This explains the slight drop in temperature in the primary fluid at the outlet. Figure 76 shows the radial fuel pin temperature profile, once again well within the thermal design limits of typical SFR fuel pins.

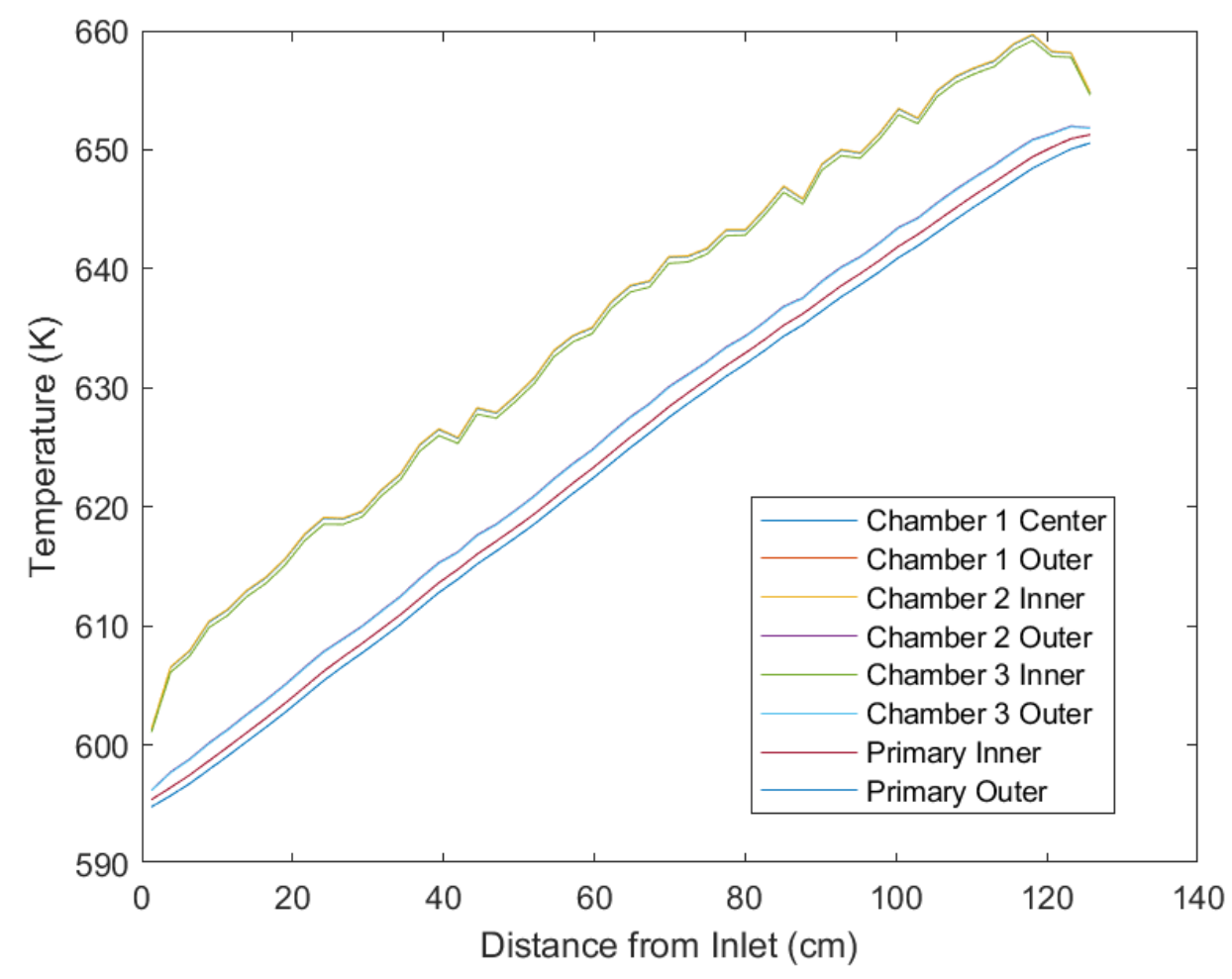

Figure 73: Primary Surface Temperatures 


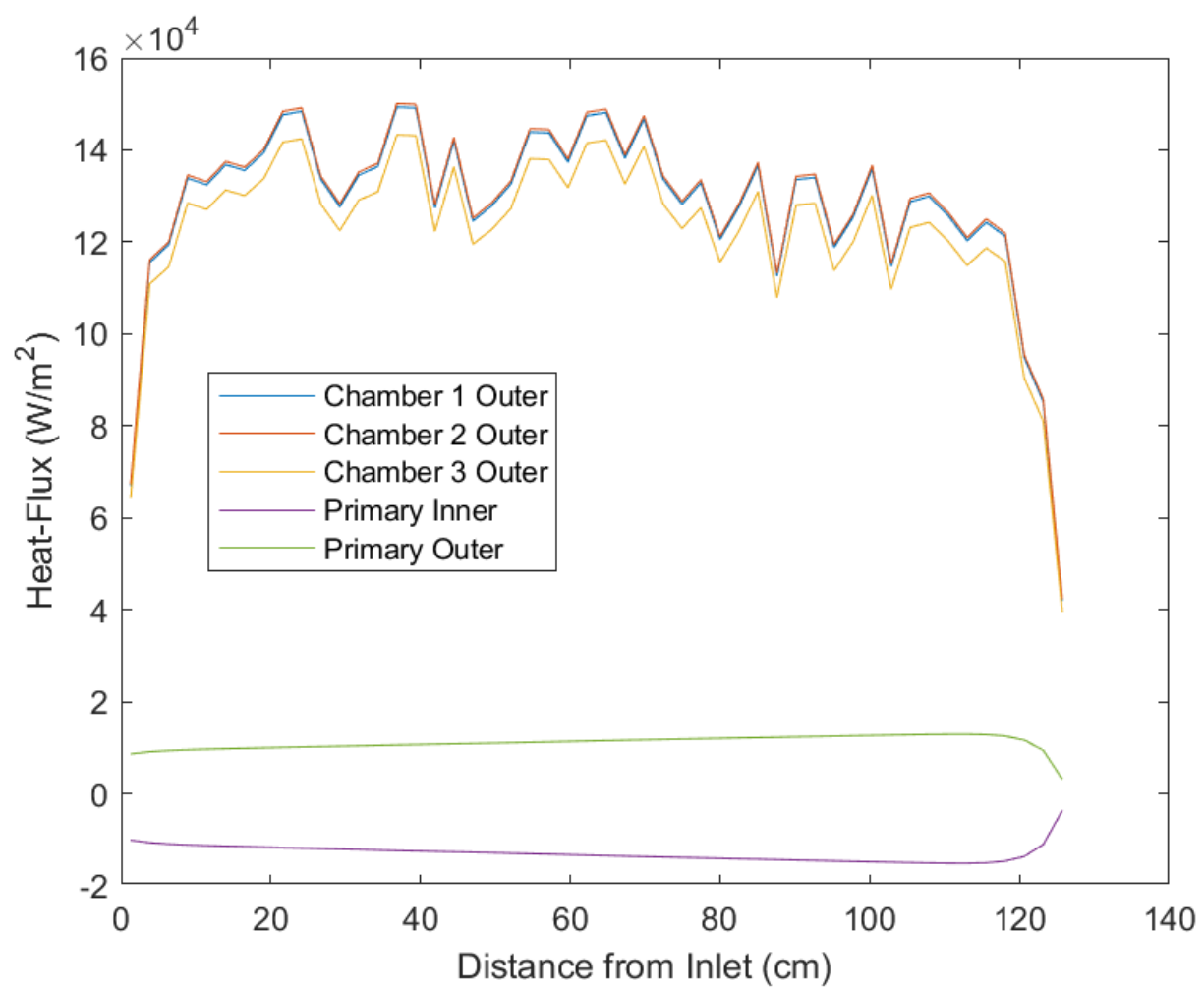

Figure 74: Primary Surface Heat Fluxes

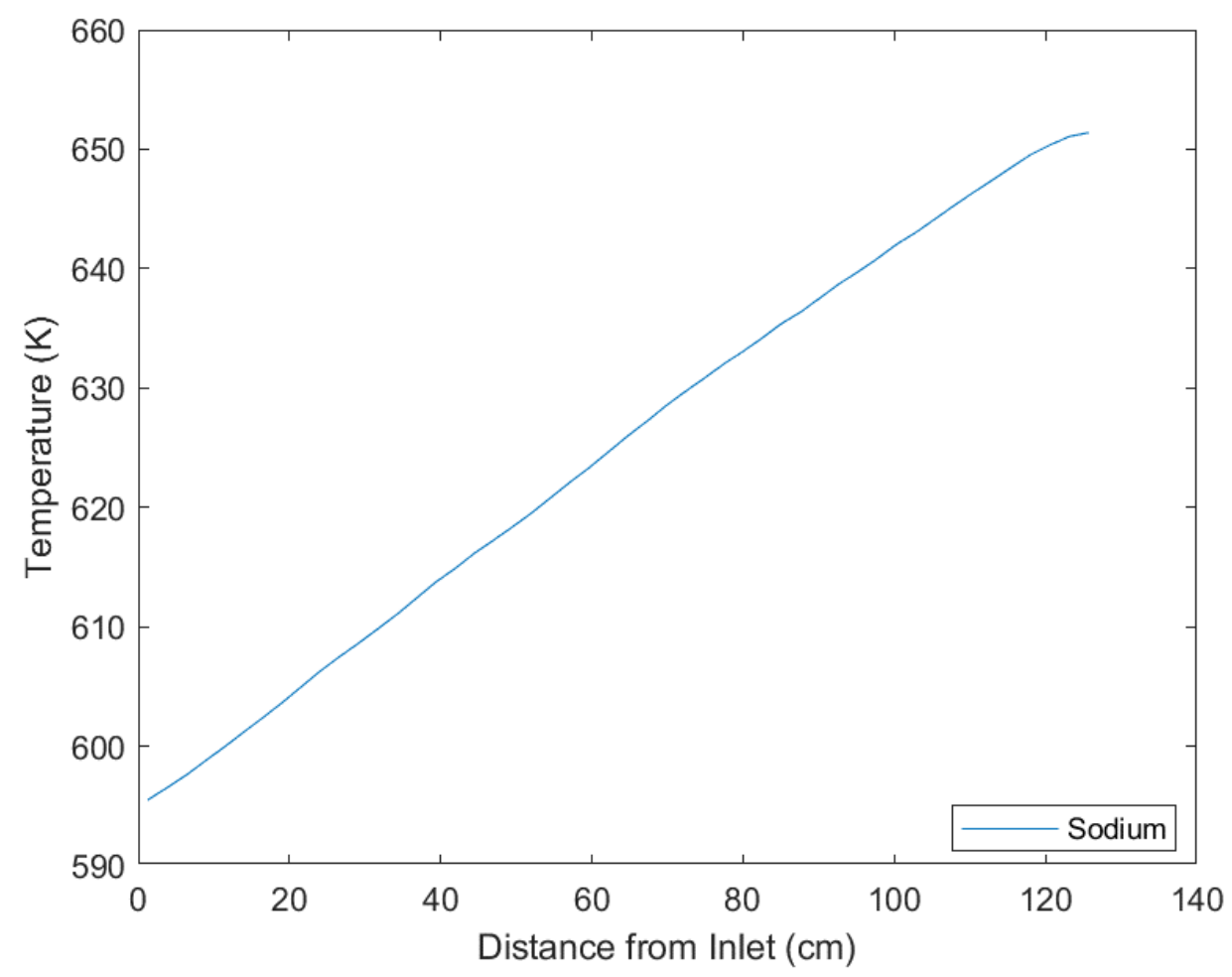

Figure 75: Primary Fluid Temperature from Inlet to Outlet 

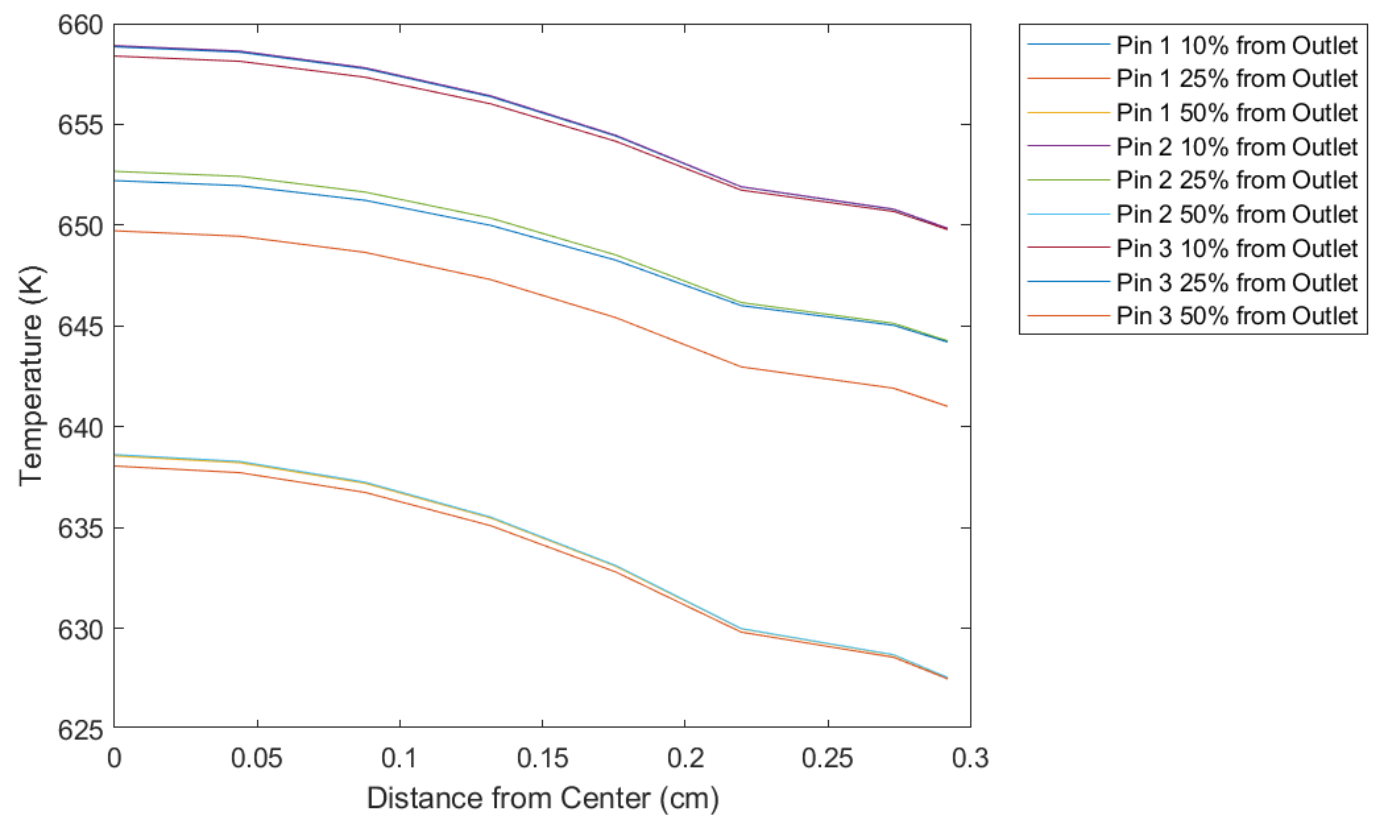

Figure 76: Fuel Pin Radial Temperature

\subsubsection{Inner Helium System}

The inner helium system is connected to all piping of the primary system, and as such is absorbs heat from all sections of the primary. Figure 77 shows the surface temperature of the piping separating the helium system and the water system, and Figure 78 shows the convective heat flux through this piping. A positive value indicates heat flux out of the structure, while a negative value indicates a heat flux into the structure. Figure 79 also shows the helium temperature from inlet to outlet. No pressure difference is used to create a flow through this system, and as such the mass flow rate is very low at $8.52908 \mathrm{E}-05 \mathrm{~kg} / \mathrm{s}$. Temperatures near the inlet and outlet are higher than the center of the system due to the time dependent volumes at these points having a high temperature of $640 \mathrm{~K}$. 


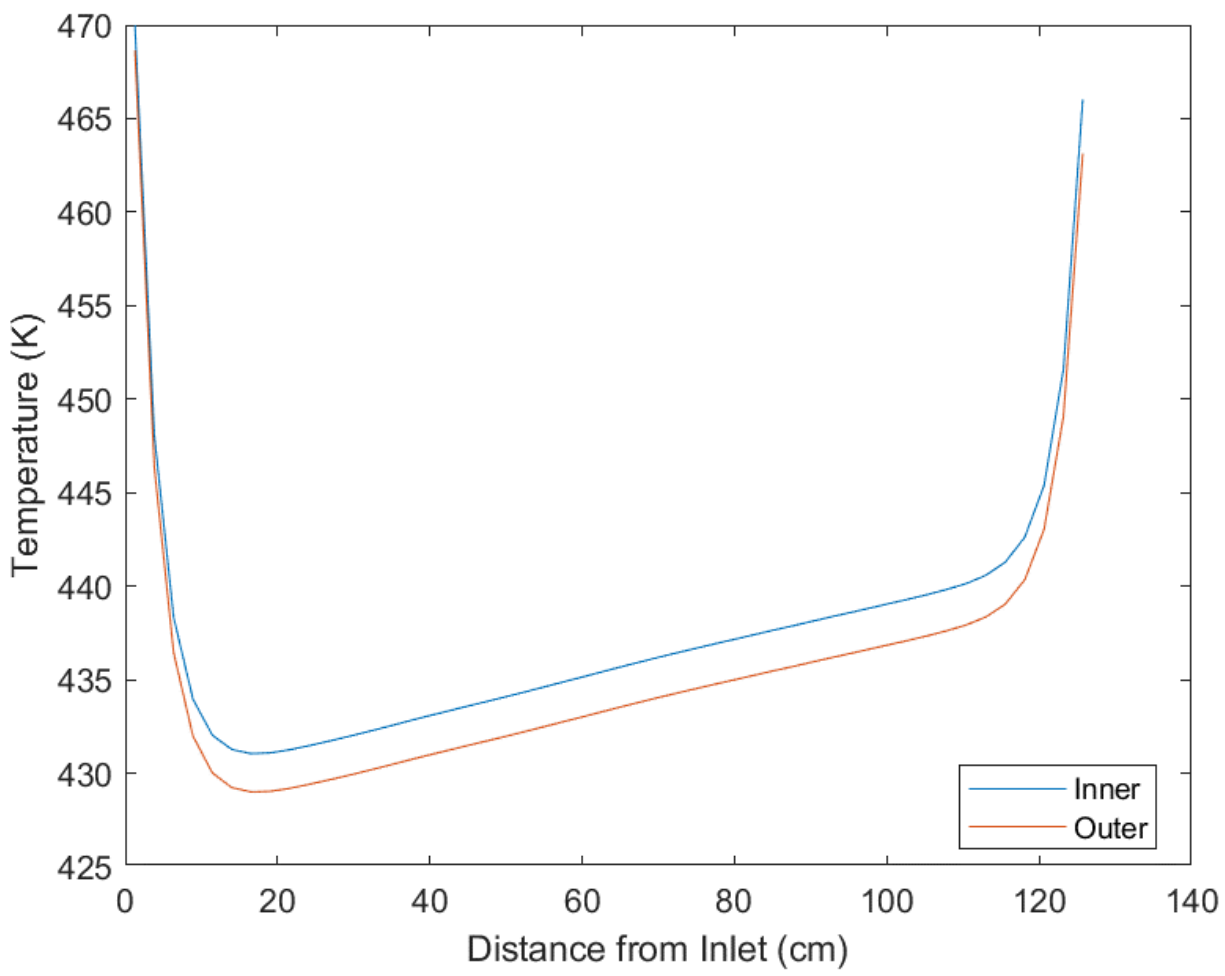

Figure 77: Inner Helium Blanket Surface Temperatures

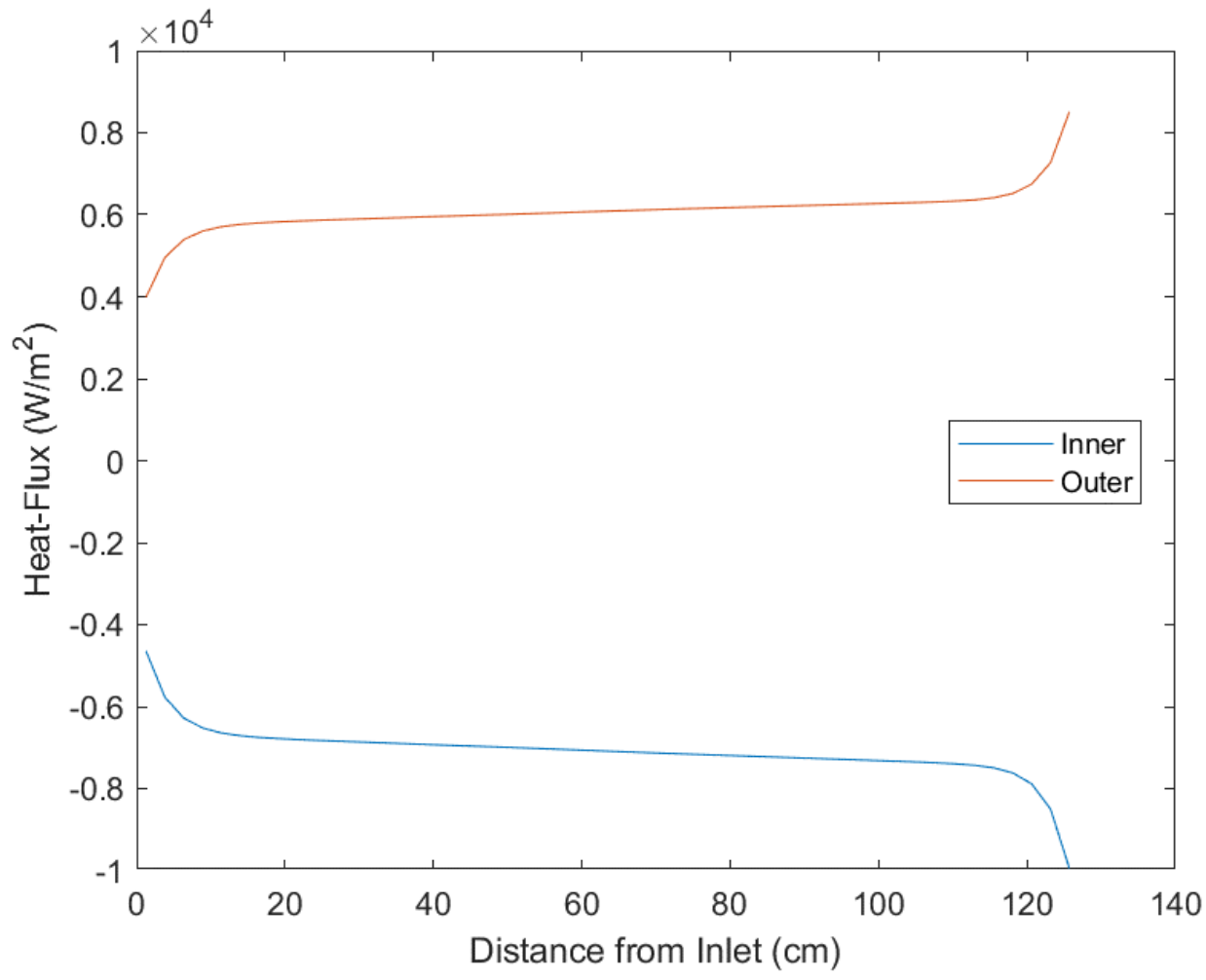

Figure 78: Inner Helium Blanket Surface Heat Fluxes 


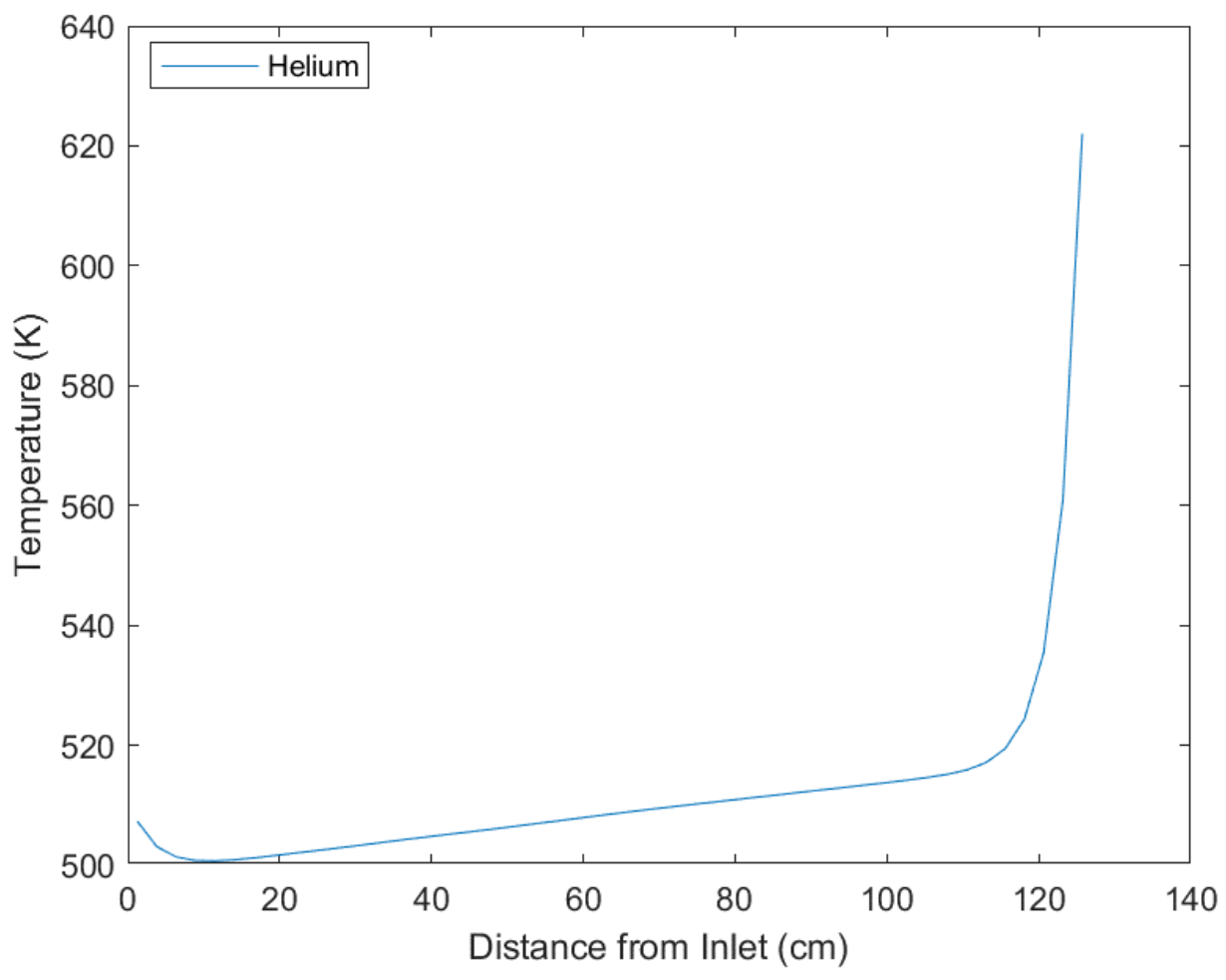

Figure 79: Inner Helium Temperature from Inlet to Outlet

\subsubsection{Outer Helium System}

Figure 80 shows the surface temperature of the piping separating the outer helium system and the water system, and Figure 81 shows the convective heat flux through this piping. A positive value indicates heat flux out of the structure, while a negative value indicates a heat flux into the structure. Figure 82 also shows the helium temperature from inlet to outlet. The piping temperature is significantly lower than the temperature of the helium system due to the cooling effect from the lower temperature water system. A mass flow rate of $1.74441 \mathrm{E}-04 \mathrm{~kg} / \mathrm{s}$ was used for this system, as the flow area for this system is relatively low. 


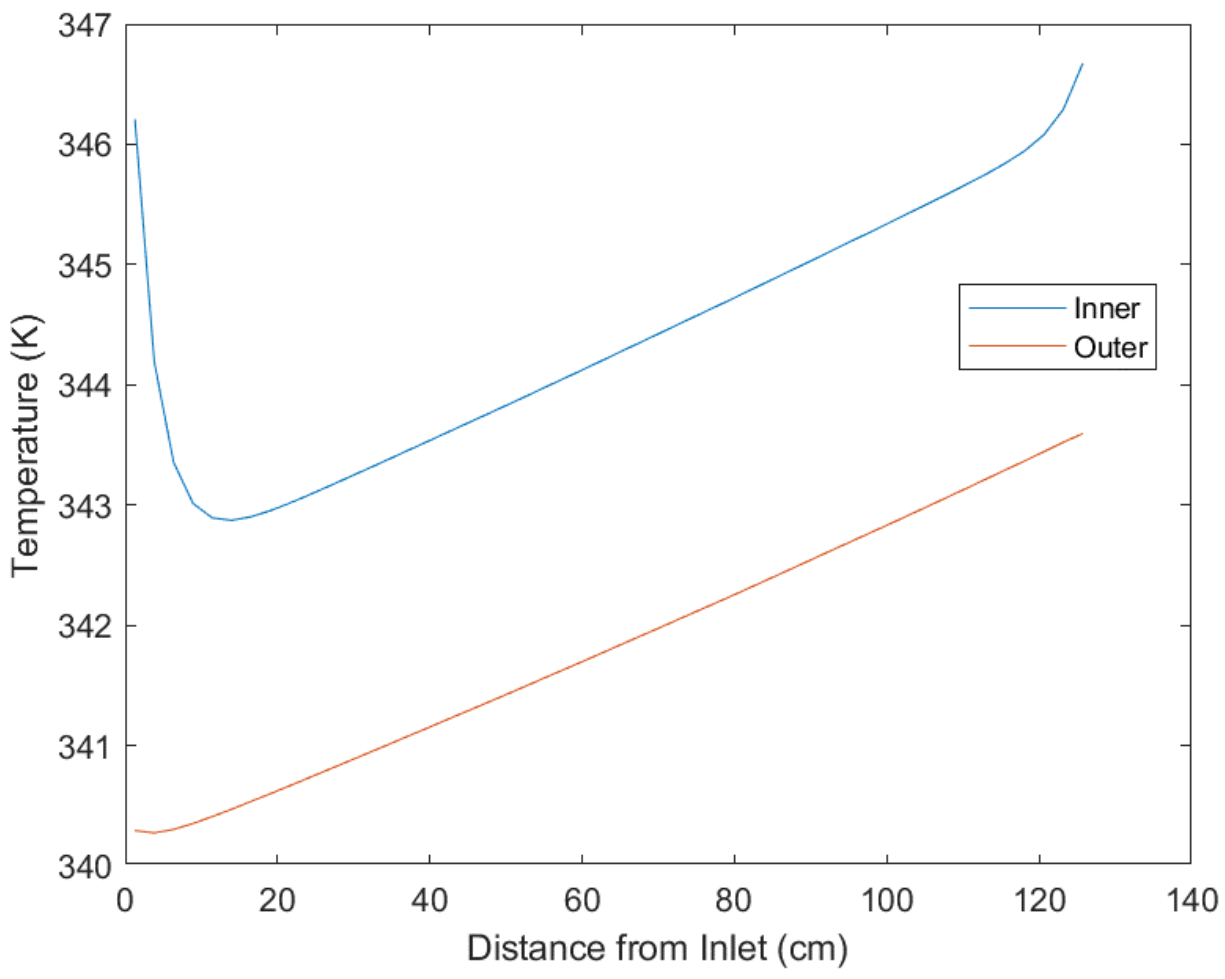

Figure 80: Outer Helium Surface Temperatures 


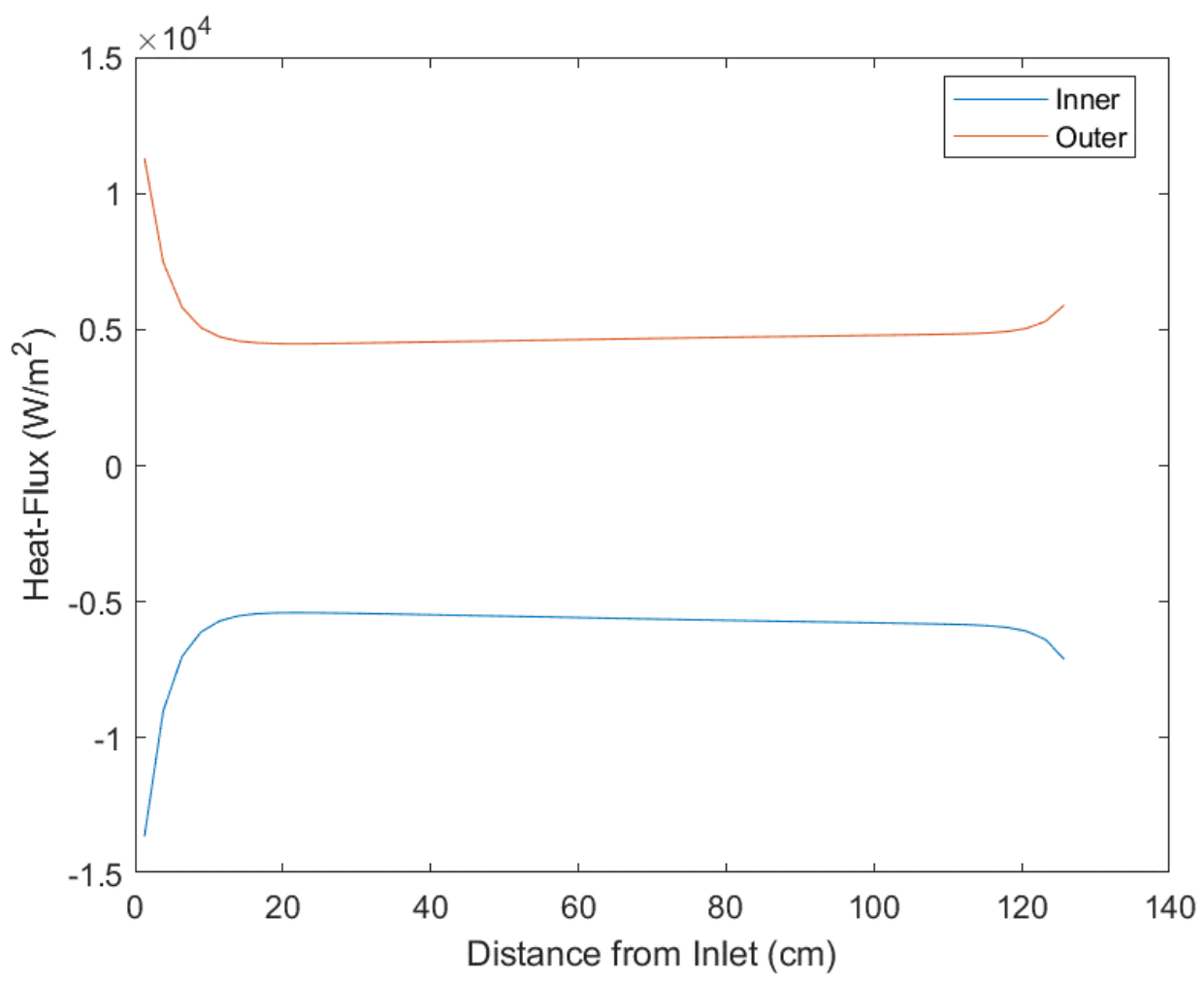

Figure 81: Outer Helium Blanket Surface Heat Fluxes

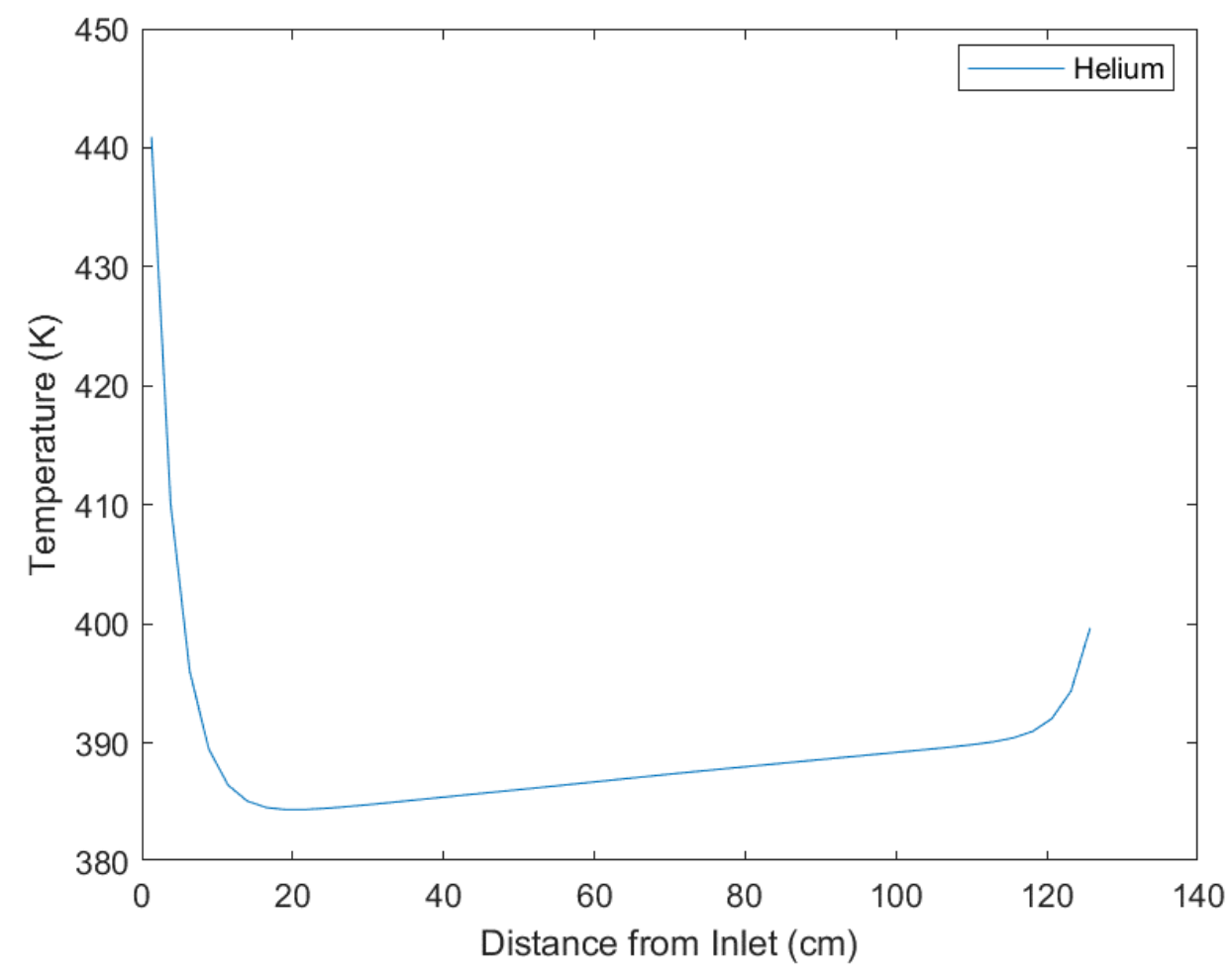

Figure 82: Outer Helium Temperatures from Inlet to Outlet 


\subsubsection{Fuel Plate Cooling System}

The fuel plate cooling system is almost identical to the previous case, the new helium system and related piping could slightly affect the fuel plate power. Neutronics testing for this system done by another student showed that the resulting change in the plate power compared to the three fuel pin system is less than 1 percent for each plate. The helium system is very different from the previous case, so the inner channel of the fuel cooling system is slightly different.

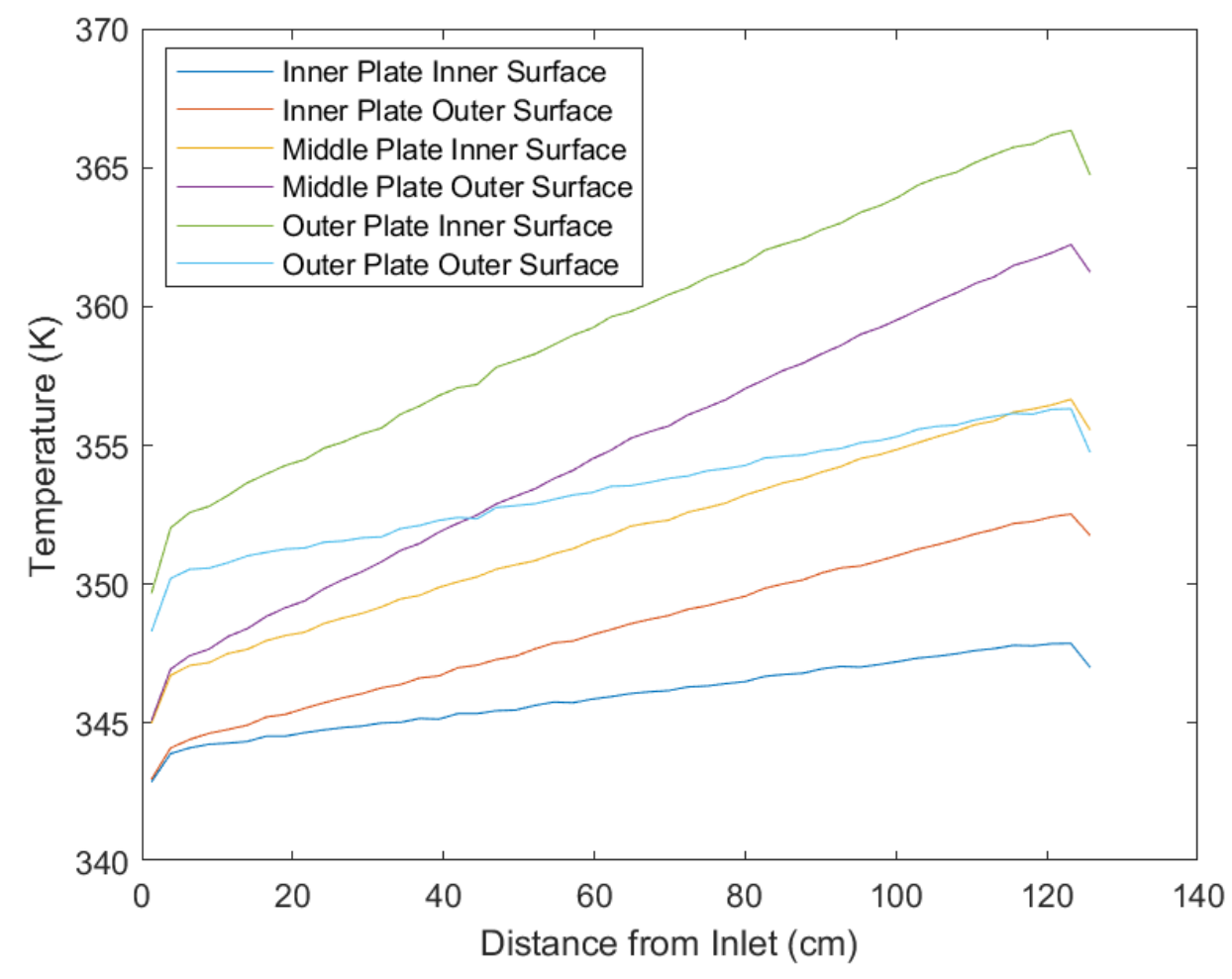

Figure 83: Fuel Plate Surface Temperatures 

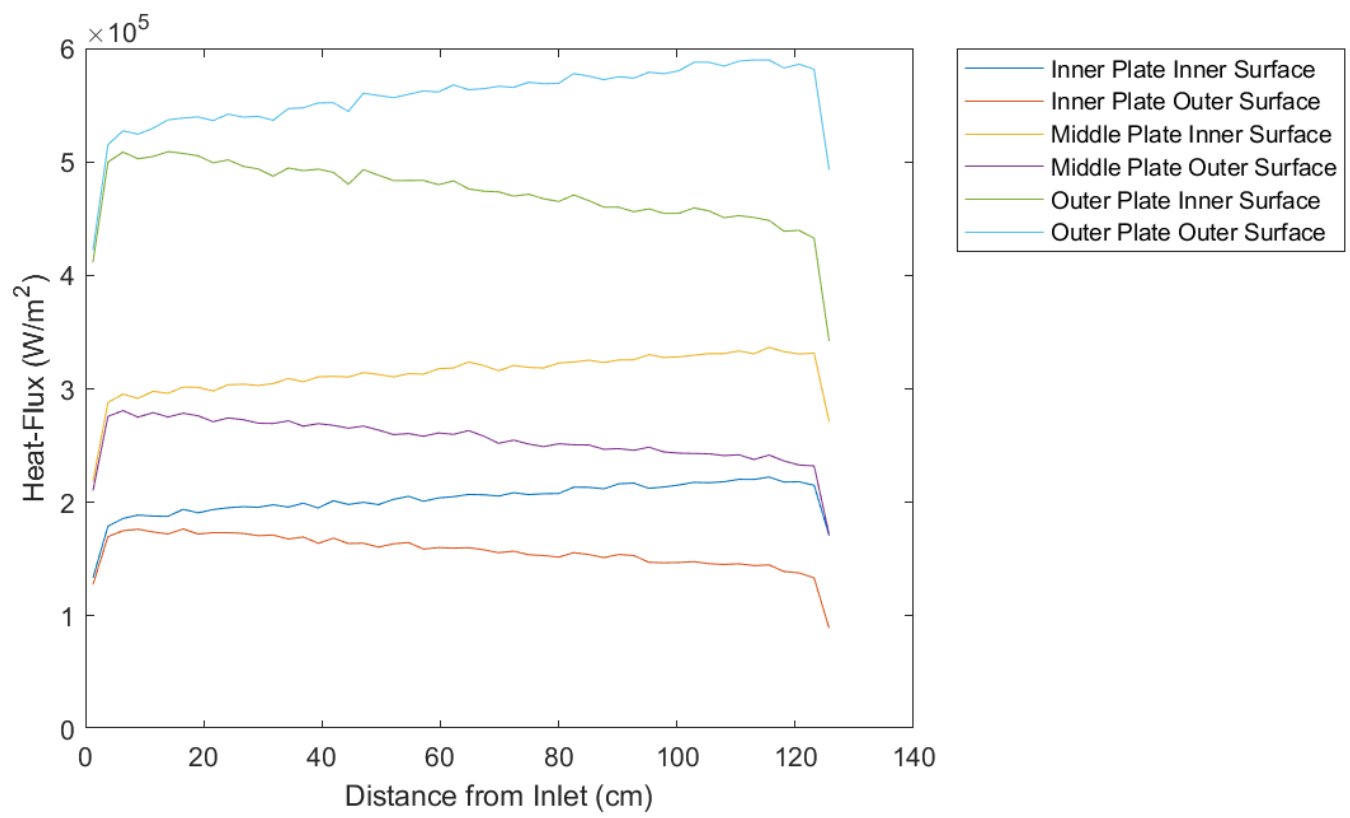

Figure 84: Fuel Plate Surface Heat Fluxes

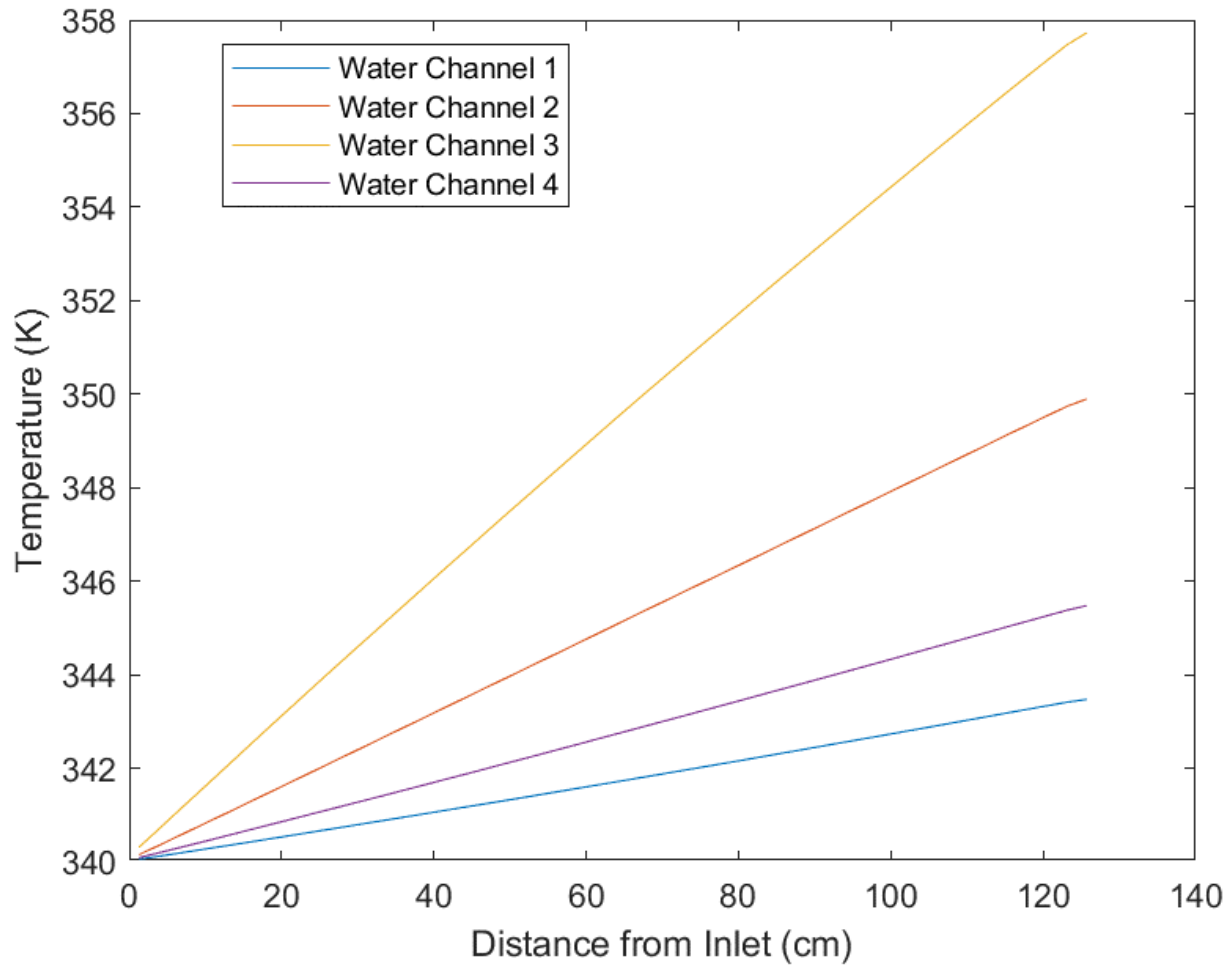

Figure 85: Fuel Plate Cooling Water Temperatures 


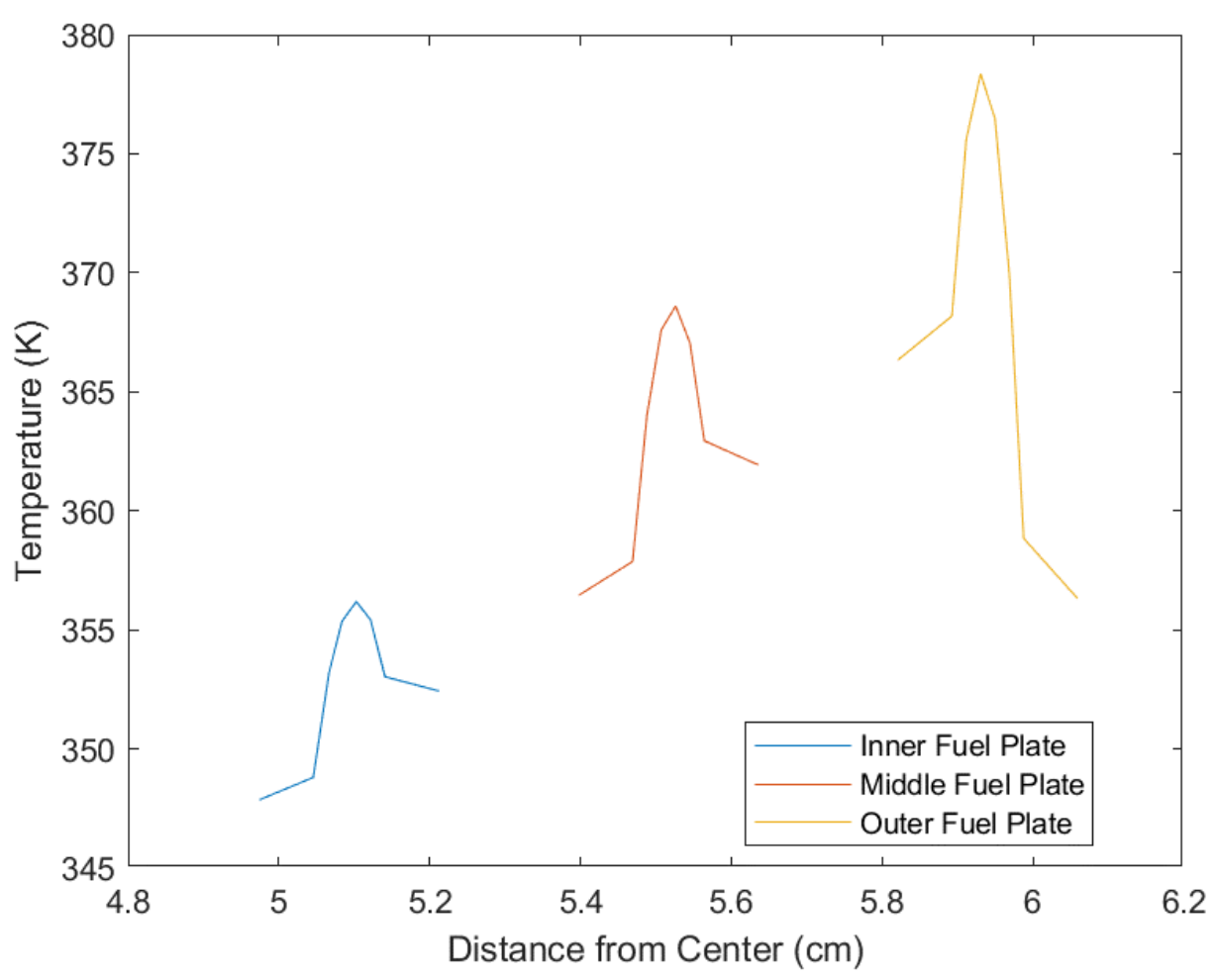

Figure 86: Peak Fuel Plate Radial Temperature Distributions

\subsubsection{Summary}

The primary system is fairly similar to the previous systems, though the U-tube design does account for some heat transfer from the primary to the inner helium system within the cold leg, hot leg, and horizontal leg. Because of this, the inlet temperature of the test section is less than $600 \mathrm{~K}$ (instead $596 \mathrm{~K}$ ), though an outlet temperature of $650 \mathrm{~K}$ is still reached. The fuel pin radial temperature profiles are largely unchanged from the three fuel pin system and show a relatively low centerline temperature. The jagged peaks present in the last two cases also appear in the primary system due to the variance in axial heat generation within the fuel pins. This model assumes that the helium would enter the system at a higher temperature than equilibrium, and as such drops significantly near the inlet. While the changed helium system does result in a slightly different temperature profile for the booster fuel cooling system, the water coolant system is very similar to the previous cases. The water does not reach boiling at any point, and the fuel plate maximum temperature reaches $378 \mathrm{~K}$. This model has shown the FSTL is capable of reaching the necessary requirements 
for providing SFR like operating conditions, though the introduction of a second helium system also introduces several discrepancies.

\subsection{Parametric Study: Three Fuel Pin Test Section}

The following section covers a parametric study conducted on the three fuel pin test case. The purpose of the parametric study is to examine and determine an operating window for this test loop, examining key parameters such as pin power, primary pressure and velocity, helium pressure and velocity, and fuel plate power.

Table 8: Parametric Study Outline

\begin{tabular}{|l|l|}
\hline Parameter & Test Range \\
\hline Pin Power - Normal Flow Conditions & $5 \mathrm{~kW}-15 \mathrm{~kW}$ per pin \\
\hline Pin Power - Optimal Flow Conditions & $5 \mathrm{~kW}-15 \mathrm{~kW}$ per pin \\
\hline Primary Fluid Velocity & $1.0-5 \mathrm{~m} / \mathrm{s}$ \\
\hline Primary Fluid Pressure & $0.5-2.5$ times normal pressure \\
\hline Helium Velocity & $0.5-2.5$ times normal velocity \\
\hline Helium Pressure & $0.5-2.5$ times normal pressure \\
\hline Fuel Plate Power & $1.0-3.0$ times normal power per plate \\
\hline
\end{tabular}

\subsubsection{Parametric Study: Pin Power with Old Flow Conditions}

The following section covers the results of varying the thermal power within the three fuel pins while retaining the same pressure difference across the test section that was used in Section 5.4. While the neutronics assessment of this project gave an expected value for the pin power, future changes to materials used or fluctuations within the core power of the ATR could lead to higher pin powers. Most important are the primary outlet temperature and the maximum fuel pin temperature to ensure the FSTL can still be operated safely. While the normal operation conditions of the loop expect the pins to have a thermal power of roughly $3 \mathrm{~kW}$ each, this section study will examine cases where each fuel pin has a thermal power value of $5 \mathrm{~kW}, 10 \mathrm{~kW}$, and $15 \mathrm{~kW}$. Figure 87 shows the outlet temperatures as a function of pin power. This shows a linear relationship with pin power to outlet 
temperature, which is to be expected. With a pin power of $15 \mathrm{~kW}$, the outlet temperature reaches $829 \mathrm{~K}$.

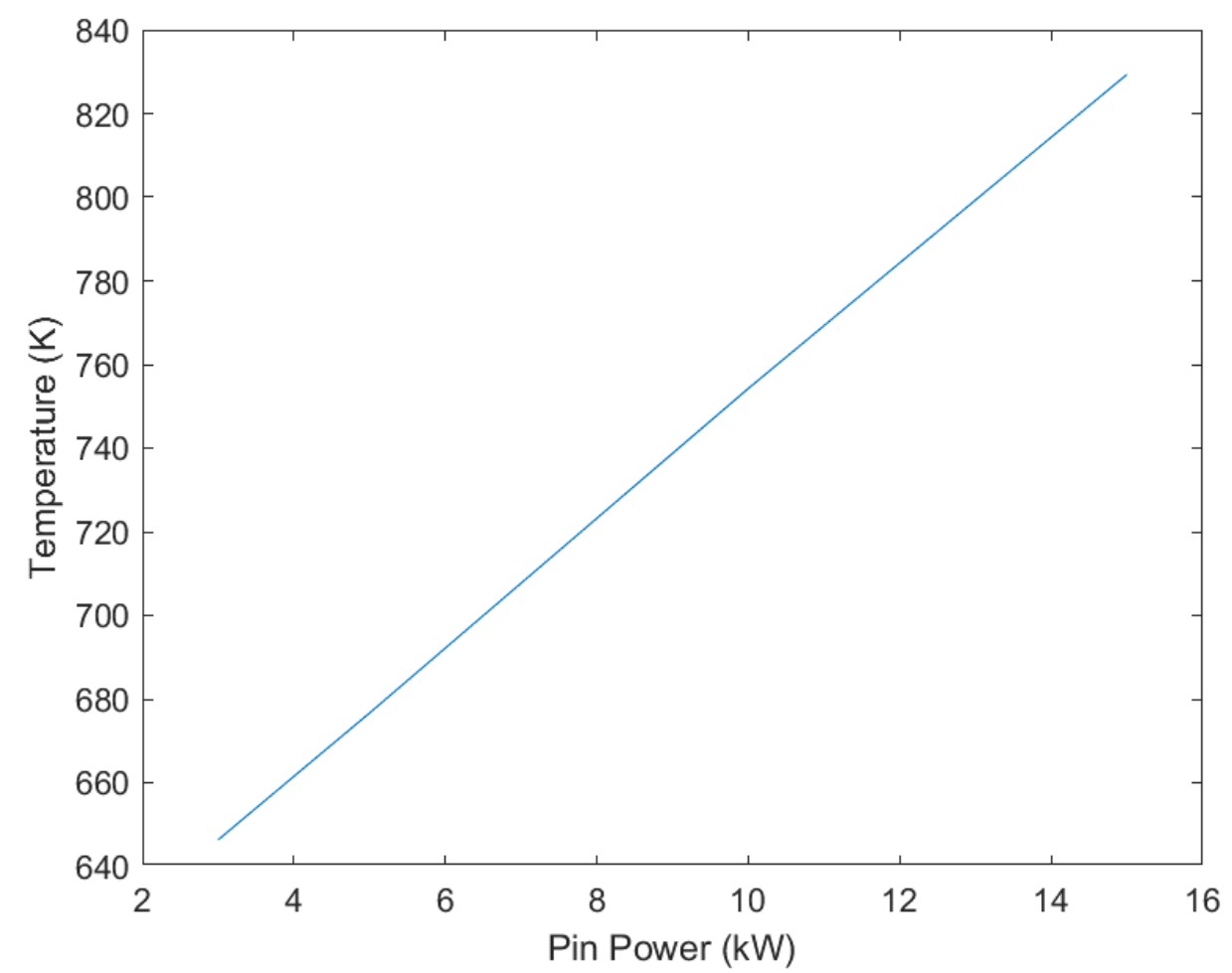

Figure 87: Outlet Temperatures with No Change to Velocity

Furthermore, the radial temperature profile of each fuel pin for the $5 \mathrm{~kW}$ case, $10 \mathrm{~kW}$ case, and $15 \mathrm{~kW}$ case is given in Figure 88, Figure 89, and Figure 90. For the most extreme case, $15 \mathrm{~kW}$, the cladding temperature reaches a maximum of $836 \mathrm{~K}(562 \mathrm{C})$, still within the 649 - $704 \mathrm{C}$ thermal design limit for typical SFR fuel pins. It is also important to note that the liquid void fraction for the sodium loop is 100 percent for the entire loop even in the 15 kW case. 

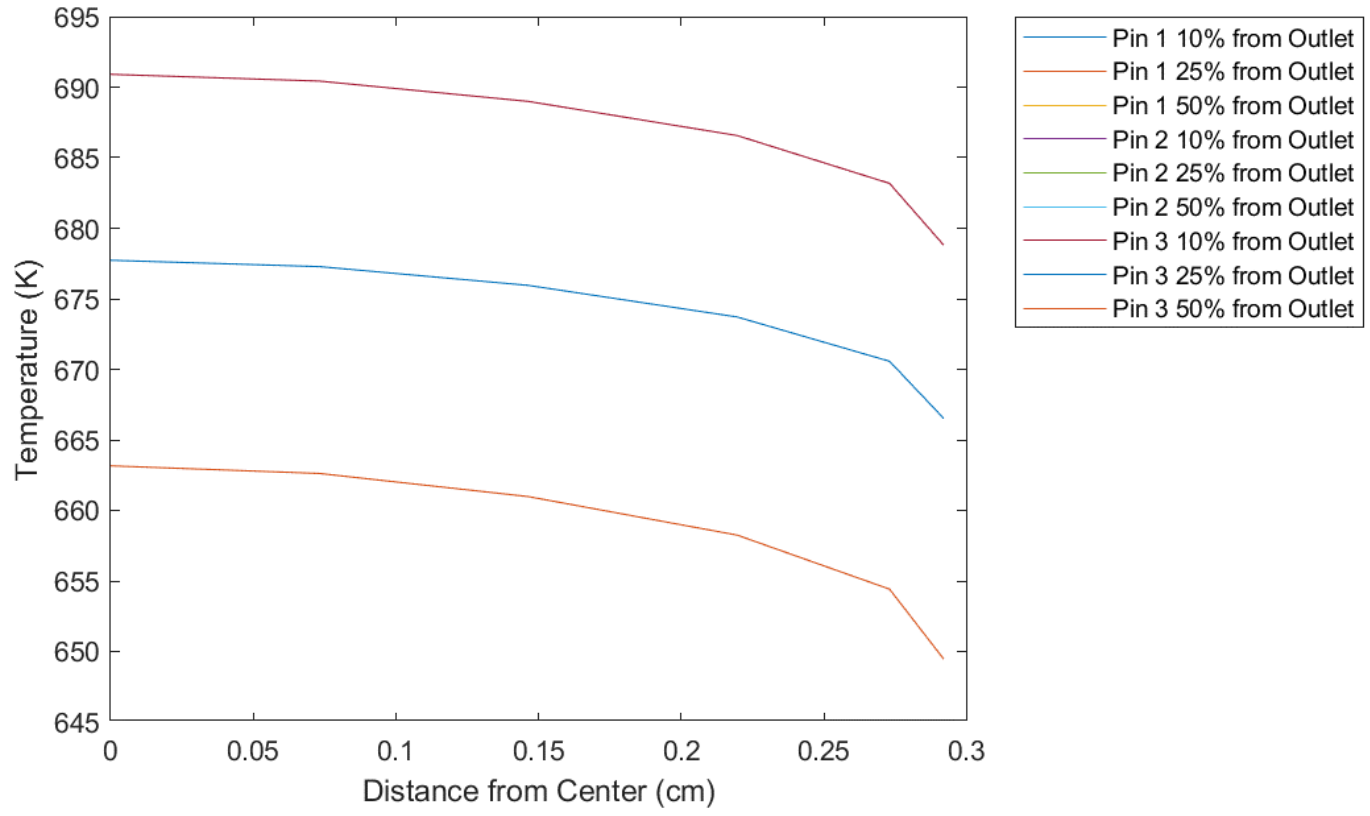

Figure 88: Fuel Pin Radial Temperature (5 kW)
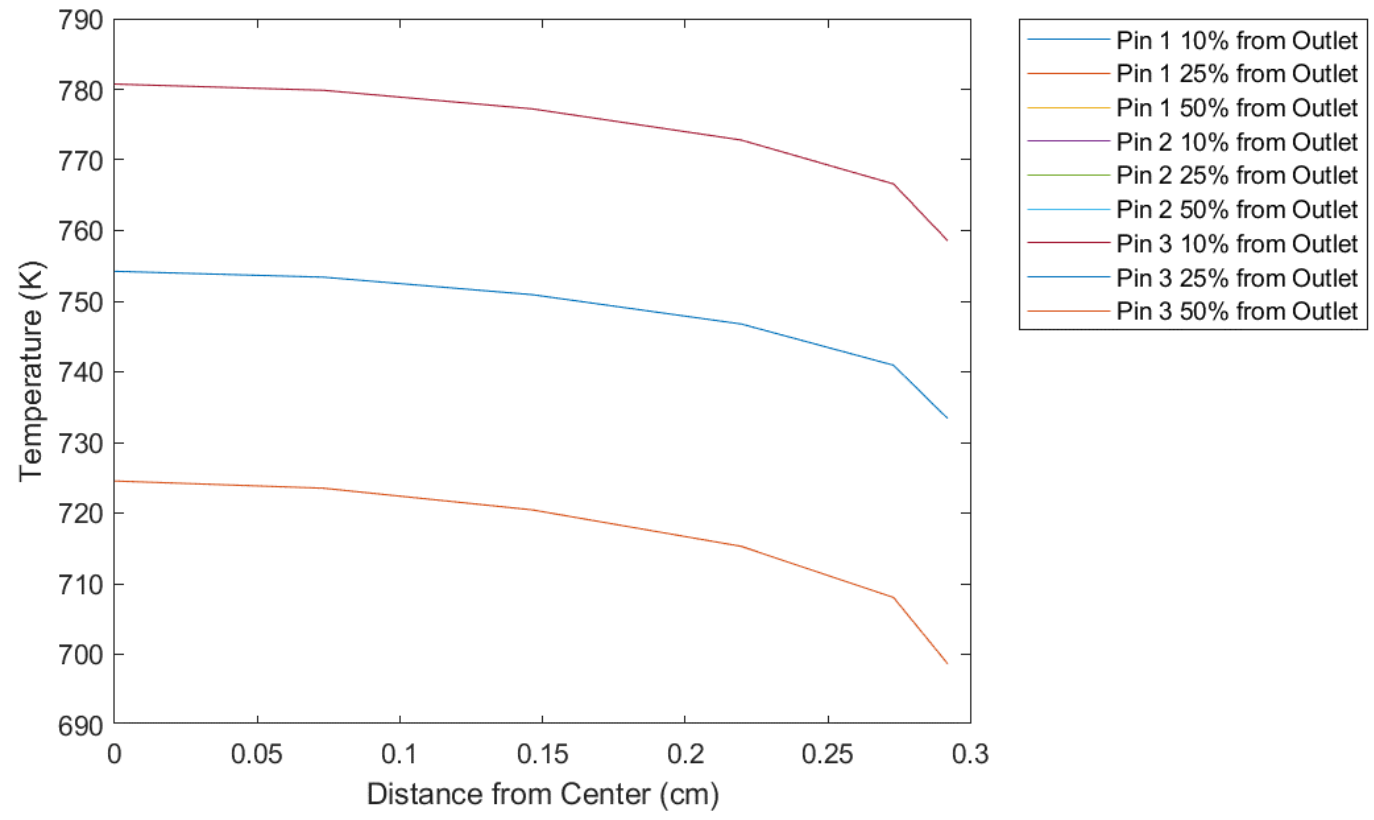

Figure 89: Fuel Pin Radial Temperature Profile (10 kW) 


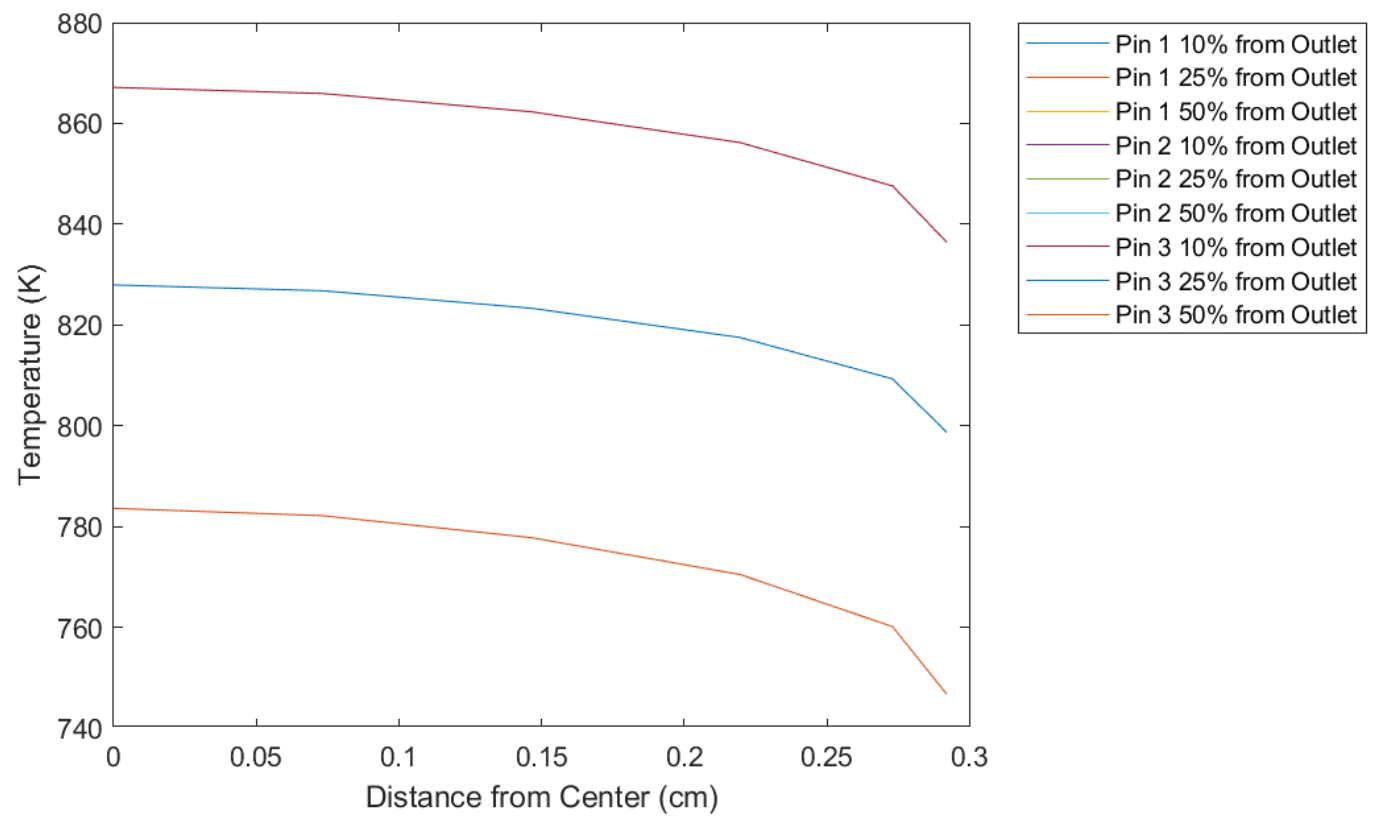

Figure 90: Fuel Pin Radial Temperature (15 kW)

The extra heat in the primary section may also have an effect on the helium system, which can be seen in Figure 91, Figure 92, and Figure 93. It can be seen here however that the effect the primary loop has on the helium outlet temperature is relatively small. As such, there is little to no effect on the booster fuel cooling loop due to an increased thermal power in the fuel pins. 


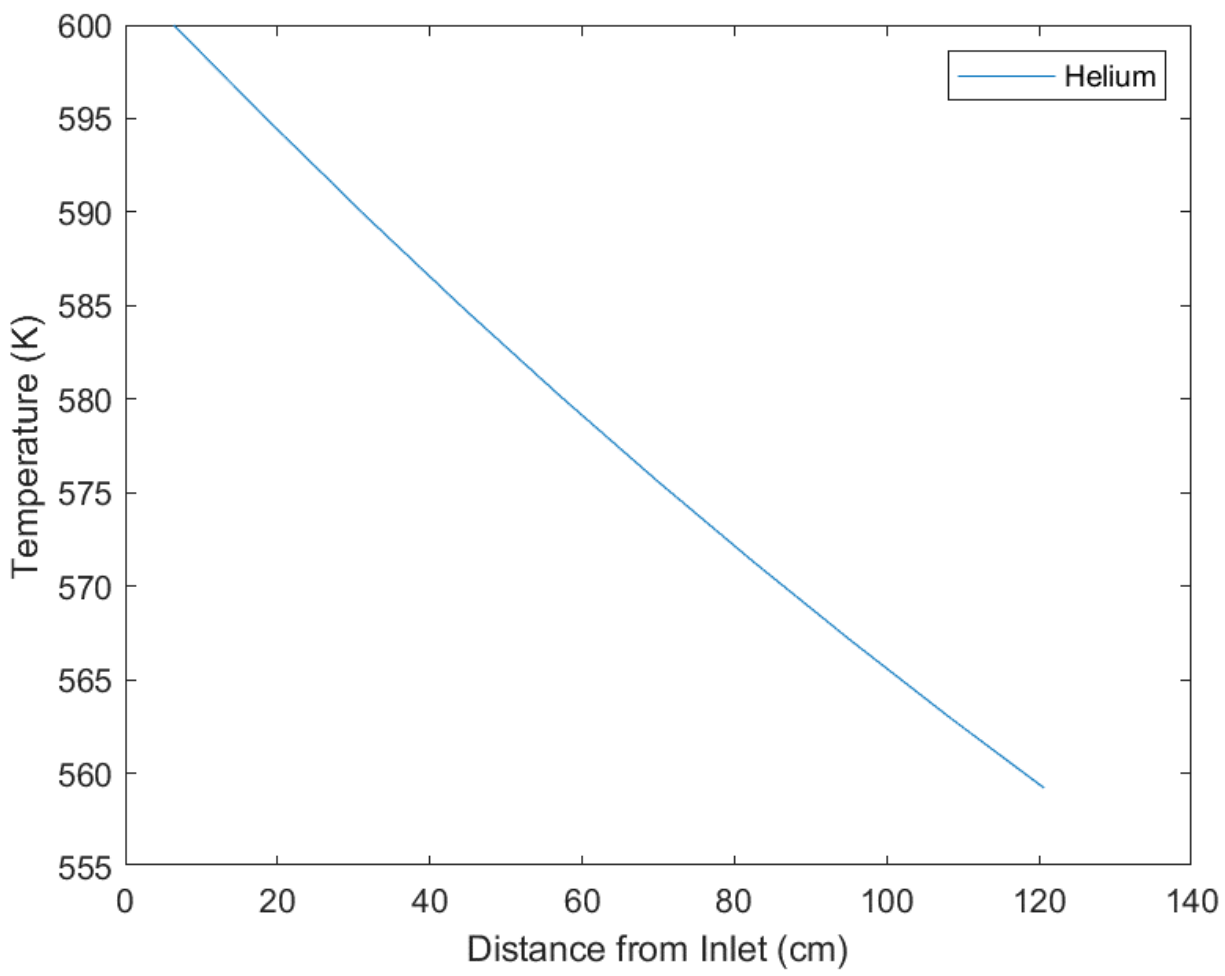

Figure 91: Helium Temperature (5 kW)

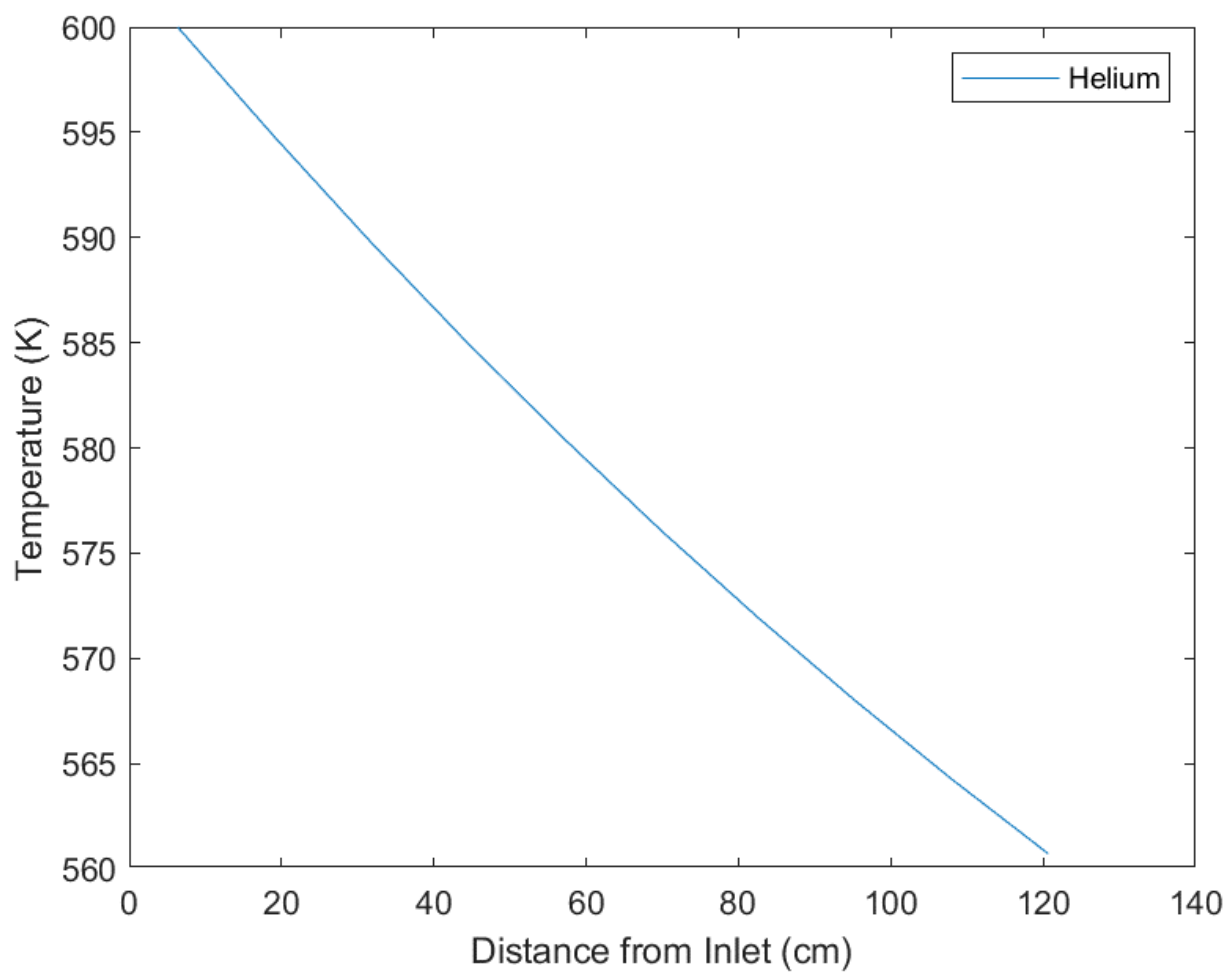

Figure 92: Helium Temperature (10 kW) 


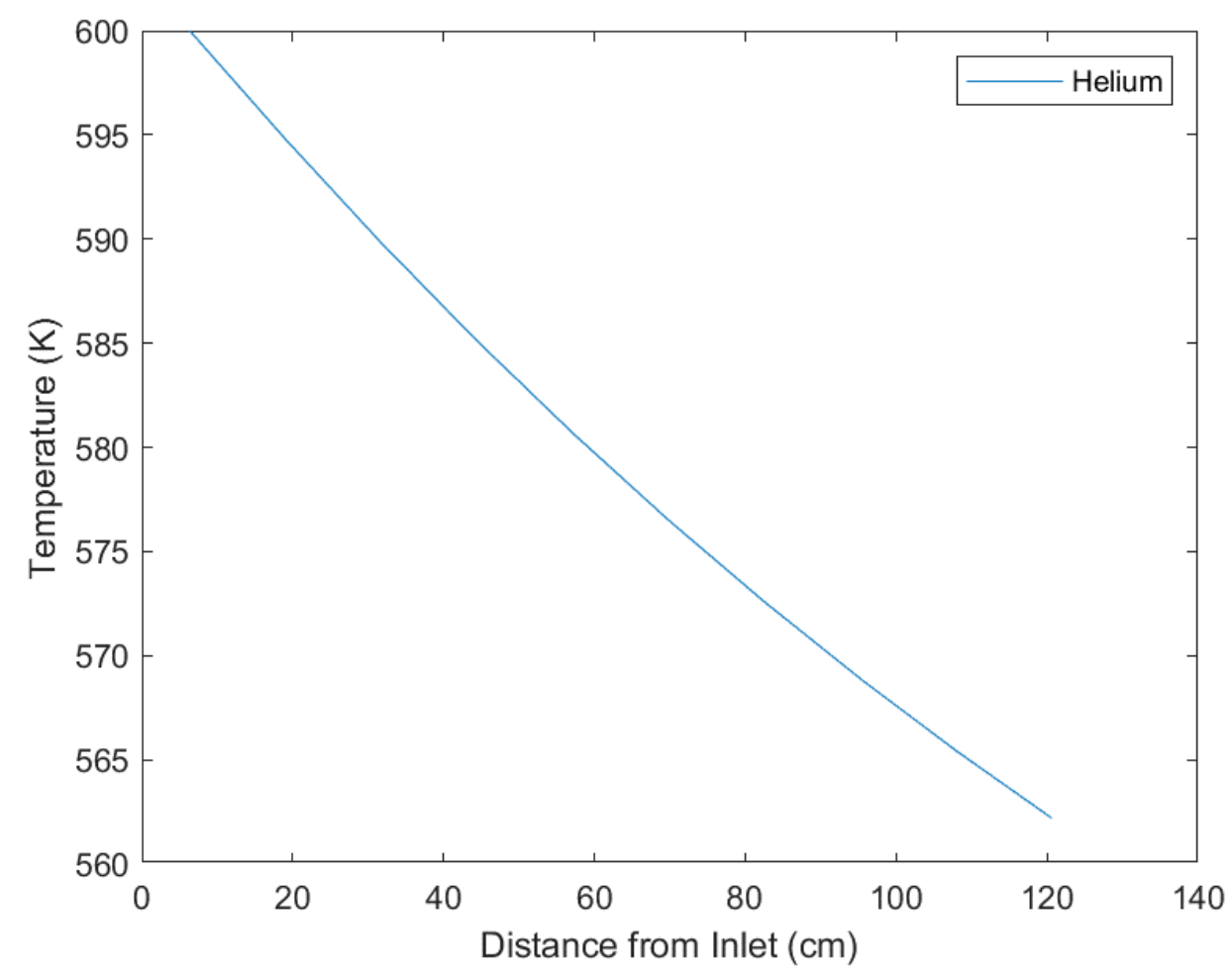

Figure 93: Helium Temperature (15 kW)

\subsubsection{Pin Power with New Flow Conditions}

While the goal of Section 5.6.1 was to examine the case where the thermal power of each pin was increased with no other changes to the loop, this section looks at reaching the 600 $-650 \mathrm{~K}$ temperature increase across the test section with these changes to thermal power. To do this, the pressure difference across the test section was increased to reach an ideal primary velocity. The following table showcases the pressure difference, resulting primary velocity, and outlet temperature for each case.

Table 9: Parameters Used for New Flow Conditions

\begin{tabular}{|l|l|l|l|}
\hline \multicolumn{1}{|c|}{$\begin{array}{c}\text { Pin Power } \\
(\mathrm{kW})\end{array}$} & $\begin{array}{c}\text { Pressure Difference } \\
(\mathrm{kPa})\end{array}$ & $\begin{array}{c}\text { Primary Velocity } \\
(\mathrm{m} / \mathrm{s})\end{array}$ & \multicolumn{1}{c|}{$\begin{array}{c}\text { Outlet Velocity } \\
(\mathrm{K})\end{array}$} \\
\hline 5 & 13.7 & 1.90 & 653.256 \\
\hline 10 & 48.7 & 3.96 & 654.984 \\
\hline 15 & 139 & 7.05 & 647.001 \\
\hline
\end{tabular}


As can be seen, the 600-650 K temperature difference can be reached for all cases, though with a significant pressure difference to achieve a high velocity. EBR-II reportedly had a maximum velocity through its core of around $9 \mathrm{~m} / \mathrm{s}$ [6], so while it may be an impractical operating condition it could be considered. Overall, it is shown here that even if the pin power were increased to $15 \mathrm{~kW}$, though highly impractical, the FSTL system could safely cool the system.

\subsubsection{Booster Fuel Plate Power}

For the purposes of this design, it was assumed that the operating conditions of the water cooling loop for the booster fuel plates would remain constant and unchangeable, with these parameters being $340 \mathrm{~K}$ inlet temperature, 150 psi operating pressure, and a flow velocity of $8 \mathrm{~m} / \mathrm{s}$. While earlier sections of Chapter 5 showed that this was adequate to cool the plates during estimated normal operating conditions, this section will examine this system with significantly different thermal powers for the fuel plates. A multiplier for each plate will be used in each test case, with these multipliers being 0.5, 1.5, 2.0, and 2.5. The liquid void fraction for each sub-volume containing water remained 1.0 across the entire test section, showing no boiling takes place. The following table shows the outlet temperatures of each water channel for each test case, all of which show plausibly safe operating conditions.

Table 10: Water Outlet Temperatures

\begin{tabular}{|l|l|l|l|l|}
\hline \multicolumn{1}{|c|}{$\begin{array}{c}\text { Power } \\
\text { Multiplier }\end{array}$} & \multicolumn{1}{|c|}{$\begin{array}{c}\text { Channel 1 } \\
(\mathrm{K})\end{array}$} & \multicolumn{1}{|c|}{$\begin{array}{c}\text { Channel 2 } \\
(\mathrm{K})\end{array}$} & $\begin{array}{c}\text { Channel 3 } \\
(\mathrm{K})\end{array}$ & $\begin{array}{c}\text { Channel 4 } \\
(\mathrm{K})\end{array}$ \\
\hline 0.5 & 342.58 & 345.02 & 348.90 & 342.76 \\
\hline 1.0 & 344.25 & 349.91 & 357.68 & 345.46 \\
\hline 1.5 & 346.12 & 359.02 & 370.94 & 348.27 \\
\hline 2.0 & 347.56 & 359.60 & 375.09 & 350.81 \\
\hline 2.5 & 349.21 & 364.41 & 383.71 & 353.46 \\
\hline
\end{tabular}

The temperature profile of each plate will also be examined to ensure the plates are within their thermal design limit. Figure 94, Figure 95, Figure 96, and Figure 97 show the peak temperatures of each fuel plate for each case. The maximum temperature reached in the 2.5 multiplier case is $433 \mathrm{~K}$, well within operating conditions for $\mathrm{U}_{3} \mathrm{Si}_{2}$. 


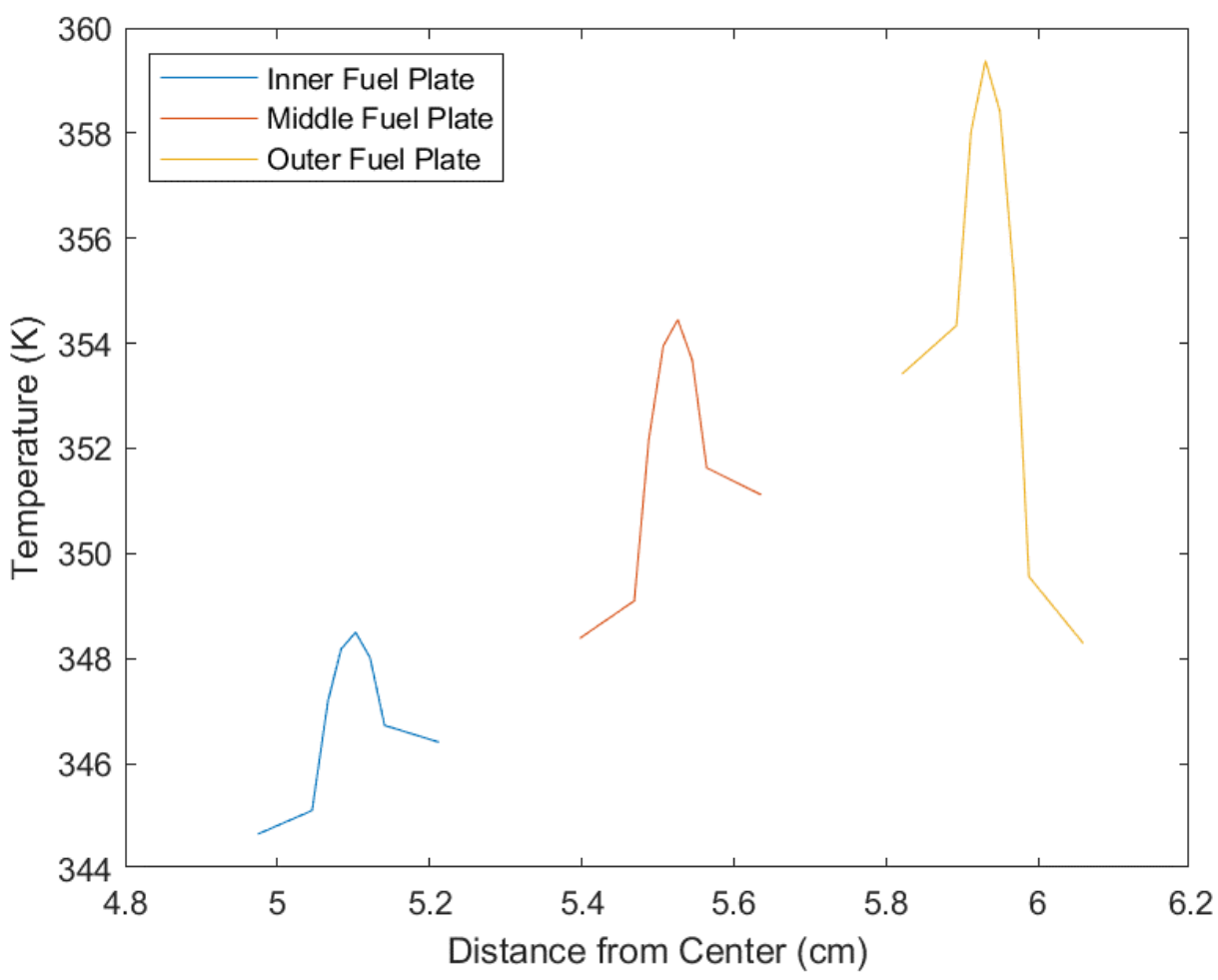

Figure 94: Peak Fuel Plate Temperatures (0.5)

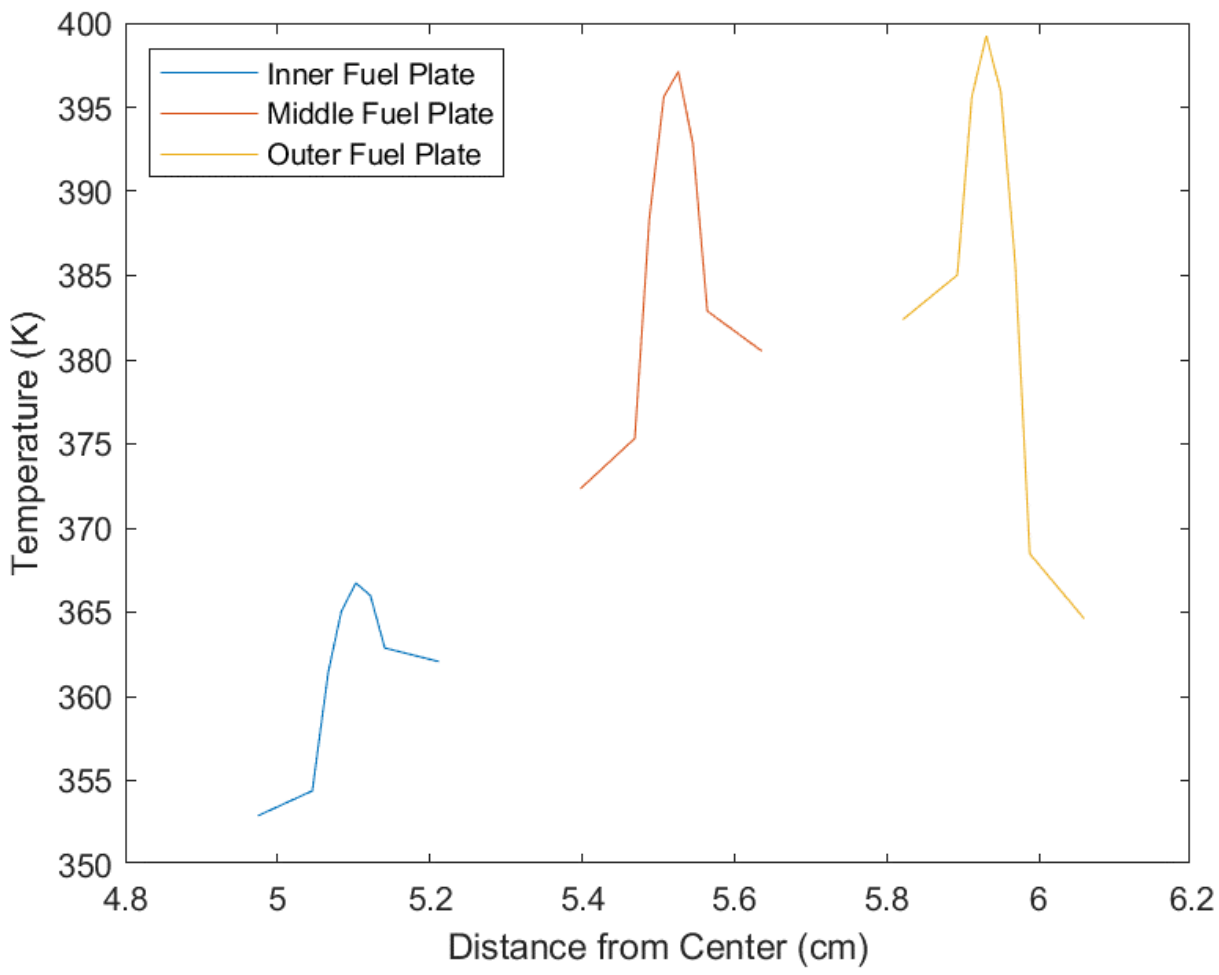

Figure 95: Peak Fuel Plate Temperatures (1.5) 


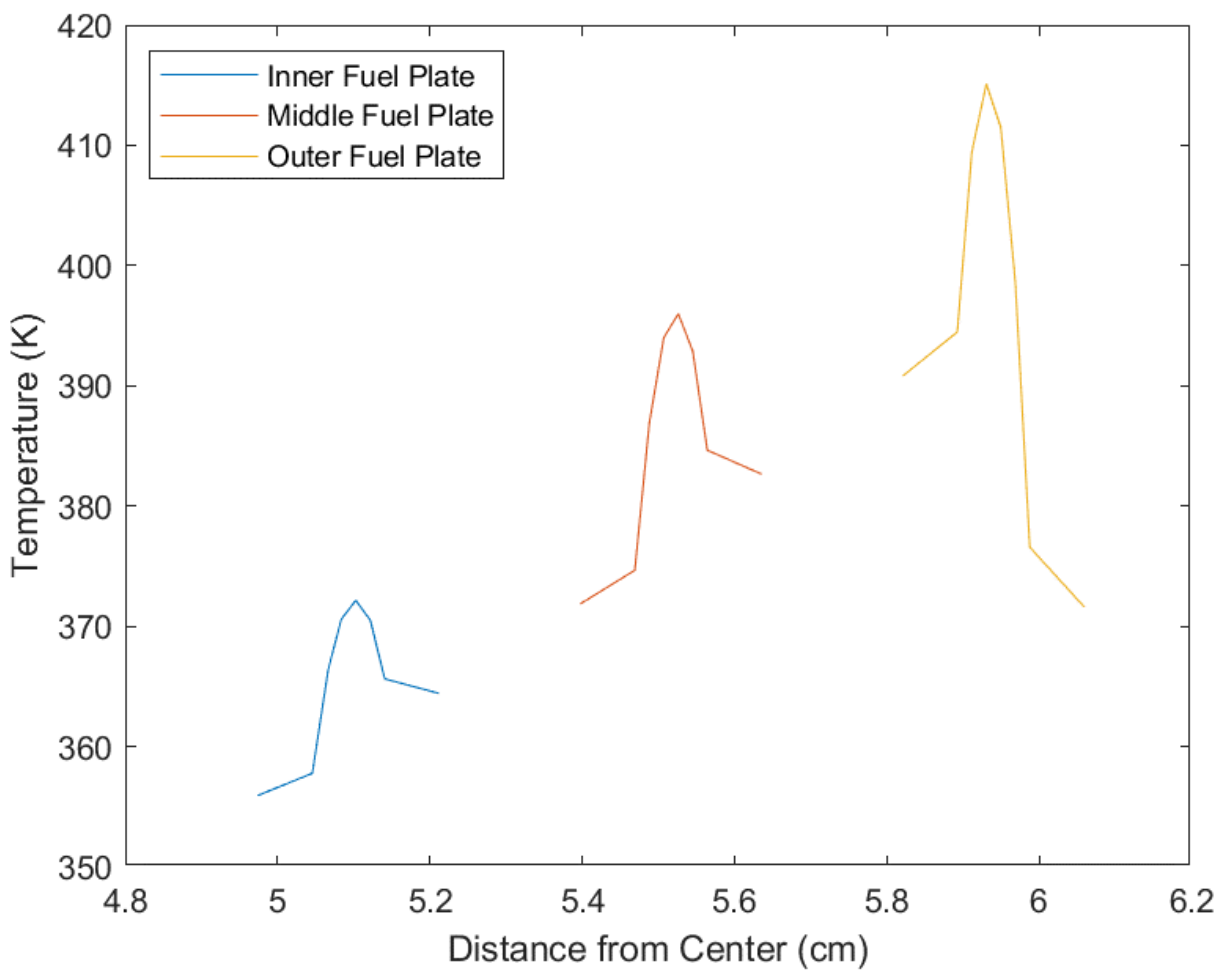

Figure 96: Peak Fuel Plate Temperatures (2.0)

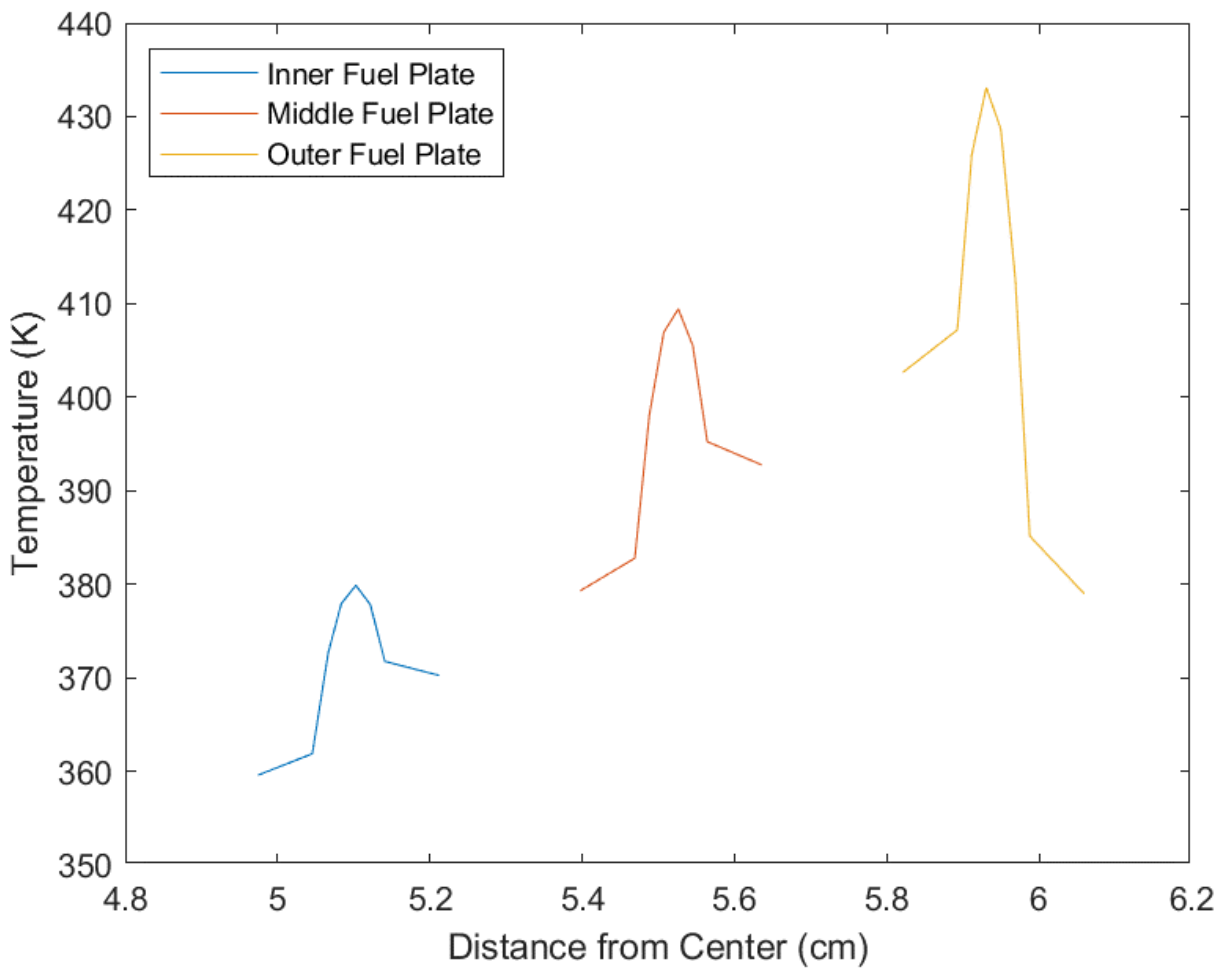

Figure 97: Peak Fuel Plate Temperatures (2.5) 
Since this case only looks at changing the fuel plate power, the helium system and primary system are largely unchanged.

\subsubsection{Primary Pressure}

The following section examines the effects of varying the operating pressure of the primary system while retaining all other parameters. In this case, a multiplier of 1.5, 2.0, and 2.5 was applied to the operating pressure of the loop. If any effect were to take place in this system, it should be visible in the sodium outlet temperature, fuel pin temperature profile, and heat flux through the inner surface of the primary piping. Table 11 shows that these parameters are independent of the primary operating pressure up to 2.5 times atmospheric pressure.

Table 11: Primary Pressure Results

\begin{tabular}{|l|l|l|}
\hline \multicolumn{1}{|c|}{$\begin{array}{c}\text { Primary Pressure } \\
(\mathrm{kPa})\end{array}$} & \multicolumn{1}{|c|}{$\begin{array}{c}\text { Outlet Temperature } \\
(\mathrm{K})\end{array}$} & $\begin{array}{c}\text { Average Primary Heat Flux } \\
\left(\mathrm{kW} / \mathrm{m}^{2}\right)\end{array}$ \\
\hline 101.3 & 646.351 & 624.8175 \\
\hline 150.0 & 646.351 & 624.8175 \\
\hline 200.0 & 646.351 & 624.8175 \\
\hline 250.0 & 646.351 & 624.8175 \\
\hline
\end{tabular}

\subsubsection{Helium Pressure}

The following section examines the effects of varying the operating pressure of the helium system while retaining all other parameters. In this case, a multiplier of $0.5,1.5,2.0$, and 2.5 was applied to the operating pressure of the loop. These changes can be seen in the following figures. 


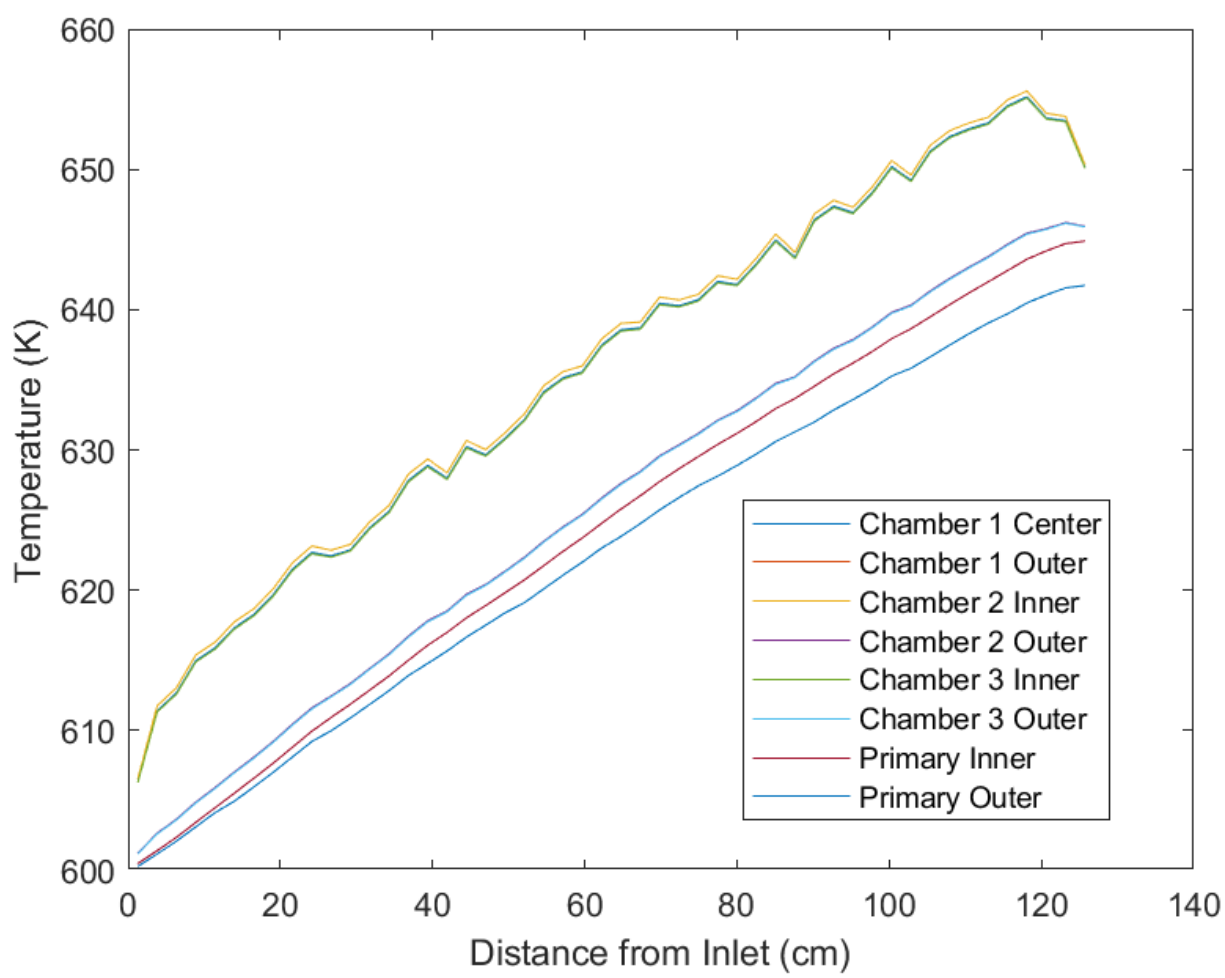

Figure 98: Primary Surfaces Temperature (1.5 Helium Pressure)

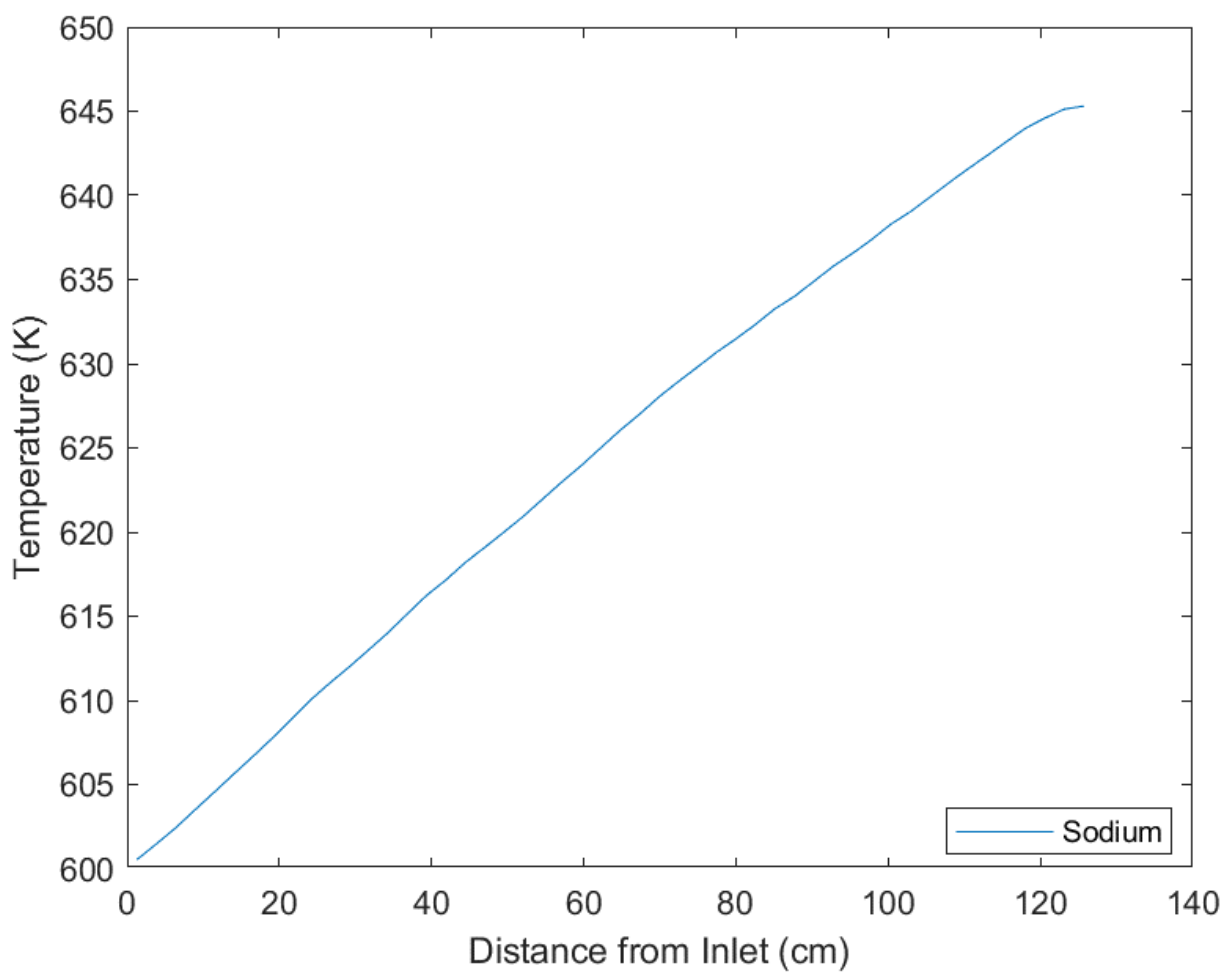

Figure 99: Primary Sodium Temperature (1.5 Helium Pressure) 


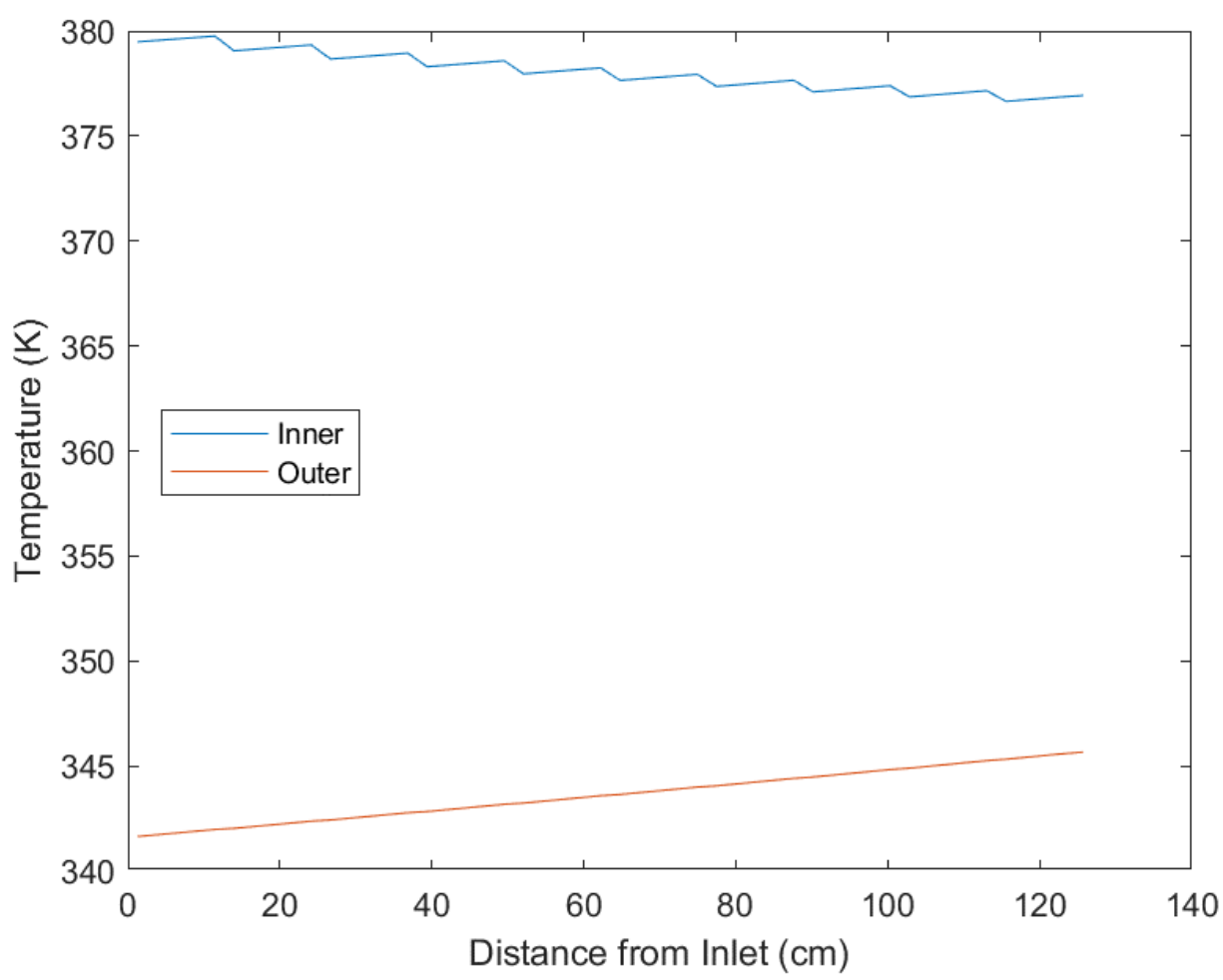

Figure 100: Helium Piping Surface Temperature (1.5 Helium Pressure)

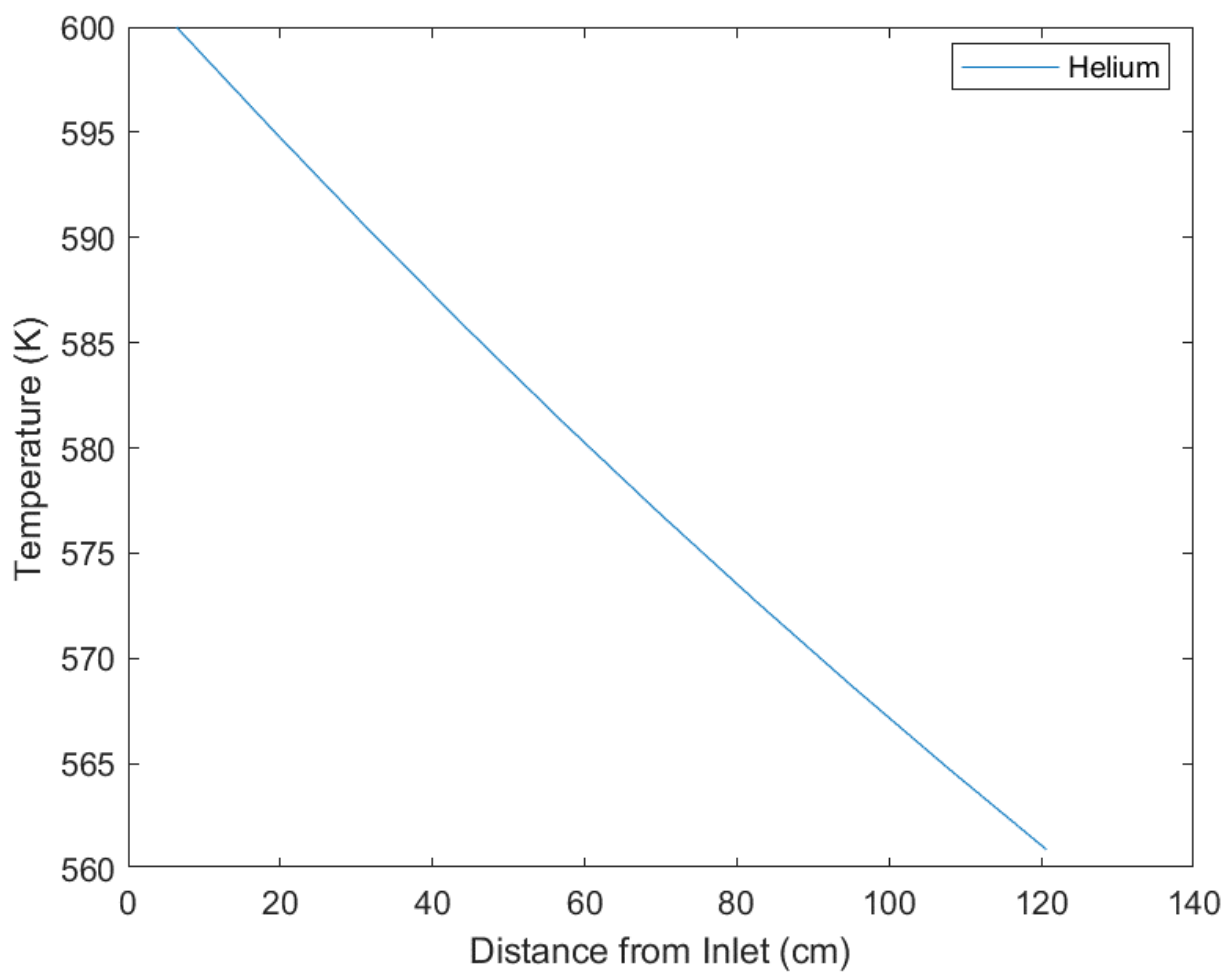

Figure 101: Helium Temperature (1.5 Helium Pressure) 


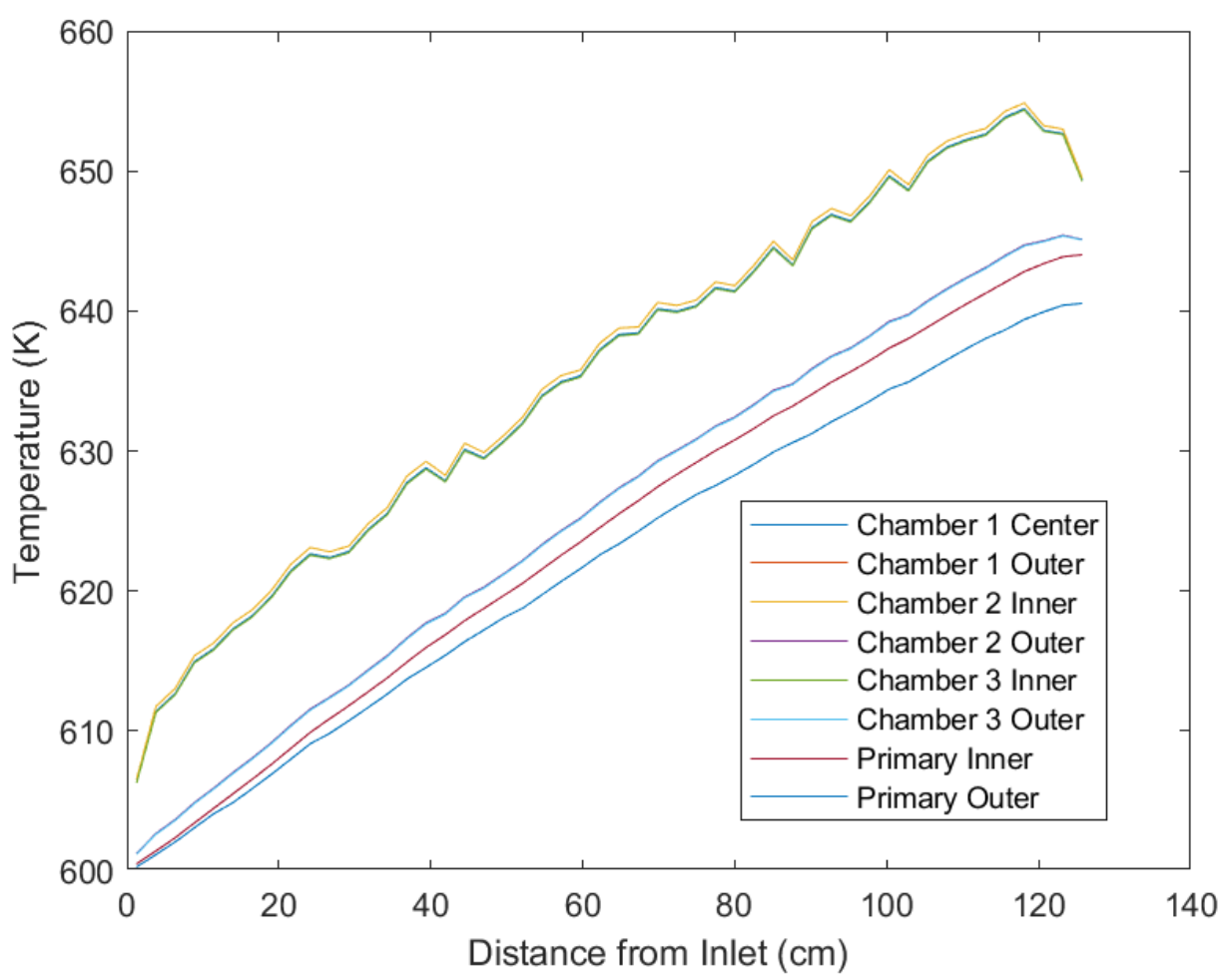

Figure 102: Primary Surface Temperature (2.0 Helium Pressure)

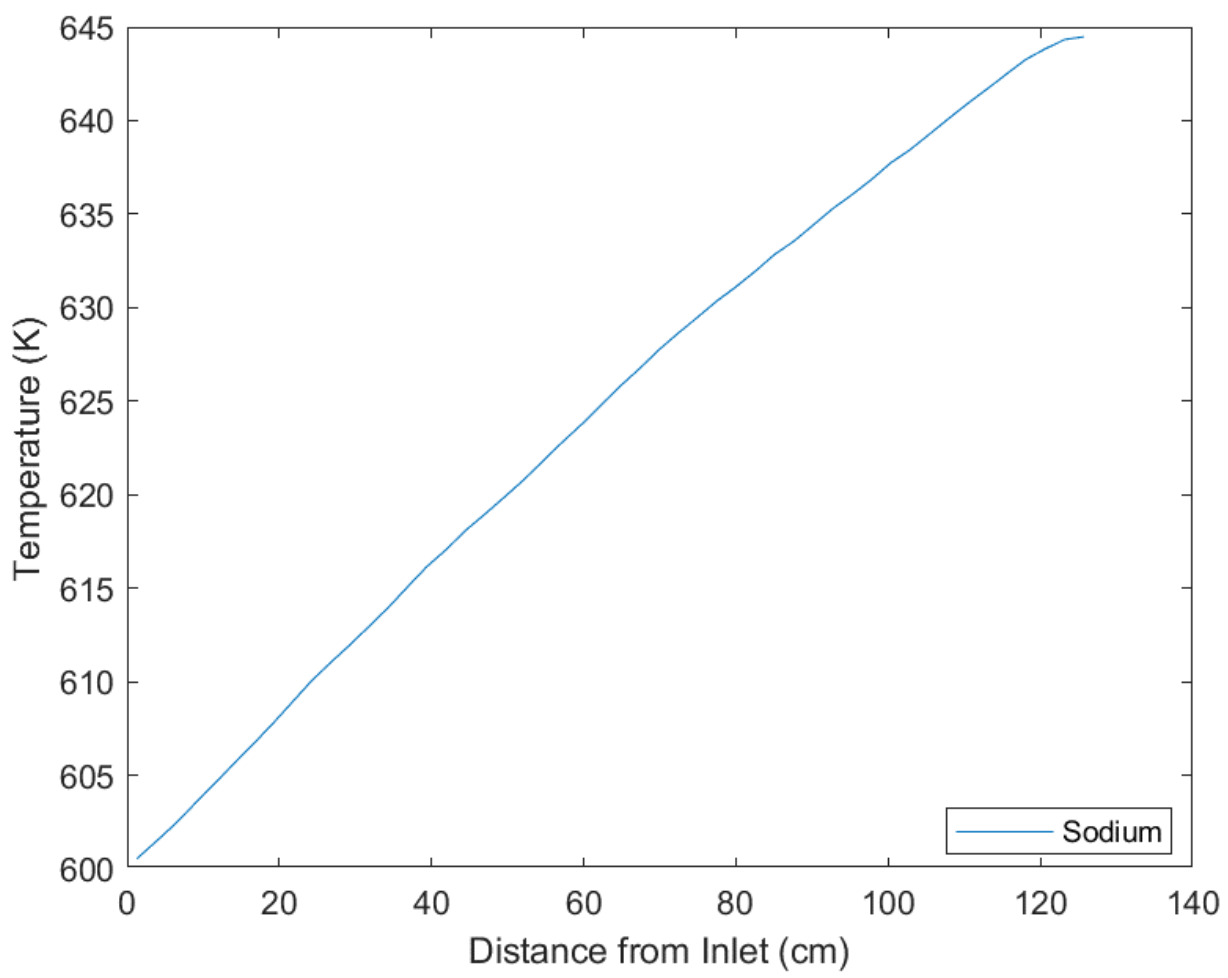

Figure 103: Primary Sodium Temperature (2.0 Helium Pressure) 


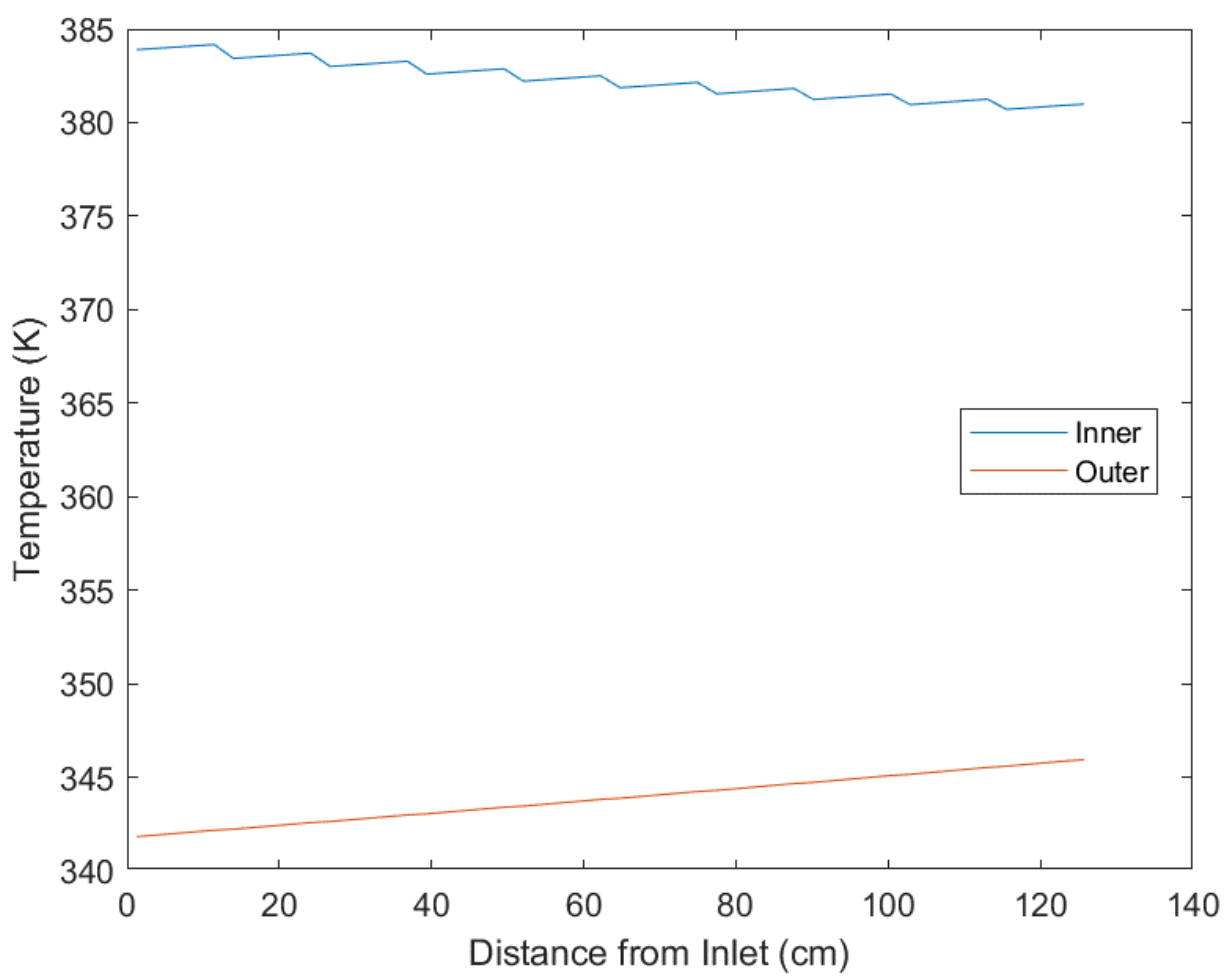

Figure 104: Helium Piping Surface Temperature (2.0 Helium Pressure)

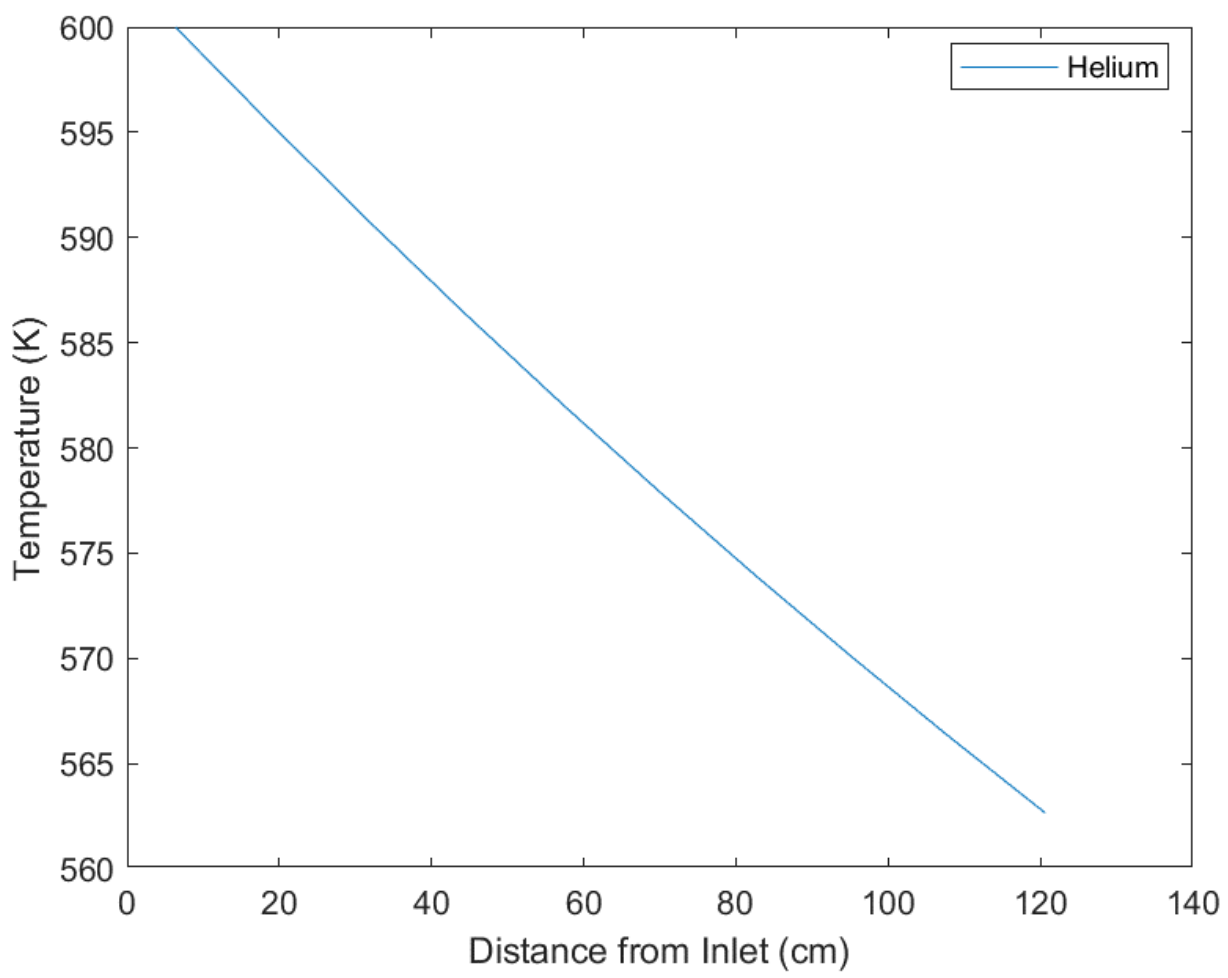

Figure 105: Helium Temperature (2.0 Helium Pressure) 


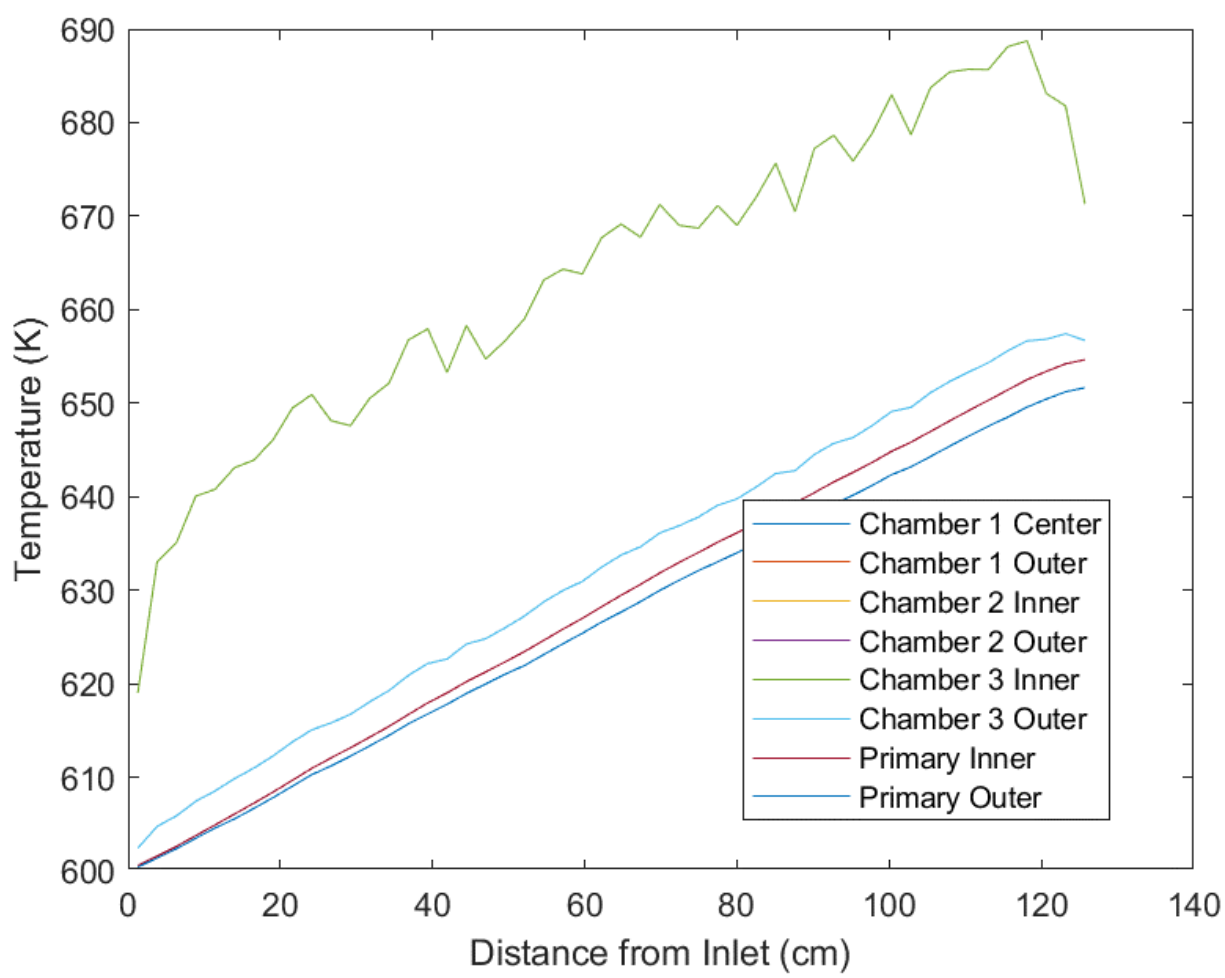

Figure 106: Primary Surface Temperatures (2.5 Helium Pressure)

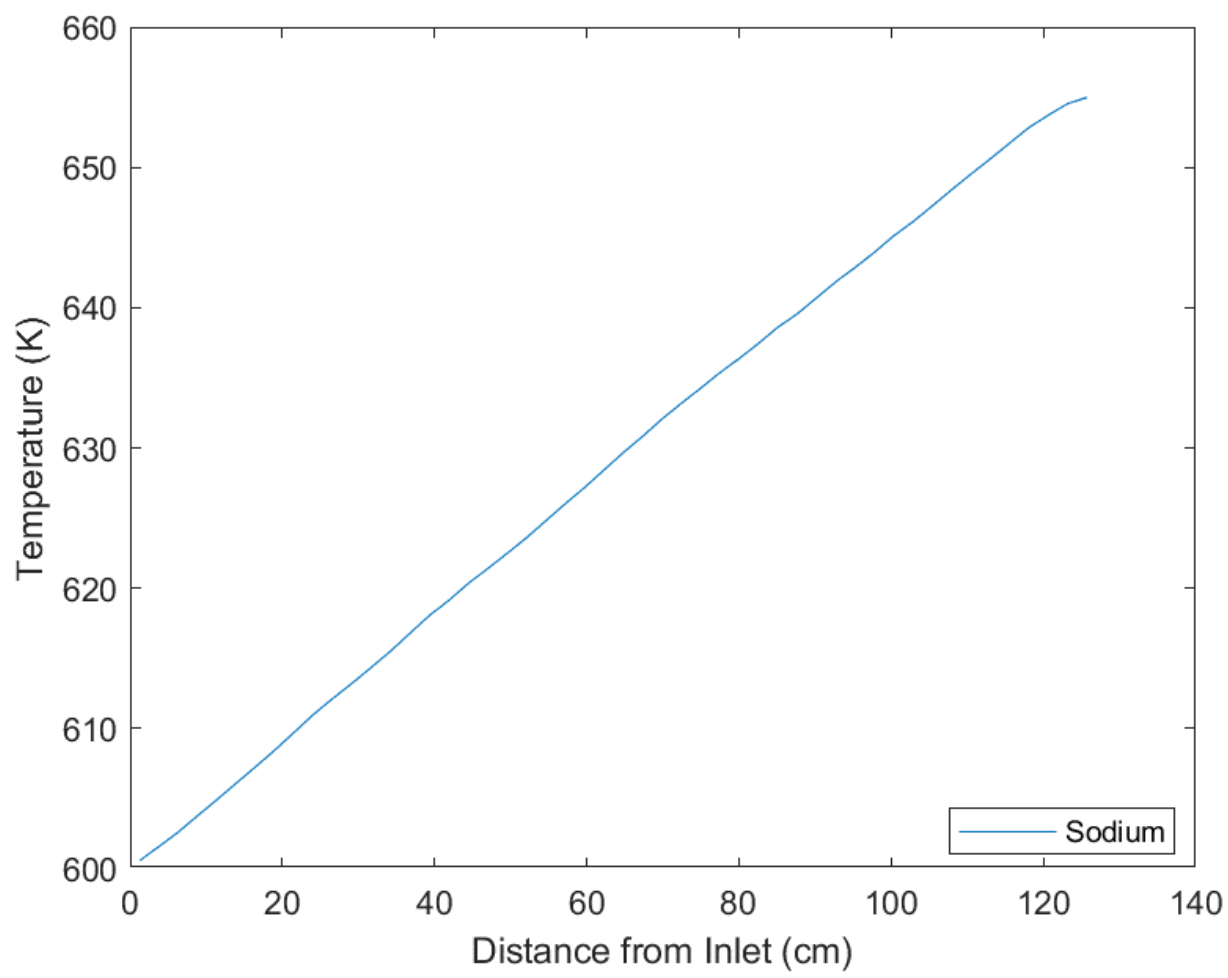

Figure 107: Primary Sodium Temperature (2.5 Helium Pressure) 


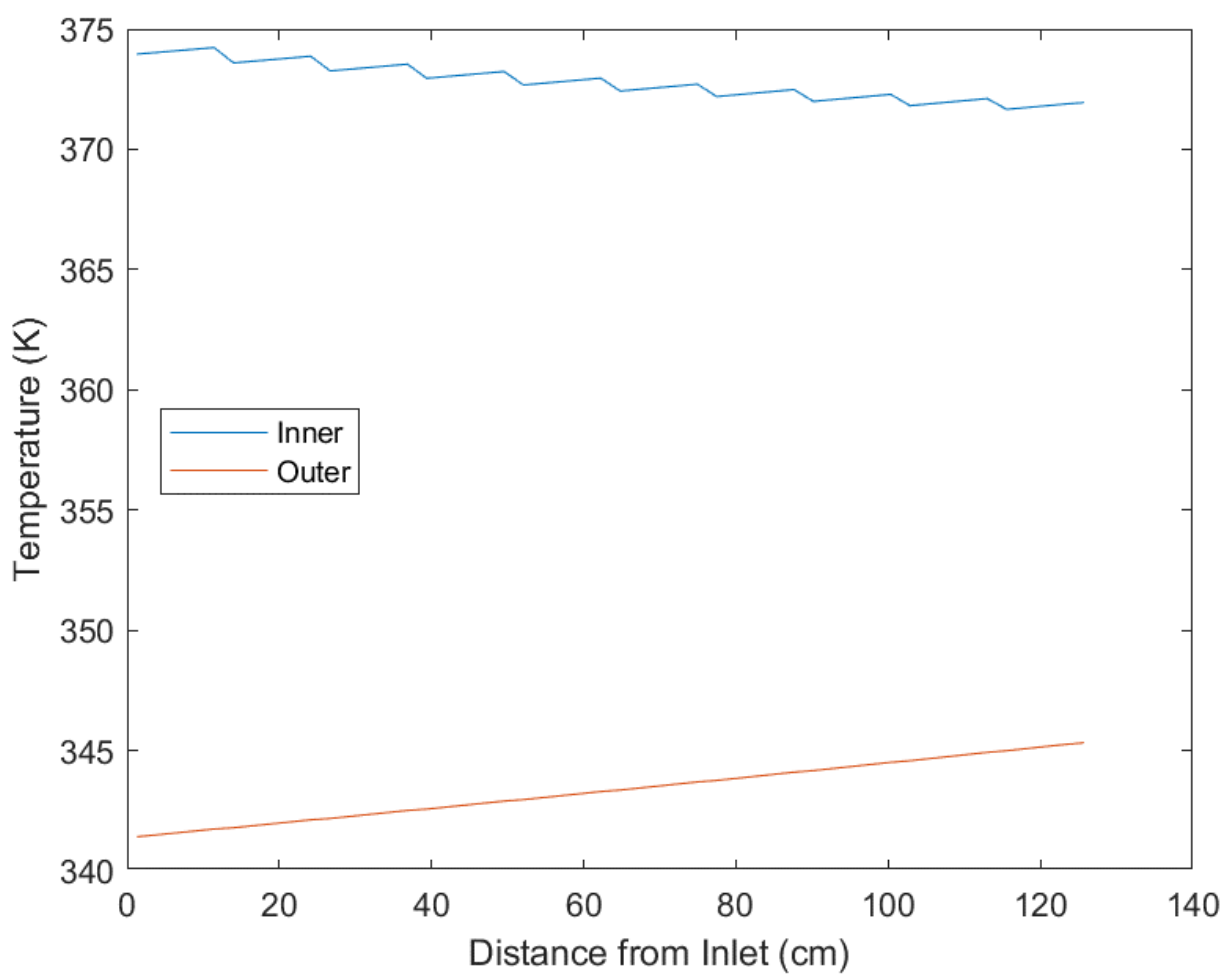

Figure 108: Helium Piping Surface Temperature (2.5 Helium Pressure)

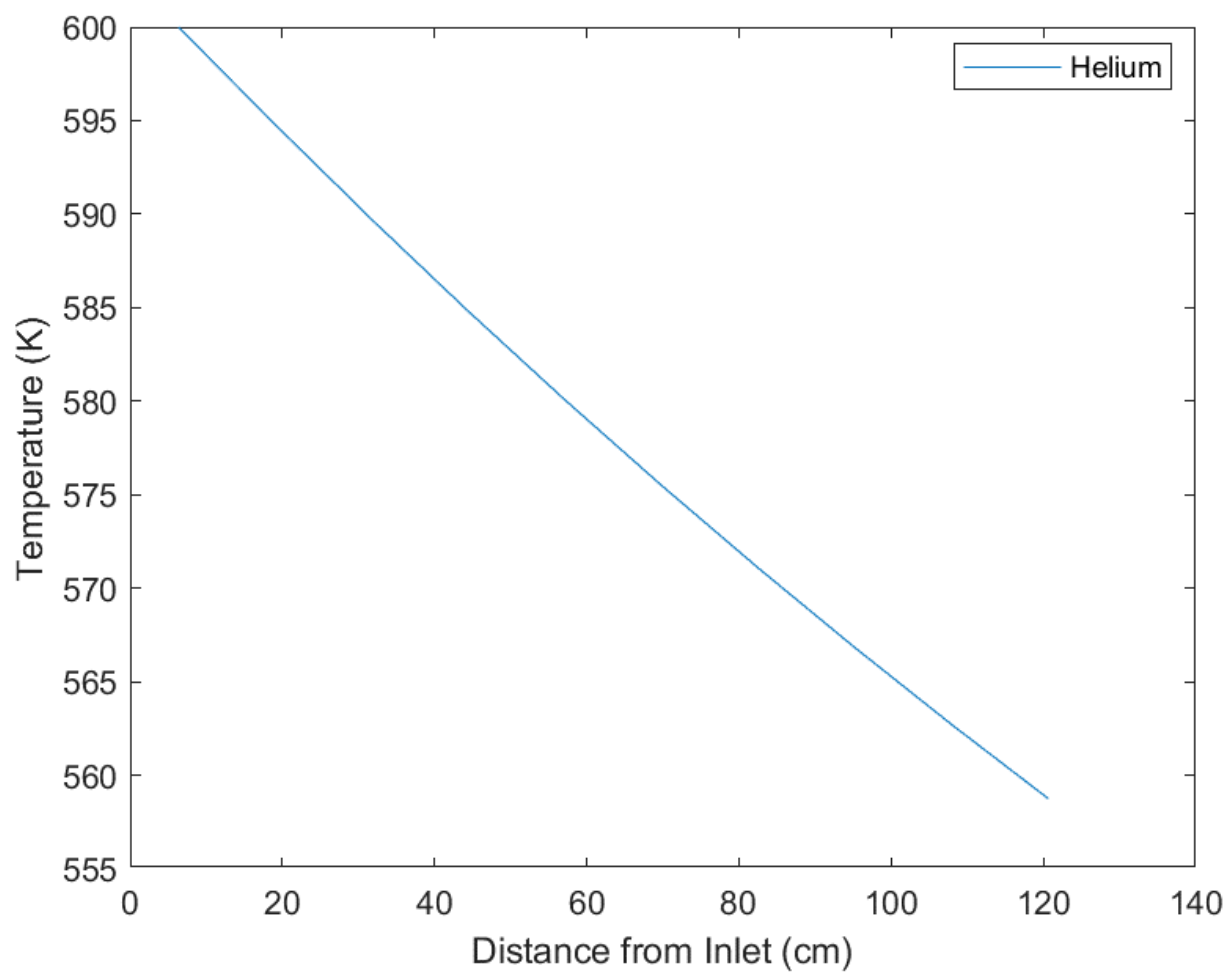

Figure 109: Helium Temperature (2.5 Helium Pressure) 
As can be seen with the varying outlet temperatures, while the helium operating pressure does have a small effect on the primary outlet temperature, it mostly negligible if the helium velocity and all other parameters remain the same.

\subsubsection{Primary Velocity}

The following section examines the effects of varying the mass flow rate of the primary system while retaining all other parameters. In this case, values of 2, 3, 4, and $5 \mathrm{~m} / \mathrm{s}$ were used as values for the velocity of the primary loop. This can be used to judge how the primary velocity affects the outlet temperature of the test section. As can be seen in Figure 110 , the outlet temperature greatly decreases with increases to the primary flow velocity.

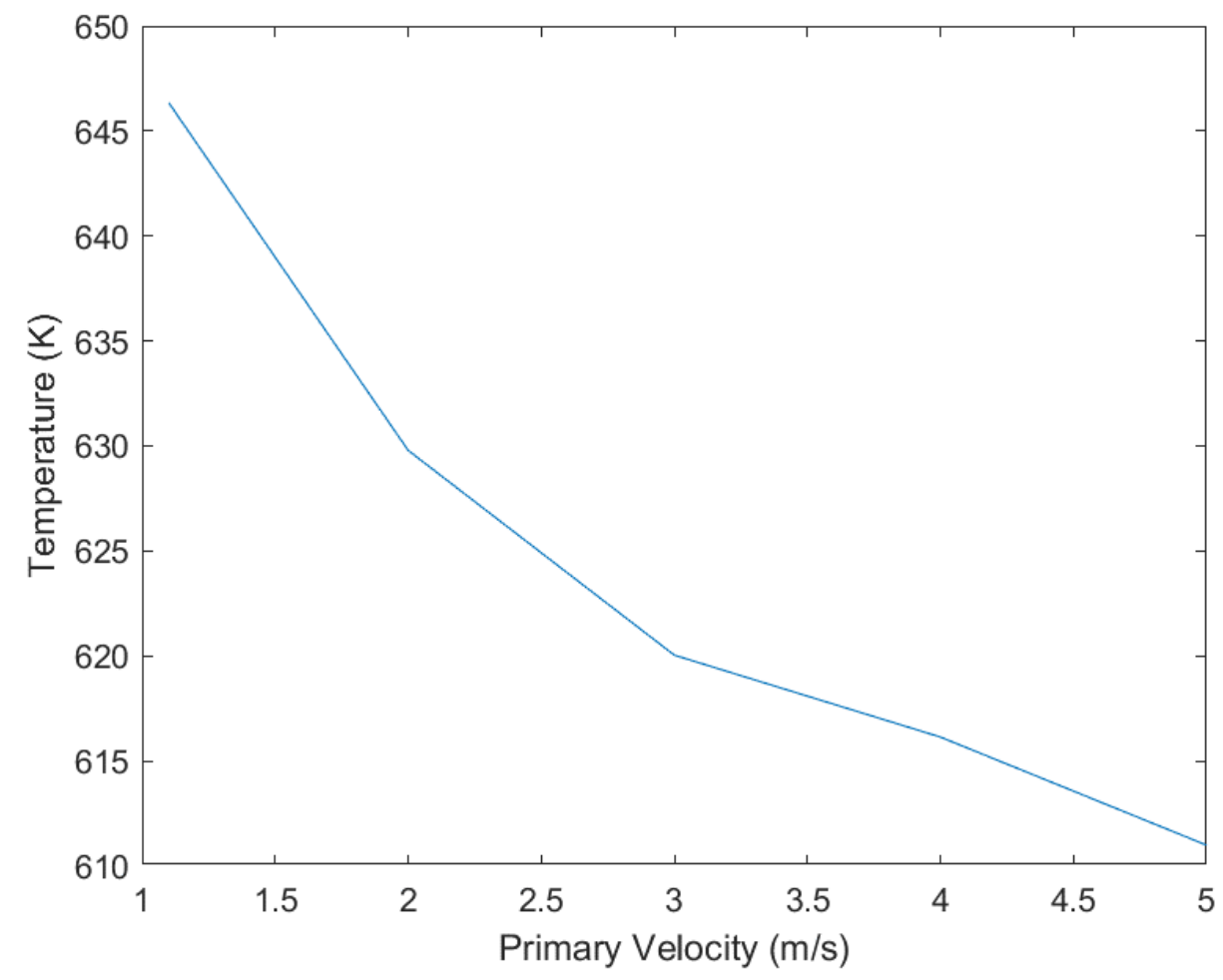

Figure 110: Primary Velocity vs Outlet Temperature

\subsubsection{Helium Mass Flow Rate}

The following section examines the effects of varying the mass flow rate of the helium system while retaining all other parameters. In this case, a multiplier of $0.5,1.5,2.0$, and 2.5 was applied to the flow mass flow rate of the helium loop. Of primary interest here is the effect of the helium mass flow rate on the outlet temperature of the primary loop. This data shows that increasing the helium mass flow rate by a factor of 2.5 decreases the outlet 
temperature to $641.7 \mathrm{~K}$. This means the helium mass flow rate could greatly influence the outlet temperature of the primary loop, and could be used as secondary cooling if the need arises in the case of an accident.

Table 12: Effects of Helium Mass Flow Rate on Primary Outlet Temperature

\begin{tabular}{|l|l|}
\hline \multicolumn{1}{|c|}{$\begin{array}{c}\text { Helium Mass Flow Rate } \\
(\mathrm{kg} / \mathrm{s})\end{array}$} & \multicolumn{1}{|c|}{$\begin{array}{c}\text { Outlet Temperature } \\
(\mathrm{K})\end{array}$} \\
\hline $4.01217 \mathrm{E}-02$ & 649.078 \\
\hline $8.61850 \mathrm{E}-02$ & 646.351 \\
\hline 0.12318 & 644.701 \\
\hline 0.17190 & 642.873 \\
\hline 0.20612 & 641.796 \\
\hline
\end{tabular}

\subsubsection{Primary Inlet Temperature}

The following section examines the effects of varying the inlet temperature of the primary system while retaining all other parameters. In this case, the pressure differential of the primary system is kept constant with the initial test to showcase the effects the inlet temperature has on the outlet temperature. Future tests for this system could desire a different inlet temperature than $600 \mathrm{~K}$ and the loop must be shown to be feasible at these operating conditions. The inlet temperatures tested and important parameters are listed in Table 13. It is also worth noting that the fluid void fraction of the primary system for each of these tests was 1.0 during the entire duration of the test, showing that the loop can operate at these conditions with no threat of boiling within the primary system. The fuel centerline temperatures are also within safe operating conditions.

Table 13: Effects of Inlet Temperature on Primary System

\begin{tabular}{|c|c|c|}
\hline $\begin{array}{c}\text { Inlet Temperature } \\
(\mathrm{K})\end{array}$ & \multicolumn{1}{|c|}{$\begin{array}{c}\text { Outlet Temperature } \\
(\mathrm{K})\end{array}$} & $\begin{array}{c}\text { Max Fuel Centerline } \\
\text { Temperature (K) }\end{array}$ \\
\hline 650 & 690.0 & 694.7 \\
\hline 700 & 734.8 & 738.4 \\
\hline 750 & 777.7 & 782.1 \\
\hline 800 & 821.6 & 826.0 \\
\hline
\end{tabular}




\section{CONCLUSIONS}

The United States lacks any infrastructure capable of producing a fast neutron spectrum and the FSTL looks to provide this safely and efficiently. The designs of the Boosted Fast Flux Loop booster fuel plates provided by Idaho National Lab were leveraged for this project to provide a hardened fast flux within the test section. The mechanical design, neutronic analysis, and thermal hydraulic analysis were developed in tandem during the course of the project. The purpose of this thesis was to outline the process taken during the thermal hydraulic analysis of the FSTL.

Overall, the system requirements include the ability to provide a neutron flux energy spectrum similar to that of an SFR and thermal hydraulic operating conditions akin to an SFR. To provide this, three separate coolant loops are required. These include the primary loop with sodium coolant to provide boundaries for the test chamber, a water cooling system for the booster fuel plates, and a helium loop to provide a separation between sodium loop and the water loop.

The mechanical design of the loop proved the installation of the system along with insertion and removal of the experiments to feasible. The loop infrastructure would be installed within the ATR during reactor downtime with the entire loop containing frozen sodium. Experiments would be inserted via one-time use test sections connected to the loop. The test section would e removed via the canal within the ATR used for removing test sections. The initial designs from the BFFL fuel plates were designed for the NE flux trap, though due to availability constraints the Large-I flux trap was used for this project. However, this required the dimensions of the fuel plates to be scaled down to fit. The Large-I flux trap is also located further from the center of the core than the BFFL plates were designed for and experience a different flux spectrum than originally designed for. This resulted in a lower fast to thermal flux ratio within the test section than was hoped for.

The thermal hydraulic analysis needed to show the loop could feasibly be operated and provide SFR-like operating conditions for SFR-fuel testing. This primarily requires a 
temperature differential from inlet to outlet of $50 \mathrm{~K}$ and a radial fuel rod temperature profile similar to that of SFR fuels. This thesis showcased the RELAP5 models used for the several different cases examined. These include the case with no test section, with a steel rod in the test section, with a single fuel rod test section, with three fuel rods within the test section, and a U-Tube primary loop design.

The test cases with the fuel rods all showcased that the desired $50 \mathrm{~K}$ inlet to outlet temperature difference could be reached with a feasible mass flow rate in the primary system. However, the fuel rod temperature profile is relatively low compared to that of a typical SFR fuel rod. This is likely due to the low power generation within the fuel rods due to the difference of the flux within the Large-I position compared to the NE flux trap the fuel plates were designed for.

The parametric study within the thesis was conducted for the three fuel pin case to showcase an operating window for the system. The study focused on fuel rod thermal power showed the increase of primary fluid temperature as well as the required velocity to reach the $50 \mathrm{~K}$ temperature differential from inlet to outlet. The velocity required for 15 $\mathrm{kW}$ per fuel rod was shown to be unfeasible at roughly $9 \mathrm{~m} / \mathrm{s}$, though the other tests showed feasible velocities. These tests also showed a temperature profile more akin to that of SFR fuel rods.

The study focused on the fuel plate thermal power showed the increase of the booster fuel coolant and the temperature profile of the fuel plates. With thermal powers up to 2.5 times that of the initial study, it was shown that with the provided water coolant operating conditions the coolant remains 100 percent fluid with no boiling present in the system. The temperature profile within the fuel plates show that the fuel plates do not reach inoperable temperatures and are safe to operate.

The study focused on inlet temperature of the primary system showed the effects on the fuel rods with varying inlet temperatures. The inlet temperatures tested were capped at 800 $\mathrm{K}$, and with the same pressure differential as the initial case resulted in an outlet 
temperature of $821 \mathrm{~K}$. A lower primary velocity could result in a $50 \mathrm{~K}$ temperature increase from inlet to outlet, though the primary velocity of $1.3 \mathrm{~m} / \mathrm{s}$ is already lower than typical SFRs. At these higher primary temperatures no boiling occurs in the sodium, showing safe operating conditions at these temperatures.

Several other parameters are varied for this study, including primary pressure, helium pressure, and helium velocity. However, these studies were shown to not greatly affect the primary outlet temperature and fuel rod temperature profiles.

Overall, the thermal hydraulic design of the FSTL was shown to be feasible using RELAP5. The $50 \mathrm{~K}$ temperature increase from inlet to outlet was achievable in all study cases with no boiling occurring in the primary system or fuel plate cooling systems. While the temperature profile within the fuel rods was lower than SFR fuel rods typically experience, the parametric study showed that higher thermal powers within the fuel rods resulted in fuel rod temperature profiles more akin to SFR fuel rods.

\subsection{Assumptions and Limitations}

\subsubsection{Low Pin Power}

The fuel rod temperature profiles are lower than ideal due to the lower thermal power. This is due to the low fast to thermal flux ratio within the test section. This could potentially be optimized by changing the designs of the fuel plate designs to be better accommodated by the Large-I position, and increase the thickness of the thermal neutron shield around the test section. The initial design of the loop did not allow for much increase in the thickness of the thermal neutron shield, but recent updates to the primary system outer diameter would allow more freedom in the size of the thermal shield.

\subsubsection{Axial Heat Conduction}

As shown in the case studies with fuel pins generating heat, there is a variance in the axial pin power. Due to this, coupled with the fact that RELAP does not allow for axial heat conduction through heat structures, results in jagged peaks in surface temperature and heat 
flux for test chamber surfaces. These jagged peaks do not represent a physical system, as heat conduction through the fuel rod would smooth out the temperature profile.

\subsection{Future Work}

Other future work for this project could include additional development of the loop, namely finding pumps capable of handling the requirements of the separate systems. The RELAP5 model could also be updated to reflect the chosen pumps as well as modeling a closed loop system that leaves the reactor and travels to the equipment room. 


\section{BIBLIOGRAPHY}

[1] W. a. M. C. Kays, Convective Heat and Mass Transfer, New York: McGraw-Hill, Inc., 1993.

[2] P. Sabharwall, "Effects of Fluid Axial Conduction on Liquid Metal Natural Circulation and Linear Stability," Oregon State University, Corvallis, 2004.

[3] C. Davis, "Evaluation of the Use of Existing RELAP5-3D Models to Represent the Actinide Burner Test Reactor," INL, Idaho Falls, 2007.

[4] M. Memmott, "On the use of RELAP5-3D as a subchannel analysis code," Nuclear Engineering and Design, pp. 807-815, 2009.

[5] H. Zhang, "RELAP5 Analysis of the Hybrid Loop-Pool Desing for the Sodium Cooled Fast Reactors," INL, Idaho Falls, 2008.

[6] L. J. Koch, Experimental Breeder Reactor-II, Lemont: Argonne National Laboratory, 1987.

[7] M. e. a. Meyer, "The EBR-II X501 minor actinide burning experiment," Journal of Nuclear Materials, pp. 176-183, 2009.

[8] H. e. a. Mochizuki, "Benchmark analyses for EBR-II shutdown heat removal tests SHRT-17 and SHRT-45R - (2) subchannel analysis of instrumented fuel subassembly," Nuclear Engineering and Design, pp. 14-27, 2017.

[9] J. e. a. Charpenel, "Fuel Pin Behavior under the Slow Power Ramp Transients in the CABRI-2 Experiments," Nuclear Technology, pp. 252-271, 2000.

[10] J. e. a. Guidez, "Fast Reactor Operation and Reactivity Control: Report on the Phenix Experience," in International Conference on the Physics of Reactors, Interlaken, 2008.

[11] D. e. a. Tenchine, "International benchmark on the natural convection test in Phenix reactor," Nuclear Engineering and Design, pp. 189-198, 2013.

[12] G. R. Longhurst, "Gas Test Loop Technical and Functional Requirements," Idaho National Engineering and Environmental Laboratory, Idaho Falls, 2004. 
[13] C. A. Wemple, "Design of a Gas Test Loop Facility for the Advanced Test Reactor," Idaho National Lab, Idaho Falls, 2005.

[14] D. P. Guillen, "Thermal Hydraulic Analysis of a Gas Test Loop System," Idaho National Lab, Idaho Falls, 2005.

[15] G. R. Longhurst, "Boosted Fast Flux Loop Alternative Cooling Assessment," Idaho National Lab, Idaho Falls, 2007.

[16] Idaho National Lab, "Boosted Fast Flux Loop Final Report," Idaho National Lab, Idaho Falls, 2009.

[17] V. H. Ransom, "Course A - Numerical Modeling of Two-Phase Flows for Presentation at Ecole d'Ete d'Analyse Numerique," Idaho National Lab, Idaho Falls, 1989.

[18] P. Moin, Fundamentals of Engineering Numerical Analysis, New York: Cambridge University Press, 2010.

[19] RELAP5-3D Code Manual Volume 1: Code Structure, System Models and Solution Methods, Idaho National Lab, 2015.

[20] R. Courant, On the Partial Difference Equations of Mathematical Physics, New York: New York University, 1956.

[21] H. K. Versteeg, An Introduction to Computational Fluid Dynamics, London: Pearson Education Limited, 2007.

[22] N. Todreas, Nuclear Systems Volume 1, Boca Raton: Taylor \& Francias Group, 2012.

[23] D. LaBrier, "Design of an In-Pile Experimental Loop for Fast Test Reactor Conditions Summary Report," Idaho National Lab, Idaho Falls, 2018.

[24] M. Memmott, "Thermal-Hydraulic Analysis of Innovative Fuel Configuration for the Sodium Fast Reactor," MIT, Cambridge, 2009. 